volume 4

ISSUE 3

2016 June

Editor in Chief Roberto Nardi

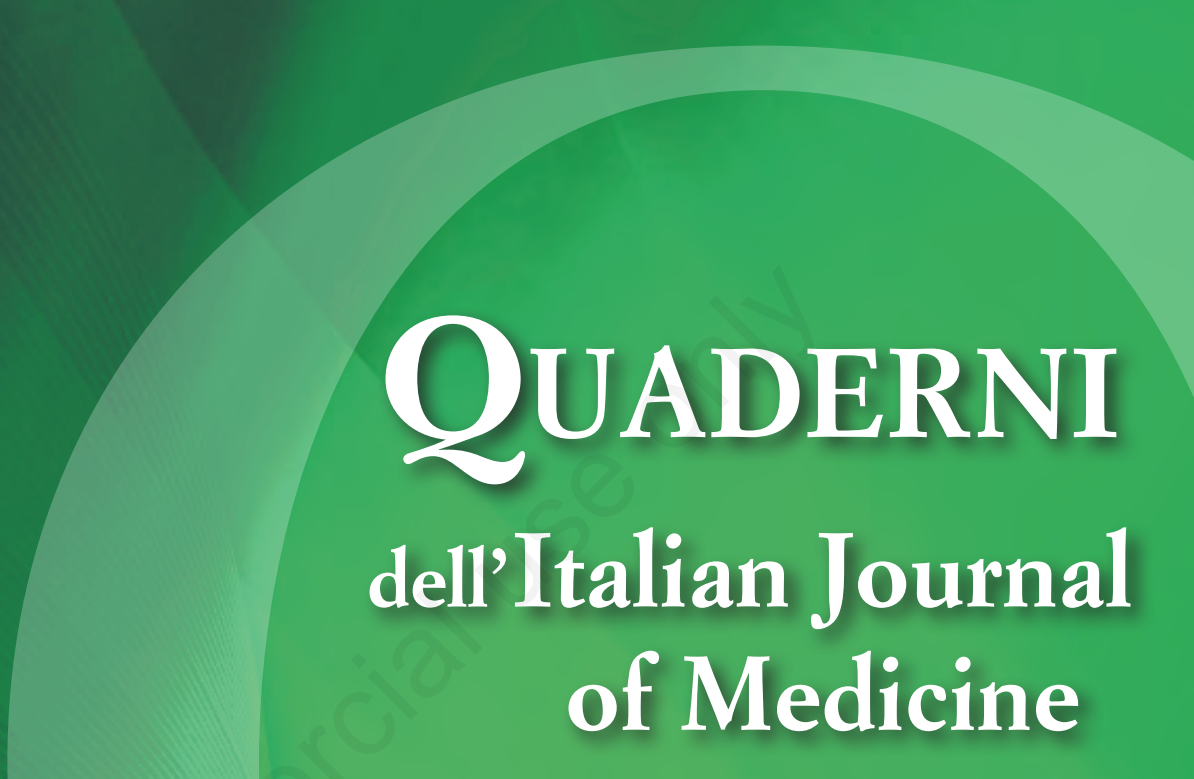

A Joumal of Hospital and Internal Medicine

The official journal of the Federation of Associations of Hospital Doctors on Internal Medicine (FADOI)

\title{
Management del paziente con diarrea, nausea e vomito, malnutrizione e malattia celiaca: lo stato dell'arte
}

Guest Editors: P. Gnerre, T.M. Attardo, a nome del Gruppo FADOI Giovani 
Mauro Campanini, Novara, Italy

\section{PRESIDENTE ELETTO}

Andrea Fontanella, Napoli, Italy

\section{PAST PRESIDENT}

Carlo Nozzoli, Firenze, Italy

\section{SEGRETARIO}

Giuseppe Augello, Canicattì (AG), Italy

\section{TESORIERE}

Dario Manfellotto, Roma, Italy

DIRETTORE RIVISTA

ITALIAN JOURNAL OF MEDICINE

Roberto Nardi, Bologna, Italy
RESPONSABILE RAPPORTI SOCIETÀ SCIENTIFICHE E ISTITUZIONI

Antonino Mazzone, Legnano (MI), Italy

RESPONSABILE SISTEMA GESTIONE QUALITÀ

Franco Berti, Roma, Italy

RESPONSABILE SITO NAZIONALE

Francesco Cipollini, Ascoli Piceno, Italy

DELEGATO FADOI ITALIAN STROKE ORGANIZATION

Michele Stornello, Siracusa, Italy

COMMISSIONE FADOI GIOVANI

Paola Gnerre, Savona, Italy

\section{Fondazione FADOI - Organigramma}

PRESIDENTE

Giorgio Vescovo, Padova, Italy

\section{COORDINATORE}

Domenico Panuccio, Bologna, Italy

\section{DIRETTORE SCIENTIFICO}

Gualberto Gussoni, Milano, Italy

DIRETTORE DIPARTIMENTO PER LA FORMAZIONE ED AGGIORNAMENTO

Mauro Silingardi, Guastalla (RE), Italy
DIRETTORE DIPARTIMENTO PER LA RICERCA CLINICA

Giancarlo Agnelli, Perugia, Italy

\section{CONSIGLIO DI AMMINISTRAZIONE}

Consigliere

Consigliere

Consigliere

Consigliere

Consigliere

Consigliere

Consigliere

Consigliere

Consigliere
Paolo Arullani, Roma, Italy

Davide Croce, Castellanza (VA), Italy

Francesco D'Amore, Roma, Italy

Salvatore Di Rosa, Palermo, Italy

Sandro Fontana, Biella, Italy

Ranieri Guerra, Roma, Italy

Ido Iori, Reggio Emilia, Italy

Giovanni Mathieu, Pinerolo (TO), Italy

Cecilia Politi, Isernia, Italy 


\section{QUADERNI - Italian Journal of Medicine}

MANAGEMENT DEL PAZIENTE CON DIARREA, NAUSEA E VOMITO:

DALLE EVIDENZE ALLA PRATICA CLINICA

La gestione del paziente con diarrea: razionale e obiettivi. . . . . . .

T.M. Attardo, C. Quarneti, R. Menichella, E. Romualdi

La gestione del paziente con nausea e vomito:

razionale e obiettivi.

T.M. Attardo, R. Menichella, C. Quarneti, E. Romualdi

\section{MALNUTRIZIONE E MALATTIA CELIACA: LO STATO DELL'ARTE}

La gestione del paziente con malnutrizione:

dalle evidenze alla pratica clinica $\ldots \ldots \ldots \ldots \ldots \ldots \ldots \ldots$

S. Ciarla, M. Poggiano, P. Gnerre, F. Risaliti, L. Magni, L. Morbidoni,

A. Maffettone, A. Paradiso, M. Rondana, A. Schimizzi, R. Risicato

La gestione del paziente con malattia celiaca: razionale e obiettivi ...

T.M. Attardo, E. Magnani, C. Casati, D. Cavalieri, P. Crispino, F. Fasci Spurio,

S. De Carli, D. Tirotta, P. Gnerre 


\title{
La gestione del paziente con diarrea: razionale e obiettivi
}

\author{
Tiziana Marcella Attardo, ${ }^{1}$ Chiara Quarneti, ${ }^{2}$ Rita Menichella, ${ }^{3}$ Erica Romualdi ${ }^{4}$ \\ ${ }^{1}$ UO di Medicina Interna, Ospedale Barone Lombardo di Canicattì, Asp 1 Agrigento; ${ }^{2}$ Unità di Area Critica dell'Ospedale di \\ Montecatone, Bologna; ${ }^{3}$ UO Medicina Interna Bolondi, Dipartimento di Malattie dell'Apparato Digerente e Medicina \\ Interna, Bologna; ${ }^{4} \mathrm{UO}$ Medicina Interna, Ospedale di Saronno, Varese, Italia
}

\section{RIASSUNTO}

La diarrea (dal greco $\delta 1 \alpha$ cioè attraverso + $\rho \varepsilon ́ \omega$ che significa scorro, per indicare lo scorrere veloce attraverso l'intestino), comune manifestazione delle malattie gastrointestinali, è una patologia estremamente diffusa, gravata da alti costi in termini di morbilità, perdita di produttività lavorativa e utilizzo di risorse sanitarie. Mentre la diarrea acuta riconosce nelle maggior parte dei casi un'eziologia infettiva (oltre il 90\%), nella diarrea cronica vanno prese in considerazione diverse cause con modalità di approccio diagnostico - terapeutico molto differenti. A tal proposito ci è sembrato opportuno valutare distintamente la gestione delle diarrea acuta e diarrea cronica, con una ulteriore trattazione per quel che riguarda il management della diarrea nei pazienti in corso di chemioterapia. La ricerca delle linee guida (LG) sul topic in questione (diarrea) e la revisione delle stesse grazie allo strumento metodologico dell' Appraisal of Guidelines, Research and Evaluation II (AGREE II) ci ha permesso di valutare la letteratura disponibile sull'argomento ed ha rappresentato il punto di partenza per un approccio metodologico al sintomo. La seguente monografia, pur nei limiti della sintesi, si propone di fornire uno strumento che aiuti l'internista ad identificare le numerose e differenti patologie alla base della diarrea, anche grazie a flowchart di snodo diagnostico.

\section{Introduzione}

Anche se la semplice emissione di feci non formate è spesso percepita dai pazienti come diarrea, la sua definizione tiene conto di frequenza, volume e consistenza delle feci, ovvero è caratterizzata dall'emissione di feci liquide con aumentata frequenza e per un peso fecale complessivo giornaliero $>200$ g.

Tale quadro va distinto dalla pseudodiarrea e dall'incontinenza fecale; la prima caratterizzata da frequenti scariche di modeste quantità di feci, spesso accompagnate da sensazione di incompleta evacuazione, che si associano alla sindrome dell'intestino irritabile (IBS) o disturbi proctologici; la seconda caratterizzata da perdita involontaria di feci seconda-

Corrispondente: Tiziana Marcella Attardo, UO di Medicina Interna, Ospedale Barone Lombardo di Canicattì, via Giudice Antonino Saetta, Canicattì, Asp 1 Agrigento, Italia. Fax: +39.0922.733217/733395;

E-mail: claudia.fantucchio@alice.it

Articolo pubblicato secondo la Creative Commons Attribution NonCommercial 4.0 License (CC BY-NC 4.0).

CCopyright T.M. Attardo et al., 2016

Licensee PAGEPress, Italy

QUADERNI - Italian Journal of Medicine 2016; 4(3):1-35 ria, in genere, a disturbi neuromuscolari o ad alterazioni strutturali del comparto anorettale. ${ }^{1}$

Per evitare indagini superflue, questi due disturbi vanno presi sempre in considerazione, soprattutto considerando che i tassi di prevalenza sono più alti di quelli della diarrea cronica e che una dettagliata anamnesi e un accurato esame obiettivo, compreso di esplorazione rettale e valutazione del tono sfinteriale, permettono di distinguere questi disturbi dalla diarrea vera e propria.

Sulla base della durata del sintomo possiamo distinguere tra: i) diarrea acuta: $<2$ settimane; ii) diarrea persistente: tra $2 / 4$ settimane; iii) diarrea cronica: $>4$ settimane.

\section{Epidemiologia}

Si calcola che nel mondo più di un miliardo di soggetti soffra di uno o più episodi di diarrea una volta all'anno.

Nei Paesi in via di sviluppo, la diarrea infettiva acuta rimane una delle più frequenti cause di mortalità, specie tra i bambini con meno di 5 anni (1,5-2 milioni di decessi annui) ed è inoltre responsabile di malnutrizione e ritardo nella crescita, sia fisica che mentale.

Nei paesi industrializzati la mortalità per diarrea è nettamente inferiore (negli USA 6000 decessi annui); tuttavia si stima che ogni individuo abbia almeno 1,3 episodi di diarrea l'anno. ${ }^{2}$

La prevalenza della diarrea cronica nei paesi occidentali non è chiaramente definita. Studi di sorveglianza della popolazione degli Stati Uniti hanno 
rilevato un tasso di prevalenza per la diarrea cronica tra il 3 e il $20 \%$. Le grande variabilità osservata nell'ambito dei diversi studi è verosimilmente secondaria alle diverse definizioni con cui è stato descritto il sintomo, ai disegni degli studi e alle differenze tra le caratteristiche delle popolazioni esaminate. Il dato più attendibile sembra attestarsi attorno al 5\% (Figura 1). ${ }^{3}$

\section{Impatto economico}

Negli Stati Uniti, dei 100 milioni di pazienti che presentano episodi di diarrea acuta nell'arco di un anno, la metà si assenta dal lavoro, 250 mila richiedono l'ospedalizzazione e circa tre mila muoiono, con un carico economico per il Paese di più di 20 miliardi di dollari.,

Sebbene l'impatto economico della diarrea cronica non sia stato ben quantificato, una stima effettuata su dati limitati rivela un costo di circa 350 milioni di dollari all'anno, considerando, oltre i costi diretti sanitari, $i$ costi indiretti rappresentati dalle giornate lavorative di astensione dal lavoro per sé o per i propri cari. ${ }^{3,4}$

\section{Effetti sulla qualità di vita}

È indubbio che la diarrea riduca la qualità di vita, in particolare se consideriamo i pazienti sottoposti a chemioterapia che sviluppano tale sintomo.

Tuttavia, in assenza di uno strumento validato di valutazione, non è possibile quantificarne il grado in maniera accurata.

\section{MORTALITA' DA DIARREA}

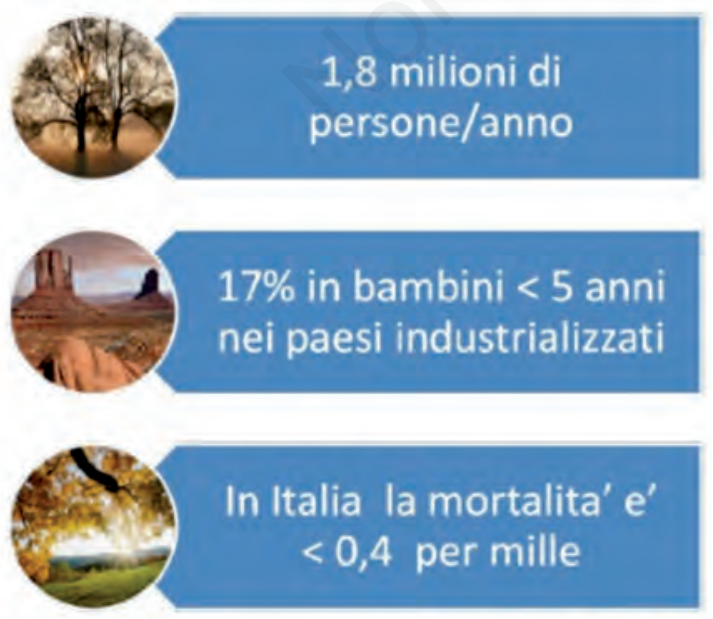

WHO, 2005

Figura 1. Dati sulla mortalità della World Health Organization 2005 (Fonte dei dati: http://apps.who.int/iris/ bitstream/10665/43209/1/9241593180.pdf).

\section{Fisiopatologia}

L'intestino tenue e il colon svolgono funzioni di secrezione e assorbimento di acqua ed elettroliti, immagazzinamento e trasporto aborale del contenuto intraluminale e recupero di alcuni nutrienti dopo il metabolismo batterico dei carboidrati che non sono assorbiti nel piccolo intestino. Alterazioni che si verifichino a qualsiasi livello possono essere responsabili dell'insorgenza di diarrea. ${ }^{1}$

\section{Innervazione}

Il tratto intestinale è controllato da una doppia innervazione: intrinseca ed estrinseca. L'innervazione intrinseca o sistema nervoso enterico è costituito dal plesso mienterico, sottomucoso e mucoso. Il plesso mienterico regola la funzione della muscolature liscia, il plesso sottomucoso influenza la funzione secretoria e l'assorbimento. Tra i neurotrasmettitori presenti a questo livello sono presenti acetilcolina, oppioidi, noradrenalina, serotonina, ATP, ossido nitrico, amine e peptidi con funzione di neurotrasmettitori. Vi sono diversi tumori neuroendocrini in grado di secernere questi tipi di ormoni, con possibile comparsa di diarrea.

Le innervazioni estrinseche del piccolo intestino e del colon sono parte del sistema nervoso autonomo e intervengono nel modulare le funzioni motorie e secretorie. Il parasimpatico fornisce fibre sia a vie sensitive viscerali, sia a vie eccitatorie per componenti motorie del colon. Le fibre parasimpatiche, attraverso il nervo vago, raggiungono il piccolo intestino e il colon prossimale lungo le branche dell'arteria mesenterica superiore. Il colon distale è innervato dai nervi parasimpatici sacrali attraverso il plesso pelvico (S2-4). I principali neurotrasmettitori eccitatori che controllano la funzione motoria sono l'acetilcolina e le chinine come la sostanza P. Questo implica che condizioni come la vagotomia o la neuropatia diabetica o amiloidotica possono determinare la comparsa di diarrea.

Il sistema simpatico prende parte alla modulazione della funzione motoria e le fibre raggiungono l'intestino tenue e il colon attraverso l'arco arterioso dei vasi mesenterici arteriosi superiori ed inferiori. Le afferenze del simpatico sono generalmente eccitatorie a livello degli sfinteri, mentre sono inibitorie a livello della muscolatura non sfinterica.

Le afferenze viscerali che veicolano la sensibilità dell'intestino al sistema nervoso centrale, inizialmente decorrono lungo le fibre simpatiche, ma in prossimità del midollo spinale si separano, hanno corpi cellulari nei gangli delle radici dorsali ed entrano nel corno dorsale del midollo spinale.

I segnali afferenti sono condotti al cervello attraverso il tratto spinotalamico laterale e la via della colonna dorsale nocicettiva. 


\section{Assorbimento e secrezione di acqua ed elettroliti}

L'intestino è attraversato in media da 9 litri di liquidi nell'arco di una giornata, di cui solo 1 litro raggiunge il colon, e da qui meno di 200 millilitri vengono espulsi con le feci. In situazione di ridotto assorbimento da parte dell'intestino tenue, il colon è in grado di quadruplicare la sua capacità riassorbitiva (arrivando quindi a più di 3 litri di liquidi riassorbiti) purché l'entità del flusso endoluminale lo consenta. Nel colon l'assorbimento del sodio avviene a livello della membrana apicale, con un compenso dato dalla pompa sodio-potassio sulla membrana basolaterale. Numerosi mediatori neuronali e non neuronali regolano l'equilibrio dei liquidi e degli elettroliti a livello del colon, inclusi mediatori colinergici, adrenergici e serotoninergici. Anche in questo caso l'aumentata concentrazione di ormoni intestinali può determinare diarrea, così come la produzione da parte di alcuni ceppi batterici di tossine che interagiscono con i canali del cloro o la distruzione dell'epitelio intestinale ad opera di altri microrganismi.

\section{Motilità dell'intestino tenue}

Durante il digiuno la motilità del piccolo intestino è caratterizzato da un evento peristaltico ciclico chiamato complesso motore migrante, che svolge funzione di ripulire il lume dalle sostante non digeribili. Questa serie di movimenti si verifica ogni 60-90 minuti per una durata di circa 4 minuti. In seguito all'ingestione di cibo, il piccolo intestino va incontro a contrazioni irregolari ed intermittenti di rimescolamento, con ampiezza relativamente bassa, ad eccezione dell'ileo terminale, dove devono garantire lo svuotamento dell'ileo dal bolo.

\section{Immagazzinamento e riassorbimento a livello dell'ileo e del colon}

L'ileo distale agisce come un serbatoio, che si svuota ad intermittenza, tale da poter consentire il riassorbimento dei liquidi, degli elettroliti e dei nutrienti. A livello del colon, la segmentazione data dalle austrature favorisce il rimestamento, la ritenzione dei residui e la formazione di feci solide. Queste funzioni sono più rappresentate nel tratto ascendente e trasverso, ove il transito dura circa 15 ore, mentre il tratto discendente rappresenta un condotto con un tempo di transito medio delle feci di circa 3 ore. Il colon è capace di ritenere sodio e acqua.

\section{Motilità del colon}

Il colon presenta una contrattilità di fondo detto tono, che influenza la capacitanza del viscere e la sua sensibilità, sulla quale si sovrappongono due tipologie di attività contrattili: una fasica, irregolare, di breve durata $(<15$ ") e non propagata con funzione di rimescola- mento del contenuto luminale, e una propagata per tutto il colon, di ampiezza elevata che si verifica generalmente la mattina al risveglio e dopo il pranzo e che è responsabile dello stimolo di defecazione. Il pasto incrementa entrambe le componenti contrattili attraverso una fase iniziale mediata dal nervo vago, in risposta alla distensione gastrica, e una successiva mediata da ormoni, quali la serotonina e la gastrina. L'atto finale della defecazione prevede alcune modificazioni del pavimento pelvico in parte neuromediate, in parte secondarie alla distensione dell'ampolla rettale e il rilascio del muscolo sfintere esterno.

\section{Diarrea acuta}

La maggior parte dei casi di diarrea acuta sono dovute a infezioni da virus e batteri e sono auto-limitanti. La valutazione dei pazienti per una eziologia non infettiva deve essere considerata in quei pazienti in cui non si riesca ad identificare un patogeno (batteri, virus, o protozoi) e nei casi in cui la diarrea peggiora o diventa cronica.

Uno dei dilemmi nella valutazione dei pazienti con diarrea acuta è decidere quando fare i test e quando iniziare la terapia. L'approccio a questi pazienti si concentra in generale sulla distinzione tra eziologie infettive acute, per le quali il trattamento è vantaggioso, da altre cause (Figura 2). ${ }^{5,6}$

\section{Eziologia}

I dati sulla frequenza delle diverse cause di diarrea acuta variano a seconda della definizione utilizzata e la popolazione studiata. Inoltre, la prevalenza di un identificabile agente infettivo è grossolanamente sottostimata in quanto molti pazienti non si rivolgono al medico o $\mathrm{i}$ test spesso non vengono eseguiti quando $\mathrm{i}$ pazienti contattano il loro medico. La maggior parte dei casi delle gastroenteriti acuta infettive sono di origine virale, come indicato dall'osservazione che coprocolture in pazienti con diarrea acuta hanno, nella maggior parte degli studi, esito positivo solo nel $1,5 / 5,6 \%$ dei casi. A conferma di ciò, in uno studio pilota su epidemie di origine alimentare in cui i kit per la raccolta delle feci venivano consegnati e ritirati a domicilio dei pazienti, l'agente patogeno è stato identificato nel $71 \%$ dei pazienti e nei tre quarti dei casi si trattava di norovirus, seguivano i rotavirus, adenovirus ed astrovirus (Tabella 1).

Le cause batteriche (Tabella 1) sono responsabili della maggior parte dei casi di diarrea grave. Infatti uno studio condotto su 173 adulti sani con diarrea acuta acquisita in comunità definita grave $(\geq 4$ scariche di feci liquide al giorno per più di tre giorni), un batterio patogeno è stato identificato nel $87 \%$ dei casi. In genere si tratta di Salmonella, Campylobacter, Shi- 


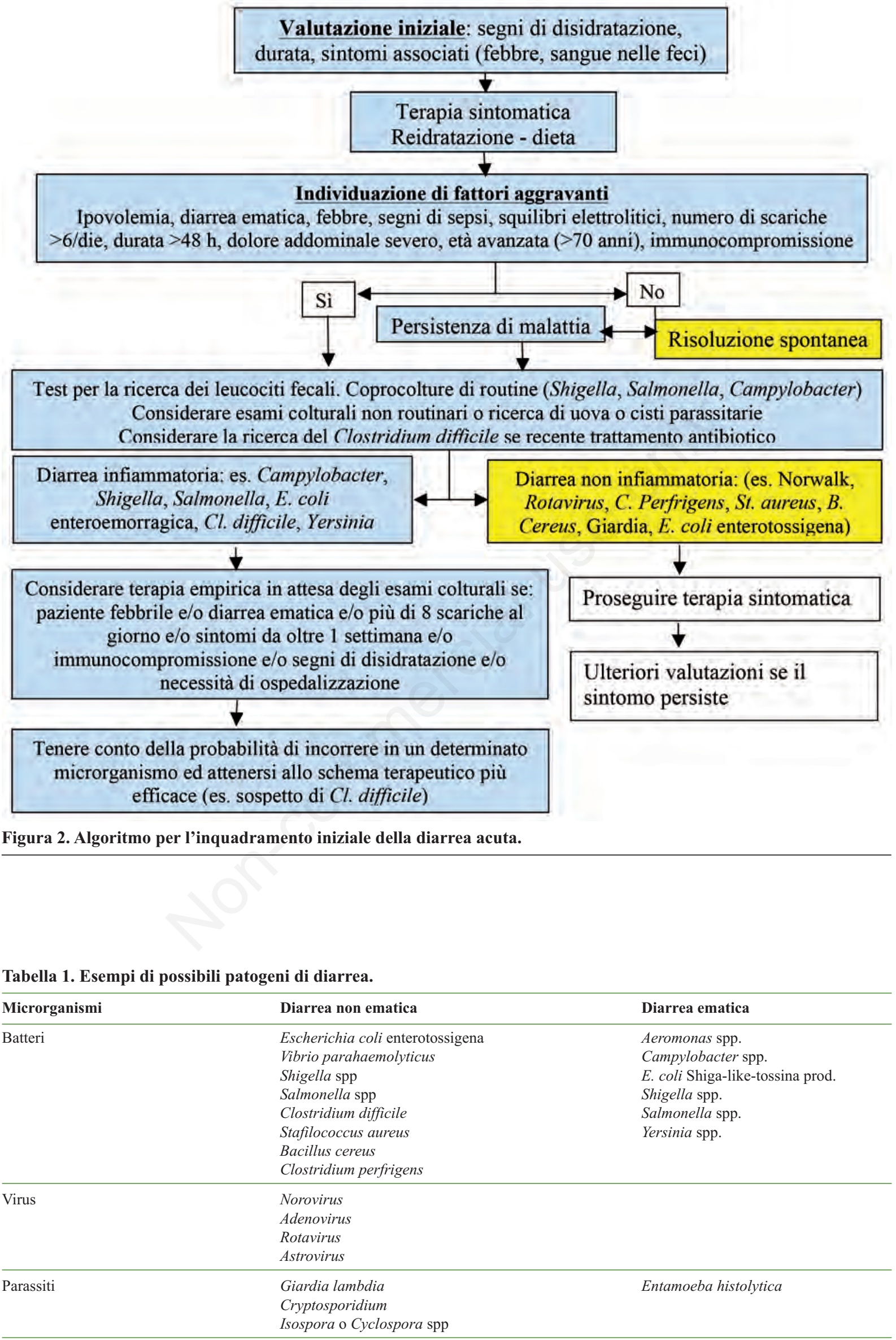


gella, Escherichia coli enterotossigena, Clostridium difficile. I protozoi (Tabella 1) (in genere Cryptosporidium, Giardia, Cyclospora, Entamoeba) sono meno comunemente identificati come agenti eziologici di malattia acuta gastrointestinale. ${ }^{?}$

Al fine di contenere i costi legati all'esecuzione di indagini colturali non necessarie, Hatchette e colleghi ${ }^{5}$ hanno proposto un algoritmo che prende in considerazzione vari elementi quali la durata della diarrea superiore alle $24 \mathrm{~h}$, la presenza di feci ematiche, di febbre, di sintomi di sepsi, di disidratazione, di uso recente di antibiotici, di immunosoppressione, ma anche dell'attività professionale del paziente e del rischio di trasmissione legato ad essa (Figura 3 ). ${ }^{5}$

\section{Approccio diagnostico}

La valutazione iniziale dei pazienti con diarrea acuta deve includere una storia accurata per determinare la durata dei sintomi e la frequenza e le caratteristiche delle feci.

\section{Indizi anamnestici}

La storia del paziente può essere utile per identificare i patogeni associati ad un episodio di diarrea acuta e può aiutare a guidare la terapia empirica quando è indicato. Oltre a identificare la diarrea come originata del piccolo intestino o del grande intestino (Tabella 2), ulteriori indizi diagnostici possono essere forniti da domande sui fattori che potrebbero avere esposto il paziente a potenziali patogeni, quali la residenza, l'esposizione professionale, l'assunzione di antibiotici, consumo di cibi e acqua potenzialmente contaminati, viaggi recenti o remoti, contatto con animali domestici e gli hobby.

\section{Indicazioni per la valutazione diagnostica}

Vanno ricercati sempre i segni indicativi di deplezione del volume extracellulare. La riduzione dell'elasticità cutanea e la secchezza delle mucose sono indici di disidratazione lieve, mentre la presenza di tachicardia, ipotensione ortostatica, riduzione dello stato di vigilanza, infossamento dei globi oculari o perdita di peso sono suggestivi di disidratazione grave.

L'obiettività addominale può evidenziare segni di peritonismo che, insieme alla febbre, possono suggerire un'infezione da un patogeno invasivo enterico o una perforazione intestinale.

Una valutazione diagnostica più approfondita è indicata in pazienti con forme relativamente gravi, come suggerito dalla presenza di uno o più dei seguenti sintomi: i) diarrea acquosa profusa con segni di ipovolemia; ii) evacuazione di feci di piccolo volume contenenti sangue e muco; iii) diarrea con sangue; iv) febbre con $\left.\mathrm{Tc} \geq 38,5^{\circ} \mathrm{C}\left(101,3^{\circ} \mathrm{F}\right) ; \mathrm{v}\right)$ evacuazione di $\geq 6$ feci non formate ogni 24 ore o una durata del sintomo $>48$ ore; vi) violento dolore addominale; vii) pazienti ospedalizzati o l'uso recente di antibiotici; viii) diarrea nei pazienti anziani ( $\geq 70$ anni di età) o immunocompromessi; ix) malattia sistemica con diarrea, soprattutto nelle donne in stato di gravidanza (in cui la listeriosi dovrebbe essere sospettata).

Un aspetto diagnostico importante è la febbre, che suggerisce infezione da batteri invasivi (ad esempio, Salmonella, Shigella, Campylobacter) o da virus enterici, o da un organismo citotossico come $C$. difficile o Entamoeba histolytica. ${ }^{8}$

Anche una storia alimentare può fornire indizi per una diagnosi.

Il consumo di prodotti lattiero-caseari non pastorizzati, di carne cruda o poco cotta o pesce, o preparati

Tabella 2. Possibili patogeni responsabili di diarrea.

\begin{tabular}{lll}
\hline Batteri & Salmonella & Campylobacter \\
& Escherichia coli* & Shigella \\
& Clostridium perfringers & Clostridium difficile \\
& Staphylococcus aureus & Yersinia \\
& Aeromonas hydrophila & Vibrio parahaemolyticus \\
& Bacillus cereus & E. coli enteroinvasiva \\
& & Plesiomonas shihelloides \\
\hline Virus & Klebsiella oxytoca \\
\hline Protozoi & Rotavirus & Adenovirus \\
& Norovirus & Cytomegalovirus ${ }^{\circ}$ \\
& & Herpes simplex virus \\
\hline & Cryptosporidium ${ }^{\circ}$ & Entamoeba histolytica \\
& Microsporidium & \\
& Isospora & \\
& Cyclospora & \\
Giardia lambdia & \\
\hline
\end{tabular}

*Indica il gruppo di E. coli nelle sue varianti enteropatogena, enteroaggregante, enteroemorragica e enterotossigena, che i normali test colturali non sono in grado di distinguere; ${ }^{\circ}$ questi microrganismi possono coinvolgere entrambi i segmenti intestinali, tuttavia appaiono maggior frequenza nell'ambiente indicato. 


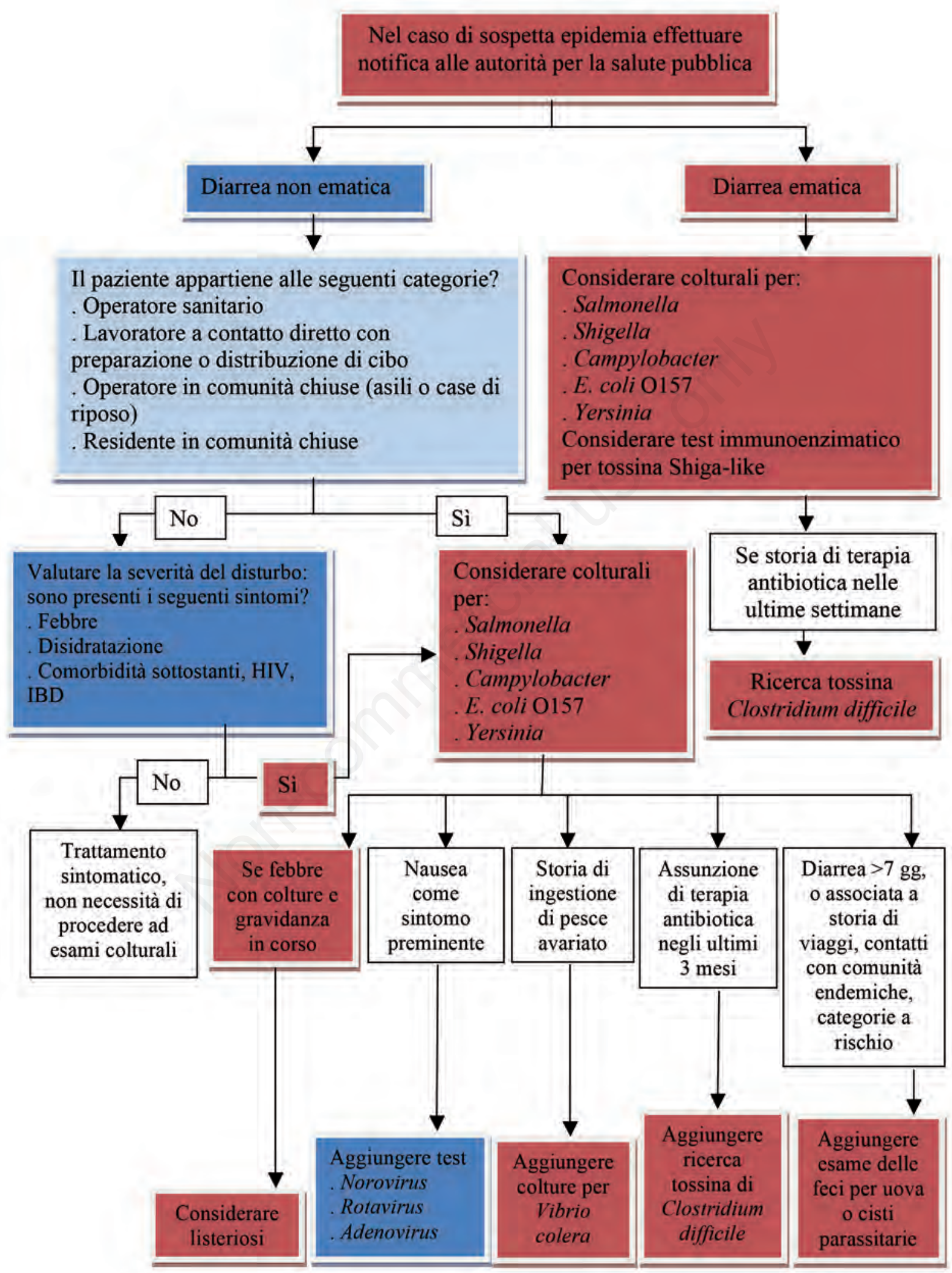

Figura 3. Algoritmo per l'adeguatezza dell'esame microbiologico (tradotta e adattata da Hachette e Farina, 2005). ${ }^{5}$ 
vitaminici organici possono indirizzare verso alcuni agenti patogeni (Tabella 3 ).

Inoltre, la temporizzazione dei sintomi in relazione all'esposizione al sospetto alimento o i sintomi associati possono essere un importante indizio diagnostico (Tabella 4). ${ }^{9}$

Sintomi che iniziano entro sei ore suggeriscono l'ingestione di una tossina preformata di Staphylococcus aureus o Bacillus cereus. Sintomi che iniziano da 8 a 16 ore suggeriscono l'infezione da Clostridium perfringens. Sintomi che iniziano a più di 16 ore pos- sono derivare da un'infezione virale o batterica (per esempio, la contaminazione degli alimenti con enterotossigeni o $E$. coli enteroemorragica).

Sindromi che possono iniziare con diarrea, ma progrediscono con febbre e disturbi sistemici come cefalea, mialgie, torcicollo possono suggerire l'infezione da Listeria monocytogenes, in particolare nelle donne in gravidanza. Infatti le donne in gravidanza hanno un rischio 20 volte maggiore di sviluppare listeriosi da prodotti a base di carne o prodotti caseari non pastorizzati (come formaggi a pasta molle).

Tabella 3. Caratteristiche epidemiologiche di possibili patogeni enterici.

\begin{tabular}{|c|c|c|}
\hline & Patogeno & Possibile richiamo anamnestico di esposizione alimentare e non \\
\hline \multirow[t]{14}{*}{ Batteri } & Staphylococcus aureus & Carne di manzo, suino, pollame e uova \\
\hline & Clostridium perfringens & Carne di manzo, suino, pollame, conserve fatte in casa \\
\hline & Bacillus cereus & Carne di manzo, suino, riso fritto, verdure \\
\hline & Escherichia coli enteroemorragico & $\begin{array}{l}\text { Carne di manzo e suino poco cotta, sidro di mele, lattuga, latticini. } \\
\text { Pazienti bambini e anziani }\end{array}$ \\
\hline & E. coli enteroinvasiva & Latte, formaggi \\
\hline & E. coli enterotossigena & Soggetti in viaggio in paesi in via di sviluppo \\
\hline & Salmonella & $\begin{array}{l}\text { Carne di manzo, suino, pollame, uova, latte fresco, gelati, verdura, succhi di frutta } \\
\text { non pastorizzati, volatili domestici, piccoli rettili e carne di serpente }\end{array}$ \\
\hline & Campylobacter & Pollame, latte fresco e formaggi \\
\hline & Shigella & Verdure. Operatori e ospiti di asili e centri diurni \\
\hline & Yersinia & Carne di suino (non comune), carne di manzo, latticini. Emocromatosi \\
\hline & Vibrio cholera & $\begin{array}{l}\text { Crostacei o molluschi provenienti dal Messico, pesce poco cotto del Sud America, } \\
\text { latte di cocco tailandese. Epidemie in aereo }\end{array}$ \\
\hline & Vibrio parahaemolyticus & Consumo di frutti di mare crudi, specie est asiatico, crostacei. Pazienti con cirrosi \\
\hline & Clostridium difficile & $\begin{array}{l}\text { Ospedalizzazione. Assunzione di antibiotici o chemioterapici sia in pazienti } \\
\text { ospedalizzati che non. Operatori o ospiti di asili e centri diurni }\end{array}$ \\
\hline & Listeria & $\begin{array}{l}\text { Carne di manzo, suino, pollame, latticini, insalate di cavolo o patate, hot dog. } \\
\text { Gravidanza, neonati, pazienti immunocompromessi. }\end{array}$ \\
\hline \multirow[t]{5}{*}{ Virus } & Rotavirus & Operatori o ospiti di asili e centri diurni, nursery. Viaggi in Australia \\
\hline & Norovirus & $\begin{array}{l}\text { Verdura, epidemie di origine alimentare, idrica o da frutti di mare. } \\
\text { Scuole, nursery, navi da crociera, campi militari. }\end{array}$ \\
\hline & Virus dell'epatite A & $\begin{array}{l}\text { Frutti di mare, indisponibilità di acqua controllata. Comunità sovraffollate, } \\
\text { operatori e ospiti di istituti, asili, centri diurni, campi militari. Uso di droghe } \\
\text { endovenose. Omosessualità }\end{array}$ \\
\hline & Adenovirus & Bambini. Pazienti con AIDS \\
\hline & Cytomegalovirus & Omosessualità, infezione da HIV o AIDS. Trapianto d'organo \\
\hline \multirow[t]{6}{*}{ Protozoi } & Giardia lambdia & $\begin{array}{l}\text { Macedonia di frutta. Operatori e ospiti di asili e centri diurni, piscine e viaggi in } \\
\text { aree a rischio (es. Russia) }\end{array}$ \\
\hline & Entamoeba histolytica & Viaggi in aree endemiche (es. Messico) per più di un mese, rapporti omosessuali \\
\hline & Cryptosporidium & $\begin{array}{l}\text { Operatori e ospiti di asili e centri diurni, piscine. Contatto con animali di fattoria, } \\
\text { AIDS, acqua contaminata }\end{array}$ \\
\hline & Cyclospora & Lamponi del Guatemala \\
\hline & Isospora & Haiti, infezione da HIV \\
\hline & Microsporidium & AIDS \\
\hline
\end{tabular}


È anche importante indagare se c'è stato recente uso di antibiotici (come indizio per la presenza di infezione da $C$. difficile, sebbene sia possibile l'infezione da $C$. difficile comunitaria in pazienti senza esposizione ad antibiotici), o di altri farmaci, e di ottenere una completa storia medica (ad esempio, per identificare un immunocompromesso o la possibilità di infezioni nosocomiali).

\section{Diarrea sanguinante}

La diarrea emorragica acuta è una malattia rara, presente in una revisione americana ${ }^{10}$ nel $3 \%$ delle 30.000 colture fecali analizzate. Un patogeno è stato identificato nel $20 \%$ dei casi.

L'E. coli O157: $\mathrm{H} 7$ era presente nel 7,8\% dei campioni visibilmente emorragici (rispetto al $0,1 \%$ di campioni che non erano visibilmente emorragici) e rappresentava il 39\% degli agenti patogeni in coltura in campioni visibilmente emorragici rispetto a solo il $7 \%$ degli agenti patogeni in coltura in tutte le feci (emorragica e senza sangue). Cause batteriche meno comuni di diarrea visibilmente ematica erano rappresentati da Shigella, Campylobacter e Salmonella spp.

\section{Leucociti fecali e sangue occulto}

Diversi studi hanno valutato l'accuratezza dei leucociti fecali soli o in combinazione con il test del sangue occulto. La capacità di questi test di prevedere la presenza di una diarrea infiammatoria è variata notevolmente, con rapporti di sensibilità e specificità variabili dal 20 al $90 \%$. $^{11,12}$

Una meta-analisi sull'accuratezza del test diagnostico ha stimato che, al picco di sensibilità del $70 \%$, la specificità di leucociti fecali era solo del $50 \%$.

Tabella 4. Patogeni responsabili di diarrea posti in relazione ai sintomi e al tempo di incubazione.

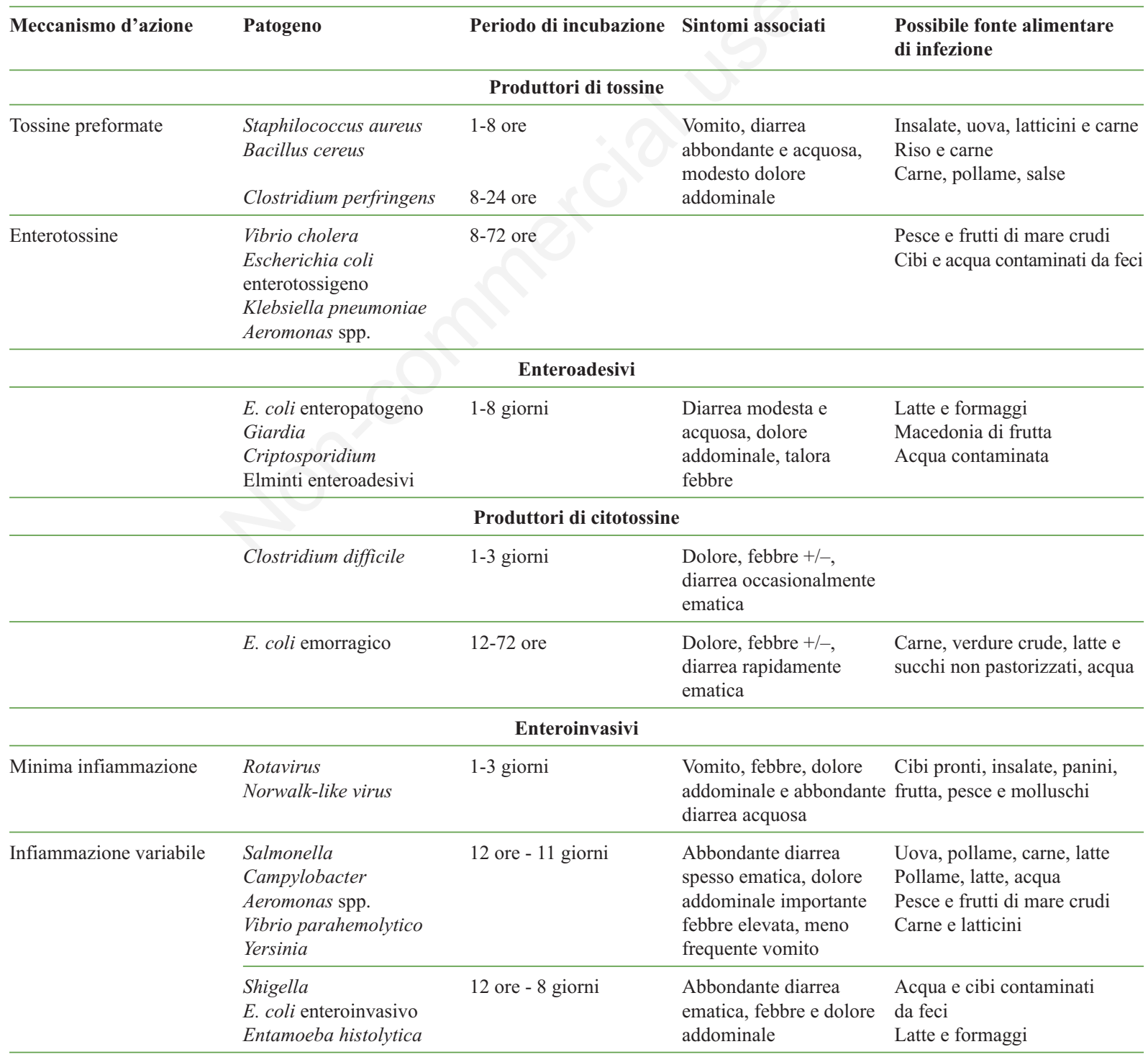


Una revisione del 2004 ha stimato che, nei paesi sviluppati, la sensibilità e la specificità dei leucociti fecali per la diarrea infiammatoria sono stati del $73 \mathrm{e}$ $84 \%$, rispettivamente. ${ }^{10}$

In altri studi, i leucociti fecali non erano predittori accurati della risposta alla terapia antibiotica. ${ }^{11,12}$

La variabilità delle stime tra gli studi può essere parzialmente dovuta a differenze di trattamento dei campioni e all'esperienza dell'operatore. A causa di questi problemi, il ruolo del test per leucociti fecali è stato messo in dubbio..$^{10}$ Tuttavia, la presenza di sangue occulto e leucociti fecali supporta la diagnosi di una causa batterica della diarrea, nel contesto della storia medica ed altre valutazioni diagnostiche. ${ }^{5}$ Pertanto è preferibile associare, in pazienti ad alto rischio, questo esame alla coprocoltura.

La determinazione dei leucociti fecali non è probabilmente di valore in pazienti che sviluppano diarrea durante il ricovero, essendo il test per il $C$. difficile di maggiore utilità. 5,10

\section{Lattoferrina fecale}

I limiti del test fecale dei leucociti sopra descritto ha fornito il razionale per lo sviluppo del test di agglutinazione della lattoferrina fecale. La lattoferrina è un marker di leucociti fecali, ma la sua misurazione è più precisa e meno vulnerabile a variazione durante la processazione dei campioni. ${ }^{5,10,11}$

I primi studi hanno descritto sensibilità e specificità che vanno dal 90 al 100\% nel distinguere la diarrea infiammatoria (per es. colite batterica o malattia infiammatoria intestinale) da cause non infiammatorie (per es., colite virale, sindrome dell'intestino irritabile). Tuttavia, il test non è diffusamente disponibile.

\section{Quando ottenere colture fecali}

Un consenso non è stato raggiunto sulle strategie ottimali per ottenere colture fecali. La discussione precedente sottolinea la difficoltà nel prevedere la presenza di cause batteriche di diarrea acuta, illustrata dal basso tasso di colture fecali positive nella maggior parte dei rapporti (da 1,5 a 5,6\%), ${ }^{5}$ con l'eccezione dei pazienti con grave malattia. Inoltre, la necessità di documentare un agente patogeno non è sempre chiara in quanto la maggior parte delle cause infettive di diarrea acuta sono auto-limitanti.

Per queste ragioni, è ragionevole continuare la terapia sintomatica per diversi giorni prima di considerare un'ulteriore valutazione in pazienti che non hanno una malattia grave, in particolare se il sangue occulto e leucociti fecali sono assenti. ${ }^{5}$ Colture di routine sono di scarsa utilità in pazienti che sviluppano diarrea dopo essere stato ricoverato in ospedale per 72 ore o più.

Nonostante queste limitazioni, si consiglia di ottenere colture fecali ab initio nei seguenti gruppi di pazienti: i) pazienti immunocompromessi, inclusi quelli infettati con il virus dell'immunodeficienza umana (HIV); ii) pazienti con comorbidità; iii) pazienti con diarrea infiammatoria in forma grave (compresi quelli con diarrea sanguinolenta); iv) pazienti con sottostante malattia infiammatoria intestinale in cui la distinzione tra riacutizzazione e infezione sovrapposta è critica; v) alcune categorie professionali, come i soggetti addetti alla lavorazione degli alimenti, che per fare ritorno al lavoro necessitano di colture fecali negative (Figura 3).

I risultati, invece, della coltura del fluido intraluminale ottenuto in corso di endoscopia sembrano aggiungere poco alle coprocolture.

\section{Processazione delle colture fecali}

Il medico dovrebbe specificare gli agenti patogeni di interesse o il sospetto clinico al momento della presentazione del campione fecale al fine di facilitare l'appropriata processazione delle feci nel laboratorio di microbiologia; supporti specifici, metodi particolari, o colorazioni, possono essere richiesti per isolare o identificare organismi di interesse..$^{10}$ Il campione deve essere inoculato su piastre di coltura il più rapidamente possibile.

Una coprocoltura di routine individua Salmonella, Campylobacter e Shigella, le tre cause più comuni di diarrea batterica negli Stati Uniti. Quando Aeromonas e la maggior parte dei ceppi di Yersinia sono possibili agenti patogeni (ad esempio, diarrea del viaggiatore o epidemie di origine alimentare, in particolare nei bambini), il laboratorio deve essere informato; questi organismi crescono in coltura di routine, ma spesso sfuggono, a meno che il loro isolamento non sia specificato.

Una coltura fecale positiva per uno di questi patogeni in un paziente con sintomi acuti diarroici può essere interpretato come un vero positivo.

Una gastroenterite da Listeria dovrebbe essere presa in considerazione in caso di epidemie di gastroenterite febbrile con diarrea non sanguinolenta se le colture di routine sono negative. A differenza di uova e parassiti, che sono spesso eliminati con intermittenza, questi agenti patogeni in genere sono escreti in modo continuo. Così, una coltura negativa di solito non è un falso negativo e ripetuti campioni sono raramente necessari.

Altri organismi che dovrebbero essere considerati in situazioni selezionate includono $E$. coli enteroemorragica (EHEC), virus e vibrioni.

\section{Quando prelevare feci per uova e parassiti}

L'invio di campioni di feci per ricerca uova e parassiti non è indicato per la maggior parte dei pazienti con diarrea acuta.

Vi sono, tuttavia, delle possibili indicazioni per la ricerca di uova e parassita: i) diarrea persistente (as- 
sociata con Giardia, Cryptosporidium e E. histolytica); ii) diarrea persistente dopo viaggi in Russia, Nepal, o regioni di montagna (associata con Giardia, Cryptosporidium e Cyclospora); iii) diarrea persistente con l'esposizione a bambini in asili nido (associata con Giardia e Cryptosporidium); iv) diarrea in uomo omosessuale o soggetto affetto da AIDS (associata con Giardia e E. histolytica nel primo caso, e una varietà di parassiti nel secondo); v) focolaio in comunità propagato attraverso l'acqua (associata con Giardia e Cryptosporidium); vi) diarrea sanguinante con pochi o assenti leucociti fecali (amebiasi intestinale).

Tre campioni devono essere inviati in giorni consecutivi (o ciascun campione a distanza di almeno 24 ore) per la ricerca di uova e parassiti poiché l'escrezione dei parassiti può essere intermittente al contrario dei batteri patogeni.

\section{Endoscopia}

L'endoscopia non è comunemente necessaria nella diagnosi di diarrea acuta. Può trovare indicazioni nelle seguenti situazioni: i) distinguere la malattia infiammatoria intestinale dalla diarrea infettiva; ii) diagnosi di infezione da $C$. difficile e ricerca di pseudomembrane. L'adozione diffusa di enzyme-linked test immunoenzimatico (ELISA) per $C$. difficile tossine A e B ha ridotto il tempo di attesa della ricerca di $C$. difficile e quindi ha diminuito la necessità di endoscopia in questi pazienti; iii) nei pazienti immunocompromessi che sono a rischio di infezioni opportunistiche con agenti come il citomegalovirus; iv) nei pazienti in cui si sospetta colite ischemica, qualora la diagnosi non sia chiara dopo la valutazione clinica e radiologica.

\section{Trattamento}

La gestione dei pazienti con diarrea acuta inizia con misure di carattere generale, come l'idratazione e le modifiche della dieta. La terapia antibiotica non è necessaria nella maggior parte dei casi in quanto la malattia è di solito autolimitante. Tuttavia, la terapia antibiotica, empirica e specifica, può essere considerata in certe situazioni.

\section{Soluzioni reidratanti orali}

La terapia più critica nella diarrea è l'idratazione, che di preferenza deve essere per os con soluzioni che contengono acqua, sale e zucchero. La terapia di reidratazione orale è gravemente sottoutilizzata negli Stati Uniti, dove gli operatori sanitari tendono ad un uso eccessivo di idratazione per via endovenosa. $\mathrm{Si}$ stima che l'uso corretto di reidratazione orale può ridurre i ricoveri di bambini per 100.000 per anno.

Le soluzioni reidratanti orali sono state sviluppate in seguito alla constatazione che, in molte malattie diarroiche del piccolo intestino, l'assorbimento intestinale del glucosio, tramite il canale di cotrasporto sodio-glucosio, rimane intatto. Così, nelle malattie diarroiche causate da qualsiasi organismo che dipende da processi secretori intestinali, l'intestino rimane in grado di assorbire acqua, sale e glucosio.

La composizione della soluzione di reidratazione orale (per ogni litro di acqua) raccomandata dall'Organizzazione Mondiale della Sanità (OMS) è costituita da: i) 3,5 $\mathrm{g}$ di cloruro di sodio; ii) $2,9 \mathrm{~g}$ di citrato trisodico o 2,5 g di bicarbonato di sodio; iii) $1,5 \mathrm{~g}$ di cloruro di potassio; iv) $20 \mathrm{~g}$ di glucosio o $40 \mathrm{~g}$ di saccarosio.

Una soluzione simile può essere fatto con l'aggiunta di un mezzo cucchiaino di sale, mezzo cucchiaino di bicarbonato di sodio, e quattro cucchiai di zucchero ad un litro d'acqua.

Le concentrazioni degli elettroliti di bevande impiegate per la reintegrazione del sudore non sono equivalenti a soluzioni di reidratazione orale, anche se possono essere sufficienti per un paziente con diarrea acuta che non abbia altre patologie e che non è disidratato.

Succhi di frutta diluiti e bevande analcoliche aromatizzate, insieme a crackers e brodi o minestre possono anche soddisfare le esigenze di acqua e sale nei pazienti non gravi. ${ }^{1}$

Se disponibile, racecadotril, un inibitore delle enkefalinasi, può essere una efficace aggiunta alle soluzioni reidratanti orali nei bambini.

\section{La terapia antibiotica empirica}

La mancanza di metodi rapidi di test diagnostici per i patogeni enterici richiede che le decisioni sulla terapia siano prese spesso empiricamente, al momento della presentazione.

In generale, la terapia empirica per la diarrea acuta acquisita in comunità può essere utile, ma non sembra alterare drammaticamente il corso della malattia in popolazioni non selezionate.

\section{Quando trattare}

Le linee guida IDSA del 2001 hanno concluso che qualsiasi considerazione di terapia antibiotica deve essere attentamente valutata rispetto alle conseguenze non volute e potenzialmente dannose. ${ }^{8}$

La decisione di trattare con la terapia antibiotica empirica nei seguenti gruppi si basa su studi randomizzati controllati che mostrano una significativa riduzione della durata della diarrea e altri sintomi, ma anche su linee guida e su una comprovata esperienza clinica: ${ }^{5,12}$ i) quelli con diarrea del viaggiatore da moderata a grave, caratterizzata da più di quattro evacuazioni di feci non formate al giorno, febbre, sangue, pus o muco nelle feci; ii) quelli con più di otto evacuazioni di feci al giorno, deplezione del volume, sintomi per 
più di una settimana, nei quali l'ospedalizzazione viene presa in considerazione; iii) gli immunocompromessi (HIV o in corso di terapia immunosoppressiva); iv) pazienti con HIV con importanti comorbidità (es. affetti da malattie infiammatorie intestinali croniche; portatori di dispositivi/protesi endovascolari, severe emoglobinopatie, dializzati); v) età $>65$ anni o $<6$ mesi; vi) terapia antibiotica empirica può essere considerata nei pazienti che si presentano con segni e sintomi di diarrea batterica, come febbre, diarrea con sangue (tranne, come già detto, per sospetto di EHEC o infezione da $C$. difficile), e la presenza di sangue occulto o leucociti fecali.

Viene raccomandata terapia empirica con un fluorochinolone orale (ciprofloxacina $500 \mathrm{mg}$ due volte al giorno, norfloxacina $400 \mathrm{mg}$ due volte al giorno, o levofloxacina $500 \mathrm{mg}$ una volta al giorno) per $3 / 5$ giorni, purchè non ci sia il sospetto di EHEC o infezione da Campylobacter resistente ai fluorochinoloni. ${ }^{5,10,11}$

Azitromicina (500 mg per os una volta al giorno per tre giorni) o eritromicina (500 $\mathrm{mg}$ per os due volte al giorno per cinque giorni) sono agenti alternativi, in particolare se si sospetta resistenza ai fluorochinoloni.

\section{Casi particolari}

\section{Escherichia coli enteroemorragico}

Gli antibiotici devono essere evitati nei pazienti con infezione sospetta o comprovata con EHEC.

Non vi è alcuna evidenza di beneficio dalla terapia antibiotica per infezione EHEC, mentre c'è una forte preoccupazione per un aumento del rischio di sindrome emolitica-uremica che potrebbe essere mediata da un aumento della produzione o rilascio di tossina Shiga quando gli antibiotici vengono somministrati. ${ }^{12}$ Infezione da EHEC deve essere sospettata nei pazienti con diarrea sanguinante, dolore addominale e malessere, non febbrili o con sola febbricola.

\section{Clostridium difficile}

I pazienti con diarrea acuta devono essere interrogati attentamente su una precedente terapia antibiotica e su altri fattori di rischio per l'infezione da $C$. difficile. La terapia appropriata per questa infezione è la sospensione degli antibiotici, se possibile, e la considerazione di metronidazolo o vancomicina se i sintomi sono più che lievi, o peggiorano, o persistono.

\section{Listeria monocytogenes}

Può presentarsi con diarrea e/o malattia sistemica. Se riscontrata in coltura, il trattamento deve essere a base di ampicillina e gentamicina o trimetoprim-sulfametossazolo.

Sebbene quest'ultimo possa essere più efficace per il trattamento di listeriosi, interferisce con il metabo- lismo di acido folico e quindi dovrebbe essere usato con cautela in donne in gravidanza.

\section{La terapia sintomatica}

La loperamide può essere utilizzata per il trattamento sintomatico dei pazienti con diarrea acuta, in cui la febbre è assente o ci sia solo febbricola e le feci non sono sanguinolente.

In due studi randomizzati e controllati, la loperamide, rispetto al placebo, ha mostrato di ridurre sensibilmente il numero di movimenti intestinali e le scariche alvine quando somministrato con ciprofloxacina. La dose di loperamide è di due compresse $(4 \mathrm{mg})$ inizialmente, poi $2 \mathrm{mg}$ dopo ogni scarica di feci non formate; la dose non dovrebbe superare i $16 \mathrm{mg} /$ die in $\leq 2$ giorni.

Il difenossilato è un agente alternativo, ma non è stato studiato in studi randomizzati controllati. La dose di difenossilato è di due compresse $(4 \mathrm{mg})$ quattro volte al giorno per $\leq 2$ giorni. Ha effetti oppiacei centrali e può causare effetti collaterali di tipo colinergico. I pazienti devono essere avvertiti che il trattamento con questi agenti possono mascherare la quantità di liquidi persi, poiché i liquidi possono accumularsi nell'intestino. Di conseguenza, i liquidi devono essere utilizzati in modo aggressivo quando sono impiegati questi agenti. Un altro potenziale problema è che entrambi i farmaci possono facilitare lo sviluppo della sindrome emolitico-uremica in pazienti con infezione da EHEC.

Il subsalicilato bismuto è stato utilizzato anche per il trattamento sintomatico della diarrea acuta. Rispetto al placebo, il subsalicilato bismuto ha ridotto significativamente il numero di feci non formate e aumentato la percentuale di guarigioni, alla fine dei cicli di trattamento. Tuttavia, in studi che lo confrontavano con la loperamide, quest'ultima ha risolto i sintomi in modo significativamente più veloce. Un suo possibile ruolo può essere in pazienti con febbre elevata e diarrea severa, condizioni in cui la loperamide dovrebbe essere evitata. La dose di subsalicilato bismuto è di 30 $\mathrm{ml}$ o due compresse ogni 30 minuti per otto dosi.

I probiotici, compresi batteri che aiutano nella ricolonizzazione dell'intestino con flora non-patogena, possono essere utilizzati come terapia alternativa. Essi hanno dimostrato di essere utili nel trattamento della diarrea del viaggiatore e nella diarrea acuta non specifica dei bambini.

\section{Consigli dietetici}

Non ci sono specifiche raccomandazioni alimentari, al di là dei consigli per l'idratazione per via orale discussa in precedenza, stabilite da studi clinici controllati. Tuttavia, una nutrizione adeguata durante un episodio di diarrea acuta è importante per facilitare il 
rinnovo degli enterociti; se i pazienti sono anoressici, un breve periodo di consumo di soli liquidi non sarà dannoso. Amidi e cereali bolliti (ad esempio, patate, pasta, riso, grano e avena) salati sono indicati in pazienti con diarrea acquosa; crackers, banane, zuppa, verdure bollite possono anche essere consumati. ${ }^{9} \mathrm{Gli}$ alimenti ad alto contenuto di grassi dovrebbero essere evitati, fino a quando la funzione intestinale non ritorni alla normalità dopo una diarrea significativa.

Inoltre, un secondario malassorbimento di lattosio è comune dopo enterite infettiva e può durare per diverse settimane o mesi. Pertanto, l'eliminazione temporanea di cibi contenenti lattosio può essere ragionevole. Il vantaggio di tentare di ripopolare la flora intestinale con yogurt contenente fermenti vivi o probiotici altri non è provata negli adulti.

\section{Prevenzione}

La prevenzione riguarda in particolar modo la categoria dei viaggiatori o comunque dei frequentatori di comunità a rischio. La prevenzione si avvale di 4 punti principali ovvero: i) indicazioni sul consumo di cibi e bevande; ii) immunizzazione; iii) uso di farmaci non antibiotici; iv) uso di farmaci per la profilassi antibiotica.

Come regola generale si impone ai soggetti ospiti di Paesi a rischio di evitare cibi potenzialmente contaminati ed in particolare acqua non imbottigliata, verdure crude, latticini e frutti di mare (Tabella 5).

Per quanto riguarda l'acqua, si consiglia l'utilizzo di prodotto imbottigliato, eventualmente con aggiunta di anidride carbonica. Particolare attenzione va rivolta al ghiaccio, spesso ottenuto da acqua di fonte. Nel caso non sia disponibile acqua adeguatamente trattata con cloro, la bollitura (che deve prolungarsi oltre un minuto) è un metodo affidabile per la disinfezione. Alternativamente possono essere utilizzate la tintura di iodio o gli appositi filtri. ${ }^{12}$
Per quanto riguarda la vaccinazione, sono disponibili due formulazioni orali e una parenterale contro l'infezione da Vibrio cholera; quest'ultima risulta scarsamente protettiva e di breve durata, mentre quelli assumibili per via orale hanno mostrato una buon profilo in termini di efficacia e durata protettive, tollerabilità e comodità di assunzione. solo l'OMS ha rimosso la vaccinazione anticolerica dalla lista delle vaccinazioni internazionali, tuttavia alcuni studi ne consigliano l'uso negli operatori sanitari, lavoratori o ospiti in campi profughi e militari.

Anche l'epatite A può essere prevenuta attraverso la somministrazione di un vaccino parenterale inattivato.

Nell'ambito della profilassi ottenuta con farmaci non antibiotici, non vi sono evidenze di efficacia di loperamide e probiotici, mentre il bismuto subsalicilato assunto 4 volte al giorno al dosaggio di $262,5 \mathrm{mg}$ è in grado di ridurre il rischio di diarrea del viaggiatore del $60 \%$ circa; tuttavia il farmaco non è disponibile nella farmacopea italiana e gli alti dosaggi non lo rendono raccomandabile per una profilassi.

Sulla prevenzione antibiotica va precisato che nessun antibiotico riporta in scheda tecnica l'indicazione per la profilassi della diarrea del viaggiatore, quindi la prescrizione è da ritenersi off label. I farmaci testati in letteratura sono stati il cotrimossazolo e ciprofloxacina o norfloxacina che si sono dimostrati efficaci, tuttavia la comparsa di spettri di resistenza e gli effetti collaterali associati portano alla conclusione che tale pratica non è raccomandabile.

\section{Sintesi e possibili raccomandazioni}

La valutazione iniziale dei pazienti con diarrea acuta dovrebbe includere la ricerca di segni di deplezione del volume extracellulare (ad esempio, riduzione dell'elasticità della pelle, ipotensione ortostatica); una raccolta

Tabella 5. Le dieci regole per prevenire il contagio nella diarrea del viaggiatore.

1. Bere acqua purificata o, se imbottigliata, addizionata di anidride carbonica

2. Mangiare cibi ben cotti e serviti molto caldi (vale a dire appena preparati)

3. Mangiare frutta dalla buccia spessa, sbucciandola da sé ed evitando le macedonie già pronte

4. Evitare insalate di verdure crude, specie se a base di vegetali in foglia

5. Non utilizzare mai ghiaccio, nemmeno nelle bibite alcoliche

6. Consumare latte e latticini solo se si è sicuri che siano stati pastorizzati

7. Evitare i molluschi e tutto il pesce crudo o poco cotto, anche se con limone, lime o aceto

8. Evitare per quanto possibile il cibo venduto nei baracchini lungo le strade

9. Asciugare prima di bere l'esterno delle lattine messe a refrigerare nel ghiaccio o nell'acqua

10. Usare acqua purificata anche per lavarsi i denti e per assumere i medicinali

Tradotta e adattata da Rossanese et al., 2005. ${ }^{11}$ 
accurata della storia per determinare la durata dei sintomi; inoltre ricercare sulla presenza di febbre e/o di reazione peritoneale, che possono essere indizi di infezione con un patogeno invasivo enterico.

Una valutazione diagnostica è indicata in pazienti con malattia relativamente grave, diarrea con sangue, $\mathrm{o}$ in pazienti ad alto rischio (ad esempio, anziani o immunocompromessi).

La storia del paziente può essere utile per identificare i patogeni associati con un episodio di diarrea acuta e può aiutare a guidare la terapia empirica, quando indicata. Una storia alimentare, compreso il consumo di prodotti lattiero-caseari non pastorizzati, a base di carne cruda o poco cotta o pesce, o preparati vitaminici organici possono suggerire alcuni agenti patogeni (Tabella 3). Inoltre, la temporizzazione dei sintomi in relazione all'esposizione a sospetto alimento responsabile possono essere importanti indizi diagnosi (Tabella 4).

Diversi studi hanno valutato l'accuratezza dei leucociti fecali soli o in combinazione con il test del sangue occulto. La capacità di questi test di prevedere una diarrea infiammatoria non è ritenuta univoca.

Si consiglia di ottenere colture fecali, su presentazione iniziale in pazienti immunocompromessi (HIVinfetti, gli anziani, i pazienti con comorbidità o con sottostante malattia infiammatoria intestinale), quelli con diarrea grave o con sangue, e nei lavoratori addetti alla manipolazione degli alimenti.

L'invio di campioni di feci per ricerca di uova e parassiti non è utile per la maggior parte dei pazienti affetti da diarrea acuta. Tuttavia, si consiglia lo studio di uova e parassita nei pazienti con diarrea persistente, negli omosessuali, durante un'epidemia di comunità a trasmissione acquosa (associata con Giardia e Cryptosporidium), o con diarrea ematica con pochi o nessun leucocita fecale (associata con amebiasi intestinale).

La gestione dei pazienti con diarrea acuta inizia con misure di carattere generale, come l'idratazione e modifica della dieta. Si consiglia una terapia antibiotica nella maggior parte dei casi (Grado 1A).

$\mathrm{Si}$ consiglia terapia antibiotica empirica per i pazienti con diarrea del viaggiatore da moderata a grave, quelli con segni e sintomi di diarrea batterica invasiva, come febbre e diarrea sanguinolenta, gli anziani e pazienti immunocompromessi (Grado 1A). Si consiglia di non intraprendere terapia antibiotica per i pazienti con infezione sospetta o comprovata con EHEC (Grado 1B).

Se la terapia empirica è indicata, si consiglia il trattamento con un fluorochinolone per tre-cinque giorni, in assenza di sospetta infezione da EHEC o da Campylobacter con sospetta resistenza a chinolonici (Grado 1A). Se si sospetta Campylobacter, si consiglia azitromicina o eritromicina come agenti alternativi, dato alti tassi di resistenza ai fluorochinoloni (Grado 1B).
Terapia antibiotica mirata deve essere somministrata quando un patogeno intestinale viene identificato.

Si consiglia la loperamide come agente antimotilità per il trattamento sintomatico dei pazienti con diarrea acuta in cui la febbre è assente o c'è solo febbricola $\mathrm{e}$ le feci non sono sanguinolente (Grado 2A) (Figura 4).

\section{Diarrea cronica}

\section{Eziologia}

Numerosi sono i disordini che possono associarsi a diarrea cronica.

L'eziologia risente del contesto socio-ambientale; come regola generale le principali cause di diarrea dipendono dalle condizioni socio-economiche della popolazione. ${ }^{13-15}$

Nei paesi in via di sviluppo la diarrea cronica è frequentemente causata da infezioni batteriche croniche, micobatteriche o parassitarie, sebbene disordini funzionali, malassorbimento e malattie infiammatorie croniche intestinali siano molto comuni.

Nei paesi sviluppati, cause comuni sono la sindrome da intestino irritabile, le IBD, sindromi da malassorbimento (intolleranza al lattosio e malattia celiaca) ed infezioni croniche (in particolare in pazienti immunodepressi). Inoltre numerosi farmaci possono essere causa di diarrea (Tabella 6).

La diarrea cronica può essere suddivisa in 3 categorie principali: acquosa, grassa (da malassorbimento) e infiammatoria (con sangue e pus). Sono tuttavia frequenti i casi con sovrapposizioni tra le categorie.

La Tabella 7 elenca le cause principali di diarrea cronica classificate in base alle caratteristiche tipiche delle feci.

La diarrea acquosa può essere a sua volta suddivisa in forme di tipo secretorio (ridotto assorbimento di acqua), di tipo osmotico (ritenzione di acqua nel colon attribuibile a diminuito assorbimento di alcune sostanze), e di tipo funzionale (da ipermotilità). La diarrea secretoria, causata da fattori esogeni (tossine batteriche, lassativi non osmotici, acidi grassi, acidi biliari) o da fattori endogeni (VIP, calcitonina, prostaglandine, serotonina) è caratterizzata da alte concentrazioni di cloro, sodio, potassio, bicarbonato e acqua. ${ }^{13,15,16}$ Pertanto clinicamente le diarree secretorie avranno feci acquose, volume superiore a $1000 / \mathrm{mL} / 24$ ore, notevoli quantità di $\mathrm{Na}^{+}, \mathrm{Cl}^{-} \mathrm{e} \mathrm{HCO}_{3}{ }^{-}$. Inoltre sono presenti anche di notte $\mathrm{e}$ in esse il test del digiuno è negativo: la sospensione dell'alimentazione per $24 / 48$ ore non comporta scomparsa della diarrea (test del digiuno negativo). ${ }^{13,15,16}$

La diarrea osmotica è, invece, caratterizzata dalla presenza nel lume intestinale di soluti osmoticamente attivi quali carboidrati alimentari, non assorbiti nel tenue o non digeriti per deficit enzimatici o sostanze non assorbibili ingerite come lassativi o antiacidi (sali 
di $\mathrm{Mg}$, solfati o fosfati di sodio, lattulosio, sorbitolo, mannitolo, fruttosio). Quando l'osmolarità delle feci supera di $100 \mathrm{mOsm} / \mathrm{kg}$ quella plasmatica che è di 290 $\mathrm{mOsm} / \mathrm{kg}$ compare diarrea. In questi casi il volume fecale varia tra $500-1000 \mathrm{~mL} / 24$ ore e le concentrazioni di elettroliti nelle feci sono basse. La sospensione dell'alimentazione per os o l'eliminazione dalla dieta dei soluti osmoticamente attivi fa regredire la diarrea (test del digiuno positivo). I pazienti con diarrea di tipo funzionale presentano un volume di feci minore (meno di $350 \mathrm{~mL}$ al giorno) e non presentano diarrea durante le ore notturne..$^{13,15,16}$

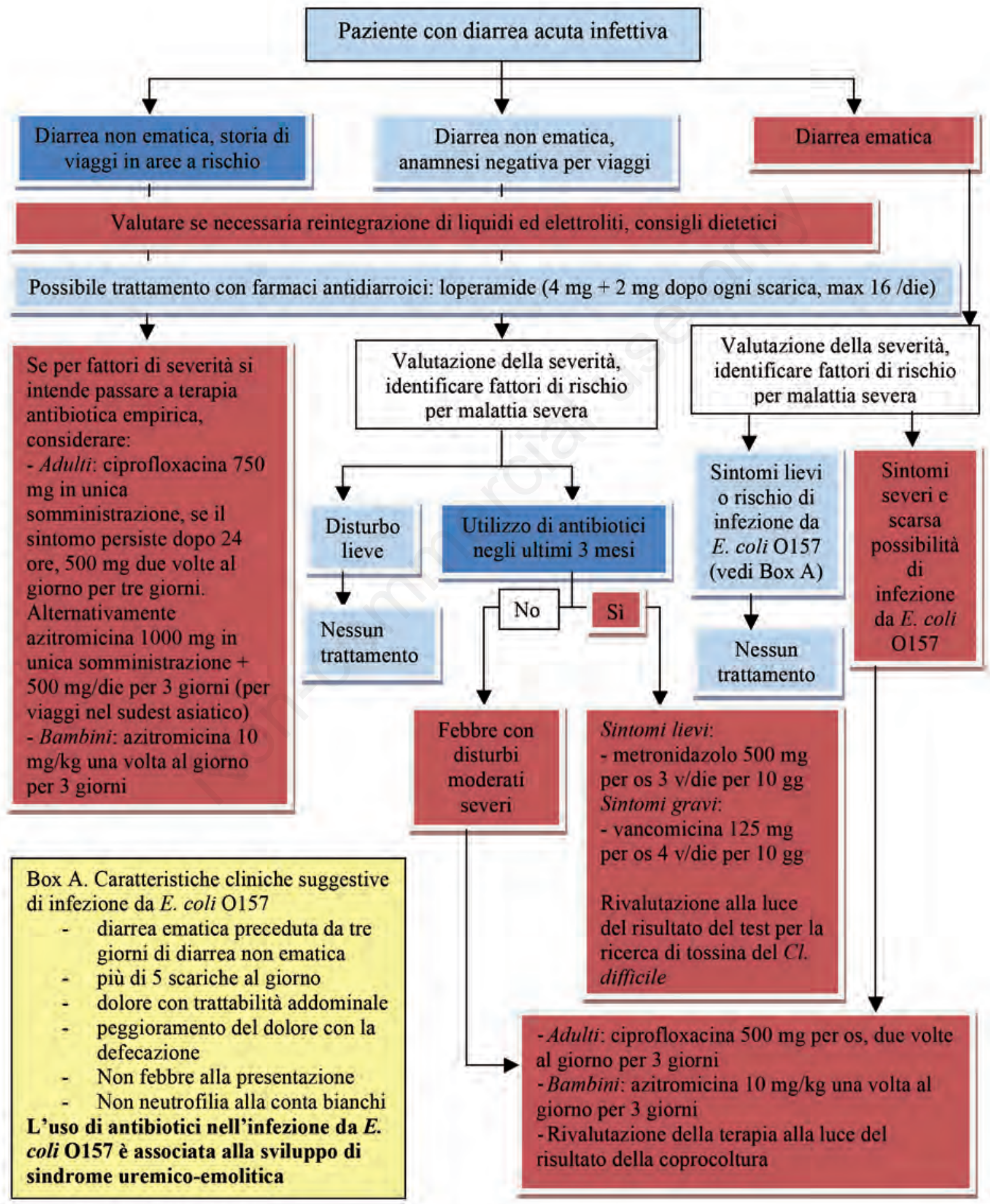

Figura 4. Approccio terapeutico antibiotico empirico della diarrea acuta infettiva. 


\section{Cause osmotiche}

La diarrea osmotica si realizza per la presenza all'interno del lume intestinale di soluti scarsamente riassorbibili ed osmoticamente attivi che richiamano acqua oltre la capacità riassorbente del colon.

Caratteristica peculiare di questo tipo di diarrea è che si arresta con il digiuno o sospendendo l'assunzione dell'agente responsabile. Difficilmente si accompagnano a rilevanti alterazioni elettrolitiche.

\begin{abstract}
Abuso di lassativi osmotici
L'assunzione di antiacidi contenenti magnesio, di integratori alimentari salini o di lassativi può indurre diarrea osmotica caratterizzata da un gap osmotico fecale $>125 \mathrm{mOsm} / \mathrm{lg}$. I lassativi osmotici contenenti solfati o fosfati causano una diarrea senza gap osmotico in quanto il sodio segue i soluti anionici. A tal fine può essere necessaria la ricerca diretta di fosfati e solfati nelle feci. Per calcolare il gap osmotico si utilizza la formula 290-2 (Na+K). Data la maggior attendibilità della misurazione degli elettroliti eseguita su campione fecale delle 48-72 ore, il test non è di semplice attuazione.
\end{abstract}

\section{Malassorbimento di carboidrati}

Il deficit di assorbimento di alcuni zuccheri, dovuto a difetti congeniti o acquisiti degli enzimi o disaccaridasi deputati al loro metabolismo, può determinare la comparsa di diarrea osmotica con gap osmotico intermedio (tra 50 e $120 \mathrm{mOsm} / \mathrm{kg}$ ) e basso $\mathrm{pH}$. Il deficit di lattasi, enzima responsabile dell'idrolisi del lattosio e residente nei microvilli degli entero- citi del piccolo intestino, è una delle cause più comuni di diarrea cronica dell'adulto. Si verifica precocemente negli individui di razza non caucasica ma interessa dal 5 al 30\% della popolazione degli Stati Uniti.

Raramente si manifesta come disturbo primitivo congenito. Spesso questi pazienti non giungono all'attenzione del medico poiché associano la comparsa del sintomo all'ingestione del latte e attuano spontaneamente una dieta di esclusione.

Il test diagnostico più utilizzato è rappresentato del breath test al lattosio che si esegue somministrando al paziente un carico di lattosio di $25 \mathrm{~g}$ e misurando la quantità di $\mathrm{H}+$ espirata dal paziente. Esiste tuttavia un $10 \%$ di pazienti che non posseggono una flora intestinale in grado di produrre $\mathrm{H}$, e risultando pertanto falsi negativi. Più invasiva e dispendiosa risulta la determinazione dell'attività lattasica sul campione bioptico che pertanto non viene utilizzata.

Va ricordato che alcuni zuccheri come il sorbitolo, utilizzati come dolcificanti in caramelle, gomme e altri prodotti ipocalorici, sono ampliamente mal assorbiti e per questo responsabili di diarrea. Allo stesso modo il lattulosio somministrato agli epatopatici per prevenire l'insorgenza di episodi di encefalopatia epatica.

Frequentemente la diarrea da malassorbimento di carboidrati si manifesta con dolore e gonfiore dell'addome.

\section{Diarrea associata a steatorrea}

Il malassorbimento dei grassi determina la presenza di feci untuose, maleodoranti che caratteristicamente si rimuovono difficilmente dalle pareti del

Tabella 6. Farmaci potenzialmente diarrogeni.

\begin{tabular}{|c|c|c|c|}
\hline Farmaci cardiovascolari & Farmaci agenti sul SNC & Farmaci gastrointestinali & Farmaci anti-infiammatori \\
\hline $\begin{array}{l}\text { Antiaritmici } \\
\text { Digitale } \\
\text { Procainamide } \\
\text { Chinidina }\end{array}$ & $\begin{array}{l}\text { Ansiolitici } \\
\text { Alprazolam } \\
\text { Mepobramato }\end{array}$ & $\begin{array}{l}\text { Antiacidi } \\
\text { Anti-H2 recettori } \\
\text { Misoprostolo } \\
\text { Antiacidi contenti } \mathrm{Mg} \\
\text { Inibitori di pompa protonica }\end{array}$ & $\begin{array}{l}\text { Sali d'oro } \\
\text { FANS } \\
\text { Ibuprofene } \\
\text { Naprossene } \\
\text { Colchicina }\end{array}$ \\
\hline $\begin{array}{l}\text { Antipertensivi } \\
\text { Ace-inibitori } \\
\text { Anti R-angotensina II } \\
\beta \text {-bloccanti } \\
\text { Idralazina } \\
\text { Metildopa } \\
\text { Litio } \\
\text { Tacrine }\end{array}$ & $\frac{\text { Antiparkinsoniani }}{\text { Levodopa }}$ & $\begin{array}{l}\text { Acidi biliari } \\
\text { Acido chenodeossicolico } \\
\text { Acido ursodeossicolico }\end{array}$ & \\
\hline $\begin{array}{l}\text { Ipocolesterolemizzanti } \\
\text { Colestiramina } \\
\text { Clorfibrato - Gemfibrozil } \\
\text { Statine }\end{array}$ & $\begin{array}{l}\text { Altro } \\
\text { Anticolinergici } \\
\text { Fluoxetina }\end{array}$ & $\begin{array}{l}\underline{\text { Lassativi }} \\
\text { Catartici } \\
\text { Lattulosio } \\
\text { Sorbitolo }\end{array}$ & \\
\hline $\begin{array}{l}\text { Diuretici } \\
\text { Acetazolamide } \\
\text { Acido etacrinico - Furosemide }\end{array}$ & & $\frac{\text { Altri }}{\text { Aminosalicilati }}$ & \\
\hline
\end{tabular}

SNC, sistema nervoso centrale; FANS, farmaci anti-infiammatori non-steroidei. 
water. I pazienti spesso mostrano calo ponderale e deficit nutrizionali dovuti al concomitante malassorbimento di aminoacidi e proteine. La massa fecale è aumentata a causa dell'effetto osmotico degli acidi grassi. Il pH è compreso tra 6 e 7 e il gap osmolare non è aumentato. Il contenuto di lipidi nelle feci è incrementato rispetto ai valori normali $(7 \mathrm{~g} / \mathrm{die}) \mathrm{e}$ indirizza verso un malassorbimento da malattie della mucosa dell'intestino tenue quando si attesta tra i 15 e $25 \mathrm{~g} /$ die o verso una insufficienza del pancreas esocrino per valori $>40 \mathrm{~g} /$ die.

\section{Malattia celiaca}

È un'intolleranza permanente al glutine, sostanza proteica presente nei cereali (avena, frumento, farro, kamut, orzo, segale, spelta e triticale).

L'incidenza di questa intolleranza in Italia è stimata in un soggetto ogni 100 persone. L'introduzione di glutine nei soggetti affetti determina una reazione infiammatoria linfocita $\mathrm{T}$ mediata che distrugge la mucosa intestinale del piccolo intestino.

Colpisce prevalentemente il sesso femminile ed è distribuita in tutte le fasce d'età.

La diagnosi prevede la ricerca di anticorpi antitranglutaminasi e anti endomisio $\operatorname{Ig} \mathrm{A}$, o qualora sia presente un deficit selettivo di IgA, di classe IgG. La ricerca di questi anticorpi è utile anche nel follow-up. La diagnosi sierologica può non essere effettuabile in paziente con ipogammaglobulinemia. Può essere effettuata anche la tipizzazione HLA, poiché l'aplotipo DQ2, è presente nel $90 \%$ dei casi e nei restanti casi si riscontra il DQ8. In tutti i casi è necessario procedere alla gastroduodenoscopia con biopsia della mucosa duodenale, che permetta di rilevarne gli aspetti istologici tipici.

Accettata ed utilizzata universalmente nell'interpretazione delle alterazioni istologiche dell'intestino tenue è la classificazione di Marsh, modificata da Oberhuber (Tabella 8). ${ }^{17}$

La terapia è rappresentata dalla dieta gluten-free.

Tabella 7. Patologie che rientrano nella diagnosi differenziale di una diarrea cronica in relazione alle caratteristiche delle feci.

\begin{tabular}{|c|c|c|}
\hline Acquosa & Grassa & Infiammatoria o essudativa \\
\hline 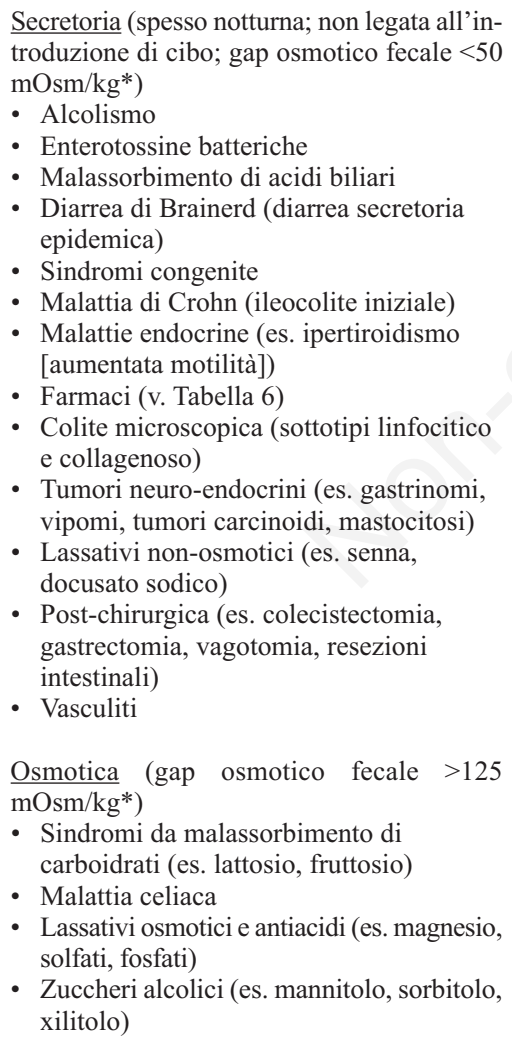 & $\begin{array}{l}\text { Sensazione di gonfiore addominale e steator- } \\
\text { rea nella maggior parte dei casi, ma non in } \\
\text { tutti } \\
\text { Sindromi da malassorbimento (diminuzione } \\
\text { o perdita della capacità di assorbimento) } \\
\text { - Amiloidosi } \\
\text { - Malassorbimento di carboidrati } \\
\text { (es. intolleranza al lattosio) } \\
\text { - Sprue celiaca (enteropatia da glutine) } \\
\text { - diverse presentazioni cliniche } \\
\text { - Bypass gastrico } \\
\text { - Danno linfatico (es. scompenso cardiaco } \\
\text { congestizio, alcuni linfomi) } \\
\text { - Farmaci (es. orlistat, acarbosio) } \\
\text { - Ischemia mesenterica } \\
\text { - Parassiti non-invasivi del piccolo intestino } \\
\text { (es. Giardia) } \\
\text { - Diarrea post-resezione } \\
\text { - Sindrome del colon breve } \\
\text { - Iperproliferazione batterica del piccolo } \\
\text { intestino (>105 batteri/mL) } \\
\text { - Sprue tropicale } \\
\text { - Malattia di Whipple (infezione da } \\
\text { Treponema Whippleii) } \\
\text { - Maldigestione (ridotta funzione digestiva) } \\
\text { - Patologie epato-biliari } \\
\text { - } \text { - Iniliari } \\
\text { regolato intraluminali inadeguati di acidi } \\
\text { - Insufficienza del pancreas esocrino } \\
\text { - }\end{array}$ & $\begin{array}{l}\text { Leucocitosi, sangue occulto o franco sangui- } \\
\text { namento nelle feci, pus fecale } \\
\text { - Malattia infiammatoria del colon } \\
\text { - Malattia di Crohn (la malattia di Crohn } \\
\text { ileale o in fase precoce può dare diarrea } \\
\text { secretoria) } \\
\text { - Diverticoliti } \\
\text { - Colite ulcerosa } \\
\text { - Digiuno-ileite ulcerosa } \\
\text { - Malattie infettive invasive } \\
\text { - Clostridium difficile (diarrea pseudo } \\
\text { membranosa - storia di trattamento } \\
\text { antibiotico) } \\
\text { - Infezioni batteriche invasive } \\
\text { (es. tubercolosi, yersiniosi) } \\
\text { - Infezioni parassitiche invasive } \\
\text { (es. Entamoeba - storia di recenti viaggi) } \\
\text { - Infezioni virali ulceranti } \\
\text { (es. Citomegalovirus, Herpes simplex) } \\
\text { - Neoplasie } \\
\text { - Carcinoma del colon } \\
\text { - Linfomi } \\
\text { - Adenocarcinoma villoso } \\
\text { Colite da radiazioni }\end{array}$ \\
\hline
\end{tabular}

*Calcolo del gap osmotico fecale $=290-2 \times($ sodio fecale + potassio fecale $)$. È utile per distinguere tra una diarrea secretoria ed una diarrea osmotica. L'osmolalità fecale normale è $290 \mathrm{mOsm} / \mathrm{kg}(290 \mathrm{mmol} / \mathrm{kg})$. Anche se la misurazione dei livelli fecali di elettroliti non viene più condotta di routine, la conoscenza del gap osmotico fecale è utile per definire se una diarrea acquosa rappresenta una diarrea cronica osmotica (gap osmotico fecale superiore a $125 \mathrm{mOsm} / \mathrm{kg}$ [125 mmol/kg]) o una diarrea cronica secretoria (gap osmotico fecale inferiore a $50 \mathrm{mOsm} / \mathrm{kg}[50 \mathrm{mmol} / \mathrm{kg}])$. Tradotta e adattata da Fine e Schiller, 1999. ${ }^{13}$ 
Il glutine è costituito a sua volta da frazioni singole, tra le quali ne esiste una in particolare che causa l'effetto tossico: la prolamina, che nel caso specifico del frumento viene denominata gliadina. Recentemente il comitato scientifico dell'Associazione Italiana Celiachia (AIC), ha espresso un parere a proposito dell'idoneità dell'avena per i celiaci: ${ }^{18}$ Fino ad ora la maggior parte dei dati disponibili ha evidenziato che, nel celiaco, l'assunzione quotidiana anche di $70 \mathrm{~g}$ d'avena non determini alcun problema sul piano clinico, sierologico elo istologico. Tuttavia l'avena conterrebbe degli epitopi in grado di determinare, in vitro, alcune alterazioni della mucosa intestinale. In particolare, $i$ risultati emersi da un 'indagine pubblicata sulla rivista scientifica Gut porrebbero in discussione la sicurezza dell'assunzione dell'avena nel soggetto celiaco. Sulla base di quanto sopra, dunque, l'atteggiamento più idoneo da adottare sembra essere per il momento quello della prudenza, in attesa ovviamente di eventuali ulteriori studi in proposito (Comitato Scientifico Nazionale AIC, novembre 2003). ${ }^{19}$

\section{Malattia di Whipple}

Enteropatia sostenuta dall'infiltrazione istiocitica della mucosa del tenue in corso di infezione da Treponema Whippleii. Si associa a febbre, artralgie, linfoadenopatie e può coinvolgere il sistema nervoso centrale e l'endocardio. Colpisce più frequentemente i maschi di razza bianca di mezza età e si diagnostica con la biopsia duodenale. Il trattamento antibiotico prevede un anno di terapia con cotrimossazolo.

La gastroduodenoscopia con biopsia permette di diagnosticare altre affezioni che si manifestano con un quadro di steatorrea quali: linfangectasie intestinali, abetalipoproteinemia, gastroenterite eosinofila, ischemia mesenterica o la giardiasi. In quest'ultimo caso è possibile identificare il parassita o le sue cisti nell'esame a fresco delle feci, o ricorrere al test ELISA o all'immunofluorescenza per identificare la ricerca di antigeni specifici fecali. I valori delle $\operatorname{IgM}$, IgG e IgA danno delle indicazioni sulla tempistica dell'infezione. La giardiasi è una parassitosi che si trasmette per via

Tabella 8. Classificazione istologica delle lesioni intestinali nella celiachia.

Aumento IEL (maggiore 40/100 ce ) (tipo 1)

Iperplasia delle cripte (tipo 2)

Atrofia lieve dei villi (tipo 3a)

Atrofia subtotale dei villi (tipo $3 b$ )

Atrofia totale dei villi (tipo 3c)

IEL, linfociti intraepiteliali; ce, cellule epiteliali. oro-fecale e il deficit di selettivo di IgA predispone a tale infezione. La terapia si basa sulla somministrazione di metronidazolo o tinidazolo, alternativamente furazolidone.

Altre infezioni potenzialmente responsabili di una diarrea cronica nei paesi in via di sviluppo sono rappresentate da E. coli enteroaggregante, E. coli enteropatogena e $C$. difficile. Nel mondo occidentale, si segnalano diarree persistenti da Campylobacter e Salmonella, rare nei pazienti immunocompetenti, ma più frequenti nella popolazione immunodepressa, interessata inoltre da infezioni da micobatteri atipici e Criptosporidium o Candida. In questi soggetti l'esame colturale delle feci deve essere effettuato in prima battuta. Va ricordato inoltre che l'utilizzo sempre più diffuso di antibiotici a largo spettro d'azione può selezionare ceppi patogeni nell'ambito della flora intestinale. Diarree croniche da infezioni virali interessano quasi esclusivamente i pazienti immunocompromessi e si avvalgono della diagnosi istologica su prelievi endoscopici, piuttosto che sulle feci. Parte di queste infezioni sono responsabili di diarree secretorie.

\section{Contaminazione batterica del tenue}

Nonostante il cibo ingerito non sia sterile e la flora batterica del colon raggiunga concentrazioni di $10^{9}$ $10^{12}$ unità formanti colonie per $\mathrm{ml}$, il piccolo intestino normalmente ha una bassa concentrazione batterica. L'acidità gastrica, la peristalsi intestinale e la valvola ileocecale producono un gradiente batterico aborale con una concentrazione batterica a livello digiunale di $10^{4} \mathrm{CFU} / \mathrm{mL}$. La contaminazione batterica del tenue è sicuramente una causa sottodiagnosticata di diarrea che opera attraverso la deconiugazione degli acidi biliari con alterazione nella formazione delle micelle che ostacola la digestione dei grassi. Tale condizione è favorita dalla stasi da ansa cieca, da diverticoli dell'intestino tenue, dall'acloridria o da presenza di dismotilità intestinale spesso presente in malattie sistemiche quali il diabete mellito o la sclerodermia. $\mathrm{Ne}$ sono maggiormente affetti gli individui anziani. L'esame colturale dell'aspirato del piccolo intestino rappresenta il test diagnostico più sensibile ma la metodica di prelievo non è standardizzata ed è piuttosto invasiva; pertanto si raccomanda l'esecuzione del breath test al glucosio. Alternativamente si può procedere ad un tentativo con ciclo di antibioticoterapia empirica di 7-10 giorni con amoxicilina + acido clavulanico o norfloxacina.

\section{Malassorbimento di acidi biliari}

Gli acidi biliari sono indispensabile per l'assorbimento degli acidi grassi e degli steroli, introdotti con 
la dieta. Più del $90 \%$ sono riassorbiti a livello dell'ileo distale con un meccanismo di uptake attivo. La quantità di acidi biliari persa con le feci $(400 \mathrm{mg})$ è ricostituita dalla costante risintesi epatica. Nel sospetto di malassorbimento da acidi biliari è molto utile un'anamnesi dettagliata del paziente che è di aiuto per differenziare i 3 tipi di malassorbimento: i) tipo 1: secondario a resezione o malattia dell'ileo terminale (malattia di Crohn, enterite attinica). Se il tratto ileale interessato è $<1 \mathrm{~m}$ il malassorbimento ed i suoi sintomi saranno lievi o del tutto assenti perché la perdita di sali biliari è efficacemente compensata da una maggiore sintesi epatica; se il tratto ileale interessato è $>1$ $\mathrm{m}$ si ha sia diarrea che steatorrea per mancato compenso epatico e quindi per un ridotto pool biliare disponibile; ii) tipo 2: malassorbimento idiopatico di acidi biliari: l'etiologia è poco conosciuta, si ipotizzano alterazioni genetiche nel funzionamento del sistema di trasporto degli acidi biliari. Un recente studio descrive una prevalenza del $10 \%$ di tale forma nell'IBS a variante diarroica; iii) tipo 3: post colecistectomia (10-20\% dei casi), vagotomia ad eziologia non ben definita.

La misurazione diretta degli acidi biliari sulle feci delle 24 ore è un test poco utilizzato nella pratica clinica. Di più semplice esecuzione per la diagnosi di malassorbimento degli acidi biliari è la scintigrafia seriata dopo somministrazione di Se75-HCAT (acido omotaurocolico marcato con selenio 75). Questo composto viene fatto assumere oralmente e il paziente è sottoposto a scintigrafia seriata dopo 7 giorni per misurare la ritenzione del Se75-HCAT all'interno dell'organismo. Una ritenzione inferiore al 10\% dopo 7 giorni è considerata indicativa di malassorbimento. Un test di semplice applicazione è rappresentato dalla risposta empirica alla colestiramina che legando gli acidi biliari impedisce l'effetto a livello colonico. Non ci sono trials clinici sull'utilizzo della colestiramina nel malassorbimento dei sali biliari e bisogna considerare anche che la colestiramina ha un possibile effetto costipante anche in soggetti normali e in pazienti con altre cause di diarrea. Nessun altro test è stato valutato nella letteratura degli ultimi anni per la diagnosi del malassorbimento da acidi biliari.

Diarree secondarie a malassorbimento dei sali biliari contemplano anche una componente secretoria data dalla stimolazione secretiva del colon da parte degli acidi biliari non riassorbiti.

\section{Deficit di funzione del pancreas esocrino}

Un danno superiore del 90\% del parenchima pancreatico è causa di un malassorbimento generalizzato caratterizzato da steatorrea e diarrea. La secrezione pancreatica esocrina può essere valutata mediante l'utilizzo di test diretti ed indiretti. Il secreto pancreatico da ana- lizzare viene aspirato dal duodeno attraverso sondino naso gastrico o durante l'esame endoscopico in seguito ad iniezione continua di secretina e CCK. Tale valutazione presenta una sensibilità e specificità del $90 \% \mathrm{ma}$ a causa della sua invasività è poco utilizzato nella pratica clinica. Tra i test diretti un importante ruolo è riservato alla colangio-risonanza magnetica in corso di stimolazione con secretina che consente di valutare l'entità della secrezione a livello dei dotti pancreatici. Il dosaggio dei grassi fecali e il breath test con mix di trigliceridi marcati con Carbonio13 sono test non invasivi che valutano indirettamente l'attività enzimatica della lipasi. La quantificazione dell'escrezione dei lipidi nelle feci delle 24 ore (metodo di van de Kamer) è considerato il gold standard per la valutazione dell'insufficienza pancreatica con malassorbimento dei grassi. Si deve però segnalare che questo test si esegue oramai in pochissimi centri ad alta specializzazione e quindi è poco utile nella pratica clinica. Il $13 \mathrm{C}$ breath test valuta l'escrezione nell'area espirata di $\mathrm{CO}_{2}$ marcato dopo ingestione di un mix di trigliceridi marcati. Un'escrezione inferiore al $58 \%$ di $13 \mathrm{CO}_{2}$, a 6 ore dall'ingestione del substrato, indica la presenza di maldigestione con una sensibilità e una sensibilità superiore $\mathrm{al} 90 \%$. La ridotta secrezione di elastina (sensibilità $70 \%$ e specificità $85 \%$ ) su un isolato campione di feci è espressione di una compromessa secrezione pancreatica, ma la sua sensibilità è troppo bassa per essere considerato un test diagnostico per la pancreatite cronica. Per i costi e per la tecnica di esecuzione (lunga e piuttosto indaginosa) l'NBT-PABA e il pancreolauryl test non sono più utilizzati nella pratica clinica. La terapia sostitutiva con enzimi pancreatici va calibrata caso per caso.

\section{Diarree infiammatorie}

Le diarree infiammatorie sono in genere accompagnate da dolore, febbre e sanguinamento. Al di là dell'essudazione, la genesi della diarrea può comprendere anche il malassorbimento, la secrezione, l'alterato assorbimento di liquidi ed elettroliti e l'ipermotilità secondaria alla produzione di citochine e altri mediatori infiammatori. All'esame delle feci è possibile evidenziare la presenza di leucociti e delle loro proteine quali la calprotectina. La dispersione proteica può diventare tale da determinare edema disprotidemico. Nei soggetti anziani particolare attenzione va osservata nei soggetti con diarrea infiammatoria con tracce di sangue, al fine di escludere neoplasie del grosso intestino.

\section{Morbo di Crohn}

È una malattia infiammatoria cronica intestinale. $\mathrm{Nel} 50 \%$ dei casi viene classificata come ileocolite di Crohn e colpisce l'ileo distale e l'intestino crasso. Nel 
$30 \%$ dei casi si manifesta all'ileo, mentre nel restante $20 \%$ colpisce esclusivamente l'intestino crasso e può risultare particolarmente difficile da distinguersi dalla colite ulcerosa. La malattia di Crohn gastroduodenale causa l'infiammazione allo stomaco e alla prima parte dell'intestino tenue, il duodeno. La malattia può tuttavia interessare qualsiasi parte del tratto digerente, dal cavo orale all'ano. Colpisce prevalentemente i giovani maschi fumatori e tende a formare fistole o stenosi. Si manifesta con febbre, dolori addominali, diarrea cronica e sintomi extraintestinali come uveiti, poliartralgie, malattie epatiche colestatiche e lesioni cutanee (eritema nodoso e pioderma gangrenoso). La diagnosi si effettua attraverso endoscopia con prelievo bioptico e pasto baritato. Test sierologici sono rappresentati dagli anticorpi anti citoplasma dei neutrofili. La terapia immunosoppressiva si avvale di formulazioni topiche e sistemiche di steroidi e acido salicilico e dei farmaci biologici.

\section{Rettocolite ulcerosa}

La rettocolite ulcerosa è una malattia infiammatoria cronica intestinale che coinvolge selettivamente la mucosa del retto e/o del colon, nella maggioranza dei casi la parte discendente. Colpisce indiscriminatamente maschi e femmine e si manifesta con dolore addominale e diarrea con perdite ematiche. La diagnosi è endoscopica ed istologica. Quest'ultimo approccio consente la diagnosi differenziale con la colite microscopica e la colite collagenosica. La terapia si avvale come per il morbo di Crohn di farmaci immunosoppressori; nel caso si sviluppi la più temuta complicanza, ovvero il megacolon tossico, bisogna ricorrere alla chirurgia.

\section{Neoplasie intestinali}

Il carcinoma del colon può manifestarsi con diarrea paradossa, con o senza tracce di sangue. A tal proposito va tenuto conto dell'età del paziente che presenta il sintomo. Sopra i 45 anni, ai pazienti con diarrea cronica è consigliata l'esecuzione di pancolonscopia. Anche il linfoma intestinale o il linfoma mantellare possono esordire con diarrea cronica e in questo caso la biopsia è diagnostica.

Tra le altre cause di diarrea infiammatoria cronica ricordiamo l'enterocolite da radiazioni, la sindrome di Bechet e la GVHD, le cui diagnosi sono indirizzate da una accurata anamnesi.

\section{Diarree secretorie}

Le diarree secretorie sono dovute alle alterazioni di trasporto degli elettroliti e liquidi attraverso la mucosa enterocolica. Sono caratterizzate dall'emissione di importanti volumi di feci acquose, senza dolore che non si arrestano con il digiuno. Il gap osmotico è normale ma a livello plasmatico si instaurano pericolose alterazioni dell'equilibrio idro-elettrolitico e acido-base.

\section{Effetto di farmaci e tossici}

Gli effetti collaterali di farmaci rappresentano la causa più comune di diarrea cronica secretoria. Sebbene numerosi farmaci possano indurre diarrea, i più frequentemente incriminati sono gli antibiotici, gli antiaritmici, gli antipertensivi, i farmaci anti-infiammatori non-steroidei, alcuni antidepressivi, i chemioterapici, i broncodilatatori, gli antiacidi e i lassativi. Un'accurata anamnesi farmacologica e la possibile correlazione temporale devono indurre il sospetto di diarrea da farmaci. Quando possibile, la sospensione del farmaco è da ritenersi indicata. Nel caso delle diarree indotte da abuso di lassativi non osmotici, va ricordato che la probabilità di diagnosi aumenta mano a mano che emergono accertamenti negativi. Il $4 \%$ dei pazienti valutati per il disturbo diarrea da uno specialista è affetto da diarrea factitia e tale percentuale sale al $20 \%$ nei pazienti che arrivano a consultare un centro di terzo livello. Questi soggetti spesso abusano contestualmente di diuretici, soffrono di disturbi alimentari o psichiatrici, e sono impiegati nel settore sanitario, più frequentemente donne. Altri ricorrono alla diluizione delle feci con soluzioni liquide (urine, soluzioni ipo o ipertoniche) per ingannare gli operatori sanitari ed essere sottoposti ad accertamenti. In questi casi l'esame delle feci andrebbe ripetuto più volte per valutare la riproducibilità delle caratteristiche chimico-fisiche. Esistono test su prelievo fecale per la rilevazione di particolari lassativi, tuttavia diversi autori ritengono questa pratica non eticamente corretta. Il consumo cronico di etanolo può causare una diarrea di tipo secretorio dovuta al danno procurato a livello della membrama degli enterociti, cui si aggiunge l'effetto del possibile danno pancreatico associato, il ridotto funzionamento delle disaccaridasi e l'aumentato transito intestinale.

\section{Resezioni intestinali, malattia mucosa e fistola enterocolica}

Queste condizioni possono provocare una diarrea secretoria, poichè la riduzione della superficie intestinale in grado di assorbire liquidi e elettroliti fa sì che non vengano riassorbite le sostanze secrete. Per lo stesso principio, paradossalmente, una stenosi intestinale, un fecaloma o un tumore possono causare diarrea. Nella maggior parte di questi casi, oltre alla storia anamnestica e al corredo sintomatologico, si rende necessario procede con esami endoscopici o tecniche di imaging quali pasto baritato o tomografia computerizzata (TC) con mezzo di contrasto. 
Come detto in precedenza il deficit di riassorbimento degli acidi biliari può rendersi responsabile di diarree secretorie e contribuire alla genesi della diarrea secretoria idiopatica nella quale gli acidi biliari non vengono riassorbiti da un ileo terminale apparentemente normale.

\section{Tumori neuroendocrini}

I tumori neuroendocrini rappresentano una patologia poco frequente, ma costituiscono il classico esempio di diarrea secretoria. Originano dalle cellule del cosiddetto sistema neuroendocrino diffuso e pertanto potenzialmente sono ubiquitari, tuttavia la frequenza maggiore si osserva nel distretto gastro-enteropancreatico e toracico. Nell'ambito di queste neoplasia la diarrea può presentarsi come sintomo isolato o far parte di una sindrome più complessa. Sia le caratteristiche della diarrea che il corollario di sintomi dipendono dalle sostanze secrete dalla neoplasia.

Nel carcinoide la diarrea, tipicamente acquosa, può accompagnarsi a flushing, broncospasmo e dispnea, espressione dell'aumentata produzione di serotonina, istamina e prostaglandine.

Nel gastrinoma la diarrea è presente in più del $30 \%$ dei casi e, al di là dell'azione degli ormoni rilasciati, dipende dalla mal digestione secondaria all'inattivazione degli enzimi pancreatici dovuta al basso $\mathrm{pH}$ duodenale.

Il VIPoma dà origine ad una diarrea acquosa imponente (anche nominato colera pancreatico), per azione del peptide intestinale vasoattivo e da altri peptidi ormonali attivi sull'intestino quali il polipeptde pancreatico, la secretina, la gastrina, la neurotensina, la gastrina, etc. Le cellule da cui origina il tumore sono quelle non-beta pancreatiche. Questo tipo di diarrea può portare a severa disidratazione con ipokaliemia $\mathrm{e}$ acloridria.

Il carcinoma midollare della tiroide può manifestarsi con diarrea acquosa nel $25-50 \%$ dei casi; il sintomo è secondario alla secrezione di calcitonina e da altri ormoni secretori. Come gli altri questo tumore può svilupparsi isolatamente o far parte di una neoplasia endocrina multipla.

Nella mastocitosi sistemica la diarrea si accompagna a orticaria ed è secondaria alla produzione di istamina o alla infiltrazione della parete intestinale da parte dei mastociti.

Per la diagnosi dei tumori neuroendocrini possono essere di utilità clinica il dosaggio dell'acido 5idrossi-indolo-acetico (5-HIAA) sempre nelle urine nei casi associati a sindrome da carcinoide. Tra i markers circolanti aspecifici il più utilizzato nella pratica clinica è il dosaggio della cromogranina $\mathrm{A}$ circolante. Sono utilizzabili inoltre alcuni markers neuroendocrini specifici circolanti per individuare l'ipersecrezione da parte del tumore, come l'insulina, il glucagone, la gastrina, il VIP, la somatostatina. In campo diagnostico sono molto utili anche le tecniche per immagini [TC e risonanza magnetica (RM)] che possono permettere di individuare la sede del tumore primitivo, i rapporti che tali neoplasie contraggono con i tessuti circostanti e le eventuali localizzazioni metastatiche. Sono disponibili alcune specifiche tecniche medico-nucleari, come l'Octreoscan e la TC a emissione di positroni con il Ga68-DOTATOC o DOTATATE, che utilizzano sostanze che presentano un'elevata affinità per il tessuto neuroendocrino analoghi della somatostatina radiomarcati. Queste metodiche sono utilizzabili per la diagnosi, la stadiazione e il follow-up di tali neoplasie. La terapia si avvale del trattamento chirurgico, chemioterapico e della somministrazione di octreotide.

\section{Difetti congeniti dell'assorbimento degli ioni}

Queste rare sindromi sono congenite e causano una diarrea acquosa per effetto dell'alterazione degli scambi tra ioni clururo e biarbonato con conseguente alcalosi, o tra ioni sodio e idrogeno con secondaria acidosi.

Con lo stesso principio anche il morbo di Addison può accompagnarsi a diarrea.

\section{Diarree da alterata motilità}

Un rapido transito intestinale può essere causa o effetto nel contesto di una diarrea, certo è che riduce il tempo di realizzazione dei processi enzimatici e riassorbitivi per cui potenzialmente può determinare la comparsa di diarree secretorie o steatorree. Al contrario una riduzione della velocità di transito può favorire la contaminazione del tenue. Vanno quindi considerati come possibile causa di diarrea: l'ipertiroidismo, le neuropatia viscerali o autonomiche come la neuropatia diabetica. Tuttavia tra le cause principali di diarrea, anche per evitare eccessivi accertamenti, va considerata la sindrome da intestino irritabile.

\section{Sindrome dell'intestino irritabile}

I pazienti con IBS possono presentare un'ampia gamma di sintomi sia gastrointestinali che extraintestinali; tuttavia il dolore addominale cronico ai quadranti inferiori, associato alle alterazioni dell'alvo rimane la caratteristica principale sebbene non specifica dell'intestino irritabile. Questa patologia riguarda sia i giovani adulti che gli anziani; la popolazione femminile è colpita più del doppio rispetto a quella maschile e i sintomi spesso sono correlati a stati di stress psichico. 
Il quadro clinico è caratterizzato da dolore crampiforme ai quadranti inferiori con diarrea, stipsi, alternanza dei due disturbi, talora intervallati da periodi di regolarità. La diarrea è di solito caratterizzata da frequenti evacuazioni, senza incremento della massa fecale; generalmente al risveglio o dopo i pasti. La maggior parte delle scariche sono precedute da una sensazione di estrema urgenza e seguite da una condizione di incompleta evacuazione. È frequente anche la presenza di incontinenza fecale. Il dolore può essere risolto dalla defecazione.

Una forma particolare di sindrome da intestino irritabile è quella che insorge dopo infezione da $C$. difficile o dopo altre diarree infettive; tuttavia una forma lieve di IBS in questi pazienti veniva riferita già precedentemente.

Approssimativamente una metà dei pazienti con IBS presenta emissione di muco con le feci. Diarrea con abbondanti volumi, con presenza di sangue, nelle ore notturne o con feci untuose non sono tipiche della IBS e suggeriscono un substrato organico.

La diagnosi di IBS può essere basata sulla presenza di caratteristiche cliniche tipiche e può avvalersi di alcuni criteri; i più comunemente usati sono quelli di Manning e quelli di Roma III (Tabella 9). ${ }^{20,21}$ Molti studi hanno valutato l'accuratezza di questi criteri. Sebbene sensibilità e specificità siano alte, risultati in studi individuali sono risultati variabili, fornendo dunque un razionale per ulteriori studi che stanno tentando di migliorarne l'accuratezza.

La presenza di alcuni sintomi d'allarme devono indurre ad effettuare ulteriori accertamenti per escludere cause organiche, in particolare: i) dolore che risveglia e interferisce con il sonno; ii) diarrea che risveglia e interferisce con il sonno; iii) sangue nelle feci (visibile o occulto); iv) perdita di peso; v) febbre; vi) anemia; vii) esame fisico anormale.

\section{Approccio al paziente}

L'inquadramento diagnostico di una diarrea cronica deve necessariamente passare attraverso una accurata anamnesi ed un attento esame obiettivo poiché, data la molteplicità delle cause che potrebbero determinarla, il rischio è quello di un'appropriatezza diagnostica in eccesso.

A questo proposito abbiamo preso in considerazione l'algoritmo proposto dalle linee guida per la diarrea cronica di Thomas e colleghi nel $2003^{14}$ e l' $A$ merican Gastroenterological Association (AGA) Medical Position Statement del 1999. ${ }^{13}$

La raccolta della storia clinica del paziente deve comprendere i seguenti punti: i) le caratteristiche di insorgenza della diarrea devono essere descritte il più precisamente possibile, in particolare se presente dalla nascita o meno, ad esordio improvviso o graduale; ii) definire se il disturbo è continuo o intercorrente; iii) individuare la durata del sintomo; iv) ricercare fattori epidemiologici, come viaggi all'estero in aree endemiche prima dell'insorgenza, esposizione a cibi o acqua contaminati, vicinanza a pazienti affetti da diarrea; v) valutazione delle caratteristiche delle feci ad esempio: feci acquose, ematiche o steatorrea; vi) la presenza di incontinenza fecale; vii) la presenza o l'assenza di dolore addominale e le caratteristiche di tale sintomo. Il dolore è tipico delle malattie infiammatorie intestinali, della IBS e dell'ischemia cronica; viii) il peso deve essere regolarmente monitorato. Sebbene in generale la diarrea determini un calo di peso, spesso legata ad un ridotto apporto alimentare volto a controllare il sintomo, severi dimagrimenti si hanno più frequentemente nelle sindromi da malassorbimento, nei tumori e nell'ischemia; ix) attenta indagine alimentare che prenda in considerazione l'uso di dolcificanti, integratori alimentari di sali, vitamine e fibre. Individuazione di fattori aggravanti il sintomo, ad esempio ingestione di alimenti (latte), o stress; $\mathrm{x}$ ) comportamenti che riducono il sintomo come variazioni della dieta o sospensione di farmaci; xi) ricostruzione degli accertamenti precedenti con eventuale rivalutazione di radiografie o biopsie; xii) questi pazienti spesso richiedono diversi pareri specialistici e ripetono più volte gli stessi esami; xiii) escludere cause iatrogene di diarrea e quindi pregressi interventi, radio e chemio terapia, farmaci in corso, abuso alcolico o di droghe; xiv) escludere diarrea fittizia da abuso di lassativi. Può essere d'aiuto valutare la presenza di di-

Tabella 9. Descrizione dei criteri di Manning e di Roma III usati per la diagnosi della sindrome dell'intestino irritabile.

\begin{tabular}{|c|c|}
\hline Criteri di Manning & Criteri di Roma III \\
\hline $\begin{array}{l}\text { Più di } 6 \text { episodi di dolore addominale nell'ultimo anno associati } \\
\text { a } 2 \text { o più dei seguenti sintomi: } \\
\text { - Dolore risolto dalla defecazione } \\
\text { - Scariche più frequenti all'esordio del dolore } \\
\text { - Feci più liquide all'esordio del dolore } \\
\text { - Distensione addominale visibile } \\
\text { - Presenza di muco } \\
\text { - Sensazione di defecazione incompleta }\end{array}$ & $\begin{array}{l}\text { Dolore o discomfort addominale per almeno tre giorni al mese } \\
\text { negli ultimi } 3 \text { mesi, associato con due o più dei seguenti sintomi: } \\
\text { - Miglioramento con la defecazione } \\
\text { - Esordio associato con cambiamento di frequenza di scarica delle feci } \\
\text { - Esordio associato a cambiamento di forma delle feci }\end{array}$ \\
\hline
\end{tabular}


sordini alimentari, scarsa attitudine al lavoro, problemi psichiatrici; xv) presenza di altri sintomi associati o di altre malattie sistemiche quali: ipertiroidismo, diabete mellito, vasculiti, collagenopatie, malattie reumatiche, HIV o AIDS, neoplasie.

\section{Indagini diagnostiche}

In questo paragrafo saranno riportati in sintesi i possibili esami laboratoristici e strumentali che il clinico ha a disposizione e che sono stati già citati nelle brevi trattazioni delle possibili cause di diarrea. In evidenza le raccomandazioni fornite dalle linee guida per la diarrea cronica, pubblicate su Gut nel 2003. ${ }^{14}$

\section{Esami ematici}

Nello studio del paziente con diarrea cronica è indicato eseguire uno screening ematico volto ad individuare incremento degli indici di flogosi, anemia o carenza marziale, deficit di vitamina B12, alterazione degli indici di funzionalità epatica o renale.

Il riscontro di anormalità sono utili sia a fini diagnostici che prognostici, possono indirizzarci verso la presenza di una malattia infiammatoria, di un malassorbimento o di una patologia neoplastica ed evidenziare la necessità di un reintegro idrico o vitaminico.

Anche un dosaggio del TSH dovrebbe essere effettuato in prima battuta, così come $\mathrm{i}$ test sierologi per la celiachia.

Non vi sono studi che prendano in considerazione l'indicazione di testare alterazioni dei marcatori tumorali in questa fase.

Va considerata l'opportunità anche di effettuare sierologia per HIV e dosaggio delle immunoglobuline nel sospetto di una immunodeficienza congenita o acquisita. L'aplotipo HLA DQ2 DQ8 può essere ricercato nel caso di dubbia celiachia.

Il dosaggio degli enzimi pancreatici sierici, in particolare lipasi, amilasi e tripsina/tripsinogeno risulta avere, in caso di riduzione combinata, un alto valore predittivo positivo, ma una scarsa sensibilità.

È infine possibile effettuare il dosaggio sierico di alcuni ormoni e peptidi intestinale, ma tale ricerca andrebbe effettuata ad uno step successivo, nel sospetto di una neoplasia neuroendocrina.

Lo screening ematico dovrebbe comprendere: emocromo, conta dei bianchi con formula, VES, proteina $\mathrm{C}$, azotemia, creatinina, sodio, potassio, calcio, cloro e magnesio, GOT, GPT, bilirubina totale e frazionata, fosfatasi alcalina, gammaGT, protidemia totale e frazionata, assetto marziale, folati, B12, TSH. Tali esami hanno un'alta specificità ma una bassa sensibilità per malattia organica $(\mathrm{B})$.

Data l'alta frequenza della celiachia nei paesi Occidentali, è opportuno effettuare lo screening sierolo- gico della celiachia con la ricerca degli anticorpi antiendomisio (A).

La diarrea da tumori neuroendocrini è estremamente rara tuttavia il dosaggio plasmatico degli ormoni vasoattivi quali VIP, gastrina e glucagone è raccomandato nei casi di diarrea acquosa imponente, una volta escluse le altre cause (C).

\section{Test su campione fecale}

È possibile eseguire diversi accertamenti sul campione di feci.

$A$. la ricerca del sangue occulto fecale è diventato un test di screening per il tumore del colon-retto. Nello studio della diarrea cronica in realtà la significatività di questo test è molto ridotta poiché diverse cause di diarrea determinano una positività come la rettocolite ulcerosa, la celiachia e le neoplasie.

$B$. L'attendibilità delle ricerca dei globuli bianchi fecali è strettamente legata all'esperienza dell'esaminatore e pertanto poco riproducibile. Il dosaggio della lattoferrina risulta più sensibile e specifico specie nel sospetto di una colite da $C$. difficile, tuttavia l'utilità di questo test non è stata confermata in letteratura.

$C$. L'esecuzione della coprocoltura nell'inquadramento diagnostico della diarrea cronica è sicuramente indicata, tuttavia si discute sulla possibilità di effettuarlo in prima battuta qualora non vi siano dati anamnestici suggestivi per causa infettiva, poiché nel soggetto immunocompetente tale causa appare piuttosto rara. Terreni di coltura particolari vanno allestiti per Aeromonas e Peiomonas. Nei pazienti immunocompromessi anche Salmonella, Campylobacter e Candida albicans possono essere responsabili della sintomatologia; pertanto in questa categoria l'indagine deve avvenire precocemente. Per quanto riguarda l'infezione da Giardia, la ricerca in ELISA dell'antigene fecale ha soppiantato l'esame microscopico delle feci. Più complessa e di difficile interpretazione è la ricerca di patogeni quali E. histolytica, Cyptosporidium e Microsporidium.

$D$. Il calcolo del $\mathrm{pH}$, dell'osmolarità fecale, degli elettroliti e la ricerca di alcuni lassativi sono utili nel differenziare una diarrea cronica fittizia, risultato di un abuso di lassativi o di aggiunta al campione fecale di soluzioni acquose o urine.

$E$. Su raccolta fecale delle 48 o 72 ore possono essere effettuati diversi test quali il peso fecale, il calcolo del gap osmolare, il dosaggio di elettroliti, il test per l'elastasi, il dosaggio quantitativo e qualitativo dei grassi fecali; tuttavia la raccolta non sempre viene eseguita correttamente e le modalità di conservazione del campione non sono ben standardizzate. Il paziente va inoltre istruito sulla necessità di redigere un diario alimentare per evitare che falsi negativi siano il risultato di una modificazione della dieta atta a ridurre il sintomo. Nonostante questo, l'esecuzione di tali indagine 
può essere utile nell'orientare verso una diarrea di tipo secretoria, osmotica, da malassorbimento, o fittizia. Il peso fecale inoltre può indirizzarci verso un'incontinenza fecale o una pseudodiarrea.

Sebbene nei paesi Occidentali, le infezioni siano una causa non frequenta di diarrea cronica nel soggetto immunocompetente, l'esame colturale e microscopico delle feci dovrebbe essere effettuato (C).

Poiché i casi di diarrea fittizia sono in aumento, $\mathrm{i}$ test mirati ad escluderla andrebbero effettuati precocemente (B).

L'indagine quantitativa dei grassi fecali su campione dei tre giorni è una tecnica poco riproducibile, scarsamente diagnostica e pertanto ne va scoraggiata l'effettuazione (C).

L'analisi qualitativa dei grassi fecali sia su singolo campione che su raccolta è un esame effettuato in pochi centri. Per l'inquadramento delle insufficienza pancreatiche vanno preferiti i più nuovi e specifici test come il dosaggio dell'elastasi fecale (B).

\section{Indagini endoscopiche}

Rappresentano il gold standard per la diagnosi di rettocolite ulcerosa e neoplasie del colon e hanno il vantaggio di poter effettuare campioni bioptici o aspirazione del contenuto luminale. Negli anni l'evoluzione dello strumentario ha consentito di ridurre il tasso di complicazioni e di rendere l'indagine meno sgradevole ai pazienti.

$A$. Per quanto riguarda la scelta tra sigmoidoscopia con endoscopio flessibile e pancoloscopia gli studi effettuati hanno dimostrato come la maggior parte dei processi patologici del grosso intestino, che determinano diarrea, siano evidenziabili ad un'indagine del colon distale. A tal proposito è stata proposta la possibilità di soprassedere ad indagini endoscopiche in quei pazienti $<45$ anni che presentino sintomi classici per IBS; 1'esecuzione di sigmoidoscopia in quei pazienti con età $<45$ anni che però presentino sintomi atipici o particolarmente importanti, riservando ai pazienti con età $>45$ anni o ai pazienti con forte sospetto di Malattia di Crohn l'indicazione alla pancoloscopia con ileoscopia. Sia in corso di sigmoidoscopia che di pancolonscopia è raccomandata l'esecuzione di multiple biopsie.

$B$. L'endoscopia del tratto digerente superiore permette di visualizzare ed effettuare biopsie della mucosa duodenale e digiunale; pertanto risulta indicata nel caso in cui si sospetti un malassorbimento o un'infezione a questo livello come nel caso di celiachia, giardiasi, linfoma, gastroenerite eosinifila, morbo di Whipple, abetalipoproteinemia, sprue in ipogammaglobulinemia, amilodosi e mastocitosi; più raramente permette di individuare localizzazioni alte di malattia di Crohn. È possibile inoltre prelevare campioni di aspirato digiunale per la valutazione di una contami- nazione batterica del tenue, anche se non sempre un risultato positivo del colturale ha avuto in letteratura un corrispettivo clinico.

Nei pazienti con meno di 45 anni, con sintomatologia tipica per IBS, esame obiettivo e screening ematico nella norma, è possibile porre diagnosi di IBS, e passare al trattamento sintomatico, senza procedere ad ulteriori indagini (C).

Nei pazienti con meno di 45 anni con diarrea cronica ma sintomi atipici, è indicato effettuare rettosigmoidoscopia con biopsie (B).

Nei pazienti con età superiore ai 45 anni va preferita la pancolonscopia con visualizzazione dell'ultima ansa ileale. Eventualmente può essere associato studio del transito con bario (B).

Nel caso in cui lo screening sierologico per la celiachia risulti negativo e si sospetti una diarrea da malassorbimento è indicato procedere con gastroduodenoscopia e biopsie del piccolo intestino (C).

L'esame colturale dell'aspirato del piccolo intestino è l'indagine più sensibile per l'individuazione di una contaminazione batterica del tenue; tuttavia le modalità di prelievo non sono ben standardizzate e il risultato non sempre riflette la significatività clinica (B).

\section{Diagnostica per immagini}

Nei casi in cui le metodiche endoscopiche risultino incomplete è possibile ricorrere alla diagnostica per immagini ed in particolare al pasto baritato e al clisma opaco per per lo studio morfologico delle anse intestinali, TC e RM nucleare (RMN)/colangioRMN nelle indagini riguardanti neoplasie e alterazioni del pancreas e dotti biliari, e studi di medicina nucleare come ad esempio scintigrafia con leucociti marcati nel sospetto di una IBD. la colangiopancreatografia endoscopica retrograda (ERCP) rappresenta il gold standard diagnostico per le alterazioni pancreatiche tuttavia la colangio-RMN sta raggiungendo una sensibilità e specificità simile riportando inoltre il beneficio di minori complicazioni e maggior compliance e facilità d'esecuzione. L'angiografia mesenterica riveste una importanza marginale essendo rilegata alla diagnostica della genesi ischemica della diarrea cronica.

Lo studio con bario del piccolo intestino va riservato a quei casi in cui si sospetti un malassorbimento con quadro endoscopico negativo (C).

Indagini di medicina nucleare come la scintigrafia con leucociti marcati possono essere utili nello studio delle malattie infiammatorie intestinali non raggiungibili endoscopicamente (B).

Per quanto riguarda la diagnosi di insufficienza pancreatica; l'ERCP rappresenta il gold standard nell'individuazione di alterazioni dei dotti pancreatici. Tuttavia la colangio-RMN ha raggiunto l'accuratezza diagnostica dell'ERCP, evitandone peraltro i rischi (B). 


\section{Studi funzionali per il malassorbimento di carboidrati e grassi}

L'esecuzione di test funzionali più o meno invasivi per evidenziare malassorbimento da danno della mucosa, maldigestione pancreatica o biliare sono sempre meno usati per la difficoltà d'esecuzione e la scarsa fruibilità nella pratica clinica. Anche i test qualitativi dei grassi fecali risultano di dubbia utilità.

Il test di assorbimento del d-xiloso è una misura indiretta, ma relativamente specifica, dell'assorbimento della parte prossimale del piccolo intestino. $\mathrm{Al}$ paziente a digiuno vengono somministrati $5 \mathrm{~g}$ di d-xiloso per os e poi vengono raccolte le urine per le successive $5 \mathrm{~h}$. Questo dosaggio è leggermente meno sensibile rispetto a una somministrazione maggiore (25 g), ma non provoca nausea o diarrea. Se il flusso urinario è adeguato e la filtrazione glomerulare è normale, una quantità $<1,2 \mathrm{~g}$ di d-xiloso nelle urine raccolte per $5 \mathrm{~h}$ è considerata alterata, mentre 1,2-1,4 $\mathrm{g}$ sono considerati valori al limite della norma.

L'esame per valutare un malassorbimento di vitamina B12 è il test di Schilling. La ridotta escrezione urinaria $(<5 \%)$ della vitamina B12 radiomarcata indica il malassorbimento. Se l'escrezione torna a valori normali ( $>9 \%)$ quando viene somministrato il fattore intrinseco legato alla vitamina B12 radiomarcata, il malassorbimento è causato da un deficit di attività del fattore intrinseco (spesso, una vera anemia perniciosa). Quando la somministrazione del fattore intrinseco non corregge l'escrezione, devono essere sospettate una pancreatite cronica, i farmaci (per es., l'acido aminosalicilico) o una malattia del piccolo intestino (per es., le anse cieche, i diverticoli digiunali e la malattia ileale).

La deconiugazione dei sali biliari da parte dei batteri intestinali, che si verifica nei disordini del piccolo intestino che causano una stasi e una crescita batterica (per es., le anse cieche, i diverticoli e la sclerodermia), può essere valutata con il breath test con l'acido glicolico con C 14. Il test, di solito, non è necessario, è costoso e spesso non è disponibile.

I test invasivi che esplorano la funzione pancreatica richiedono entrambi l'intubazione duodenale: il test di Lundh, in cui la secrezione pancreatica viene stimolata indirettamente mediante l'assunzione orale di un pasto apposito, misura i livelli della lipasi nell'aspirato duodenale. La secrezione pancreatica può essere stimolata anche direttamente da un'iniezione di secretina EV. Il test alla bentiromide è stato, invece, introdotto per valutare la funzione pancreatica, ma la sua accuratezza e la sua utilità devono essere ancora definite. Il test è basato sulla scissione del peptide sintetico bentiromide, da parte dell'enzima pancreatico chimotripsina. La molecola dell'acido para-amminobenzoico è assorbita ed escreta nelle urine. L'accuratezza dipende dal normale svuotamento gastrico, dal normale assorbimento e da una normale funzione renale; alcuni farmaci (per es., i sulfamidici e l'acetaminofene) possono provocare dei falsi risultati.

Il test indiretto 13CMTG (mixed 13C-triglyceride breath) rappresenta una misurazione semplice ed efficace del malassorbimento da insufficienza pancreatica. Il substrato marcato, somministrato al paziente insieme al pasto, viene idrolizzato nell'intestino a opera degli enzimi pancreatici, assorbito e metabolizzato nel fegato. In seguito al metabolismo epatico, viene rilasciata $13 \mathrm{CO}_{2}$, eliminata attraverso la respirazione. La quota di $13 \mathrm{CO}_{2}$ espirata riflette la funzionalità del pancreas esocrino ed è quantificata mediante la spettrometria di massa. Il test è caratterizzato da una sensibilità superiore al $90 \%$ per la diagnosi di cattiva digestione dei lipidi primaria o secondaria a gastrectomia o duodenoctomia; inoltre viene utilizzato anche per monitorare l'efficacia della terapia enzimatica sostitutiva. Questo esame può essere utilizzato qualora non sia disponibile il dosaggio dell'elastasi fecale che a tutt'ora rappresenta l'indagine più fruibile e dotata di buona specificità ma una sensibilità ancora piuttosto bassa negli stadi iniziali. L'indagine attualmente in uso per la diagnosi di malassorbimento da deficit di lattasi è il breath test al lattosio. Nel caso di sindrome da contaminazione del tenue viene utilizzato il breath test al glucosio. Per la diagnosi di malassorbimento degli acidi biliari è la scintigrafia seriata dopo somministrazione di Se75-HCAT. Questo composto viene fatto assumere oralmente e il paziente è sottoposto a scintigrafia seriata dopo 7 giorni per misurare la ritenzione del Se75-HCAT all'interno dell'organismo. Una ritenzione inferiore al $10 \%$ dopo 7 giorni è considerata indicativa di malassorbimento. Un test di semplice applicazione è rappresentato dalla risposta empirica alla colestiramina che legando gli acidi biliari impedisce l'effetto a livello colonico. Non ci sono trial clinici sull'utilizzo della colestiramina nel malassorbimento dei sali biliari e bisogna considerare anche che la colestiramina ha un possibile effetto costipante anche in soggetti normali e in pazienti con altre cause di diarrea.

I test non invasivi sull'assorbimento intestinale degli zuccheri inerti sebbene mostrino un'alta sensibilità non sono facilmente utilizzabili nella pratica clinica. Il loro utilizzo è pertanto sconsigliato (C).

I test non invasivi di funzionalità pancreatica come l'NBT-PABA e il pancreolauryl test non sono più utilizzati nella pratica clinica. Il dosaggio dell'elastasi e della chemotripsina risulta poco sensibile nei casi di disturbo lieve (B).

Il dosaggio dell'elastasi fecale risulta essere un test riproducile, conveniente e di facile esecuzione. Per questo è indicato come esame di prima scelta nei pazienti con diarrea da sospetta insufficienza pancreatica (B).

L'esecuzione del breath test $13 \mathrm{C}$ ha una bassa sensibilità nei casi di malassorbimento lieve-moderato; 
tuttavia i bassi costi e la disponibilità lo rendono un'alternativa ai test fecali (B).

Il breath test al glucosio ha una ridotta sensibilità ma una specificità accettabile ed è pertanto raccomandato (B).

In assenza di un test ottimale per la sindrome da contaminazione del tenue, è possibile effettuare un tentativo di trattamento antibiotico empirico i cui benefici, però, non sono valutati da nessuno studio $(\mathrm{C})$.

Il malassorbimento di acidi biliari può verificarsi nei casi di malattia dell'ileo terminale o resezione intestinale. La scintigrafia seriata dopo somministrazione di Se75-HCAT è un esame abbastanza diffuso e sensibile. In assenza di questa metodico può essere effettuato un tentativo con colestiramina. La diagnosi ex adiuvanibus non è stata validata da studi (B).

La Tabella 10 riassume le principali cause di diarrea cronica e i relativi tests diagnostici $\mathrm{c}$ di più frequente utilizzo per giungere alla diagnosi. ${ }^{22}$

La Figura 5 mostra l'algoritmo diagnostico per l'inquadramento delle diarree croniche.

\section{Principi di terapia per la diarrea cronica}

Il trattamento della diarrea cronica dipende dalla specifica eziologia e può essere curativo, soppressivo o empirico.

Se è possibile eliminare la causa il trattamento sarà curativo come nel caso di resezione di neoplasie, antibioticoterapia nel morbo di Whipple o alte infezioni o sospensione dell'assunzione di un farmaco dannoso.

$\mathrm{Nel}$ caso in cui la diarrea possa essere controllata agendo sull'elemento scatenante parliamo di trattamento soppressivo. Ne sono un esempio: la dieta aglutinata nel paziente celiaco, l'esclusione del latte in presenza di deficit di lattamasi, la terapia immunosoppressiva nel paziente con IBD, la somministrazione di inibitori di pompa protonica nella sindrome di Zollinger-Ellison, di enzimi pancreatici nell'insufficienza epatica, di colestiramina nel malassorbimento di sali biliari o di analoghi della somatostatina nella sindrome da carcinoide.

La terapia empirica è utilizzata in tre situazioni: i) trattamento temporaneo prima dei test diagnostici; ii) dopo che i test diagnostici non hanno portato ad una diagnosi; iii) quando è stata fatta la diagnosi ma non c'è uno specifico trattamento o il trattamento specifico per quella condizione non ha sortito effetto.

Un ciclo di terapia empirica (per esempio antibiotica) può essere preso in considerazione come terapia iniziale se la prevalenza di infezioni batteriche o protozoarie è elevata in una comunità o in una determinata situazione.

Un ciclo terapeutico efficace eliminerebbe la necessità di ulteriori valutazioni.

Ad esempio, un caso di diarrea cronica in un lavo- ratore di asilo nido potrebbe essere trattato empiricamente con metronidazolo per sospetta giardiasi. Nessuna analisi di utilità di questo tipo di approccio è disponibile per la maggior parte delle situazioni di più probabile riscontro negli Stati Uniti.

Uno studio messicano pubblicato nel 1974 ha valutato l'efficacia di amoxicillina empirica nel trattamento della diarrea cronica in pazienti con basso status socio-economico; il $96 \%$ erano asintomatici dal terzo giorno. È improbabile che una terapia antibiotica empirica possa avere un successo simile nei paesi Occidentali, visto che la diarrea cronica è poco probabile che possa essere causata da un'infezione batterica nel paziente immunocompetente.

Una terapia sintomatica per una diarrea cronica non diagnosticata o scarsamente responsiva può coinvolgere una varietà di farmaci. Oppiacei naturali e sintetici sono i più usati, ma altri agenti, come quelli leganti acidi biliari, bismuto e fibre sono talvolta utilizzati. Molti di questi agenti sono stati introdotti prima dell'era degli studi randomizzati e controllati e solo i più moderni sono stati oggetto di studio appropriati. Tuttavia, un considerevole numero di esperienze guida l'uso di questi agenti.

L'oppio è stato usato per 2500 anni per controllare la diarrea e rimane un rimedio molto potente. $\mathrm{La}$ maggior parte dei casi di diarrea, tranne che per le situazioni con elevata secrezione, rispondono a dosi sufficientemente alta di oppio o morfina. La codeina è un po' meno potente e gli oppioidi sintetici quali difenossilato e loperamide sono chiaramente meno potenti.

A causa del potenziale abuso, questi farmaci, ad eccezione della loperamide, sono sostanze controllate negli Stati Uniti. In pratica, però, i pazienti con diarrea cronica raramente abusano di questi agenti, ed è raro richiedere dosi sempre più elevate per controllare la diarrea una volta che una dose efficace sia stata raggiunta. Narcotici potenti sono sottoutilizzati nel trattamento della grave diarrea cronica. Oppioidi minori, come ad esempio difenossilato e loperamide, sono soddisfacenti per il controllo di diarrea meno gravi e dovrebbe essere provati prima di ricorrere a farmaci più potenti.

Il profarmaco loperamide-N-ossido e l'acetorfano, un inibitore dell'encefalinasi, sono in fase di sviluppo e possono avere alcuni vantaggi terapeutici rispetto agli agenti attualmente disponibili.

L'octreotide, analogo della somatostatina si è dimostrato efficace nei tumori carcinoidi ed altri tumori peptide-secernenti, la dumping syndrome, e la diarrea chemioterapia indotta. Ha avuto un successo limitato nei pazienti con diarrea AIDS-associata e sindrome da intestino corto.

L'octreotide non sembra avere alcun vantaggio rispetto agli oppiacei nel trattamento della diarrea cro- 
nica idiopatica e probabilmente dovrebbe essere utilizzata come agente di seconda linea per questa indicazione a causa della necessità di somministrazione mediante iniezione e del suo costo.

Gli agenti intraluminali includono adsorbenti, quali argilla, carbone attivo, e resine leganti; bismuto e modificatori delle feci come le fibre. Pochi studi controllati sono stati condotti con questi farmaci ed i risultati sono stati equivoci. Colestiramina e altre resine leganti simili hanno ridotto il peso delle feci in

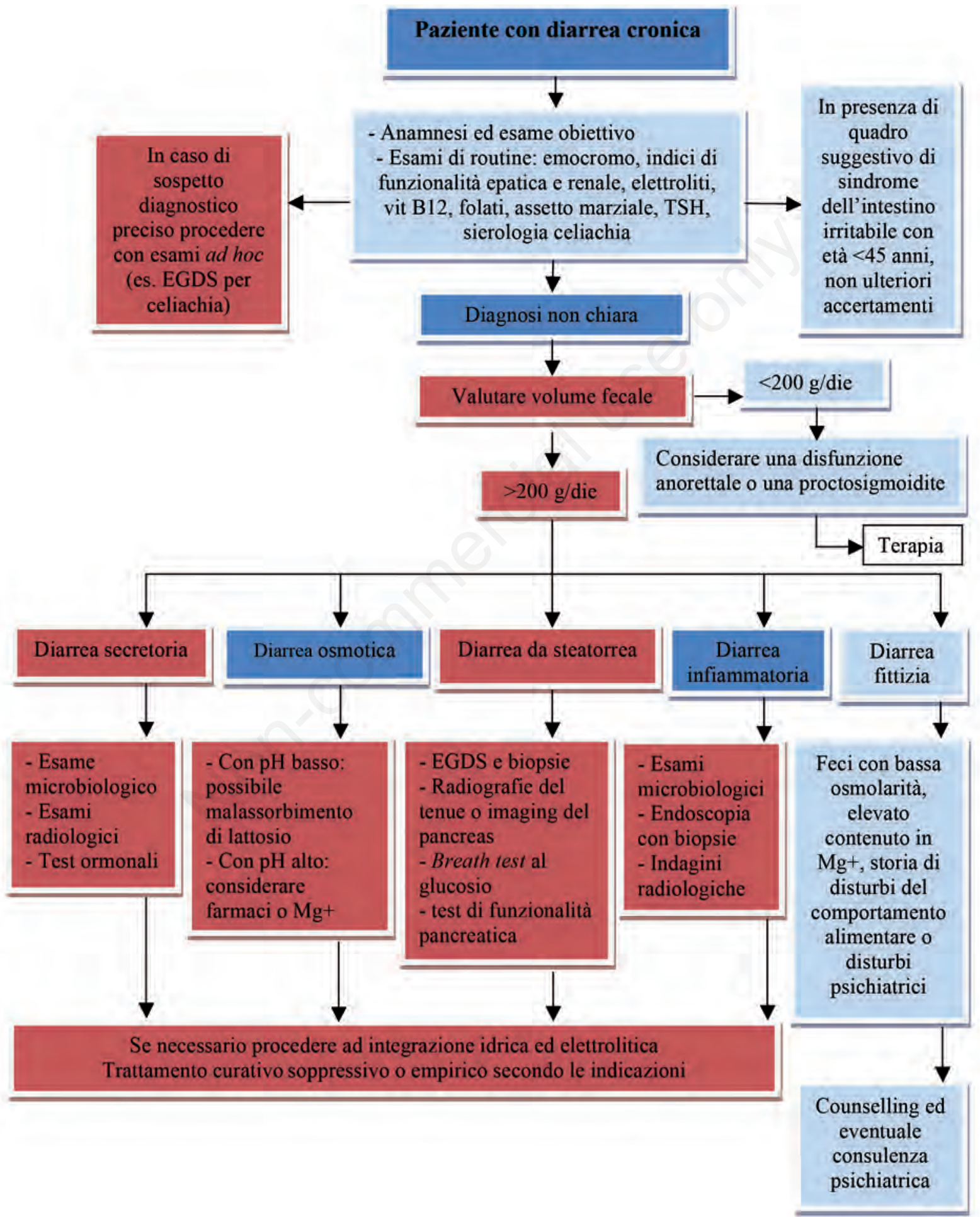

Figura 5. Algoritmo diagnostico per l'inquadramento delle diarree croniche. 
studi europei in cui i pazienti con diarrea cronica idiopatica avevano una frequenza elevata di malassorbimento degli acidi biliari. In una serie americana, la colestiramina ha avuto poco effetto in questi pazienti, anche quando era presente malassorbimento degli acidi biliari.

Il subsalicilato di bismuto si è dimostrato efficace nella diarrea acuta del viaggiatore, ma la sua efficacia in caso di diarrea cronica non è provata; il trattamento prolungato nel paziente immunocompromesso è da evitare a causa del rischio di encefalopatia da bismuto. Modificatori di feci, come lo Psyllium, possono alterare la consistenza delle feci, ma non ridurre il peso delle feci.

Soluzioni di reidratazione orale che includono glucosio o altri nutrienti e sale sono utili per replezione dei fluidi corporei. Soluzioni reidratanti orali a base di cereali si sono affermati negli ultimi anni. Possono essere terapia salva-vita per la disidratazione nelle diarree acute secretorie, come il colera, ma hanno un'applicazione limitata nella maggior parte delle diarree croniche e non sono stati ben studiati in queste situazioni. Sebbene queste soluzioni aumentino l'assorbimento di sale e acqua, essi non sono indicati per ridurre il peso feci, e la diarrea (definita come peso delle feci o fecale) può peggiorare con il loro uso.

\section{Riassumendo}

La terapia empirica è usato in tre situazioni: come trattamento iniziale o per temporeggiare prima dei test diagnostici, dopo che i test diagnostici non siano riusciti a confermare una diagnosi, e quando la diagnosi è stata fatta ma nessun trattamento specifico è disponibile o il trattamento specifico non riesce ad essere efficace.

Cicli empirici di terapia antimicrobica possono essere giustificati se la prevalenza di infezione bat-

Tabella 10. Principali cause di diarrea cronica e tests diagnostici correlati di più frequente utilizzo.

\begin{tabular}{|c|c|c|}
\hline Diagnosi & Reperti clinici & Esami diagnostici \\
\hline Malattia celiaca & $\begin{array}{l}\text { Diarrea cronica con malassorbimento, facile } \\
\text { affaticabilità, anemia sideropenica, calo ponderale, } \\
\text { dermatite erpetiforme, storia familiare }\end{array}$ & $\begin{array}{l}\text { Test più accurati: immunoglobuline } \mathrm{Ab} \text { anti- } \\
\text { endomisio e anticorpi anti-tranglutaminasi } \\
\text { tessutale; diagnosi definitiva mediante } \\
\text { biopsia duodenale }\end{array}$ \\
\hline Infezione da Clostridium difficile & $\begin{array}{l}\text { Spesso significativa diarrea infiammatoria con calo } \\
\text { ponderale. Terapie antibiotiche recenti, evidenze di } \\
\text { colite e febbre. Può non risolversi con l'interruzione } \\
\text { del trattamento antibiotico }\end{array}$ & $\begin{array}{l}\text { Leucociti fecali; immunoassay enzimatico } \\
\text { per individuare le tossine A e B; assay per } \\
\text { tossine fecali positivo; la sigmoidoscopia } \\
\text { evidenzia pseudomembrane }\end{array}$ \\
\hline Diarrea da farmaci & $\begin{array}{l}\text { Osmotica (es. magnesio, fosfati, solfati, sorbitolo), } \\
\text { da ipermotilità (lassativi stimolanti) o da } \\
\text { malassorbimento (es. acarbosio, orlistat) }\end{array}$ & $\begin{array}{l}\text { Eliminazione del farmaco responsabile; } \\
\text { prendere sempre in considerazione la } \\
\text { possibilità di un abuso di lassativi }\end{array}$ \\
\hline Diarrea endocrina & Diarrea secretoria o da ipermotilità (ipertiroidismo) & $\begin{array}{l}\text { TSH, FT3/FT4, peptidi sierici, livelli urinari } \\
\text { di istamina }\end{array}$ \\
\hline Giardiasi & Flatulenza, steatorrea (malassorbimento) & Test antigenici nelle feci \\
\hline $\begin{array}{l}\text { Enterite o colite infettiva } \\
\text { (diarrea non associata ad infezione } \\
\text { da } C \text {. difficile): gastroenterite } \\
\text { batterica, gastroenterite virale, } \\
\text { dissenteria amebica }\end{array}$ & $\begin{array}{l}\text { Diarrea infiammatoria, nausea, vomito, febbre, } \\
\text { dolore addominale. Storia di recenti viaggi, } \\
\text { vacanze in campeggio, contatto con pazienti infetti, } \\
\text { frequenza in asili }\end{array}$ & $\begin{array}{l}\text { Leucociti fecali, VES. Maggiormente } \\
\text { definitivi gli esami colturali o la colorazione } \\
\text { di campioni di feci per la ricerca di specifici } \\
\text { microorganismi }\end{array}$ \\
\hline $\begin{array}{l}\text { Malattia infiammatoria cronica: } \\
\text { colite ulcerosa, malattia di Crohn }\end{array}$ & $\begin{array}{l}\text { Diarrea infiammatoria sanguinolenta, dolore } \\
\text { addominale, nausea, vomito, inappetenza, storia } \\
\text { familiare, reperti oculari (es. episclerite), fistole } \\
\text { perianali, febbre, tenesmo, emorragie rettali, } \\
\text { calo ponderale }\end{array}$ & $\begin{array}{l}\text { Emocromo fecale, leucociti fecali, VES, } \\
\text { calprotectina fecale }\end{array}$ \\
\hline Sindrome del colon irritabile & $\begin{array}{l}\text { Feci con muco, dolore addominale crampiforme, } \\
\text { modificazioni dell'alvo, diarrea funzionale acquosa } \\
\text { dopo i pasti, esacerbazioni da stress emotivi o } \\
\text { dopo i pasti. Più frequente tra le donne }\end{array}$ & $\begin{array}{l}\text { Tutti gli esami di laboratorio sono normali. } \\
\text { Aumentare l'introduzione di fibre, esercizio } \\
\text { fisico, modificazioni della dieta }\end{array}$ \\
\hline Colite ischemica & $\begin{array}{l}\text { Storia di patologie vascolari; dolore associato } \\
\text { all'introduzione di cibo }\end{array}$ & Colonscopia, arteriografia addominale \\
\hline Colite microscopica & $\begin{array}{l}\text { Diarrea secretoria acquosa che interessa pazienti } \\
\text { anziani. Possibile l'associazione con farmaci } \\
\text { anti-infiammatori non-steroidei }\end{array}$ & $\begin{array}{l}\text { Nessuna risposta al digiuno; diarrea notturna; } \\
\text { biopsia del colon }\end{array}$ \\
\hline
\end{tabular}

Adattata da Juckett e Trivedi, 2011. ${ }^{22}$ 
terica o protozoaria è alta in una specifica comunità o situazione.

Un ciclo empirico con resine leganti acidi biliari, come la colestiramina, può essere il modo meno costoso per diagnosticare una diarrea indotta da acidi biliari.

Gli oppiacei sono gli agenti antidiarroici non specifici più efficaci. L'octreotide dovrebbe essere riservato come agente secondario.

Un'adeguata idratazione è una parte essenziale del trattamento delle malattie diarroiche, e le soluzioni reidratanti orali possono essere necessarie in alcuni casi. In alcuni pazienti, in particolare quelli con diarrea post-resezione, la somministrazione endovenosa di liquidi potrebbe essere necessaria per lungo periodo.

La nutrizione parenterale deve essere riservata ai pazienti che non sono in grado di mantenere un adeguato stato nutrizionale a causa della diarrea.

\section{Diarrea secondaria a chemioterapia}

La diarrea è un noto effetto collaterale dei regimi chemioterapici, in particolar modo per quelli che prevedono la somministrazione di fluorouracile, leucovorin ed irinotecan (Tabella 11). Anche i pazienti sottoposti a radiazioni a livello pelvico o addominale vanno incontro a sviluppo di diarrea nel $50 \%$ dei casi.

Il sintomo rappresenta la manifestazione della mucosite, conseguenza del danno apportato dalla terapia alle cellule intestinali nella fase iniziale della linea maturativa; tuttavia può essere secondaria ad infezioni acquisite in pazienti che frequentemente sono neutropenici.

La diarrea può insorgere immediatamente dopo la somministrazione della chemioterapia o a distanza di alcuni giorni, con una durata che può andare oltre la sospensione della terapia, determinando deplezione di fluidi ed elettroliti, malnutrizione, disidratazione, ospedalizzazione. Ognuno di questi eventi può causare compromissione cardiovascolare, insufficienza renale ed aumento della suscettibilità alle infezioni, fino all'exitus. Inoltre può interferire con il normale svolgimento della terapia, richiedendo una riduzione dei dosaggi o la sospensione, con un impatto significativo sulla sopravvivenza. È possibile individuare pazienti a rischio di sviluppare una diarrea indotta da chemioterapia, tenendo conto di quelli che sono i fattori di rischio (Tabella 12$)^{23-25}$ e dei farmaci più implicati (Tabella 13).

A tal proposito è stata proposta una classificazione che considera le modifiche dell'alvo rispetto alla condizione pretrattamento. ${ }^{26}$ Poiché il paziente neoplastico non può essere assimilato ad un normale paziente con diarrea, necessario delineare dei criteri ad hoc per definire la gravità del sintomo.

Allo stesso modo è opportuno che vengano segnalati sintomi associati, quali dolore addominale mode- rato-severo, febbre, stato settico, neutropenia, riduzione del performance status, nausea e vomito, sanguinamento significativo, ipotensione ortostatica e disidratazione. La combinazione del grado di diarrea con la presenza di eventuali associati consente di individuare pazienti non complicati (gradi 1 e 2 senza altri sintomi), rispetto a pazienti complicati (gradi 1-2 con sintomi aggravanti e gradi 3 e 4).

La gestione iniziale della diarrea lieve-moderata dovrebbe includere modificazioni della dieta, quali eliminazione dei prodotti contenenti lattosio o ad alto contenuto di fibre a favore di alimenti ricchi di proteine (BRAT diet: banana, riso, succo di mela, toast); aumento dell'introito idrico e monitoraggio della quantità e delle caratteristiche delle feci.

Gli accorgimenti dietetici vanno proseguiti per almeno una settimana dalla risoluzione del sintomo. Può essere iniziato un trattamento con loperamide con 4 mg seguito da $2 \mathrm{mg}$ ogni 4 ore fino alla comparsa di feci formate, evitando di oltrepassare il dosaggio di 16 $\mathrm{mg} / \mathrm{die}$.

La loperamide è un oppiaceo di derivazione sintetica che riduce la peristalsi intestinale ed esercita un'attività antisecretoria attraverso l'inibizione del trombossano A2. Il trattamento andrebbe sospeso dopo 12 ore di assenza del sintomo nelle diarree da chemioterapia, mentre se ne consiglia la prosecuzione durante tutta la terapia antitumorale nel caso di diarrea secondaria a radioterapia. In caso di una diarrea che persiste oltre 24 ore nonostante il trattamento, è indicato l'incremento della posologia della loperamide a $2 \mathrm{mg}$ ogni 2 ore e l'inizio di antibioticoterapia (consigliato ciclo di 5 giorni di ciprofloxacina).

La mancata risposta alla terapia dopo 48 ore giustifica la sospensione della loperamide e l'introduzione di un antidiarroico di seconda linea, come l'octreotide ad un dosaggio di 100-150 ng, o farmaci oppiacei.

L'octreotide, un analogo sintetico della somatostatina, riduce la secrezione di alcuni enzimi pancreatici e peptidi intestinali, allunga il tempo di transito e favorisce il riassorbimento di liquidi dal lume intestinale.

Mentre nei casi di diarrea indotta da chemioterapia è necessario a questo punto ospedalizzare il paziente per impostare un adeguato iter diagnostico-terapeutico, nel paziente con diarrea radio-indotta in cui non siano presenti segni di severa disidratazione o infezione è possibile proseguire la terapia con loperamide a domicilio ad alti dosaggi.

Nel paziente con diarrea complicata secondaria a chemioterapia è opportuno impostare una terapia aggressiva con ripristino idrico endovenoso, somministrazione di octreotide al dosaggio di $100-150 \mathrm{mcg}$ sottocute TID o $25-50 \mathrm{mcg} / \mathrm{h}$ ev e trattamento antibiotico con chinolonici.

È necessario il ricovero ospedaliero, l'esecuzione 
di esami ematici volti ad escludere uno stato settico o la presenza di squilibri idro-elettrolitici e di indagini su campione fecale come la ricerca di sangue e globuli bianchi nelle feci, coprocolture per salmonelle, E. coli, Campylobacter e ricerca della tossina del $C$. difficile. In quest'ultimo caso è indicato pas- sare ad una terapia antibiotica con metronidazolo o vancomicina. Non è necessario ricorrere ad un atteggiamento così aggressivo nel caso in cui una malattia complicata sia causata da radioterapia. Le modifiche e le sospensioni delle schedule chemioterapiche vanno esaminate caso per caso.

Tabella 11. Fattori di rischio associati alla comparsa di diarrea da chemioterapia.

Rischi associati al paziente
Paziente anziano ( $>65$ anni) Sesso femminile

Performance status ridotto (ECOG $20>2$ )

Patologia intestinale associata

Neoplasia intestinale

Sindrome di Gilbert o DPD carenza

Ostruzione delle vie biliari

Rischi associati alla terapia

Irinotecan o 5-fluorouracile

Schedule di somministrazione settimanale

Chemioterapia infusionale

Boli di 5-fluorouracile

Storia di diarrea indotta da chemioterapia

Precedente o concomitante radioterapia

Tabella 12. Farmaci associati alla comparsa di diarrea.

\begin{tabular}{ll}
\hline Capecitabina & Interferone \\
\hline Cisplatino & Irinotecano \\
\hline Ciclofosfamide & Leucovorin \\
\hline Citosina arabinoside & Metotrexato \\
\hline Daunorubicina & Oxaliplatino \\
\hline Docetaxel & Paclitaxolo \\
\hline Doxorubicina & Raltitrexed 2 \\
\hline Fluorouracile & Topotecano \\
\hline Gefitinib 6 &
\end{tabular}

Tabella 13. Criteri di severità della diarrea.

\begin{tabular}{|c|c|c|c|c|c|}
\hline \multicolumn{6}{|l|}{ Grado } \\
\hline & $\mathbf{0}$ & 1 & 2 & 3 & 4 \\
\hline Pazienti senza colonstomia & Asintomatici & $\begin{array}{l}\text { Aumento delle } \\
\text { scariche fino a } \\
4 \text { volte rispetto al } \\
\text { pretrattamento }\end{array}$ & $\begin{array}{l}\text { Aumento di 4-6 } \\
\text { volte rispetto al } \\
\text { pretrattamento } \\
\text { o evacuazione } \\
\text { notturna }\end{array}$ & $\begin{array}{l}\text { Aumento di }>7 \\
\text { volte nella frequenza } \\
\text { di scarica o } \\
\text { incontinenza o } \\
\text { necessità di } \\
\text { reidratazione } \\
\text { parenterale }\end{array}$ & $\begin{array}{l}\text { Comparsa di gravi } \\
\text { effetti che necessitino } \\
\text { di trattamento } \\
\text { intensivo o collasso } \\
\text { emodinamico }\end{array}$ \\
\hline Pazienti con colonstomia & Asintomatici & $\begin{array}{l}\text { Lieve incremento } \\
\text { nella produzione } \\
\text { di feci acquose }\end{array}$ & $\begin{array}{l}\text { Incremento moderato } \\
\text { della produzione di } \\
\text { feci liquide che } \\
\text { tuttavia non } \\
\text { interferisce con le } \\
\text { attività quotidiane }\end{array}$ & $\begin{array}{l}\text { Incremento severo } \\
\text { della produzione di } \\
\text { feci liquide che } \\
\text { interferisce con le } \\
\text { attività quotidiane }\end{array}$ & $\begin{array}{l}\text { Comparsa di gravi } \\
\text { effetti che necessitino } \\
\text { di trattamento } \\
\text { intensivo o collasso } \\
\text { emodinamico }\end{array}$ \\
\hline
\end{tabular}

Adattata da Cancer Therapy Evaluation Program, 2003. ${ }^{26}$ 


\section{Altri farmaci di seconda linea}

Tra gli altri farmaci di seconda linea proposti abbiamo: i) atropina: agisce come un antagonista dei recettori muscarinici. Viene somministrata al dosaggio di $0,25-1 \mathrm{mg}$ ev o sc sia come profilassi che come trattamento della diarrea da irinotecan, associando un adeguato monitoraggio emodinamico; ii) budesonide: è uno steroide somministrato per via orale, scarsamente assorbito e pertanto attivo a livello della mucosa intestinale, ove esplica un'azione di riparazione e miglioramento della capacità assorbente attraverso l'inibizione delle prostaglandine. Questo farmaco va preso in considerazione nei casi di diarrea non complicata, non responsiva a trattamento con loperamide. La dose consigliata è di $9 \mathrm{mg}$ al giorno per $3 / 5$ giorni; iii) tintura d'oppio: riduce la motilità intestinale e pertanto viene utilizzata come terapia di seconda linea nelle diarree non complicate. La dose raccomandata è di 10-15 gocce ogni 3-4 ore; iv) difenossilato: è un altro oppiaceo di derivazione sintetica come la loperamide ed insieme ad essa può essere prescritto; la dose raccomandata è di 1-2 compresse ogni 6 ore. Non vi sono sufficienti per confermare la sua efficacia nella diarrea da chemioterapia; v) sostanze adsorbenti come Psyllium, pectina e agenti formanti massa non sono di uso frequente nella diarrea da chemioterapia a causa degli effetti collaterali ad essi imputati quali gonfiore addominale e discomfort; vi) carbone attivo: il suo utilizzo è stato testato in un solo studio, non controllato, nella prevenzione della diarrea da irinotecan, sfruttando le capacità di assorbire il metabolita tossico del farmaco SN-38. Questo approccio necessita di ulteriori studi di conferma; vii) la somministrazione di probiotici come Lactobacillus acidophilus e Bifidobacterium ha dato risultati incoraggianti solo in studi preclinici; viii) tutt'ora in corso di valutazione sono i trattamenti con glutamina, inibitori selettivi delle COX2 e talidomide.

La Figura 6 propone un algoritmo gestionale del paziente oncologico con diarrea indotta da chemioterapici.

\section{La gestione del paziente con diarrea: razionale e obiettivi}

Essendo la diarrea una condizione comune nei pazienti medici, la gestione del paziente con diarrea è senza dubbio una competenza dell'internista.

Nella maggior parte dei casi, per esempio, la diarrea infettiva è autolimitante e il trattamento non dipende dall'identificazione del patogeno responsabile.

Da qui la sfida per i medici per identificare e riconoscere quale paziente richiede i tests diagnostici e la terapia specifica. Nel presente lavoro non abbiamo affrontato la diarrea in età pediatrica.
Il presente lavoro si è proposto, quindi, i seguenti obiettivi: i) distinguere l'approccio metodologico a seconda della diarrea acuta, persistente o cronica, sensibilizzando il clinico al management della diarrea nelle sue differenti presentazioni; ii) offrire uno strumento pratico per fare diagnosi differenziale di diarrea e per definire un corretto inquadramento diagnostico-terapeutico; iii) fornire strumenti che aiutino l'internista a identificare le classi di rischio e flow chart per diagnosi e trattamento al fine di permettere l'allocazione del paziente nel setting di cura più appropriato (trattamento ambulatoriale, ricovero in $\mathrm{OBI}$, ricovero in reparto di medicina interna, malattie infettive, ecc.).

\section{La gestione del paziente con diarrea: metodologia}

Al fine di fornire raccomandazioni evidence-based per la gestione del paziente con diarrea, abbiamo innanzitutto verificato l'esistenza di linee guida in merito.

Abbiamo, pertanto, condotto una ricerca utilizzando i seguenti database di linee guida:

- Scottish Intercollegiate Guidelines Network (SIGN)

- Institute for Clinical Systematic Improvement (ICSI)

- National Institute for Health and Clinical Excellence (NICE) (NHS evidence)

- National Guideline Cleringhouse (NGC)

- Agency for Healthcare Research and Quality (AHRQ)

- Canadian Medical Association, CMA infobase

- New Zeland Guidelines Group

- Sistema Nazionale Linee Guida (SNLG)

- Clinical Practice Guidelines Portal

- eGuidelines

La ricerca è stata eseguita da tutto il gruppo costituito da sei medici, indipendentemente, utilizzando come key word il termine diarrhea or diarrhoea, quando il sito prevedeva la funzione di ricerca; negli altri casi abbiamo scorso manualmente la lista delle linee guida archiviate nel database o fatto riferimento alla sezione gastroenterologia. I risultati ottenuti separatamente sono poi stati confrontati e discussi insieme.

Le linee guida così ottenute sono state valutate utilizzando lo strumento Appraisal of Guidelines, Research and Evaluation II (AGREE II) ${ }^{27}$ da 3 autori indipendentemente, al fine di identificare la/e linee guida qualitativamente migliori.

L'AGREE II è stato, infatti, sviluppato per gestire adeguatamente la variabile qualità delle LG; esso valuta il rigore metodologico e la trasparenza con cui sono esse state sviluppate.

L'AGREE II è costituito da 23 item raggruppati in 6 dimensioni, oltre a 2 item di valutazione complessiva. 


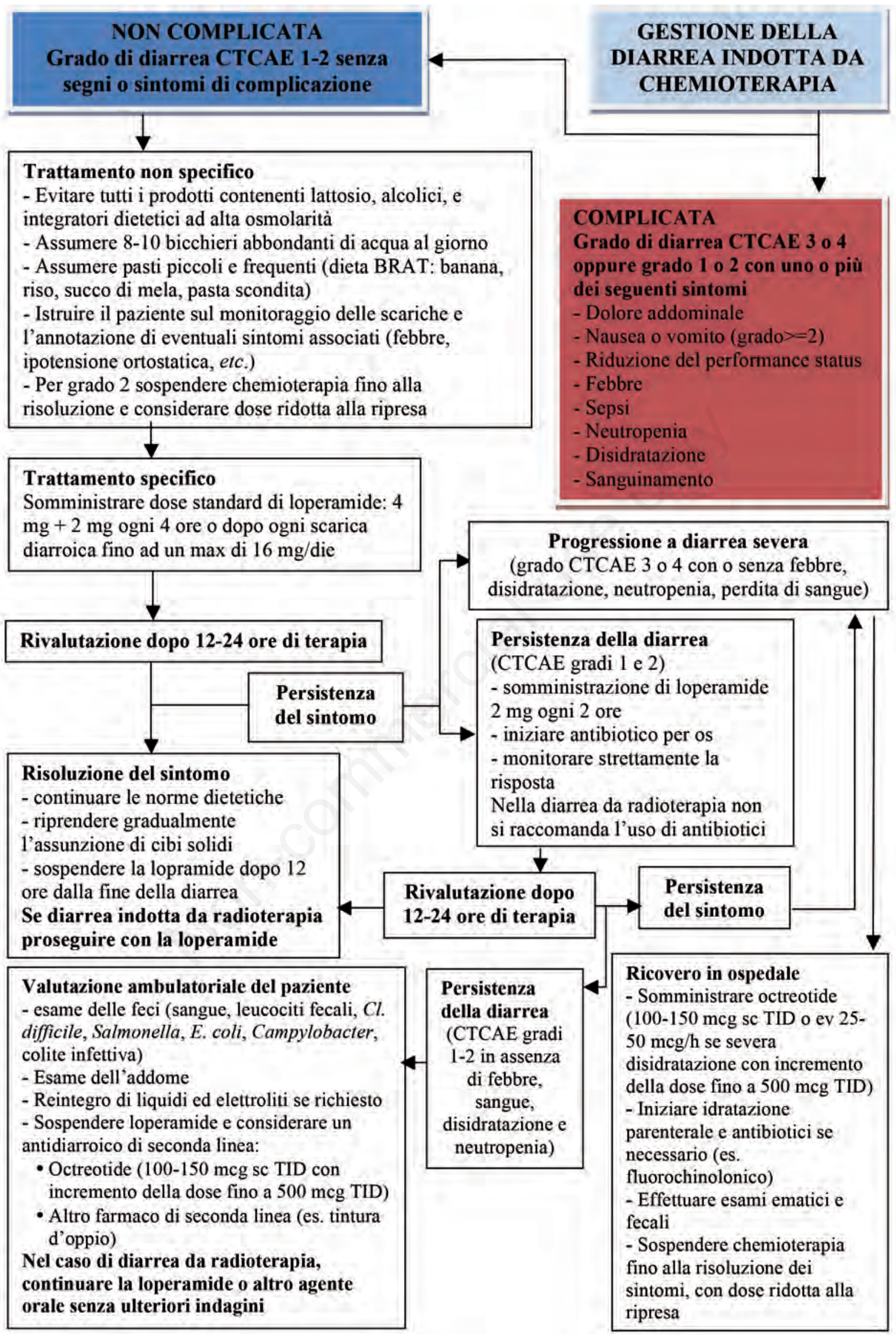

Figura 6. Algoritmo gestionale della diarrea indotta da chemioterapici. 
Esso valuta il rispetto di definiti requisiti raggruppati in sei differenti dimensioni quali gli obiettivi e gli ambiti di applicazione (analizza l'obiettivo generale della LG, i quesiti clinico-assistenziali a cui risponde la LG e la popolazione target - item 1-3), il coinvolgimento dei soggetti portatori di interesse (verifica l'entità del coinvolgimento di tutti gli stakeholders, oltre che il punto di vista dei potenziali utenti della LG item 4-6), il rigore metodologico (analizza metodi e strumenti utilizzati per la ricerca bibliografica, la valutazione critica e la selezione delle evidenze scientifiche, la formulazione delle raccomandazioni cliniche e l'aggiornamento delle LG - item 7-14), la chiarezza espositiva (esamina il linguaggio, la struttura ed il formato delle LG - item 15-17), l'applicabilità delle stesse (analizza le possibili barriere e i fattori facilitanti l'implementazione delle LG, le possibili strategie per favorirne l'adozione, l'implicazione sulle risorse economiche conseguenti alla loro applicazione - item 18-21); infine l'indipendenza editoriale per escludere eventuali conflitti di interesse (item 22-23).

I due item, poi, di valutazione complessiva permettono poi di assegnare un punteggio alla qualità delle linea guida e di raccomandarne o meno l'utilizzo.

Ciascun autore ha valutato il rispetto dei singoli requisiti con un punteggio da 1 (disaccordo completo) a 7 (accordo completo). I punteggi assegnati da ciascun autore sono stati sommati all'interno dei singoli domini e rapportati con il massimo e il minimo punteggio possibile all'interno del dominio in base al numero di requisiti inclusi e al numero dei valutatori.

Per ottenere un elaborato aggiornato, inoltre, un quarto autore ha condotto una ricerca post hoc delle evidenze scientifiche pubblicate nell'anno 2012.

\section{La gestione del paziente con diarrea: risultati}

Attraverso i databases sopraelencati abbiamo identificato 10 linee guida che sono state successivamente valutate con il metodo AGRE II.

Due si approcciano alla diarrea in maniera generale: Diarrea OBI, SIMEU sezione Piemonte ${ }^{10}$ e Diagnosis and treatment of acute and persistent diarrhea ${ }^{6}$

Cinque affrontano la gestione della diarrea acuta: due offrono un focus sulla diarrea acuta, quali Focus on acute diarrhoeal disease ${ }^{9}$ e $W G O$ practice guideline: acute diarrhea $;{ }^{4}$ altre tre si riferiscono specificatamente al management della diarrea acuta su base infettiva, quali Practice guidelines for the Management of infectious Diarrhea, ${ }^{7}$ e Linea guida per la prevenzione $e$ il trattamento della diarrea dei viaggatori-SIMVIM, SIMe $T^{11}$ e Infectious diarrhea: when to test and when to treat. ${ }^{5}$

Due affrontano il management della diarrea persistente e cronica (Guidelines for the investigation of chronic diarrhea ${ }^{14}$ e Position Statement dell'American
Gastroenterological Association Medical: Guidelines for the evaluation and management of chronic diarrhea). ${ }^{12}$

Una è estremamente specialistica e si sofferma sulla prevenzione e il trattamento della diarrea nel paziente oncologico sottoposto a chemio e radioterapia (Putting evidence into practice: evidence-based intervention to prevent, manage, and treat chemotherapy and radiotherapy-induced diarrhea) ${ }^{23}$

La qualità globale delle linee guida selezionate è stata valutata da 3 autori (TMA, RM e CQ) separatamente utilizzando lo strumento AGREE II.

I risultati della valutazione sono riportati nella Tabella 14 da cui risulta che: i) la World Gastroenterology Organisation Practice Guideline ${ }^{4}$ sulla diarrea acuta ha totalizzato il punteggio maggiore (384 punti) con buon equilibrio tra i vari domini; ii) ottimo pure il punteggio delle Guidelines for the investigation of chronic diarrhoea, 2nd edition, Gut $2003^{14}$ che hanno totalizzato 364 punti anche queste con un buon equilibrio tra i domini, eccellendo nell'ambito dell'applicabilità e della definizione degli obiettivi e motivazione; iii) di rilievo pure il punteggio totalizzato dal National Guideline Clearinghouse $e^{19}$ (345 punti) che però ha mostrato minor rispetto dei requisiti di applicabilità; iv) le Practice Guidelines for the Management of Infectious Diarrhea, ${ }^{7}$ pur avendo ottenuto un alto punteggio (324 punti) hanno dimostrato una disomogeneità tra i diversi domini raggiungendo un rigore non adeguato nella elaborazione e, al contrario, ottima definizione della metodologia e degli obiettivi, come anche alta chiarezza espositiva; v) la Medical Position Statement dell' $\mathrm{AGA}^{13}$ per la valutazione della diarrea cronica ha conseguito un discreto punteggio (235 punti), ma significativa disparità nei diversi domini, con basso punteggio per ciò che riguarda il coinvolgimento delle parti, l'applicabilità e il rigore metolodologico, ma buona chiarezza espositiva e buona definizione di obiettivo e motivazione; vi) anche le linee guida per la prevenzione e il trattamento della diarrea dei viaggiatori (Linea guida per la prevenzione e il trattamento della diarrea dei viaggatori - SIMVIM, SIMeT) ${ }^{10}$ si sono attestate con un punteggio intermedio (264 punti), ma hanno evidenziato una forte disomogeneità tra $\mathrm{i}$ domini tanto da raggiungere una percentuale dell' $83 \%$ nel primo domino (obiettivo e motivazione), ma appena il $25 \%$ per ciò che riguarda il rigore nell'esposizione e il $48 \%$ per il coinvolgimento delle parti interessate.

La Tabella 14 presenta i risultati di valutazione delle linee guida sulla diarrea mediante AGREE II.

\section{Valutazione post hoc}

Al fine di aggiornare le evidenze riportate dalle guidelines, un quarto autore ha effettuato un'ulteriore 
ricerca sul principale database online (Medline), a partire dal 31 dicembre 2011 e fino al 31 gennaio 2013. La ricerca è stata ristretta ai soli articoli scritti in lingua inglese, applicando come filtro l'argomento diarrhea e, con particolare attenzione agli aspetti terapeutici.

Sono stati esclusi studi sulla popolazione pediatrica, i case reports e i case series.

Alcuni studi hanno preso in esame diverse strategie di supplementazione da attuare in corso di diarrea, come agenti probiotici o altri elementi. L'utilità di somministrare agenti probiotici è stato studiato in diverse metanalisi che hanno concluso per una loro utilità, soprattutto nella prevenzione e terapia della diarrea associata a terapia antibiotica.

In particolare in una metanalisi di Hempel e colleghi che ha analizzato 82 studi randomizzati e controllati comprendenti più di 11.000 pazienti, è stato evidenziato che la terapia a base di lactobacillo, uti- lizzato da solo o in combinazione, è senza dubbio la più diffusa in caso di diarrea associata a antibioticoterapia. Inoltre gli autori hanno concluso che la somministrazione di probiotici è utile nel contenere la diarrea in corso di terapia antibiotica [relative risk (RR), 0,58; $95 \%$ intervallo di confidenza (CI), 0,50 to 0,68; $\mathrm{P}<0,001]$, ma non è stato possibile definire quale sia l'agente che abbia una maggiore efficacia in tal senso. ${ }^{28}$

In un'altra metanalisi, Videlock e colleghi hanno analizzato il ruolo degli agenti probiotici nella prevenzione della diarrea associata alla terapia antibiotica; dopo aver analizzato 34 studi per un totale di più di 4000 pazienti hanno concluso che gli agenti probiotici sono capaci di ridurre il rischio di diarrea in pazienti in trattamento antibiotico (RR 0,53 95\% CI 0,44$0,63) .^{29}$

Il ruolo degli agenti probiotici è stato studiato anche da Ritchie e colleghi che hanno evidenziato

Tabella 14. Risultati di valutazione delle linee guida mediante AGREE II.

\begin{tabular}{|c|c|c|c|c|c|c|}
\hline Linee guida & $\begin{array}{l}\text { Dominio } 1 \\
\text { Obiettivo e } \\
\text { motivazione }\end{array}$ & $\begin{array}{l}\text { Dominio } 2 \\
\text { Coinvolgimento } \\
\text { delle parti } \\
\text { interessate }\end{array}$ & $\begin{array}{l}\text { Dominio } 3 \\
\text { Rigore nella } \\
\text { elaborazione }\end{array}$ & $\begin{array}{c}\text { Dominio } 4 \\
\text { Chiarezza } \\
\text { nell'esposizione }\end{array}$ & $\begin{array}{c}\text { Dominio } 5 \\
\text { Applicabilità }\end{array}$ & $\begin{array}{c}\text { Dominio } 6 \\
\text { Indipendenza } \\
\text { editoriale }\end{array}$ \\
\hline $\begin{array}{l}\text { Diarrea OBI, SIMEU sezione } \\
\text { Piemonte }^{10}\end{array}$ & $59,3 \%$ & $50 \%$ & $20 \%$ & $85 \%$ & $46 \%$ & $47 \%$ \\
\hline Punteggio totale 253 & $41 / 63$ & $36 / 63$ & $53 / 168$ & $55 / 63$ & $45 / 84$ & $23 / 42$ \\
\hline $\begin{array}{l}\text { Putting evidence into practice: } \\
\text { National Guideline Clearinghouse }{ }^{23}\end{array}$ & $86 \%$ & $74 \%$ & $64 \%$ & $80 \%$ & $33 \%$ & $81 \%$ \\
\hline Punteggio totale 345 & $57 / 63$ & $49 / 63$ & $116 / 168$ & $52 / 63$ & $36 / 84$ & $35 / 42$ \\
\hline $\begin{array}{l}\text { Practice guidelines for the } \\
\text { Management of infectious Diarrhea }\end{array}$ & $91 \%$ & $59 \%$ & $54 \%$ & $85 \%$ & $58 \%$ & $50 \%$ \\
\hline Punteggio totale 324 & $58 / 63$ & $41 / 63$ & $102 / 168$ & $55 / 63$ & $54 / 84$ & $24 / 42$ \\
\hline Focus on acute diarrhoeal disease ${ }^{9}$ & $39 \%$ & $30 \%$ & $15 \%$ & $48 \%$ & $26 \%$ & $50 \%$ \\
\hline Punteggio totale 190 & $30 / 63$ & $25 / 63$ & $45 / 168$ & $35 / 63$ & $31 / 84$ & $24 / 42$ \\
\hline $\begin{array}{l}\text { World Gastroenterology Organisation } \\
\text { practice guideline: Acute diarrhea }\end{array}$ & $72 \%$ & $83 \%$ & $79 \%$ & $93 \%$ & $68 \%$ & $50 \%$ \\
\hline Punteggio totale 384 & $48 / 63$ & $54 / 63$ & $138 / 168$ & $59 / 63$ & $61 / 84$ & $24 / 42$ \\
\hline $\begin{array}{l}\text { Guidelines for the investigation of } \\
\text { chronic diarrhoea, } 2^{\text {nd }} \text { edition }{ }^{14}\end{array}$ & $85 \%$ & $61 \%$ & $73 \%$ & $91 \%$ & $53 \%$ & $67 \%$ \\
\hline Punteggio totale 364 & $55 / 63$ & $42 / 63$ & $129 / 168$ & $58 / 63$ & $50 / 84$ & $30 / 42$ \\
\hline $\begin{array}{l}\text { Diagnosis and Treatment of Acute } \\
\text { or Persistent Diarrhea }\end{array}$ & $65 \%$ & $26 \%$ & $15 \%$ & $39 \%$ & $36 \%$ & $84 \%$ \\
\hline Punteggio totale 216 & $44 / 63$ & $23 / 63$ & $45 / 168$ & $30 / 63$ & $38 / 84$ & $36 / 42$ \\
\hline $\begin{array}{l}\text { Linee Guida per la prevenzione e il } \\
\text { trattamento della diarrea dei viaggiatori }{ }^{1}\end{array}$ & $\mathrm{ri}^{11} 83 \%$ & $48 \%$ & $25 \%$ & $69 \%$ & $46 \%$ & $50 \%$ \\
\hline Punteggio totale 264 & $54 / 63$ & $35 / 63$ & $60 / 168$ & $46 / 63$ & $45 / 84$ & $24 / 42$ \\
\hline $\begin{array}{l}\text { American Gastroenterological } \\
\text { Association medical position statement: } \\
\text { Guidelines for the evaluation and } \\
\text { management of chronic diarrhea }{ }^{12}\end{array}$ & $59 \%$ & $30 \%$ & $29 \%$ & $67 \%$ & $22 \%$ & $67 \%$ \\
\hline Punteggio totale 235 & $41 / 63$ & $25 / 63$ & $66 / 168$ & $45 / 63$ & $28 / 84$ & $30 / 42$ \\
\hline $\begin{array}{l}\text { Infectious diarrhea: when to test } \\
\text { and when to treat }{ }^{5}\end{array}$ & $72 \%$ & $43 \%$ & $20 \%$ & $87 \%$ & $42 \%$ & $84 \%$ \\
\hline Punteggio totale 267 & $48 / 63$ & $32 / 63$ & $53 / 168$ & $56 / 63$ & $42 / 84$ & $36 / 42$ \\
\hline
\end{tabular}


come questi non siano utili nella terapia della diarrea del viaggiatore; inoltre alcuni ceppi particolari come Lactobacillus acidophilus, L. plantarum, and Bifidobacterium infantis non sembrano avere un ruolo attivo nel trattamento dei disturbi gastrointestinali. ${ }^{30}$

Al contrario, in uno studio condotto su 70 pazienti ricoverati per diarrea acuta secondaria a terapia antibiotica, l'utilizzo di Lactobacillus casei and Bifidobacterium breve non si è dimostrato utile nel ridurre la durata della diarrea. ${ }^{31}$

La supplementazione con zinco e rame invece non si è dimostrata cost-effective in popolazioni in via di sviluppo. In uno studio di Patel e colleghi su 808 pazienti affetti da diarrea acuta zinco e rame non sembrano offrire benefici aggiuntivi rispetto alla terapia standard attuata in caso di diarrea. ${ }^{32}$

In caso di diarrea infettiva è stato dimostrato che la fidaxomicina può avere un ruolo nel trattamento delle coliti da $C$. difficile. In una metanalisi su più di 1000 pazienti la fidaxomicina si è dimostrata essere non inferiore alla vancomicina nella cura dell'enterite da $C$. difficile, essendo anche capace di ridurre la durata della sintomatologia e le recidive. ${ }^{33}$

Il ruolo della ofloxacina con ornidazole nel trattamento della diarrea è stata valutato in uno studio su 290 adulti affetti da diarrea, dissenteria o gastroenterite. Si è assistito ad una riduzione dell'intensità della diarrea, ad un miglioramento dei sintomi di accompagnamento (quali febbre, vomito e dolori addominali), con una buona tollerabilità dei farmaci. ${ }^{34}$

Una recente revisione della Cochrane Collaboration si è occupata di analizzare il ruolo della vaccinazione contro il rotavirus e ha dimostrato che sia il vaccino monovalente sia il polivalente sembrano essere efficaci nel contrastare gli episodi di diarrea da rotaviris. ${ }^{35}$

Una metanalisi ${ }^{36}$ del 2012, infine, ha indagato un possibile ruolo della videocapsula endoscopica (VCE) nella diagnosi della malattia celiaca (CD). I risultati di questa metanalisi evidenziano che, anche se la VCE può rappresentare una metodica interessante, allo stato dell'arte comunque non è da considerare una alternativa per la diagnosi di CD.

\section{Bibliografia}

1. Longo DL, Fauci AS, Kasper DL et al. Harrison. Principi di medicina interna, $18^{\mathrm{a}}$ ed. Milano: CEA Casa Editrice Ambrosiana; 2012.

2. Everhart JE. Digestive disease in the United States: epidemiology and impact. NIH Publ 94-1447. Bethesda, MD: National Institutes of Health; 1994.

3. Herikstad H, Yang S, Van Gilder TJ, et al. A populationbased estimate of the burden of diarrhoeal illness in the United States: FoodNet, 1996-7. Epidemiol Infect 2002; 129:9-17.

4. World Gastroenterology Organisation. Practice guide- line: acute diarrhea. WGO 2008. Available from: http://www.worldgastroenterology.org/guidelines/global -guidelines/acute-diarrhea/acute-diarrhea-english

5. Hachette TF, Farina D. Infectious diarrhea: when to test and when to treat. CMAJ 2011;183:339-44.

6. Pawlowski SW, Warren CA, Guerrant R. Diagnosis and treatment of acute and persistent diarrhea. Gastroenterol 2009;136:1874-86.

7. Guerrant RL, Van Gilder T, Steiner TS, et al. Practice guidelines for the management of Infectious Diarrhea. Clin Inf Dis 2001;32:331-51.

8. DuPont HL. Clinical practice. Bacterial diarrhea. N Engl J Med 2009;361:1560-9.

9. Baldi F, Bianco MA, Nardone G, et al. Focus on acute diarrhhoeal disease. World J Gastroenterol 2009;15:3341-8.

10. Simeu, Sezione Piemonte. Diarrrea OBI; 2009. Available from: http://prontosoccorso.eumed.org/area-professionale/2513/lbreve-osservazione-intensiva-in-piemonte/

11. Rossanese A, Nguyen TMD, Castelli F, Napoletano EG. Linee guida per la prevenzione e il trattamento della diarrea dei viaggiatori. Giorn Ital Med Trop 2005;10:1-23.

12. American Gastroenterological Association. Medical position statement: guidelines for the evaluation and management of chronic diarrhea. Gastroenterology 1999; 116:1461-3.

13. Fine KD, Schiller LR. AGA technical review on the evaluation and management of chronic diarrhea. Gastroenterology 1999;116:1464-86.

14. Thomas PD, Forbes A, Green J, et al. Guidelines for the investigation of chronic diarrhea, $2^{\text {nd }}$ edition. Gut 2003; 52:1-15.

15. Feldman M, Friedman LS, Sleisenger MH, eds. Sleisenger and Fordtran's gastrointestinal and liver disease: pathophysiology, diagnosis, and management. 7th ed. Philadelphia, PA: Saunders; 2002. p 137.

16. Schiller L, Sellin J. Diarrhea. In: Sleisenger MH, Feldman M, Friedman LS, Brandt LJ, eds. Sleisenger and Fordtran's gastrointestinal and liver disease: pathophysiology, diagnosis, management. 9th ed. Philadelphia, PA: Saunders/Elsevier; 2010. pp 211-232.

17. Comino I, Real A, de Lorenzo L, et al. Diversity in oat potential immunogenicity: basis for the selection of oat varieties with no toxicity in coeliac disease. Gut 2011; 60:915-22.

18 Oberhuber G, Granditsch G, Vogelsang H. The histopathology of coeliac disease: time for a standardized report scheme for pathologists. Eur J Gastroenterol Hepatol 1999;11:1185-94.

19. Associazione Italiana Celiachia. Comitato Scientifico Nazionale AIC; novembre 2003. Available from: http://www.celiachia.it/home/HomePage.aspx

20. Manning AP, Thompson WG, Heaton KW, Morris AF. Towards positive diagnosis of the irritable bowel. $\mathrm{Br}$ Med J 1978;2:653-4.

21. Mostafa R. Rome III: The functional gastrointestinal disorders. World J Gastroenterol 2008;14:2124-5.

22. Juckett G, Trivedi R. Evaluation of chronic diarrhea. Am Fam Physician 2011;15;84:1119-26.

23. Muehlbauer PM, Thorpe D, Davis A et al. Putting evidence into practice: evidence-based intervention to prevent, manage, and treat chemotherapy and radiotherapyinduced diarrhea. Clin J Oncol Nurs 2009;13:336-41.

24. Benson AB 3rd, Ajani JA, Catalano RB, et al. Recom- 
mended guidelines for the treatment of cancer treatmentinduced diarrhea. J Clin Oncol 2004;22:2918-26.

25. Richardson G, Dobish R. Chemotherapy induced diarrhea. J Oncol Pharm Pract 2007;13:181-98.

26. Cancer Therapy Evaluation Program. Common terminology criteria for adverse effects, version 3.0. National Cancer Institute, Bethesda; National Institutes of Health, U.S. Department of Health and Human Services; December 12, 2003.

27. Appraisal of Guidelines for Research and Evaluation II AGREE II. Maggio 2009. Versione Italiana della Fondazione GIMBE. Available from: http://www.gimbe.org/ pagine/569/it/agree-ii

28. Hempel S, Newberry SJ, Maher AR, et al. Probiotics for the prevention and treatment of antibiotic-associated diarrhea: a systematic review and meta-analysis. JAMA 2012;307:1959-69.

29. Videlock EJ, Cremonini F. Meta-analysis: probiotics in antibiotic-associated diarrhoea. Aliment Pharmacol Ther 2012;35:1355-69.

30. Ritchie ML, Romanuk TN. A meta-analysis of probiotic efficacy for gastrointestinal diseases. PLoS One. 2012; 7:e34938.

31. Souza DN, Jorge MT. The effect of lactobacillus casei and bifidobacterium breve on antibiotic-associated diarrhea treatment: randomized double-blind clinical trial. Rev Soc Bras Med Trop 2012;45:112-6.

32. Patel AB, Badhoniya N, Dibley MJ. Zinc and copper supplementation are not cost-effective interventions in the treatment of acute diarrhea. J Clin Epidemiol 2013;66:52-61.

33. Cornely OA, Crook DW, Esposito R, et al. Fidaxomicin versus vancomycin for infection with clostridium difficile in Europe, Canada, and the USA: a double-blind, non-inferiority, randomised controlled trial. Lancet Infect Dis 2012;281:1-9.

34. Faruqui AA, Joshi C. Evaluation of efficacy and tolerability of fixed dose combination of ofloxacin with ornidazole infusion (infusion $\mathrm{O} 2$ ) in the management of diarrhoea and dysentery. J Indian Med Assoc 2012; 110:193-6.

35. Soares-Weiser K, Maclehose H, Bergman H, et al. Vaccines for preventing rotavirus diarrhoea: vaccines in use. Cochrane Database Syst Rev 2012;11:CD008521.

36. Rokkas T, Niv Y. The role of video capsule endoscopy in the diagnosis of celiac disease: a meta-analysis. Eur J Gastroenterol Hepatol 2012;24:303-8. 


\title{
La gestione del paziente con nausea e vomito: razionale e obiettivi
}

\author{
Tiziana Marcella Attardo, ${ }^{1}$ Rita Menichella, ${ }^{2}$ Chiara Quarneti, ${ }^{3}$ Erica Romualdi ${ }^{4}$ \\ ${ }^{1}$ UO di Medicina Interna, Ospedale Barone Lombardo di Canicattì, Asp 1 Agrigento; ${ }^{2}$ UO Medicina Interna Bolondi, \\ Dipartimento di Malattie dell'Apparato Digerente e Medicina Interna, Bologna; ${ }^{3}$ Unità di Area Critica dell'Ospedale di \\ Montecatone, Bologna; ${ }^{4} U O$ Medicina Interna, Ospedale di Saronno, Varese, Italia
}

\section{RIASSUNTO}

Essendo la nausea e il vomito una condizione comune nei pazienti internistici e potendo riconoscere svariate cause ed essere espressione di varie patologie dell'apparato gastroenterico e non, la gestione del paziente con questi sintomi è senza dubbio una competenza dell'internista. Il presente lavoro si è proposto di definire un approccio metodologico unico al sintomo, sensibilizzando il clinico al management dello stesso nelle sue differenti presentazioni. La ricerca delle linee guida (LG) sui topics in questione (nausea e vomito) e la revisione delle stesse grazie allo strumento metodologico dell' Appraisal of Guidelines, Research and Evaluation II (AGREE II) ci ha permesso di valutare la letteratura disponibile e la sua fruibilità nella pratica clinica. Il lavoro, pur nei limiti della sintesi, ha cercato di fornire uno strumento che aiuti l'internista ad identificare le possibili diverse patologie alla base dei sintomi suddetti, grazie anche a flowchart di snodo diagnostico, e a cercare di supportare una allocazione del paziente nel setting di cura più appropriato.

\section{Introduzione}

La nausea e il vomito, espressione di varie patologie dell'apparato gastroenterico e non, sono condizioni comuni nei pazienti internistici.

Con la presente monografia si siamo posti i seguenti obiettivi: i) definire un approccio metodologico unico al sintomo, sensibilizzando il clinico al management dello stesso nelle sue differenti presentazioni; ii) offrire uno strumento pratico per definire un corretto iter diagnostico-terapeutico; iii) fornire strumenti che supportino l'internista ad una appropriata allocazione del paziente (ricovero in OBI o in Medicina Interna, regime ambulatoriale, etc).

Non abbiamo ritenuto di nostro interesse l'età pediatrica e l'iperemesi gravidica.

\section{Definizione}

La nausea può essere definita come una sensazione sgradevole nella parte posteriore dell'orofa-

Corrispondente: Tiziana Marcella Attardo, UO di Medicina Interna, Ospedale Barone Lombardo di Canicattì, via Giudice Antonino Saetta, Canicattì, Asp 1 Agrigento, Italia.

Fax: $+39.0922 .733217 / 733395$.

E-mail: claudia.fantucchio@alice.it

Articolo pubblicato secondo la Creative Commons Attribution NonCommercial 4.0 License (CC BY-NC 4.0).

CCopyright T.M. Attardo et al., 2016

Licensee PAGEPress, Italy

QUADERNI - Italian Journal of Medicine 2016; 4(3):36-52 ringe e del tratto gastroesofageo che può accompagnarsi a vomito. ${ }^{1}$ I meccanismi responsabili della nausea, poco noti, richiedono una percezione cosciente per cui coinvolgono la corteccia cerebrale.

Il vomito è una rapida e forzata espulsione orale del contenuto del tratto gastrointestinale superiore causato dalle contrazioni dell'intestino e della muscolatura della parete toraco-addominale. Si differenzia quindi dal rigurgito (passaggio senza sforzo del contenuto gastrico nella bocca) e dalla ruminazione (ripetuto rigurgito di contenuto gastrico spesso rimasticato e reingoiato) che possono essere controllati volontariamente.

Il vomito può essere preceduto da nausea e associarsi a scialorrea, sudorazione, pallore, tachi e bradicardia.

In base al tipo di materiale emesso, il vomito può essere: i) alimentare (cibo più o meno digerito); ii) acquoso (succo gastrico chiaro misto a mucina); iii) biliare (reflusso di materiale biliare dal duodeno nello stomaco); iv) ematemesi (sangue rosso vivo); v) caffeano (materiale nerastro derivato dalla digestione di sangue ristagnato nello stomaco); vi) fecaloide (materiale fecale).

Esso si può distinguere anche per il meccanismo d'origine: ${ }^{2}$ i) da stenosi od occlusione, che è tanto più precoce quanto più alta è la sede anatomica; ii) vomito riflesso legato ad irritazione meccanica o chimica del tubo digerente o a livello vestibolare; iii) vomito centrale per stimolazione diretta del centro del vomito chimica o meccanica (in genere associato a bradicardia, cefalea e papilla da stasi), o da riflessi condizionati per percezioni sgradevoli.

\section{Epidemiologia}

La nausea e il vomito possono influenzare in modo significativo la qualità della vita. Nel 2002 uno studio 
statunitense $\mathrm{e}^{3}$ che prendeva in considerazione 17 patologie gastrointestinali ha stimato un costo delle infezioni acute del tratto gastrointestinale superiore a 3,4 miliardi dollari/anno.

Prendendo in considerazione altre cause di nausea e vomito, notevoli sono, oltre i costi sanitari diretti, quelli indiretti legati alla perdita di produttività lavorativa. ${ }^{4}$

\section{Meccanismi fisiopatologici}

Il centro del vomito, responsabile della coordinazione motoria del vomito, si trova nella porzione dorsolaterale della formazione reticolare del midollo allungato (in vicinanza del centro respiratorio e della salivazione).

La zona trigger dei chemorecettori, a livello del pavimento del IV ventricolo, é in grado di rispondere agli stimoli emetici ematogeni (tossici endogeni ed esogeni, metabolici, farmacologici) e di attivare il centro del vomito tramite connessioni nervose multiple.

Essa ha recettori per diversi neurotrasmettitori, quali dopamina, serotonina, idrossitreptamina, noradrenalina, neurochinina $\mathrm{K}$ e vasopressina.

Gli stimoli emetici agiscono a livello di numerosi siti anatomici: ${ }^{5}$ 'emesi da pensieri e odori sgradevoli ha origine nella corteccia cerebrale, il vomito attivato dal riflesso faringeo è mediato dai nervi cranici, le cinetosi e le patologie dell'orecchio interno dal nervo vestibolare, gli irritanti gastrici ed alcuni farmaci chemioterapici stimolano i nervi gastroduodenali vagali o afferenti.

In ciascuna sede diversi neurotrasmettitori sono responsabili dell'induzione del vomito: i disordini labirintici stimolano i recettori vestibolari colinergici muscarinici M1 ed istaminergici H1, gli stimoli gastroduodenali attivano quelli 5-HT3 e 5-HT4 serotoninergici, $\mathrm{H} 2$ istaminergici e M1 e D2 dopaminergici; l'area postrema agisce su recettori 5-HT3, M1, H1, D2, NK1.

\section{Diagnosi}

La maggior parte dei casi di nausea e vomito acuti sono di facile diagnosi in base alla clinica. In caso di nausea e del vomito cronici (definiti come sintomi persistenti da più di un mese), l'identificazione della causa e la successiva terapia mirata possono risultare difficili.

La valutazione del paziente con nausea e vomito inizia con la differenziazione di questi sintomi dalla bulimia, dal rigurgito e dalla ruminazione e include una chiara definizione della durata, frequenza e gravità dei sintomi, con una descrizione delle loro caratteristiche e la natura di eventuali sintomi associati.

L'esame fisico deve essere rivolto alla ricerca e identificazione di tutti i segni che possono indicare la causa di questi sintomi. È evidente, infatti, che l'esame obiettivo e gli altri sintomi associati possono orientare verso le specifiche categorie che fanno capo alle differenti vie di trasmissione su cui intervenire.
Quando la causa è infettiva (ad eziologia virale o batterica), ad esempio, l'esordio dei sintomi è in genere acuto. Nausea e vomito secondari all'ingestione di una tossina si verificano da una a sei ore dall'ingestione, sono di solito autolimitantesi, durando uno-due giorni al massimo (ad esempio, l'enterotossina nella tossinfezione alimentare da stafilococco o la tossina del Bacillus cereus).

Le cause legate ad una patologia gastrointestinale si associano a dolore locale, spesso esacerbato dal pasto, reflusso gastroesofageo, nausea intermittente risolta dal vomito, sazietà precoce, flatulenza. Nausea e vomito possono essere presenti, anche se in genere non sono i sintomi principali, nei pazienti affetti da dispepsia, malattia da reflusso gastroesofageo, ulcera peptica e sindrome dell'intestino irritabile.

Sebbene disturbi del plesso neuromuscolare possono essere causa di nausea e vomito, non é del tutto chiaro il ruolo della motilità gastrointestinale e, in particolare, della gastroparesi nella nausea e vomito cronici, specie in alcune entità come il vomito funzionale e psicogeno, la gastroparesi idiopatica e la dispepsia funzionale.

Pertanto nella valutazione dei pazienti con cronici ed inspiegabili nausea e vomito, il clinico dovrebbe sempre considerare i fattori psicogeni e rimandare ad una valutazione psicologica, specie se i pazienti sperimentano questi sintomi in risposta a stress emotivi o fisici.

Qualsiasi condizione che causi ipertensione endocranica può dare vomito, con o senza nausea. In questi casi in genere sono presenti altri sintomi e/o segni neurologici che orientano nella diagnosi. Anche l'emicrania classica si accompagna a nausea e vomito; le cause vestibolari e le condizioni che influenzano il labirinto (infezioni, malattia di Ménière, tumori) si caratterizzano per nausea, con o senza vomito, evocata dal movimento e sono spesso associate con le vertigini. ${ }^{6-10}$

La Tabella 1 è una proposta di classificazione delle diverse cause di questi sintomi.

\section{Approccio clinico-diagnostico}

L'acronimo OPQRSTUV $V^{11}$ propone un rapido inquadramento del problema (Tabella 2).

La Tabella 3 offre un orientamento diagnostico del paziente con nausea e vomito.

L'American Gastroenterological Association $(\mathrm{AGA}){ }^{10}$ individua tre goals fondamentali: i) il riconoscimento e la correzione, quando possibile, della causa, nonché di eventuali complicanze quali le disionie, la disidratazione, la denutrizione, ecc.; ii) l'identificazione di una terapia specifica correlata alla causa; iii) la messa in opera, se necessario, di strategie terapeutiche per sopprimere o eliminare i sintomi.

L'AGA propone una flowchart (Figura 1) per un rapido management dei sintomi (nausea e vomito), step by step. 
La Tabella 4 elenca una serie di raccomandazioni cliniche sulla nausea e il vomito e il relativo grado di evidenza.

In Figura 2 si riporta l'algoritmo proposto dalla New Mexico Medical Review Association (NMMRA) nell'anziano. ${ }^{5,10,12}$

\section{Complicanze del vomito}

Il vomito acuto e violento può causare lesioni gastriche o esofagee responsabili di emorragie digestive (sindrome di Mallory-Weiss), asfissia e polmoniti $a b$ ingestis (sindrome di Meldelson), specie in soggetti defedati o privi di coscienza.

Inoltre una temibile complicanza è la rottura dell'esofago (sindrome di Boerhaave), che nel $40 \%$ dei casi interessa alcolisti e nel $41 \%$ pazienti affetti da ulcera peptica. I sintomi in genere sono il dolore (83\%) e il vomito (79\%), spesso associati a dispnea (39\%) e shock (32\%). All'esame fisico si evidenzia un reperto di crepitio alla base del collo; la xgrafia del torace può mostrare enfisema sottocutaneo, idro-pneumotorace, pneumomediastino ma in $1 / 3$ dei pazienti solo una TAC può essere diagnostica. Il tasso di mortalità è del $31 \%$, più basso rispetto al passato $(50 \%)$.

Tabella 1. Classificazione delle cause di nausea e vomito.

\begin{tabular}{|c|c|c|}
\hline Intraperitoneali & Extraperitoneali & Tossico/metaboliche \\
\hline Malattie ostruttive & Malattie cardiopolmonari & Farmaci \\
\hline \multirow{2}{*}{$\begin{array}{l}\text { Ostruzione pilorica, dell'intestino tenue e } \\
\text { del colon, sindrome dell'arteria mesenterica } \\
\text { superiore }\end{array}$} & Cardiomiopatie, infarto del miocardio & $\begin{array}{l}\text { Chemioterapia antineoplastica, analgesici, } \\
\text { antibiotici, antivirali, antitubercolari, }\end{array}$ \\
\hline & Malattie del labirinto & antiaritmici cardiaci, ipoglicemizzanti orali, \\
\hline \multirow[t]{2}{*}{$\begin{array}{l}\text { Infezioni enteriche } \\
\text { Virali e batteriche }\end{array}$} & $\begin{array}{l}\text { Cinetosi, labirintite, malattia di Ménière, } \\
\text { neoplasie maligne }\end{array}$ & $\begin{array}{l}\text { contraccettivi orali, narcotici, } \\
\text { anticonvulsivanti, anti-Parkinsoniani, } \\
\text { teofillina }\end{array}$ \\
\hline & Malattie intracerebrali & \\
\hline Malattie infiammatorie & Neoplasie maligne, emorragie, ictus & Alterazioni endocrino-metaboliche \\
\hline Colecistite, pancreatite, appendicite, epatite & $\begin{array}{l}\text { ischemico, meningite, ascesso cerebrale, } \\
\text { idrocefalo, pseudotumor cerebri, malattie }\end{array}$ & $\begin{array}{l}\text { Gravidanza, uremia, chetoacidosi, malattie } \\
\text { della tiroide e delle paratiroidi, insufficienza }\end{array}$ \\
\hline Disturbi della motilità & demielinizzanti & surrenale, porfiria acuta intermittente \\
\hline \multirow[t]{2}{*}{$\begin{array}{l}\text { Gastroparesi, pseudostruzione intestinale, } \\
\text { dispepsia funzionale e sindrome del colon } \\
\text { irritabile, reflusso gastroesofageo }\end{array}$} & Emicrania & $\begin{array}{l}\text { Tossine } \\
\text { Etanolo }\end{array}$ \\
\hline & Irradiazione intracranica & \\
\hline \multirow[t]{2}{*}{ Colica biliare } & & \\
\hline & Malattie psichiatriche & \\
\hline Colica renale & $\begin{array}{l}\text { Anoressia o bulimia nervosa, depressione, } \\
\text { vomito psicogeno }\end{array}$ & \\
\hline \multirow[t]{3}{*}{ Irradiazione addominale } & & \\
\hline & Vomito post-operatorio & \\
\hline & Sindrome del vomito ciclico & \\
\hline
\end{tabular}

Adattata da American Gastroenterology Association, $2011 .{ }^{10}$

Tabella 2. Assessment di nausea e vomito tramite l'acronimo OPQRSTUV.

\begin{tabular}{ll}
\hline$O$ - onset & Esordio, durata, frequenza, andamento \\
\hline$P$ - provoking/palliating & Fattori scatenanti, elementi di sollievo, cause esacerbanti \\
\hline$Q$ - quality & Caratteristiche ed assimilazione \\
\hline$R$ - region/radiation & Associazione a nausea \\
\hline$S$ - severity & $\begin{array}{l}\text { Intensità (scala da } 0 \text { a } 10, \text { con } 0 \text { come nullo e } 10 \text { come il massimo immaginabile), sintomi di } \\
\text { accompagnamento, limitazione personale }\end{array}$ \\
\hline$T$ - treatment & Terapia in corso, efficacia ed effetti collaterali della terapia domiciliare \\
\hline$U$ - understanding/impact on you & Impatto nella vita privata, apparenti elementi aggravanti \\
\hline$V$ - values & $\begin{array}{l}\text { Obiettivo personale di comfort o di livello accettabile, altre problematiche collaterali } \\
\text { di accompagnamento }\end{array}$ \\
\hline
\end{tabular}

Adattata da Vancouver Island Health Authority (VIHA), 2008. ${ }^{11}$ 
Il vomito, specie quello cronico, può causare alterazioni del bilancio idrosalino e dell'equilibrio acidobase con conseguente alcalosi metabolica ipokaliemica ed ipocloremica, iposodiemia con ipovolemia. L'alcalosi è legata alla contrazione del liquido extracellulare con perdita di ioni $\mathrm{H}^{+}$(senza perdita di bicarbonati) legata all'ingresso degli ioni $\mathrm{H}^{+}$ nelle cellule per compensare il deficit di K. L'ipokaliemia è legata sia a deficit di introito che all'eccessiva perdita con il vomito e per via renale (a causa dell'alcalosi). Si manifesta clinicamente con astenia muscolare, stipsi, polidipsia, nicturia ed aritmie cardiache. L'iponatremia è secondaria, legata all'eccessiva perdita con il vomito e per via renale con le urine (bicarbonato di $\mathrm{Na}^{+}$) e all'eccessiva secrezione di ADH (ormone antidiuretico).

La Tabella 5 riassume le principali complicanze del vomito, la loro diagnosi e il trattamento.

\section{Approccio terapeutico}

Le linee guida della Vancouver Island Health Authority (VIHA) ${ }^{11}$ propongono, nell'ambito della te- rapia, raccomandazioni legate sia allo stile di vita che ad un approccio farmacologico mirato.

Il paziente deve essere informato dei multipli fattori che possono scatenare, esacerbare ed alleviare i sintomi. Il paziente dovrà eliminare gli alimenti ai quali è intollerante e ridurre l'introito se la distensione gastrica è un aggravante. In particolare si consiglia, dopo la risoluzione della nausea, di cominciare col bere a piccoli sorsi, provare con cubetti di ghiaccio o ghiaccioli e gradualmente aumentare con cibi fluidi, poi semisolidi e poi solidi. Se la nausea recidiva si torna allo step precedente. Bisogna evitare alimenti speziati, grassi e salati o dall'odore forte, bevande gassate e fredde, evitare di mescolare alimenti fluidi e solidi e di sdraiarsi dopo il pasto; preferire pasti leggeri e frequenti in caso di appetito, mantenere una accurata igiene orale, soprattutto dopo ogni episodio di vomito, ed eliminare dall'ambiente domestico odori e luci forti.

Come supporto psicologico si possono provare l' $\mathrm{i}-$ pnosi, la distrazione, l'agopuntura e la consultazione di psicoterapisti.

Per quanto riguarda la terapia farmacologica vale come regola generale di assumere un principio attivo a dosaggio pieno, prima di associare un'altra mole-

Tabella 3. Assessment della nausea e del vomito tramite la storia clinica del paziente con nausea e vomito.

L'insorgenza di sintomi Brusco (colecistite, intossicazioni alimentari, gastroenteriti, droghe, farmaci, pancreatite) Insidioso (malattia da reflusso gastroesofageo, gastroparesi, farmaci, disturbi metabolici, gravidanza)

Temporizzazione dei sintomi

Prima di colazione (alcol etilico, aumento della pressione intracranica, gravidanza, uremia) Durante o subito dopo i pasti (cause psichiatriche; meno probabile: ulcera peptica o stenosi pilorica)

Da uno a quattro ore dopo un pasto (ostruzioni dello svuotamento gastrico, per esempio, da ulcera peptica, neoplasie; gastroparesi)

Continuo (disturbo di conversione, depressione)

Irregolare (depressione maggiore)

La natura del vomito

Cibo non digerito (acalasia o altri disturbi esofagei come diverticoli o stenosi)

Cibo parzialmente digerito (ostruzione gastrica, gastroparesi)

Biliare (ostruzione prossimale del piccolo intestino)

Fecale (fistola, ostruzione con degradazione batterica dei contenuti)

Grande volume (>1500 mL nelle 24 ore, suggerisce una causa organica e non psichiatrica)

Associato a dolore addominale

Quadrante superiore destro (affezioni del tratto biliare, colecistite)

Epigastrico (malattie del pancreas, ulcera peptica)

Violento dolore (malattia biliare, malattie pancreatiche, irritazione peritoneale, ostruzione del piccolo intestino)

Grave dolore che precede il vomito (occlusione intestinale)

Associato a dimagrimento

Sospetto neoplastico (anche se un significativo calo ponderale può presentarsi anche nella sitofobia secondaria a disturbi funzionali e all'ulcera peptica)

Associato a cefalea, rigidità nucale, vertigini, Cause neurologiche (per esempio, l'encefalite/meningite, trauma cranico, massa occupante deficit neurologici focali spazio o altra causa di aumento della pressione intracranica, emicrania)

Associato a diarrea, mialgie, febbricola, Eziologia virale

contatto con persone malate

Precoce sazietà, tensione e discomfort

Gastroparesi

addominale

Associato a crisi emicraniche ripetitive o

Sindrome del vomito ciclico

sintomi dell'intestino irritabile 


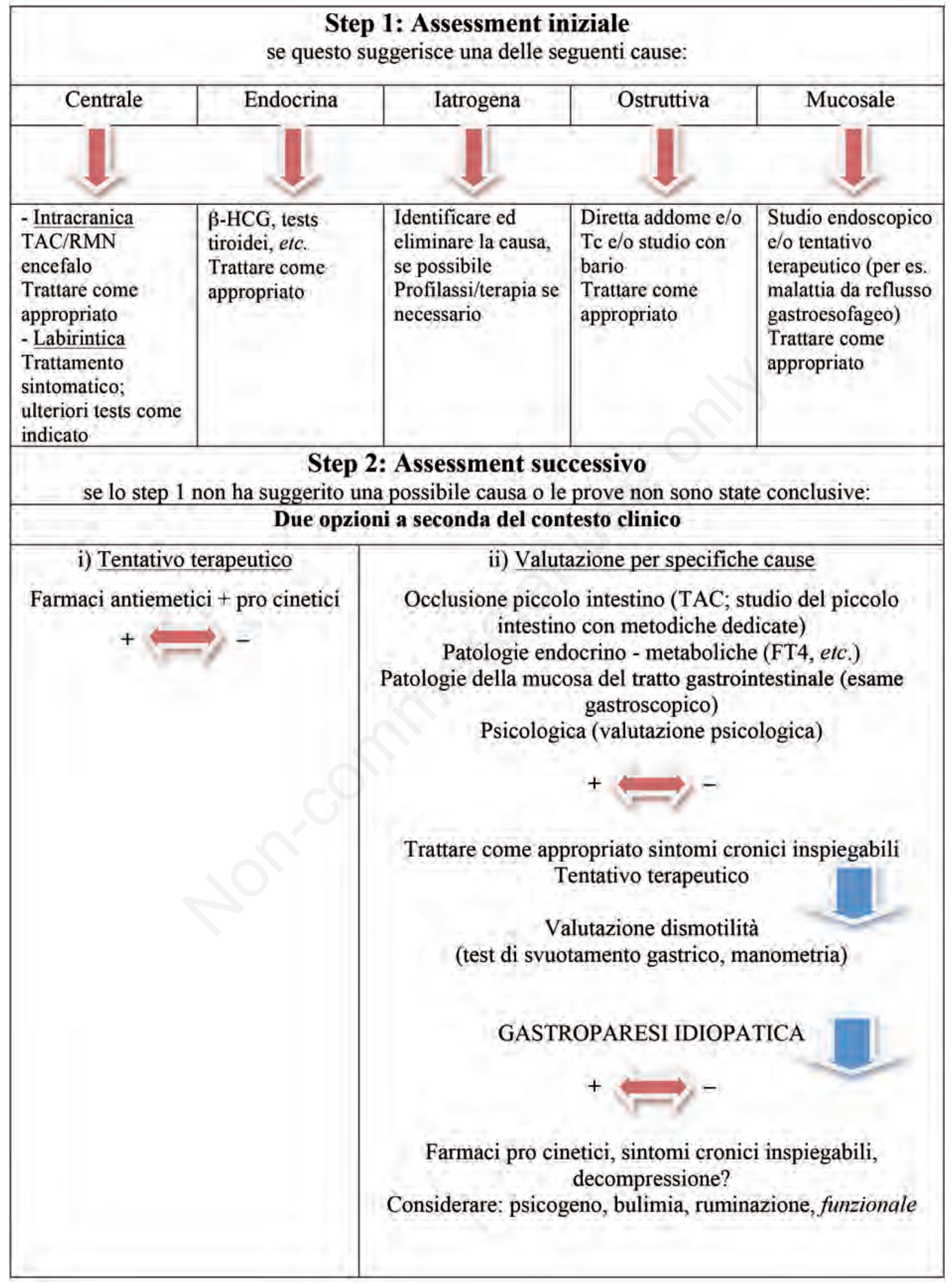

Figura 1. Management del vomito e della diarrea. TAC, tomografia assiale computerizzata; RMN, risonanza magnetica nucleare. Adattata da American Gastroenterology Association, $2011 .^{10}$ 
cola. In questo caso, se il sintomo persiste per almeno 48 ore, bisogna scegliere un farmaco di diversa categoria rispetto al primo, che a sua volta non va sospeso, facendo attenzione alla potenziale tossicità.

La terapia va individualizzata prevedendo una po- sologia fissa con anche una dose di salvataggio; in particolare, si raccomanda la somministrazione preventiva di antiemetici in corso di terapia oppiacea e chemioterapia.

Il farmaco di prima scelta è la metoclopramide per-

Tabella 4. Raccomandazioni chiavi per la pratica clinica.

Raccomandazioni cliniche

Evidence rating*

La maggior parte delle cause di nausea e vomito acuti può essere determinata dalla storia e l'esame fisico

$\mathrm{C}$

La valutazione iniziale dovrebbe concentrarsi su segni o sintomi che indicano un trattamento urgente, $\mathrm{C}$ intervento chirurgico o necessità di ospedalizzazione

I test diagnostici per la nausea e il vomito devono essere mirati a trovare l'eziologia suggerita da una storia completa $\mathrm{C}$ e dall'esame fisico

Squilibri dei fluidi, alterazioni degli elettroliti, e le carenze nutrizionali devono essere corretti

Il trattamento deve essere diretto verso la sottostante causa della nausea e vomito

Se non si è trovata la causa, il paziente deve essere trattato con una terapia sintomatica con antiemetico e/o pro cinetico, si dovrebbero escludere altre cause di inspiegabile nausea e vomito cronici (ad esempio, psicogena, bulimica, ruminazione, funzionale)

*A, coerente, di buona qualità ed orientata sul paziente; B, incoerente o di qualità limitata, orientata sul paziente; $\mathrm{C}$, consenso, evidenza orientata sulla malattia, dedotta dalla pratica clinica usuale, da opinione di esperti o serie di casi.

Tabella 5. Complicanze del vomito: segni, sintomi e trattamento.

\begin{tabular}{|c|c|c|c|c|}
\hline Problema & Segni e sintomi & Altri risultati & Trattamento & \\
\hline $\begin{array}{l}\text { Deplezione del volume } \\
\text { intravascolare, } \\
\text { ipovolemia }\end{array}$ & $\begin{array}{l}\text { Sete, vertigini, sincope, } \\
\text { ipotensione ortostatica, } \\
\text { riduzione del turgore cutaneo, } \\
\text { oliguria, tachicardia, azotemia, } \\
\text { shock, coma }\end{array}$ & $\begin{array}{l}\text { Pressione arteriosa, } \\
\text { frequenza cardiaca } \\
\text { ed elettroliti } \\
\text { sierici ed urinari }\end{array}$ & $\begin{array}{l}\text { Liquidi orali }(2-4 \mathrm{~L} / \text { die }) \\
\text { Soluzione orale } \\
\text { elettrolitica }\end{array}$ & $\begin{array}{l}\text { Fluidi isotonici (soluzione } \\
\text { salina } 0,9 \% \text { ) ( }>-2 \mathrm{~L} 1 \text { ora), } \\
\text { quindi proseguire sulla } \\
\text { base del monitoraggio } \\
\text { dei segni vitali e della diuresi. } \\
\text { Considerare misurazione } \\
\text { della pressione venosa } \\
\text { centrale per guidare la terapia } \\
\text { Monitorare elettroliti sierici } \\
\text { Integrare } \mathrm{K}+\text { e } \mathrm{Mg}+\text {, come } \\
\text { necessario }\end{array}$ \\
\hline
\end{tabular}

\begin{tabular}{ll}
\hline Alcalosi ipokaliemica & Ipotensione \\
ipocloremica & Ipoventilazione crampi \\
& muscolari, tetania
\end{tabular}

EGA
Elettroliti sierici ed
urinari

Correggere 1'ipokaliemia con $\mathrm{K}$ ev

Monitoraggio continuo dell'ECG, se ipokaliemia severa Se alcalosi grave $(\mathrm{pH}>7,55)$, monitoraggio EGA ed elettroliti ogni 4 ore

Se insufficienza renale, dializzare il paziente Usare con cautela l'acidoterapia. Calcolo $\mathrm{H}^{+}(\mathrm{mEq})$ : $\underline{0,5 \times \text { peso corporeo }(\mathrm{kg}) \times[(\mathrm{HCO} 3 \text { misurato })-}$ (desiderato $\mathrm{HCO} 3$ )] Sostituire la metà del deficit nelle prime 12 ore, il resto nelle successive 24 ore (una soluzione di $\mathrm{HCl}=150 \mathrm{~mL}$ di $\mathrm{HCl}$ in $1 \mathrm{~L} \mathrm{H}_{2} \mathrm{O}$ sterile)

\begin{tabular}{llll}
\hline $\begin{array}{l}\text { Sanguinamento } \\
\text { gastroenterico }\end{array}$ & $\begin{array}{l}\text { Ematemesi, melena } \\
\text { Ipotensione, tachicardia } \\
\text { Disfagia, dolore toracico/dolore } \\
\text { alla schiena (ematoma } \\
\text { intramurale) }\end{array}$ & Trasfusione di sangue e di piastrine; di FFP se coagulopatia \\
\hline Sindrome di Boerhaave & $\begin{array}{l}\text { Febbre, dolore toracico e/o } \\
\text { addominale, dispnea, shock, } \\
\text { reperto di crepitance } \\
\text { Segni Tc di pneumodiastino }\end{array}$ & $\begin{array}{l}\text { Leucocitosi } \\
\text { Ipossiemia }\end{array}$ & $\begin{array}{l}\text { Tubo NG a cavallo del sito di perforazione } \\
\text { antibioticoterapia a largo spettro - con copertura per } \\
\text { anaerobi, aerobi Gram neg e Staphylococcus aureus, } \\
\text { se recente ospedalizzazione }\end{array}$ \\
\hline $\begin{array}{l}\text { Aspirazione ed } \\
\text { ab ingestis }\end{array}$ & Febbre, tosse, dispnea & $\begin{array}{l}\text { Ipossiemia; infiltrati } \\
\text { alla xgrafia del torace }\end{array}$ & \\
\hline
\end{tabular}




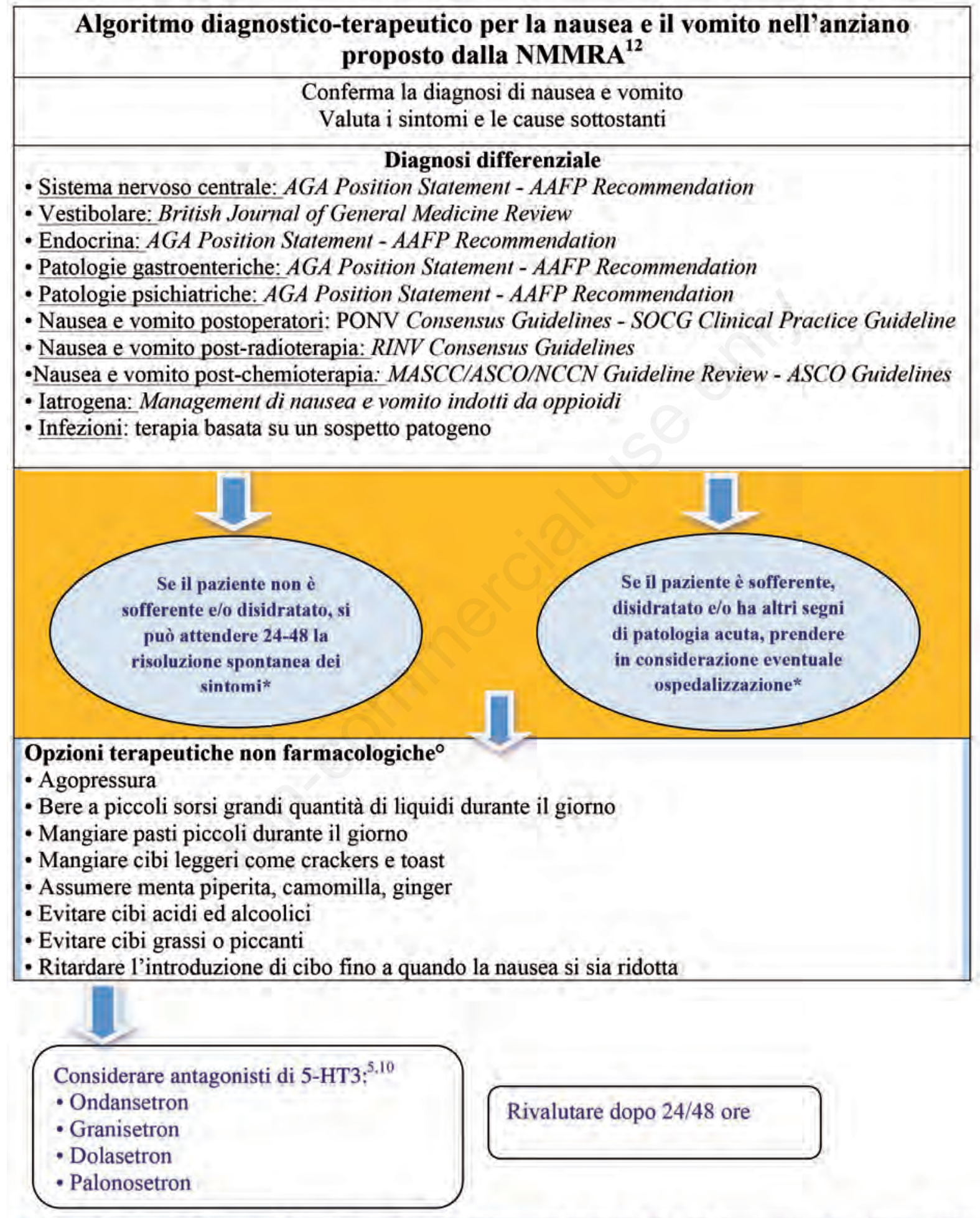

*Dati da: Reuben et al. Geriatrics at your fingertips: nausea and vomiting. New York, NY: The American Geriatrics Society; 2009. 'Dati da: McWhorter et al. Handbook of nonprescription drugs. Washington, DC: APhA; 2006.

Figura 2. Algoritmo diagnostico-terapeutico per la nausea e il vomito nell'anziano adattato da quello proposto dalla $\mathrm{New}$ Mexico Medical Review Association (NMMRA). 
ché agisce sulle cause più comuni della nausea, mentre ondansetron ed apripetant, anche se molto efficaci per nausea e vomito indotti da chemio- e radioterapia, sono considerati di quarta linea.

Gli antiemetici possono essere selezionati in base al meccanismo fisiopatologico interessato o anche in base a specifiche situazioni (Tabella 6).

La Tabella 7 elenca i principi attivi con i relativi nomi commerciali, le principali indicazioni e i più comuni effetti collaterali

\section{Anticolinergici}

L'antagonista dei recettori M1 più usato è la scopolamina transdermica, usata prevalentemente per la profilassi della cinetosi (cerotto da $1,5 \mathrm{mg}$ ogni 72 ore). ${ }^{13}$ Gli effetti collaterali più frequenti sono secchezza delle fauci, sonnolenza e disturbi visivi.

\section{Antistaminici}

Sono utilizzati soprattutto per la cinetosi ma sono utili anche nelle ostruzioni meccaniche e nell'ipertensione endocranica (uso supportato solo dall'esperienza clinica). Il maggiore effetto collaterale è la sonnolenza.

Comprendono: i) difenidramina, da 25 a $50 \mathrm{mg} / 6$ ore per os, da 10 a $50 \mathrm{mg}$ im o ev; ii) dimenidrinato $50 \mathrm{mg} / 4$ ore per os; iii) ciclizina, $50 \mathrm{mg} / 4$ ore per os o im, $100 \mathrm{mg} / 4$ ore in supposta; iv) meclizina, da 25 a $50 \mathrm{mg}$ per os/die; v) prometazina, da $12,5 \mathrm{a} 25 \mathrm{mg} / 4$ ore per os o im, da 12,5 a $25 \mathrm{mg} / 12$ ore per via rettale.

\section{Antidopaminergici}

Ne sono utilizzate tre classi: i) fenotiazine (la più usata è la proclorperazina) che agiscono principalmente sui recettori D2 dell'area postrema, ma esercitano anche un blocco H1 e M1. I maggiori effetti collaterali sono reazioni extrapiramidali come la distonia (se acuta trattabile con difenidramina) e, con l'uso prolungato, la discinesia tardiva; ii) butirrofenoni (tra i più usati il droperidolo (im) a rapida azione e il domperidone (per os), che ha attività D2 periferica selettiva a livello del tratto gastrointestinale superiore, non attraversa la barriera ematoencefalica e non ha gli effetti collaterali della metoclopramide) usati principalmente come agenti preanestetici o per la sedazione pre-procedurale, ma efficaci anche per la nausea e il vomito postoperatori, con effetti collaterali simili alle fenotiazine. La somministrazione ev ha un rischio dose-dipendente di allungamento del QT con torsioni di punta per cuii pazienti critici, anziani o in terapia con altri farmaci che allungano il QT devono essere attentamente monitorati; iii) tra le benzamidi, la più nota e usata la metoclopramide caratterizzata da un profilo farmacodinamico misto. Essa, infatti, a basse dosi si comporta da antagonista dei recettori D2 centrali e periferici, mentre ad alte dosi é in grado di bloccare i recettori 5-HT3. Stimola anche i recettori colinergici sulla muscolatura gastrica, favorendo il rilascio di acetilcolina sulle giunzioni muscolari. L'efficacia antiemetica della metoclopramide (10-20 mg/6 ore per os, ev o sc) é stata dimostrata nei confronti di diversi tipi di vomito, compreso quello post-chemioterapia. A dosi medie quotidiane di 1-1,2 $\mathrm{mg} / \mathrm{kg} / \mathrm{ev}$ causa generalmente effetti collaterali piuttosto lievi, che scompaiono rapidamente dopo interruzione del trattamento. Dal momento che attraversa la barriera ematoencefalica, può causare effetti collaterali come atassia, distonia, discinesia tardiva che compaiono generalmente dopo un breve intervallo di tempo dall'ini-

Tabella 6. Indicazioni terapeutiche ragionate.

\begin{tabular}{lll}
\hline Situazione/sede stimolata & Neurotrasmettitore & Antiemetico \\
\hline Cefalea & Dopamina & Metoclopramide, proclorperazina \\
\hline Nausea vestibolare & Istamina, acetilcolina & Antistaminici ed anticolinergici \\
\hline Gravidanza & & $\begin{array}{l}\text { Ginger e vit B6 per la nausea } \\
\text { Prometazina ed antagonisti della serotonina per l'iperemesi }\end{array}$ \\
\hline Gastroenteriti e distensione gastrointestinale & Dopamina, serotonina & Antidopaminergici, antiserotoninergici, octeotride, desametasone \\
\hline Nausea e vomito postoperatori & Dopamina, serotonina & $\begin{array}{l}\text { Prevenzione con antagonisti della serotonina, droperidolo e } \\
\text { desametasone } \\
\text { Trattamento con antidopaminergici, antiserotoninergici e } \\
\text { desametasone }\end{array}$ \\
\hline $\begin{array}{l}\text { Stimoli tossici e chimici sull'area postrema } \\
\text { (oppiacei, chemioterapici, uremia, ipercalcemia, } \\
\text { sepsi) }\end{array}$ & $\begin{array}{l}\text { Dopamina, serotonina, } \\
\text { sostanza P }\end{array}$ & $\begin{array}{l}\text { Antidopaminergici, antiserotoninergici, aprepitant } \\
\text { Ipertensione intracranica }\end{array}$ \\
\hline $\begin{array}{l}\text { Stimoli sensoriali superiori (odori e sapori } \\
\text { sgradevoli, dolore, ansia, nausea anticipatoria, } \\
\text { ricordi sgradevoli) }\end{array}$ & & Desametasone \\
\hline
\end{tabular}


zio della terapia, più frequentemente negli anziani, nei bambini e nelle donne, trattabili con premedicazione a base di difenidramina; iv) le benzamidi sostituite (in commercio in Italia amisulpride, levosulpiride, sulpiride, sultopride e tiapride) sono una classe eterogenea di composti ad azione antidopaminergica (in maniera selettiva sui D2).

\section{Antiserotoninergici}

Gli antiserotoninergici $5-\mathrm{HT}^{14}$ (tra i più usati l'ondansetron, il granisetron, il palonosetron, dronasetron, tropisetron) sono la classe di antiemetici più efficaci per l'emesi acuta indotta da chemioterapici a medio ed alto rischio, nonché per l'emesi tardiva da chemioterapici a moderato potere emetogeno, con un'efficacia della dose orale paragonabile a quella parenterale.

Non ci sono, invece, trials clinici che ne dimostrino l'efficacia in altre circostanze cliniche.

Sono generalmente ben tollerati con modesti effetti collaterali quali cefalea, astenia e costipazione. Dal momento che possono provocare transitorie modifiche elettrocardiografiche con rischio di aritmie fatali, si raccomanda monitoraggio ECGgrafico in pazienti con ipokaliemia, ipomagnesemia, scompenso cardiaco, bradiaritmie e/o in caso di associazione con altri farmaci proaritmogeni.

\section{Antagonisti dei recettori della neurochinina}

La sostanza P è un neuropeptide presente a livello del nucleo del tratto solitario e dell'area postrema dove media un effetto emetogeno a livello del recettore NK1.

L'aprepitant (per os) e il fosaprepitant (per via parenterale) sono una nuova classe di antiemetici utilizzati per prevenire l'emesi acuta e tardiva da chemioterapici; risultano più efficaci se associati con gli antiserotoninergici e il desametasone. È da segnalare il rischio di una tossicità da farmaci metabolizzati dal CYP3A4 come la ciclofosfamide e il docetaxel, a causa di un effetto inibitorio sul citocromo stesso da parte dell'aprepitant.

\section{Glucocorticoidi}

Con un meccanismo non del tutto chiaro, sono efficaci e ben tollerati nell'emesi da chemioterapici. Co-

Tabella 7. Elenco dei principi attivi, principali indicazioni ed effetti collaterali.

\begin{tabular}{|c|c|c|}
\hline Classe di farmaco & Comune impiego & Comuni effetti collaterali \\
\hline Anticolinergico (scopolamina) & $\begin{array}{l}\text { Eventuale aggiunta in corso di } \\
\text { chemioterapia citotossica; nella profilassi } \\
\text { e trattamento delle cinetosi }\end{array}$ & $\begin{array}{l}\text { Sonnolenza, secchezza delle fauci, } \\
\text { disturbi della visione }\end{array}$ \\
\hline $\begin{array}{l}\text { Antistaminici (ciclizina - non in vendita in Italia; } \\
\text { dimenidrinato; difenidramina; meclizina) }\end{array}$ & Emicrania, cinetosi, vertigine & Sonnolenza \\
\hline Benzodiazepine (alprazolam; diazepam; lorazepam) & $\begin{array}{l}\text { Adiuvanti per i sintomi correlati alla } \\
\text { chemioterapia }\end{array}$ & Sedazione \\
\hline Butirrofenoni (aloperidolo) & $\begin{array}{l}\text { PONV e nausea e vomito anticipatori ed } \\
\text { acuti in corso di chemioterapia }\end{array}$ & Agitazione, irrequitezza, sedazione \\
\hline Cannabinoidi (solo prodotti galenici in Italia) & $\begin{array}{l}\text { Nausea e vomiti refrattari in corso di } \\
\text { chemioterapia }\end{array}$ & $\begin{array}{l}\text { Atassia, vertigini, euforia, ipotensione, } \\
\text { sedazione }\end{array}$ \\
\hline Corticosteroidi (desametasone) & $\begin{array}{l}\text { Adiuvanti per i sintomi correlati alla } \\
\text { chemioterapia }\end{array}$ & $\begin{array}{l}\text { Insonnia, iperattività, modifiche del } \\
\text { carattere }\end{array}$ \\
\hline $\begin{array}{l}\text { Fenotiazine (clorpropamide [è un potente } \\
\text { ipoglicemizzante], prometazina) }\end{array}$ & $\begin{array}{l}\text { Emicrania, cinetosi, nausea e vomito } \\
\text { postchemioterapia, PONV, gravi episodi } \\
\text { di nausea e vomito, vertigini }\end{array}$ & $\begin{array}{l}\text { Sintomi extrapiramidali (per es. distonia, } \\
\text { discinesia tardiva), ipotensione } \\
\text { ortostatica, sedazione }\end{array}$ \\
\hline $\begin{array}{l}\text { Antiserotoninergici (sono in vendita in Italia: } \\
\text { dolasetron, odansetron, granisetron, palonosetron) } \\
\text { Tutti possono essere somministrati per via orale o } \\
\text { iniettiva (per l'ondansetron esiste anche una } \\
\text { formulazione in supposte), fatta eccezione per il } \\
\text { palonosetron (il più recente) che ha una più lunga } \\
\text { durata d'azione (emivita plasmatica di } 40 \text { ore circa) e } \\
\text { viene somministrato in una singola iniezione } \\
\text { endovenosa prima della chemioterapia }\end{array}$ & $\begin{array}{l}\text { Nausea e vomito severi, nausea e vomiti } \\
\text { refrattari in corso di chemioterapia }\end{array}$ & $\begin{array}{l}\text { Astenia, costipazione, vertigini e } \\
\text { modesta cefalea }\end{array}$ \\
\hline
\end{tabular}

Succedanei delle benzamidi (metoclopramide trimethobenzamide [non in vendita in Italia])
Gastroenteropatia diabetica discinesia, distonia, crisi oculogiri, opistotono), astenia, iperprolattinemia

PONV, nausea e vomito post-operatori. 
muni effetti collaterali sono l'insonnia, i rialzi pressori e glicemici e l'alterazione del tono dell'umore.

Utilizzati da soli per chemioterapie a lieve rischio emetogeno, si associano agli antiserotoninergici nelle chemioterapie a moderato rischio emetogeno e agli antiserotoninergici ed aprepitant in quelle ad alto rischio.

I più usati sono il desametasone ed il metilprednisolone.

\section{Cannabinoidi}

Proposti (nabilone e dronabinolo) per la nausea postchemioterapia, ma il modesto potere antiemetico a dispetto degli effetti collaterali (vertigine, xerostomia, ipotensione e disforia) ne limita l'uso. In Italia in vendita come prodotti galenici.

\section{Benzodiazepine}

Antiemetici deboli, i più usati sono il lorazepam e l'alprazolam, come terapia adiuvante per ridurre ansia ed acatisia e, associati al desametasone e alla metoclopramide, l'emesi anticipatoria. Il maggiore effetto collaterale è la sedazione.

\section{Nausea e vomito in pazienti oncologici}

Nausea e vomito continuano ad essere un evento avverso frequente e fastidioso per i pazienti oncologici. La nausea anticipatoria si presenta prima della somministrazione della terapia ed è una risposta condizionata conseguente ad una precedente esperienza negativa con la stessa. La nausea acuta si presenta da pochi minuti ad alcune ore dopo la somministrazione del chemioterapico e spesso si risolve nelle prime 24 ore. La nausea ritardata compare dopo più di 24 ore dopo la terapia con un picco a circa 48-72 ore e può durare 6-7 giorni. ${ }^{15-20}$ Anche in questo contesto sono valide le norme relative alle abitudini di vita, ma solo la terapia farmacologica è supportata da evidenze scientifiche per raccomandarla nella pratica clinica. ${ }^{19-21} \mathrm{La}$ terapia di supporto ha un ruolo limitato e può essere indicata in associazione a quella farmacologica (Tabella 8$){ }^{21}$

La Tabella 9 riepiloga alcuni interventi efficaci nella gestione della nausea e vomito post-chemioterapici.

L'Update Committe raccomanda come endpoint primario nei trial clinici oncologici la valutazione del

Tabella 8. Interventi terapeutici basati su studi empirici.

Raccomandati per la pratica clinica

- Interventi farmacologici inclusi le benzodiazepine, gli antagonisti dei recettori 5-HT3, cortisonici ed antagonisti per i recettori NK1

Potenzialmente efficaci

- Agopuntura

- Agopressione

- Musicoterapia

- Progressivo rilassamento muscolare

- Immaginazione guidata

- Supporto psicoeducazionale ed informazione

Benefici bilanciati con i rischi

- Realtà virtuale

Efficacia non stabilita

- Esercizi

- Ipnosi

- Massaggi ed aromaterapia

- Stimolazione acustica con dispositivo a bracciale

- Ginger

Adattata da Tripton et al., 2007. ${ }^{21}$

Tabella 9. Interventi efficaci nella gestione di nausea e vomito indotte da chemioterapia.

- Gli entimetici per via orale e ev sono ugualmente efficaci

- Il periodo di attesa della nausea e vomito deve essere coperto con antiemetici appropriati

- Dovrebbe essere utilizzata la più bassa dose efficace di antiemetici

- La scelta di antiemetici dovrebbe essere basata sul potenziale emetico dell'agente chemioterapico

- Si raccomanda di seguire alcuni consigli dietetici:

- Mangia pasti piccoli e frequenti

- $\quad$ Riduci gli aromi alimentari e cibi con odori forti

- Evita alimenti piccanti, grassi o molto salati

- Prendi antiemetici prima dei pasti in modo che l'effetto è presente durante e dopo i pasti

- Scegli gli alimenti che riducono al minimo la nausea (cibi consolatori) 
vomito (numero di episodi) e della nausea (percepita dal paziente) nei cinque giorni seguenti alla chemioterapia.

Si considera risposta completa alla terapia l'assenza di vomito e la non necessità di somministrazione di antiemetici di salvataggio.

I farmaci sono scelti in base al tipo di nausea/vomito e al potere emetogeno della chemioterapia. ${ }^{20-27}$

I farmaci antineoplastici sono raggruppati in base al rischio di emesi in quattro categorie individuate dalla MASCC Consensus Conference (Figure 3-6), a cui cor-

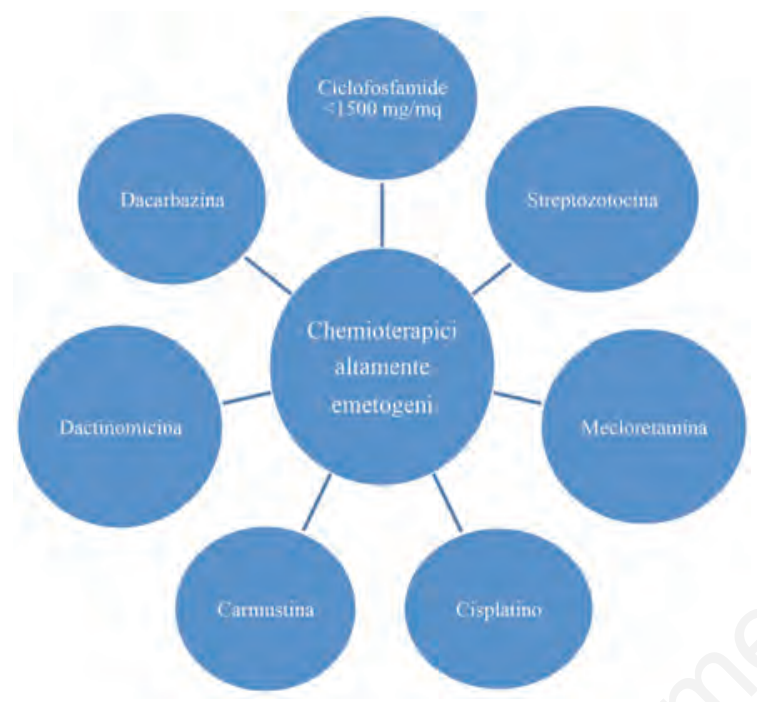

Figura 3. Chemioterapici ad alto rischio di emesi $(>90 \%)$.

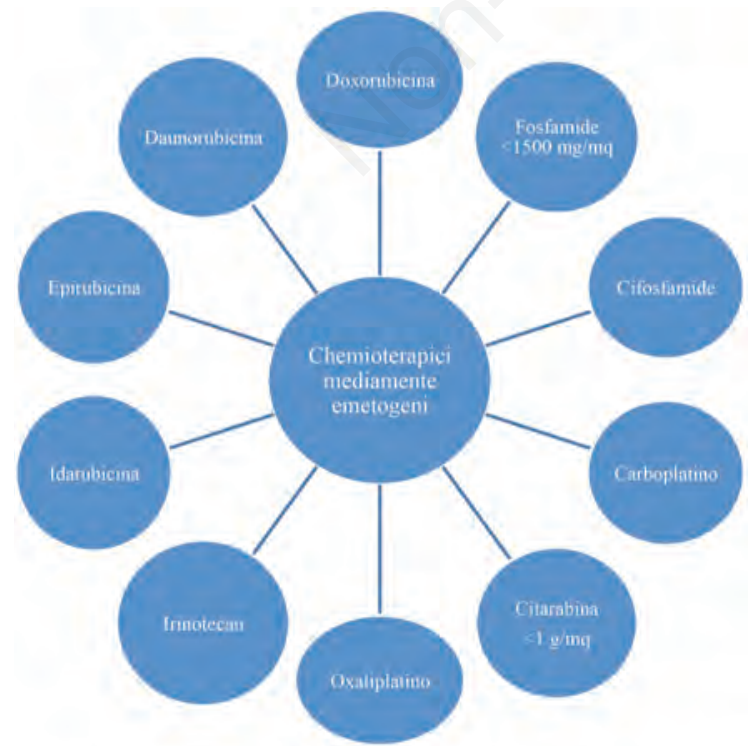

Figura 4. Chemioterapici a medio rischio di emesi (30$90 \%)$. rispondono diversi schemi di terapia antiemetica che combinano antagonisti 5-HT3, steroidi, antirecettoriali NK1 per la emesi acuta (Tabelle 10-12). ${ }^{23}$

In corso di terapia antitumorale ad alto rischio non sono raccomandati antiemetici a minore indice terapeutico che sono invece riservati ai pazienti che non tollerano o sono refrattari agli anti 5-HT3, agli anti NK1, al desametasone e all'aprepitant.

Nei casi invece di nausea e vomito refrattari alle profilassi, si raccomanda di rivalutare il grado di rischio del regime terapeutico e che sia stata rispettata

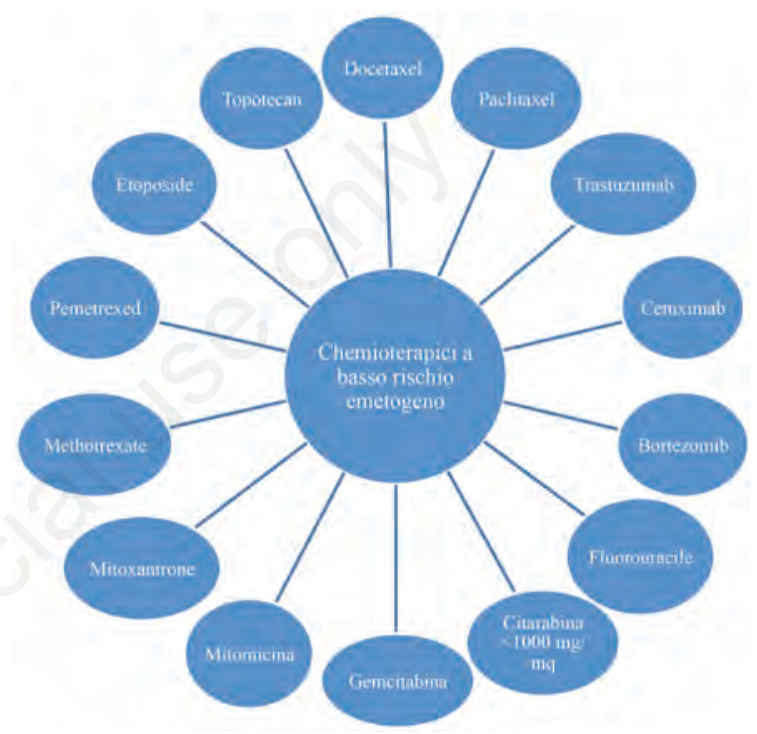

Figura 5. Chemioterapici a basso rischio di emesi (10$30 \%)$.

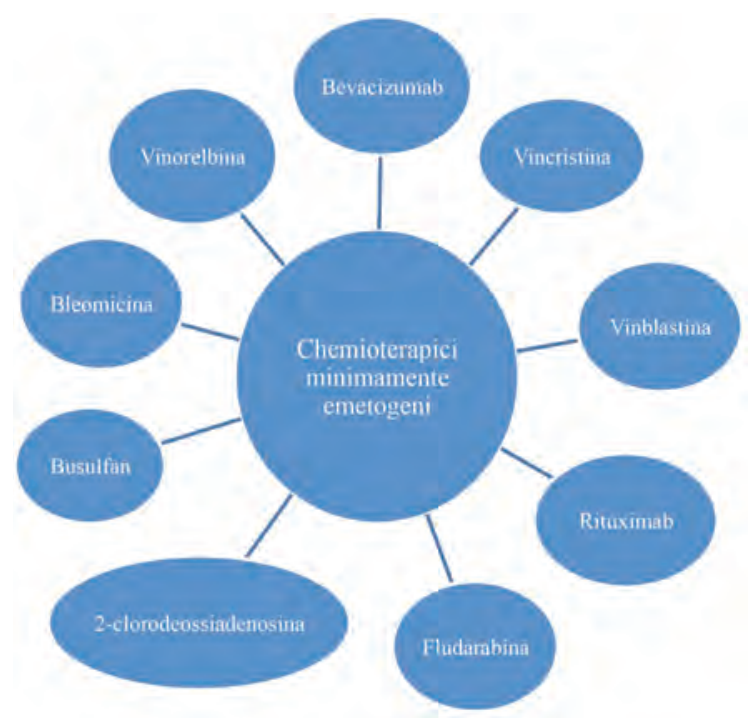

Figura 6. Chemioterapici a rischio minimo di emesi $(<\mathbf{1 0 \%})$. 
la relativa prevenzione, considerare l'eventuale aggiunta di ansiolitici, sostituire l'anti 5-HT3 con metoclopramide ev ad alto dosaggio o aggiungere un antidopaminergico. Sulla base di studi osservazionali ed esperienza clinica può essere efficace anche la gastrostomia nei casi più resistenti. Non sono sostenuti da trials clinici ben condotti gli anticolinergici, i cannabinoidi, gli antipsicotici. ${ }^{27}$

\section{Nausea e vomito post-operatori}

Nel $20-30 \%$ dei casi nausea e vomito post-operatori (PONV) ${ }^{28-34}$ si presentano entro 24 ore dopo l'intervento. È una complicanza legata a diversi fattori, sia individuali che anestesiologici e chirurgici, che può prolungare il ricovero e, a sua volta, può complicarsi con altri eventi come le polmoniti $a b$ ingestis.

Tabella 10. Regimi terapeutici per la prevenzione dell'emesi acuta indotta da chemioterapia.

\begin{tabular}{|c|c|}
\hline Categoria di rischio & Protocollo \\
\hline Alto rischio & $\begin{array}{ll}\text { - } & \text { 5-HT3 antagonisti al giorno } 1 \\
\text { - } & \text { Desametasone dal giorno } 1 \text { al } 4 \\
& \text { Aprepitant giorno 1,2,3 }\end{array}$ \\
\hline Moderato & $\begin{array}{l}\text { - } 5 \text {-HT3 antagonisti al giorno } 1 \\
\text { - } \quad \text { Desametasone al giorno } 1 \text { (anche } 2 \text { e } 3 \text { se non associato aprepitant) } \\
\text { Aprepitant al giorno } 1,2,3 \text { per i pazienti che ricevono ciclofosfamide ed antracicline in associazione }\end{array}$ \\
\hline Basso & - Desametasone al giorno 1 \\
\hline
\end{tabular}

Tabella 11. Regimi terapeutici per la prevenzione dell'emesi acuta da chemioterapia a rischio emetogeno alto.

\begin{tabular}{lcc}
\hline Farmaco antiemetico & Dose singola prima della terapia & Dose quotidiana \\
\hline Dolasetron & $100 \mathrm{mg}$ per os \\
$100 \mathrm{mg}(\mathrm{o} 1,8 \mathrm{mg} / \mathrm{kg}) \mathrm{ev}$ & - \\
\hline Granisetron & $\begin{array}{c}2 \mathrm{mg} \text { per os } \\
1 \mathrm{mg}(\mathrm{o} 0,01 \mathrm{mg} / \mathrm{kg}) \mathrm{ev}\end{array}$ & - \\
\hline Ondansetron & $24 \mathrm{mg} \mathrm{per} \mathrm{os}$ \\
& $8 \mathrm{mg}(\mathrm{o} 0,15 \mathrm{mg} / \mathrm{kg}) \mathrm{ev}$ & - \\
\hline Palonosetron & $0,25 \mathrm{mg}$ ev & - \\
\hline Tropisetron & $5 \mathrm{mg}$ per os o ev & - \\
\hline Desametasone & $12 \mathrm{mg}$ per os & $8 \mathrm{mg}$ per os o ev nei giorni 2- 4 \\
\hline Aprepitant & $125 \mathrm{mg}$ per os & $80 \mathrm{mg}$ nei giorni 2 e 3 per os \\
\hline
\end{tabular}

Tabella 12. Regimi terapeutici per la prevenzione dell'emesi acuta da chemioterapia a rischio emetogeno moderato.

\begin{tabular}{|c|c|c|}
\hline Farmaco antiemetico & Dose singola prima della terapia & Dose quotidiana \\
\hline Dolasetron & $100 \mathrm{mg}$ per os o ev (o $1,8 \mathrm{mg} / \mathrm{kg}$ ev) & - \\
\hline Granisetron & $\begin{array}{l}1-2 \mathrm{mg} \text { per os }(\mathrm{o} 1 \mathrm{mg} \times 2) \\
1 \mathrm{mg}(\mathrm{o} 0,01 \mathrm{mg} / \mathrm{kg}) \mathrm{ev}\end{array}$ & - \\
\hline Ondansetron & $\begin{array}{l}16 \mathrm{mg}(\text { o } 8 \mathrm{mg} \times 2) \text { per os } \\
8 \mathrm{mg}(\text { o } 0,15 \mathrm{mg} / \mathrm{kg}) \text { ev }\end{array}$ & - \\
\hline Palonosetron & $\begin{array}{l}5 \mathrm{mg} \text { per os } \\
0,25 \mathrm{mg} \text { ev }\end{array}$ & - \\
\hline Tropisetron & $5 \mathrm{mg} \mathrm{ev}$ & - \\
\hline $\begin{array}{l}\text { Desametasone } \\
\text { - senza aprepitant } \\
\text { - con aprepitant }\end{array}$ & $\begin{array}{c}8 \mathrm{mg} \mathrm{ev} \\
12 \mathrm{mg} \text { per os }\end{array}$ & $8 \mathrm{mg}$ nei giorni 2 e 3 per os \\
\hline $\begin{array}{l}\text { Aprepitant (per combinazioni di } \\
\text { ciclofosfamide ed antraciciline) }\end{array}$ & $125 \mathrm{mg}$ per os & $80 \mathrm{mg}$ nei giorni 2 e 3 per os \\
\hline
\end{tabular}


Per tale motivo sono state studiate possibili misure di profilassi ${ }^{34}$ da adottare nei pazienti a maggior rischio, mentre in quelli a basso rischio non è necessaria alcuna profilassi, tranne se predisposti da particolari condizioni (per es., una ipertensione endocranica).

È stato formulato uno score ${ }^{34}$ per prevedere il rischio di nausea e vomito postoperatorio che individua quattro fattori di rischio maggiore (sesso femminile, precedente storia di disturbi della motilità e PONV, non fumatori, uso di oppiacei nel postoperatorio), con una probabilità che sale dal $10 \mathrm{al} 21,39$ e $78 \%$ con 0 , $1,2,3$ e 4 fattori di rischio rispettivamente. ${ }^{34}$

Tra i fattori di rischio anestesiologici sono da considerare anche l'uso di anestetici volatili entro due ore, l'uso di NO, di oppiacei intra e postoperatori o di alte dosi di neostigmina. A livello chirurgico, poi, espone a maggiore rischio un intervento di lunga durata (con un incremento ogni 30 minuti del $60 \%$ del rischio). Nel perioperatorio si può ridurre il rischio con l'uso di una anestesia locale, quando possibile; preferendo l'uso del propofol nella fase di induzione in caso di anestesia generale, ${ }^{35}$ i FANS agli oppiacei; somministrando supplementi di ossigeno nel perioperatorio e fluidi per evitare l'ipossia gastrointestinale e il rilascio di serotonina secondario all'ipoperfusione intestinale legata all'uso di alcuni farmaci per l'induzione.

La profilassi anti PONV si è dimostrata economicamente più conveniente dei costi aggiuntivi legati al trattamento dell'emesi nei pazienti ad alto-moderato rischio anche per il prolungamento della degenza nei controlli in placebo. ${ }^{35}$

Poiché il PONV è un fenomeno mediato da diversi meccanismi, nessun singolo farmaco è sufficiente nella profilassi per cui le linee guida propongono combinazioni di anti 5-HT3 con droperidolo o desametasone (Tabella 13).

La Figura 7 è un algoritmo di profilassi e trattamento del PONV in base al rischio preoperatorio. ${ }^{28}$

\section{La gestione del paziente con nausea e vomito: metodologia}

Al fine di fornire raccomandazioni EvidenceBased per la gestione del paziente con nausea e vomito, abbiamo innanzitutto verificato l'esistenza di LG, conducendo una ricerca attraverso i seguenti database (DB) di LG:

- Scottish Intercollegiate Guidelines Network (SIGN)

- Institute for Clinical Systematic Improvement (ICSI)

- National Institute for Health and Clinical Excellence (NICE) (NHS evidence)

- National Guideline Cleringhouse (NGC)

- Agency for Healthcare Research and Quality (AHRQ)

- Canadian Medical Association, CMA infobase

- New Zeland Guidelines Group

- Sistema Nazionale Linee Guida (SNLG)

- Clinical Practice Guidelines Portal

- eGuidelines

La ricerca è stata eseguita da tutto il gruppo costituito da quattro medici, in maniera indipendente, utilizzando come key words il termine vomiting and/or nausea, quando il sito prevedeva la funzione di ricerca; negli altri casi abbiamo scorso manualmente la lista delle LG archiviate nel database o fatto riferimento alla sezione gastroenterologia.

I risultati ottenuti separatamente sono poi stati confrontati e discussi insieme.

Le LG così ottenute sono state valutate utilizzando lo strumento AGREE II $^{36-39}$ da 3 autori indipendentemente, al fine di identificare la/e LG qualitativamente migliori.

L'AGREE II, sviluppato per gestire adeguatamente la variabile qualità delle LG, valuta il rigore metodo-

Tabella 13. Dosaggio degli antimetici per la profilassi di nausea e vomito post-operatori.

\begin{tabular}{|c|c|c|}
\hline Farmaco & Dose & Evidenza \\
\hline Ondansetron & $4-8 \mathrm{mg} \mathrm{ev}$ & IA \\
\hline Dolasetron & $12,5 \mathrm{mg} \mathrm{ev}$ & IA \\
\hline Granisetron & $0,35-1 \mathrm{mg} \mathrm{ev}$ & IA \\
\hline Tropisetron & $5 \mathrm{mg} \mathrm{ev}$ & IA \\
\hline Desametasone & $5-10 \mathrm{mg} \mathrm{ev}$ & IIA \\
\hline Droperidolo & $0,625-1,25 \mathrm{mg} \mathrm{ev}$ & IA \\
\hline Dimenidrinato & $1-2 \mathrm{mg} / \mathrm{kg} \mathrm{ev}$ & IIA \\
\hline Efedrina & $0,5 \mathrm{mg} / \mathrm{kg} \mathrm{im}$ & IIIB \\
\hline Proclorperazina & $5-10 \mathrm{mg} \mathrm{ev}$ & IIIA \\
\hline Prometazina & $12,5-25 \mathrm{mg} \mathrm{ev}$ & IIIB \\
\hline Scopolamina & Cerotto transdermico & IIB \\
\hline
\end{tabular}


logico e la trasparenza con cui sono state sviluppate. È costituito da 23 item raggruppati in 6 domini. ${ }^{37}$

I sei differenti domini esplorano gli obiettivi e gli ambiti di applicazione (l'obiettivo generale della LG, i quesiti clinico-assistenziali a cui risponde la LG e la popolazione target - item 1-3), il coinvolgimento dei soggetti portatori di interesse (l'entità del coinvolgimento di tutti gli stakeholders, oltre che il punto di vista dei potenziali utenti della LG - item 4-6), il rigore metodologico (metodi e strumenti utilizzati per la ricerca bibliografica, la valutazione critica e la selezione delle evidenze scientifiche,la formulazione e l'aggiornamento delle LG - item 7-14), la chiarezza espositiva (il linguaggio, la struttura ed il formato delle LG - item 15-17), l'applicabilità delle stesse (le possibili barriere e i fattori facilitanti l'implementazione delle LG, le possibili strategie per favorirne l'adozione, l'implicazione sulle risorse economiche conseguenti alla loro applicazione - item 18-21); infine l'indipendenza editoriale per escludere eventuali conflitti di interesse (item 22-23).

Sono poi presenti due items di valutazione complessiva che permettono di assegnare un punteggio alla qualità delle LG e di raccomandarne o meno l'utilizzo.

Ciascun autore ha valutato il rispetto dei singoli requisiti con un punteggio da 1 (disaccordo completo) a 7 (accordo completo). I punteggi assegnati da ciascun autore sono stati sommati all'interno dei singoli domini e rapportati con il massimo e il minimo punteggio ottenibile in base al numero di requisiti inclusi e al numero dei valutatori.

Per ottenere un elaborato aggiornato, inoltre, un quarto autore ha condotto una ricerca post-hoc delle evidenze disponibili in letteratura sul principale DB online (Medline) a partire dal 31 dicembre 2011 fino al 31 gennaio 2013 .

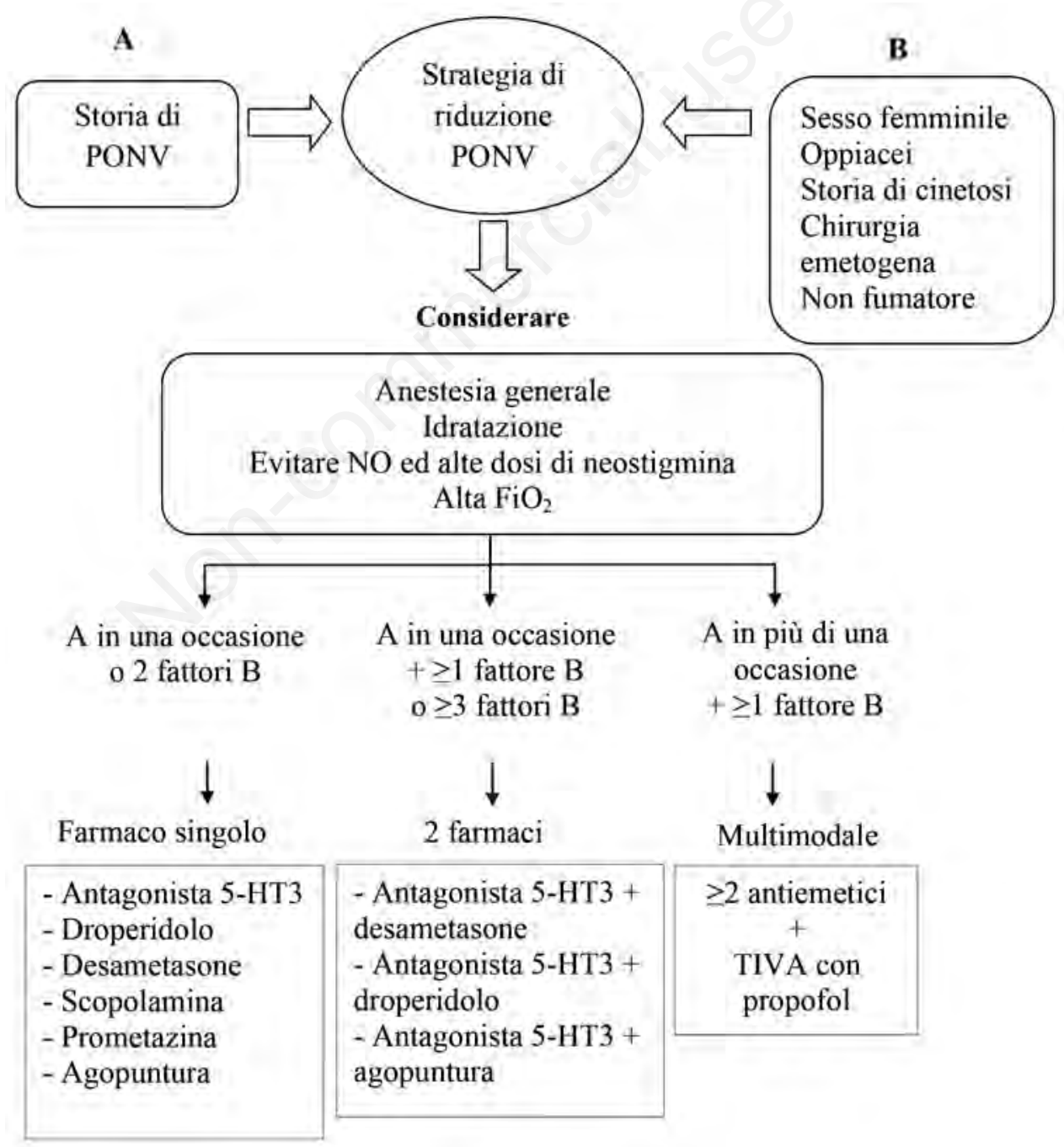

Figura 7. Algoritmo di profilassi e trattamento di nausea e vomito post-operatori (PONV). Adattata da McCracken et al., $2008 .^{28}$ 


\section{La gestione del paziente con nausea e vomito: risultati}

Attraverso i DB sopraelencati abbiamo identificato 7 LG: tre di carattere generale quale la Position Statement dell'AGA, ${ }^{10}$ la VIHA EOL Symptom Guidelines nausea and vomiting $2008^{11} \mathrm{e}$ la Nausea and Vomiting in people with cancer and other chronic diseases; ${ }^{22}$ due specialistiche in ambito oncologico come le $L G$ dell'ASCO ${ }^{20}$ e quelle della Clinical Journal of Oncology Nursing: ${ }^{21}$ altre per il PONV, quali quelle della $S O G C^{28}$ e il Consensus Guidelines for Managing Postoperative Nausea and Vomiting. ${ }^{34}$

La successiva valutazione dei tre autori secondo AGREE II (Tabella 14) ha evidenziato: i) la LG che ha ottenuto il maggiore punteggio è stata quella prodotta in ambito anestesiologico ${ }^{34}$ con un punteggio di 390. Ha raggiunto un buon equilibrio tra i domini ed ha conseguito quasi il $100 \%$ (98\%) nel primo domino (obiettivo e motivazione) e il massimo punteggio rispetto alle altre LG per ciò che riguarda l'applicabilità (69\%); ii) poco dopo con un punteggio di 386 si è classificata la LG dell'ASCO ${ }^{20}$ anch'essa con un buon equilibrio tra i domini, tranne che per il domino 5 il cui basso punteggio esprime la scarsa applicabilità della LG; ha riportato di contro il più alto punteggio rispetto alle altre LG per il rigore nell'elaborazione; iii) tutte le LG valutate hanno ottenuto un alto punteggio per ciò che riguarda la chiarezza espositiva (domino 4) con un punteggio minimo di 47 del VIHA ${ }^{11} \mathrm{e}$ massimo di 61 su 63 della LG prodotta in ambito anestesiologico sul PONV; ${ }^{34}$ iv) più difettoso invece il do- mino 5 riguardante l'applicabilità con un punteggio minimo di $12^{22}$ e massimo di 63 su $84 .{ }^{34}$

Alla luce di questa valutazione, per quanto riguarda la gestione della nausea e vomito nei pazienti oncologici si sono scelte le LG dell' $A S C O,{ }^{20}$ anche se spunti pratici possono essere raccolti dal documento della Clinical Journal of Oncology Nursing. ${ }^{21}$

Nell'ambito del vomito postoperatorio, le LG di riferimento sono state quelle pubblicate su Anesth Analg ${ }^{34}$ anche se anche quelle della $S O G C^{28}$ sono caratterizzate da alta chiarezza espositiva e da una buona definizione di obiettivi e motivazione.

In ambito internistico, interessanti sono le LG del VIHA, ${ }^{11}$ che pur gravate da una bassa applicabilità, hanno ottenuto un buon punteggio per ciò che concerne la chiarezza espositiva e la definizione dell'obiettivo e della motivazione.

Le LG della Clinical Evidence ${ }^{22}$ sono state caratterizzate da alta chiarezza espositiva, ma bassa applicabilità.

\section{Valutazione post hoc}

La ricerca è stata ristretta ad articoli scritti in lingua inglese, applicando come filtro l'argomento nausea and/or vomiting e il tipo di studio (studi clinici randomizzati controllati e metanalisi). Sono stati esclusi case reports e case series e studi riguardanti popolazioni particolari, come la popolazione pediatrica e le donne gravide.

Nell'ambito di evidenze sull'uso di farmaci per il PONV, è stato selezionato uno studio su 120 pazienti

Tabella 14. Risultati di valutazione delle linee guida mediante AGREE II.

\begin{tabular}{|c|c|c|c|c|c|c|}
\hline Linee guida & $\begin{array}{l}\text { Dominio } 1 \\
\text { Obiettivo e } \\
\text { motivazione }\end{array}$ & $\begin{array}{c}\text { Dominio } 2 \\
\text { Coinvolgimento } \\
\text { delle parti } \\
\text { interessate }\end{array}$ & $\begin{array}{c}\text { Dominio } 3 \\
\text { Rigore nella } \\
\text { elaborazione }\end{array}$ & $\begin{array}{c}\text { Dominio } 4 \\
\text { Chiarezza } \\
\text { nell'esposizione }\end{array}$ & $\begin{array}{l}\text { Dominio } 5 \\
\text { Applicabilità } \\
\text { editoriale }\end{array}$ & $\begin{array}{c}\text { Dominio } 6 \\
\text { Indipendenza }\end{array}$ \\
\hline$A G A$ Medical $^{10}$ & $\begin{array}{c}55 \% \\
39 / 63\end{array}$ & $\begin{array}{l}12 \% \\
9 / 63\end{array}$ & $\begin{array}{c}16 \% \\
48 / 168\end{array}$ & $\begin{array}{c}73 \% \\
49 / 63\end{array}$ & $\begin{array}{c}28 \% \\
33 / 84\end{array}$ & $\begin{array}{c}50 \% \\
24 / 42\end{array}$ \\
\hline $\begin{array}{l}\text { Nausea and Vomiting in people with } \\
\text { cancer and other chronic diseases }{ }^{22}\end{array}$ & $\begin{array}{c}91 \% \\
57 / 63\end{array}$ & $\begin{array}{c}16 \% \\
18 / 63\end{array}$ & $\begin{array}{c}58 \% \\
108 / 168\end{array}$ & $\begin{array}{c}75 \% \\
50 / 63\end{array}$ & $\begin{array}{c}19 \% \\
12 / 84\end{array}$ & $\begin{array}{c}50 \% \\
24 / 42\end{array}$ \\
\hline $\begin{array}{l}\text { American Society of Clinical } \\
\text { Oncology Guideline for Antiemetics } \\
\text { in Oncology: Update } 2006^{20}\end{array}$ & $\begin{array}{c}83 \% \\
53 / 63\end{array}$ & $\begin{array}{c}89 \% \\
57 / 63\end{array}$ & $\begin{array}{c}80 \% \\
139 / 168\end{array}$ & $\begin{array}{c}87 \% \\
56 / 63\end{array}$ & $\begin{array}{c}46 \% \\
39 / 84\end{array}$ & $\begin{array}{l}100 \% \\
42 / 42\end{array}$ \\
\hline $\begin{array}{l}\text { VIHA EOL Symptom Guidelines } \\
\text { nausea and vomiting }{ }^{11}\end{array}$ & $\begin{array}{c}72 \% \\
48 / 63\end{array}$ & $\begin{array}{c}47 \% \\
33 / 63\end{array}$ & $\begin{array}{c}40 \% \\
82 / 168\end{array}$ & $\begin{array}{c}70 \% \\
47 / 63\end{array}$ & $\begin{array}{c}12 \% \\
21 / 84\end{array}$ & $\begin{array}{c}50 \% \\
24 / 42\end{array}$ \\
\hline $\begin{array}{l}\text { Guideline for the management } \\
\text { of postoperative nausea and vomiting } 28\end{array}$ & $\begin{array}{c}75 \% \\
28 \quad 50 / 63\end{array}$ & $\begin{array}{c}51 \% \\
37 / 63\end{array}$ & $\begin{array}{c}64 \% \\
117 / 168\end{array}$ & $\begin{array}{c}85 \% \\
55 / 63\end{array}$ & $\begin{array}{c}57 \% \\
53 / 84\end{array}$ & $\begin{array}{c}50 \% \\
24 / 42\end{array}$ \\
\hline Putting evidence into practice ${ }^{21}$ & $\begin{array}{c}81 \% \\
53 / 63\end{array}$ & $\begin{array}{c}87 \% \\
46 / 63\end{array}$ & $\begin{array}{c}75 \% \\
131 / 168\end{array}$ & $\begin{array}{c}75 \% \\
50 / 63\end{array}$ & $\begin{array}{c}47 \% \\
46 / 84\end{array}$ & $\begin{array}{c}67 \% \\
30 / 42\end{array}$ \\
\hline $\begin{array}{l}\text { Consensus Guidelines for Managing } \\
\text { Postoperative Nausea and Vomiting - } \\
\text { Anesth Analg }\end{array}$ & $\begin{array}{l}98 \% \\
60 / 63\end{array}$ & $\begin{array}{c}80 \% \\
41 / 63\end{array}$ & $\begin{array}{c}73 \% \\
123 / 168\end{array}$ & $\begin{array}{l}99 \% \\
61 / 63\end{array}$ & $\begin{array}{l}69 \% \\
63 / 84\end{array}$ & $\begin{array}{l}100 \% \\
42 / 42\end{array}$ \\
\hline
\end{tabular}


sottoposti a procedure chirurgiche con alto rischio di sviluppare PONV in cui è stato testato l'utilizzo di aprepitant da solo o in associazione con scopolamina per via transdermica e non è stata evidenziata alcuna differenza statistica tra la monoterapia e la terapia in associazione. ${ }^{39}$

L'aprepitant è stato anche valutato in associazione all'ondansetron in 150 pazienti ambulatoriali sottoposti a interventi di chirurgia plastica e si è dimostrato che l'associazione è in grado di ridurre l'insorgenza di vomito e la gravità della nausea per le prime 48 ore dopo l'intervento chirurgico. ${ }^{40}$

In un altro studio sono stati arruolati 150 pazienti e la terapia di associazione con $5 \mathrm{mg}$ di tropisetron e $8 \mathrm{mg}$ di desametasone, somministrati prima di un intervento di tiroidectomia,si è dimostrata essere più efficace della monoterapia nel prevenire il PONV, soprattutto dopo le prime 6 ore. ${ }^{41}$

Anche il gabapentin ha dimostrato in 140 pazienti sottoposte ad isterectomia di prevenire il PONV e la necessità di farmaci antiemetici. ${ }^{42}$

Tra i metodi non farmacologici nel ridurre l'insorgenza di PONV, la stimolazione elettrica transcutanea, associata alla terapia antiemetica standard, si è dimostrata utile in caso di craniotomia o di laparoscopia massiva. ${ }^{43,44}$

Per quanto riguarda il vomito postchemioterapia, in uno studio in pazienti affetti da carcinoma del colon, il casopitant endovena (non disponibile in Italia), in associazione con ondasetron per os e desametasone ev, non ha ridotto l'insorgenza di vomito secondario alla terapia con oxaliplatino. ${ }^{45}$

In un altro studio in più di 300 pazienti è stato dimostrato che $1 \mathrm{mg}$ di ganisetron non è inferiore ai $3 \mathrm{mg}$ nel prevenire l'insorgenza di vomito da chemioterapia. ${ }^{46}$

Ithimakin e colleghi hanno dimostrato che l'aggiunta della metoclopramide all'ondasetron e al desametasone riduce il rischio di sviluppare vomito dopo chemioterapia con alte dosi di cisplatino. ${ }^{47}$

Il ruolo del ginger è stato studiato in 100 donne affette da carcinoma mammario invasivo sottoposte a chemioterapia con docetaxel, epirubicina, e ciclofosfamide: l'aggiunta di ginger alla terapia antiemetica standard ha ridotta l'insorgenza di nausea, ma non ha avuto effetti sull'incidenza e sulla gravità del vomito. ${ }^{48}$

\section{Bibliografia}

1. Rhodes VA, McDaniel R, Nausea, vomiting, and retching: complex problems in palliative care. Can Cancer J Clin 2001;51:232-48.

2. Nuti R, Caniggia A. Metodologia clinica. 8th ed. Torino: Minerva Medica; 2002.

3. Sandler RS, Everhart JE, Donowitz M, et al. The burden of selected digestive diseases in the United States. Gastroenterology 2002;122:1500-11.
4. Shaheen NJ, Hansen RA, Morgan DR, et al. The burden of gastrointestinal and liver diseases. Am J Gastroenterol 2006;101:2128-38.

5. Scorza K, Williams A, Philipps JD, et al. Army community hospital family medicine residency, Fort Belvoir, Virginia. Evaluation of nausea and vomiting. Am Fam Physician 2007;76:76-84.

6. Dix M, Hallpike C. The pathology, symptomatology, and diagnosis of certain common disorders of the vestibular system. Ann Otol Rhinol Laryngol 1952;61:987-1017.

7. Coates A. Vestibular neuronitis. Trans Am Acad Ophthalmol Otolaryngol 1969;73:395-408.

8. Harrison M. Vestibular neuronitis. Acta Otolaryngol (Stockh) 1969;67:379-88.

9. Morgenstein K, Seung H. Vestibular neuronitis. Laryngoscope 1971;81:131-9.

10. American Gastroenterology Association. Technical review on nausea and vomiting. Gastroenterology 2001; 120:263-70.

11. Vancouver Island Health Authority (VIHA) - End of Life (EOL) Program. Symptom guidelines: nausea and vomiting. Victoria: VIHA Quality Council; 2008.

12. New Mexico Medical Review Association. Nausea and vomiting treatment. Algorihtm for the elderly. Health Insight New Mexico; 2000. Available from: www.nmra.org

13. Hasler WL. Nausea, vomito e indigestione. In: Kaspers DL, ed. Harrison's principles of internal medicine, 16 ed. Milano: McGraw Hill, 2005. pp 256-9.

14. Currow DC, Coughlan M, Fardell B, Cooney NJ. Use of ondansetron in palliative medicine. J Pain Symptom Manage 1997;13:302-7.

15. Doris B. Nausea and vomiting. In: Vancouver Island Health Authority (VIHA) - End of Life (EOL) Program. Symptom guidelines: nausea and vomiting. Victoria: VIHA Quality Council; 2008. pp 103-111.

16. Longstreth GF, Hesketh PJ. Characteristics of antiemetic drugs; 2015. Available from: http://www.uptodate.com/ contents/characteristics-of-antiemetic-drugs

17. Devine EC, Westlake SK. The effects of psychoeducational care provided to adults with cancer: meta-analysis of 116 studies. Oncol Nurs Forum 1995;22:1369-81.

18. Ezzone S, Baker C, Rosselet R, Terepka E. Music as an adjunct to antiemetic therapy. Oncol Nurs Forum 1998;25:1551-6.

19. Collins KB, Thomas DJ. Acupuncture and acupressure for the management of chemotherapy-induced nausea and vomiting. J Am Acad Nurse Pract 2004; 16:76-80.

20. Kris GM, Hesketh PJ, Somerfield MR, et al. American society of clinical oncology guideline for antiemetics in oncology. J Clin Oncol 2006;24:2932-47.

21. Tipton JM, McDaniel RW, Barbour L, et al. Putting evidence into practice: evidence-based interventions to prevent, manage, and treat chemotherapy-induced nausea and vomiting. Clin J Oncol Nurs 2007;11:69-78.

22. Keeley PW. Nausea and vomiting in people with cancer and other chronic diseases. BMJ Clin Evid 2009;2009. pii:2406.

23. Bender CM, McDaniel RW, Murphy-Ende K, et al. Chemotherapy-induced nausea and vomiting. Clin J Oncol Nurs 2002;6:94-102.

24. Pan CX, Morrison SR, Ness J, et al. Complementary and alternative medicine in the management of pain, dyspnea, 
and nausea and vomiting near the end of life: a systematic review. J Pain Symptom Manage 1999;20:374-87.

25. Yates R, Lyons M, Horstman A. Symptom control in advanced cancer. JAAPA 2003;16:40-52.

26. Neymark N, Crott R. Impact of emesis on clinical and economic outcomes of cancer therapy with highly emetogenic chemotherapy regimens: a retrospective analysis of three clinical trials. Support Care Cancer 2005;13:812-8.

27. Thompson I. The management of nausea and vomiting in palliative care. Nurs Standard 2004;19:46-53.

28. McCracken G, Houston P, Lefebvre G. Guideline for the management of postoperative nausea and vomiting. J Obstet Gynaecol Can 2008;30:600-7.

29. Kovac AL. Prevention and treatment of postoperative nausea and vomiting. Drugs 2000;59:213-43.

30. Watcha MF, White PF. Postoperative nausea and vomiting: its aetiology, treatment and prevention. Anesthesiology 1992;77:162-84.

31. Leman J. Surgical and patient factors involved in postoperative nausea and vomiting. $\mathrm{Br} \mathrm{J}$ Anaesth 1992;69:24-32.

32. Camu F, Lauwers MH, Verbessem D. Incidence and aetiology of postoperative nausea and vomiting. Eur J Anaesthesiol 1992;9:25-31.

33. Tramèr MR. A rational approach to the control of postoperative nausea and vomiting: evidence from systematic reviews. Part II. Recommendations for prevention and treatment, and research agenda. Acta Anaesthesiol Scand 2001;45:14-9.

34. Gan TJ, Meyer T, Apfel CC, et al. Consensus guidelines for managing postoperative nausea and vomiting. Anesth Analg 2003;97:62-71.

35. Sukhani R, Vazquez J, Pappas AL, et al. Recovery after propofol with and without intraoperative fentanyl in patients undergoing ambulatory gynecologic laparoscopy. Anesth Analg 1996;83:975-81.

36. Brouwers M, Kho ME, Browman GP, et al. AGREE II: advancing guideline development, reporting and evaluation in health care. CMAJ 2010;182:E839-42.

37. Appraisal of Guidelines for Research and Evaluation II. AGREE II. 2009 Versione Italiana della Fondazione GIMBE. Available from: http://www.gimbe.org/pagine/ 569/it/agree-ii

38. Cartabellotta A. AGREE II: come valutare la qualità delle linee guida recenti. Prog Med 2011;102:217-9.

39. Green MS, Green P, Malayaman SN, et al. Randomized, double-blind comparison of oral aprepitant alone compared with aprepitant and transdermal scopolamine for prevention of postoperative nausea and vomiting. $\mathrm{Br} \mathrm{J}$ Anaesth 2012;109:716-22.

40. Vallejo MC, Phelps AL, Ibinson JW, et al. Aprepitant plus ondansetron compared with ondansetron alone in reducing postoperative nausea and vomiting in ambulatory patients undergoing plastic surgery. Plast Reconstr Surg 2012;129:519-26.

41. Zhou H, Xu H, Zhang J, et al. Combination of dexamethasone and tropisetron before thyroidectomy to alleviate postoperative nausea, vomiting, and pain: randomized controlled trial. World J Surg 2012;36:1217-24.

42. Ajori L, Nazari L, Mazloomfard MM, Amiri Z. Effects of gabapentin on postoperative pain, nausea and vomiting after abdominal hysterectomy: a double blind randomized clinical trial. Arch Gynecol Obstet 2012;285: 677-82.

43. Xu M, Zhou SJ, Jiang CC, et al. The effects of P6 electrical acustimulation on postoperative nausea and vomiting in patients after infratentorial craniotomy. J Neurosurg Anesthesiol 2012;24:312-6.

44. White PF, Zhao M, Tang J, et al. Use of a disposable acupressure device as part of a multimodal antiemetic strategy for reducing postoperative nausea and vomiting. Anesth Analg 2012;115:31-7.

45. Hesketh PJ, Wright O, Rosati G, et al. Single-dose intravenous casopitant in combination with ondansetron and dexamethasone for the prevention of oxaliplatin-induced nausea and vomiting: a multicenter, randomized, double-blind, active-controlled, two arm, parallel group study. Support Care Cancer 2012;20:1471-8.

46. Tsuji D, Kim YI, Taku K, et al. Comparative trial of two intravenous doses of granisetron (1 versus $3 \mathrm{mg}$ ) in the prevention of chemotherapy-induced acute emesis: a double-blind, randomized, non-inferiority trial. Support Care Cancer 2012;20:1057-64.

47. Ithimakin S, Runglodvatana K, Nimmannit A, et al. Randomized, double-blinded, placebo-controlled trial of ondansetron plus dexamethasone with or without metoclopramide as antiemetic prophylaxis in patients receiving high-dose cisplatin in medical practice. Support Care Cancer 2012;20:849-55.

48. Panahi Y, Saadat A, Sahebkar A, et al. Effect of ginger on acute and delayed chemotherapy-induced nausea and vomiting: a pilot, randomized, open-label clinical trial. Integr Cancer Ther 2012;11:204-11. 


\title{
La gestione del paziente con malnutrizione: dalle evidenze alla pratica clinica
}

\author{
Maria Rita Poggiano, ${ }^{1}$ Sara Ciarla, ${ }^{2}$ Paola Gnerre, ${ }^{3}$ Anna Roberts, ${ }^{4}$ Laura Magni, ${ }^{5}$ Laura Morbidoni, ${ }^{6}$ Ada Maffettone, ${ }^{7}$ \\ Antonella Paradiso, ${ }^{8}$ Massimo Rondana, ${ }^{9}$ Anna Maria Schimizzi, ${ }^{10}$ Roberto Risicato ${ }^{11}$ \\ ${ }^{1}$ Dipartimento di Medicina Interna, Ospedale Buonconsiglio Fatebenefratelli, Napoli; ${ }^{2}$ Dipartimento di Medicina Interna, \\ Ospedale Giuseppe Mazzini, Teramo; ${ }^{3}$ Dipartimento di Medicina Interna, Ospedale San Paolo, Savona; ${ }^{4}$ Dipartimento di Geriatria, \\ AUSL 4, Prato; ${ }^{5}$ Dipartimento di Medicina Interna, Ospedale Sacra Famiglia - Fatebenefratelli, Erba (CO); ${ }^{6}$ Dipartimento di \\ Medicina Interna, Ospedale Principe di Piemonte, Senigallia (AN); ${ }^{7}$ Dipartimento di Medicina Interna, AORN A.O. Colli, Ospedale \\ Monaldi, Napoli; ${ }^{8}$ Dipartimento di Medicina Interna, Ospedale Sant'Eugenio, Roma; ${ }^{9}$ Dipartimento di Medicina Interna e \\ Direzione Sanitaria, AAS 5 Friuli Occidentale, Ospedale Santa Maria degli Angeli, Pordenone; ${ }^{10}$ Dipartimento di Medicina \\ Interna, Ospedale Carlo Urbani, Jesi (AN); ${ }^{11}$ Dipartimento di Medicina Interna, Ospedale Augusta, ASP Siracusa, Italia
}

\section{RIASSUNTO}

La malnutrizione può essere definita come uno stato nutrizionale in cui la carenza o l'eccesso (o lo squilibrio) di energia, proteine ed altri nutrienti provoca effetti negativi sull'organismo (forma corporea, dimensione, composizione), sulla funzionalità di organi ed apparati e sull'outcome clinico. La malnutrizione rappresenta un problema di comune riscontro nei soggetti ospedalizzati, con una prevalenza di circa il $40 \%$ riportata in alcuni studi. La malnutrizione si associa a diversi outcome negativi tra cui la depressione del sistema immunitario, la difficoltà nella guarigione, l'atrofia muscolare, il prolungamento della degenza in ospedale e l'aumento della mortalità. Il mancato riconoscimento della condizione di malnutrizione comporta non solo un aumentato rischio di complicanze, ma anche un incremento dei costi sanitari. Questo può essere evitato ponendo una particolare attenzione all'assistenza nutrizionale. Per questo motivo, le organizzazioni ospedaliere e sanitarie dovrebbero seguire delle strategie e dei protocolli specifici per identificare i pazienti a rischio nutrizionale ed intraprendere adeguati piani di cura. L'obiettivo di questa monografia è quello di fornire raccomandazioni, basate sulle evidenze ed estrapolate da un'analisi multiparametrica delle linee guida ad oggi disponibili, per la corretta gestione della malnutrizione e di illustrare un progetto di applicazione dei sopracitati strumenti di clinical governance ad un problema clinico così rilevante quale la gestione della malnutrizione nel paziente ricoverato nelle nostre Unità Operative di Medicina Interna.

\section{Introduzione}

Gli esperti definiscono la malnutrizione come uno stato nutrizionale acuto, subacuto e cronico, nel quale vari gradi di carente o eccessiva nutrizione, con o senza stato infiammatorio sottostante, determinano un cambiamento nella composizione corporea ed una compromissione funzionale. ${ }^{1}$ La malnutrizione nell'adulto si verifica in genere attraverso un continuum di apporto inadeguato di nutrienti e/o aumentato fabbisogno, ridotto assorbimento, alterato trasporto e utilizzo dei nutrienti. Inoltre, esiste una relazione indissolubile tra stato nutri-

Corrispondente: Maria Rita Poggiano, Dipartimento di Medicina Interna, Ospedale Buonconsiglio Fatebenefratelli, via Manzoni 220, 80100 Napoli, Italia.

Tel.: +39.081.5981426 - Fax: +39.081.5981157.

E-mail: marypoggiano@gmail.com

Articolo pubblicato secondo la Creative Commons Attribution NonCommercial 4.0 License (CC BY-NC 4.0).

(C) Copyright S. Ciarla et al., 2016

Licensee PAGEPress, Italy

QUADERNI - Italian Journal of Medicine 2016; 4(3):53-70 zionale e gravità di malattia. Gli individui possono presentare condizioni infiammatorie, ipermetaboliche e/o ipercataboliche. L'infiammazione è sempre più identificata come un fattore sottostante fondamentale in grado di aumentare il rischio di malnutrizione, contribuire alla risposta non ottimale all'intervento nutrizionale ed incrementare il rischio di mortalità.

La malnutrizione rappresenta un problema di comune riscontro nei soggetti ospedalizzati, con una prevalenza del $40 \%$ circa secondo quanto riportato in alcuni studi. ${ }^{2}$ La malnutrizione si associa a diversi outcome negativi tra cui la depressione del sistema immunitario, la difficoltà nella guarigione, l'atrofia muscolare, il prolungamento della degenza in ospedale e l'aumento della mortalità. ${ }^{3}$ Per questo motivo, i parametri utilizzati per la diagnosi di malnutrizione nei processi di valutazione e di screening riflettono sia l'assunzione di nutrienti, sia la gravità e la durata della patologia di base. ${ }^{4}$ In conclusione, la malnutrizione si correla con outcome negativi, tra cui l'aumento della morbilità e della mortalità, la compromissione funzionale, il peggioramento della qualità della vita, il prolungamento della degenza ospedaliera, l'aumento delle riospedalizzazioni, l'incremento delle infezioni e delle complicanze. ${ }^{5}$ 


\section{Epidemiologia}

La malnutrizione è un riscontro comune nei pazienti ospedalizzati, con un'incidenza del $30-55 \%{ }^{6}{ }^{6}$ Molteplici studi condotti in diversi paesi confermano l'alta prevalenza della malnutrizione soprattutto nella popolazione geriatrica. La malnutrizione risulta essere più frequente nei pazienti anziani che vivono a casa, ma che hanno bisogno di assistenza domiciliare, suggerendo una probabile perdita di autonomia funzionale. I dati derivanti da studi condotti su circa 1300 pazienti anziani ospedalizzati hanno dimostrato che circa il $40-55 \%$ di essi era malnutrito o ad alto rischio di malnutrizione, mentre circa il $12 \%$ era affetto da un grado severo di malnutrizione proteico-calorica. Tra i giovani anziani fino ai 75 anni, la prevalenza della malnutrizione risultava inferiore $(<10 \%){ }^{7}$ Alcuni dati suggeriscono che i pazienti chirurgici con malnutrizione rispetto ai pazienti ben nutriti hanno un rischio di due o tre volte maggiore di incorrere in complicanze minori o maggiori, un'aumentata mortalità e un prolungamento della degenza in ospedale fino al $90 \%$ in più. Nell'Europa occidentale si stima che circa il 25$30 \%$ dei pazienti chirurgici sia esposto ad un aumentato rischio nutrizionale nel periodo preoperatorio. Una parte considerevole di questi pazienti è malnutrita al momento del ricovero in ospedale e nella maggior parte di questi la denutrizione peggiora ulteriormente durante l'ospedalizzazione. ${ }^{4}$ Questi dati giustificano l'impatto economico della malnutrizione nei soggetti ospedalizzati, con i costi che sono superiori del 35$75 \%$ nei pazienti malnutriti rispetto a quelli in buono stato nutrizionale. ${ }^{?}$

\section{Diagnosi}

Il processo di cura nutrizionale si articola in diversi step. Questi includono lo screening nutrizionale, la valutazione nutrizione, la formulazione di un piano di assistenza nutrizionale, l'attuazione del piano, il monitoraggio del paziente, la rivalutazione del piano di cura, la rivalutazione del setting di cura, infine l'eventuale riformulazione del piano di cura o l'interruzione del trattamento (Figura 1). ${ }^{6}$

\section{Screening nutrizionale}

Lo screening nutrizionale è il primo step nel processo di cura nutrizionale.

Lo screening nutrizionale è stato definito dall' American Society for Parenteral and Enteral Nutrition (ASPEN) come un processo per identificare gli individui malnutriti o che sono a rischio di malnutrizione per stabilire in quali soggetti è indicata una valutazione nutrizionale dettagliata. ${ }^{1}$ Lo screening nutrizionale è un processo dinamico finalizzato al riconoscimento dei cambiamenti nelle condizioni cliniche di un paziente che possono ripercuotersi sullo stato nutrizionale. ${ }^{6}$

Lo screening nutrizionale è un processo rapido e semplice condotto dal personale sanitario o dagli operatori dell'assistenza sanitaria di comunità. Tutti i pazienti dovrebbero essere sottoposti allo screening nutrizionale al momento del ricovero in ospedale o nelle altre istituzioni. Negli Stati Uniti, la Joint Commission raccomanda l'esecuzione dello screening nutrizionale entro 24 ore dal ricovero in un centro di terapia intensiva. ${ }^{1}$

Dati obiettivi come altezza, peso corporeo, variazioni del peso corporeo, diagnosi principale e presenza di comorbidità possono essere utilizzati nello screening nutrizionale per identificare la presenza di malnutrizione o il rischio di malnutrizione. Fattori suggestivi di malnutrizione includono: ${ }^{6}$ i) perdita involontaria o incremento negli ultimi 6 mesi $\geq 10 \%$ del peso corporeo abituale, $o \geq 5 \%$ in un mese; ii) peso corporeo inferiore o maggiore del $20 \%$ rispetto al peso corporeo ideale, soprattutto in presenza di malattie croniche o di maggior fabbisogno metabolico; iii) inadeguata assunzione di nutrienti compresa la ridotta capacità di assumere $\mathrm{o}$ di assorbire adeguatamente cibo.

Gli strumenti di screening nutrizionali per gli adulti sono stati testati per validità e riproducibilità e valutati per facilità d'uso, economicità, validità, affidabilità, sensibilità e specificità. ${ }^{6}$

Gli strumenti di screening soddisfano i seguenti quattro principi fondamentali: ${ }^{4}$ i) qual è la condizione attuale? Altezza e peso permettono di calcolare l'indice di massa corporea (body mass index, BMI). Il range di normalità è compreso tra $20-25$, valori $>30$ indicano obesità, valori tra 18,5-20 sono considerati borderline, mentre valori $<18,5$ sono indicativi di denutrizione. Nei casi in cui non è possibile misurare altezza e peso corporeo, un surrogato utile è rappresentato dalla circonferenza del braccio, misurata con un nastro metrico a livello del punto medio della lunghezza del braccio tra acromion e olecrano. Questo può essere correlato ai centili di tabelle elaborate per quella particolare popolazione, età e sesso; ii) La condizione è stabile? La recente perdita di peso corporeo è ricavata dalla storia del paziente, $\mathrm{o}$, più correttamente, dalle misurazioni registrate nelle cartelle cliniche precedenti. La perdita involontaria o l'aumento $\geq 10 \%$ rispetto al peso corporeo abituale negli ultimi 6 mesi, oppure $\geq 5 \%$ del peso corporeo abituale in 1 mese, oppure un peso corporeo inferiore o maggiore del $20 \%$ al peso corporeo ideale sono di solito considerati significativi; iii) La condizione peggiorerà? Dati obiettivi possono essere ricavati dalla quantificazione dell'introito di cibo del paziente in ospedale o dal diario alimentare; iv) La malattia potrà accelerare il deterioramento nutrizionale? Oltre a diminuire l'appetito, la patologia di base può aumentare il fabbisogno nutrizionale a causa dello stress me- 
tabolico associato a condizioni cliniche severe (interventi di chirurgia maggiore, sepsi, politrauma), che può conseguentemente indurre un rapido peggioramento dello stato nutrizionale o il rapido instaurarsi di una condizione di malnutrizione.

Strumenti fruibili per lo screening nutrizionale sono il malnutrition universal screening tool (MUST), il nutritional risk screening 2002 (NRS-2002) e il mini nutritional assessment (MNA). Il National Institute for Health and Care Excellence (NICE) raccomanda l'utilizzo del MUST, uno strumento di screening articolato in cinque step per identificare gli adulti malnutriti o a rischio di malnutrizione, oppure obesi: i) step 1: misurare altezza e peso per ottenere un punteggio di BMI (BMI $\geq 20=$ punteggio 0; BMI 18,5-20=punteggio 1 ; $\mathrm{BMI} \leq 18,5=$ punteggio 2 ); ii) step 2: considerare la perdita non volontaria di peso in percentuale negli ultimi 3-6 mesi $(\leq 5 \%=$ punteggio $0 ; 5-10 \%=$ punteggio $1 ; \geq 10 \%=$ punteggio 2); iii) step 3: stabilire l'effetto della patologia di base (se il paziente è in fase acuta di malattia e non si è verificato, o è probabile che non vi sarà, alcun apporto nutrizionale per più di 5 giorni=punteggio 2); iv) step 4: addizionare il punteggio degli step 1, 2 e 3 per ottenere il rischio complessivo di malnutrizione (rischio basso, medio o alto); v) step 5: utilizzare le linee guida e/o i protocolli locali per sviluppare un piano di cura nutrizionale. La European Society for Clinical Nutrition and Metabolism (ESPEN) raccomanda l'uso del NRS-2002 per identificare i pazienti a rischio nutrizionale tra quelli ospedalizzati (Figura 2). ${ }^{4}$ Lo score NRS-2002 è prevalentemente utilizzato per la popolazione ospedalizzata. Esso contiene i componenti del MUST e in aggiunta una classificazione di gravità della patologia di base che correla in maniera direttamente proporzionale con un maggior fabbisogno nutrizionale. Secondo questo strumento di screening nutrizionale, il paziente viene classificato come non a rischio, se il BMI è $\geq 20,5 \mathrm{~kg} / \mathrm{m}^{2}, 1$ 'assunzione di cibo è normale, il peso non è diminuito nel corso delle ultime settimane e la malattia attuale non è grave (nessun incremento dello stress metabolico). Se questi criteri non sono soddisfatti, la valutazione procede assegnando 0-3 punti in relazione al BMI, alla recente perdita di peso e all'assunzione di cibo durante le settimane precedenti, 0-3 punti in base alla gravità della malattia e allo stress metabolico, con un punto in più in caso di età $>70$ anni. I soggetti che ricevono $\geq 3$ punti sono identificati soggetti a rischio nutrizionale (Figura 2).

Lo score MNA identifica la malnutrizione tra i pazienti anziani. Esso considera anche gli aspetti fisici e mentali che frequentemente affliggono lo stato nutrizionale degli anziani, nonché un questionario dietetico.

\section{Valutazione nutrizionale}

La valutazione nutrizionale è stata definita dalla ASPEN come un approccio globale per la diagnosi dei problemi nutrizionali che si avvale della combinazione dei seguenti strumenti: ${ }^{1}$ i) l'anamnesi patologica, nutrizionale e farmacologica; ii) la valutazione fisica;iii) le misure antropometriche; iv) $i$ dati di laboratorio.

La valutazione nutrizionale è consigliata per tutti i pazienti che sono individuati a rischio nutrizionale dalla procedura di screening. La valutazione nutrizionale fornisce la base per un intervento nutrizionale. ${ }^{1}$

È un processo più articolato dello screening nutrizionale che conduce ad un piano di assistenza appropriata considerando le indicazioni, i possibili effetti collaterali e, in alcuni casi, le tecniche di alimentazione particolari. ${ }^{4}$ Gli obiettivi di una valutazione nutrizionale sono l'identificazione di pazienti malnutriti o che sono a rischio di malnutrizione, la raccolta delle informazioni necessarie per creare un piano di assi-

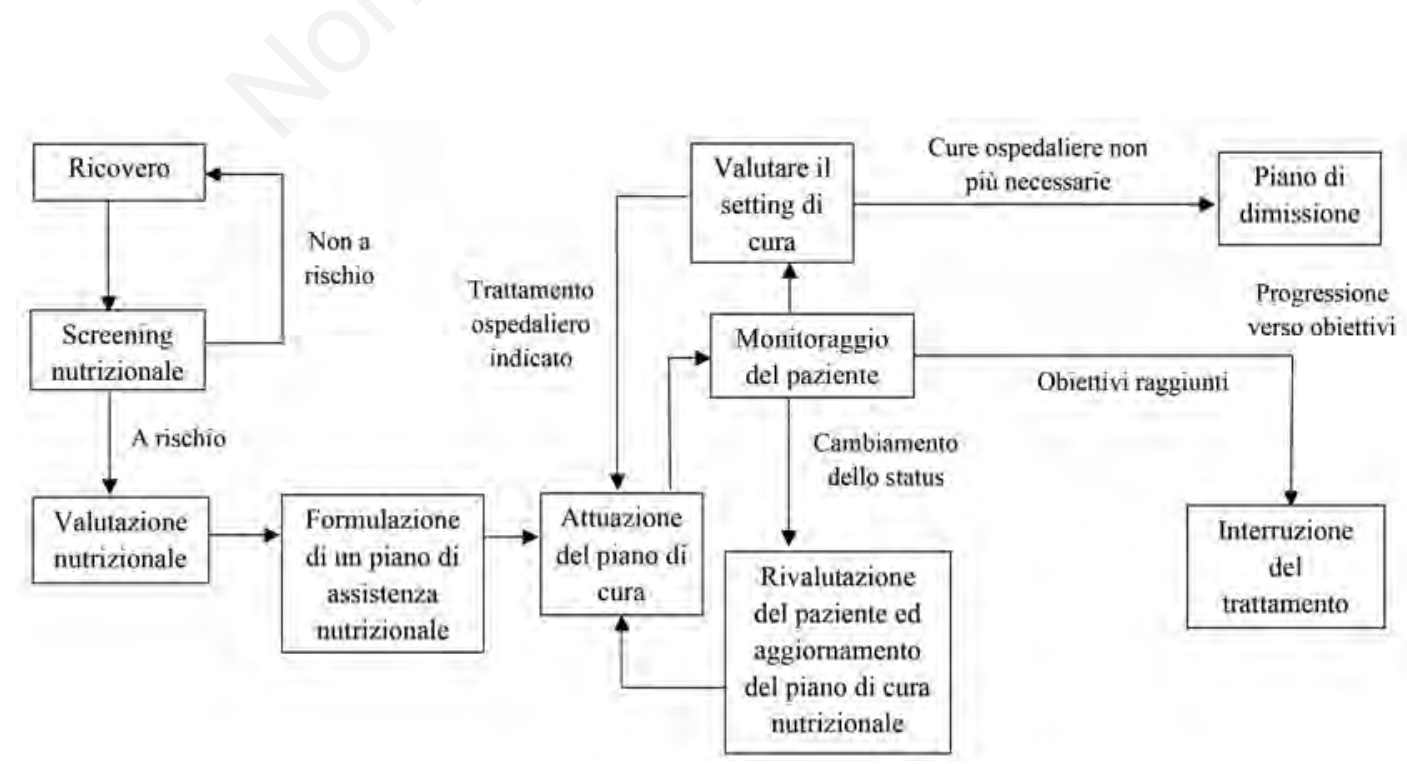

Figura 1. Il processo di cura nutrizionale. 
stenza nutrizionale e il monitoraggio dell'adeguatezza della terapia nutrizionale. ${ }^{6}$

La valutazione dello stato nutrizionale è articolata in due parti: la valutazione nutrizionale e la valutazione metabolica. La valutazione nutrizionale utilizza le misurazioni statiche di segmenti corporei ed esa- mina le alterazioni causate dalla denutrizione. La valutazione metabolica include un'indagine sul funzionamento di organi ed apparati e su alterazioni del metabolismo che possono influenzare la perdita di massa magra e la risposta metabolica al trattamento nutrizionale. Esiste infatti una relazione molto stretta

\begin{tabular}{|l|l|l|}
\hline Screening iniziale & si & no \\
\hline IMC $<20,5$ ? & & \\
\hline Il paziente ha perso peso negli ultimi 3 mesi ? & & \\
\hline Il paziente ha ridotto l'alimentazione nell'ultima settimana ? & & \\
\hline Il paziente è severamente ammalato ? & & \\
\hline
\end{tabular}

Se futte e 4 le domande hanno risposta NO il paziente non è a rischio e va rivalutato dopo 1 settimana Se anche solo una risposta è SI. si procede allo screening finale

\begin{tabular}{|c|c|c|c|c|c|}
\hline \multicolumn{6}{|c|}{ Screening finale } \\
\hline \multicolumn{3}{|r|}{ Malnutrizione } & \multicolumn{3}{|r|}{ Severità di malattia } \\
\hline Assente & 0 & Stato nutrizionale normale & Assente & 0 & Non patologie acute in atto \\
\hline Lieve & 1 & $\begin{array}{c}\text { "perdita di peso }<5 \% \text { in } 3 \text { mesi } \\
\text { oppure } \\
\text { punteggio ingesta } 11 / 15\end{array}$ & Lieve & 1 & $\begin{array}{c}\text { Frattura femore } \\
\begin{array}{c}\text { Malattie croniche con complicanze } \\
\text { (cirrosi, diabete, dialisi, BPCO) } \\
\text { Neoplasie }\end{array} \\
\end{array}$ \\
\hline Moderata & 2 & $\begin{array}{c}\text { "perdita di peso }>5 \% \text { in } 2 \text { mesi } \\
\text { oppure } \\
\text { IMC } 18,5 / 20,5 \\
\text { oppure } \\
\text { punteggio ingesta } 10 / 5\end{array}$ & Moderata & 2 & $\begin{array}{c}\text { Chirurgia maggiore } \\
\text { Stroke } \\
\text { Emoblastosi } \\
\text { Polmoniti gravi }\end{array}$ \\
\hline Grave & 3 & $\begin{array}{c}\text { "perdita di peso }>5 \% \text { in } 1 \text { mese } \\
>15 \% \text { in } 3 \text { mesi } \\
\text { oppure } \\
\text { IMC }<18,5 \\
\text { oppure } \\
\text { punteggio ingesta }<5\end{array}$ & Severa & 3 & $\begin{array}{c}\text { Trauma cranico } \\
\text { Trapianto midollo osseo } \\
\text { Terapia intensiva }\end{array}$ \\
\hline \multicolumn{3}{|c|}{ Punteggio malnutrizione: } & \multicolumn{3}{|c|}{ Punteggio severità di malattia: } \\
\hline
\end{tabular}

Se paziente $>70$ anni, aggiungere 1 al punteggio totale

\begin{tabular}{|l|l|}
\hline \multicolumn{2}{|c|}{ Valutazione rischio nutrizionale } \\
\hline Punteggio totale $<3$ & Rivalutazione dopo 1 settimana \\
\hline Punteggio totale $>3$ & Paziente a rischio che richiede piano nutrizionale \\
\hline
\end{tabular}

Figura 2. Nutritional risk screening 2002 (NRS-2002). IMC, indice di massa corporea; BPCO, broncopneumopatia cronica ostruttiva. 
tra stato nutrizionale e gravità della patologia di base: il supporto nutrizionale può migliorare l'efficacia della terapia specifica per la patologia di base, prevenire lo sviluppo della malnutrizione e favorire la guarigione.

La combinazione di parametri clinici e biochimici dovrebbe essere utilizzata per valutare la presenza di malnutrizione. L'anamnesi patologica remota può essere utile qualora si sospetti un aumentato rischio di malnutrizione e per indagare la presenza o l'assenza di stato infiammatorio sottostante. La storia del paziente dovrebbe essere incentrata sul peso corporeo (ideale, usuale, peso attuale e recente calo ponderale), sui cambiamenti delle abitudini alimentari, sulla funzionalità dell'apparato gastrointestinale, sulla natura e sulla gravità della patologia di base, sulle abitudini dietetiche personali inusuali o sulle restrizioni alimentari. ${ }^{5,6}$

L'esame obiettivo può rivelare la presenza di alcune delle caratteristiche patognomoniche della malnutrizione, come la perdita o l'incremento di peso corporeo, la ritenzione di liquidi, la perdita di massa muscolare o di adipe e altri segni specifici di carenza di macro e/o micronutrienti, quali ad esempio la perdita di capelli o le alterazioni della mucosa orale. ${ }^{5}$ Tuttavia, i segni e sintomi clinici della maggior parte delle carenze nutrizionali non si manifestano fin quando non si sviluppa un avanzato stato carenziale. Inoltre, se si riscontrano segni e sintomi indicativi di una carenza nutrizionale, questi devono essere correlati con le informazioni anamnestiche del paziente e i dati di laboratorio per poter diagnosticare il deficit nutrizionale. ${ }^{6}$

A proposito dei dati antropometrici, il principale parametro utilizzato per valutare l'entità della malnutrizione è la perdita di peso corporeo non intenzionale. Il peso corporeo dovrebbe essere registrato al momento del ricovero in qualsiasi setting di cura per poi essere monitorato frequentemente durante la degenza. Anche il BMI rientra tra gli indicatori di uno stato di malnutrizione. Valori di BMI inferiori a $18,5 \mathrm{~kg} / \mathrm{m}^{2}$ sono indicativi di malnutrizione, valori di BMI compresi tra 14 e $15 \mathrm{~kg} / \mathrm{m}^{2}$ sono associati ad aumentata mortalità, valori superiori a $25 \mathrm{~kg} / \mathrm{m}^{2}$ indicano sovrappeso, e quelli maggiore di $30 \mathrm{~kg} / \mathrm{m}^{2}$ obesità. ${ }^{6.8}$ Anche se la malnutrizione può verificarsi per qualsiasi valore di BMI, i soggetti che si collocano agli estremi della scala dei valori di BMI possono essere ad aumentato rischio di malnutrizione. ${ }^{5}$

Tradizionalmente, i livelli di alcune proteine sieriche correlano con lo stato nutrizionale e la gravità della patologia di base. Le proteine più frequentemente considerate nella valutazione nutrizionale sono la sieroalbumina, la transferrina e la prealbumina (Tabella 1). ${ }^{6}$ Tuttavia, occorre sottolineare che i parametri sierici non sono indici specifici dell'assetto nutrizionale, in quanto possono essere influenzati dalla patologia sottostante e non riflettere fedelmente le variazioni dello stato nutrizionale di un individuo. In particolare, in ambito intensivistico i tradizionali marcatori proteici possono rappresentare il riflesso della risposta della fase acuta (aumento della permeabilità vascolare ed incremento della sintesi proteica epatica) e non rappresentare pertanto lo stato nutrizionale in maniera accurata. ${ }^{9}$

Le informazioni riguardanti l'introito alimentare possono essere ottenute dal paziente e/o dal caregiver. Nella raccolta dei dati anamnestici di un paziente possono essere utilizzate come indicatori di inadeguato apporto nutrizionale la storia di cambiamento dietetico, la conta calorica inadeguata e/o la pregressa insufficiente assunzione di cibo. Anche lo stato funzionale dovrebbe essere indagato. ${ }^{5}$

La calorimetria indiretta e l'analisi della composizione corporea sono state suggerite per l'uso clinico per quantificare il fabbisogno energetico e valutare lo stato di nutrizione. Tuttavia, il loro uso routinario non può essere perseguito perché sono metodiche costose e tecnicamente complesse. Sono stati sviluppati altri indici multifattoriali, quelli prognostici, che utilizzano

Tabella 1. Parametri nutrizionali.

\begin{tabular}{lccc}
\hline \multirow{2}{*}{ Parametri } & \multicolumn{2}{c}{ Malnutrizione } & Severa \\
\cline { 2 - 4 } Antropometrici & Lieve & Moderata & $>20 \%$ \\
\hline Calo ponderale su peso abituale & $5-10 \%$ & $11-20 \%$ & $<16$ \\
\hline Indice di massa corporea $\left(\mathrm{kg} / \mathrm{m}^{2}\right)$ & $18,4-17$ & $16,9-16$ & $<2,5$ \\
\hline Biochimici e immunologici & & & $<100$ \\
\hline Albumina $(\mathrm{g} / \mathrm{dL})$ & $3,5-3$ & $2,9-2,5$ & $<10$ \\
\hline Transferrina $(\mathrm{mg} / \mathrm{dL})$ & $150-200$ & $100-149$ & $<00$ \\
\hline Prealbumina $(\mathrm{mg} / \mathrm{dL})$ & $18-22$ & $10-17$ & $<2,1$ \\
\hline Linfociti $\left(\mathrm{mm}{ }^{3}\right)$ & $1200-1500$ & $800-1199$ & $2,4-2,1$ \\
\hline Retinol-binding protein $(\mathrm{mg} / \mathrm{dL})$ & $2,9-2,5$ & & $<800$ \\
\hline
\end{tabular}


differenti associazioni di parametri nutrizionali: il prognostic nutrition index (PNI), il prognostic inflammatory and nutritional index (PINI) e il nutritional risk index (NRI). ${ }^{6}$

Infine, il giudizio clinico e l'esperienza sono necessari per integrare i risultati della valutazione nutrizionale e convogliarli nell'elaborazione di un piano di cura nutrizionale individualizzato. ${ }^{5} \mathrm{Il}$ giudizio professionale della figura sanitaria adibita alla tutela della salute resta la componente principale della cura medica di qualità. ${ }^{1}$

Il piano di assistenza nutrizionale è lo step finale della valutazione nutrizione. Il piano di assistenza viene utilizzato per organizzare le informazioni ottenute nella valutazione ed esprimere un giudizio professionale. Il piano di assistenza nutrizionale dovrebbe includere gli obiettivi nutrizionali e la via di somministrazione dei supporti nutrizionali. ${ }^{6}$ Le valutazioni nutrizionali possono portare all'elaborazione di raccomandazioni per migliorare lo stato nutrizionale o per rivalutarlo. La valutazione clinica (compresi il rescreening e la rivalutazione) è un processo continuo.

\section{Intervento nutrizionale}

I pazienti identificati come malnutriti o a rischio di malnutrizione dallo screening e dalla valutazione nutrizionale devono ricevere un supporto nutrizionale specializzato (SNS). La somministrazione di tale supporto non costituisce mai un intervento di emergenza e non deve essere intrapreso fin quando il paziente non diventa emodinamicamente stabile. Il SNS consiste nella somministrazione di sostanze nutritive per via orale, enterale o parenterale con intento terapeutico. ${ }^{6}$

La nutrizione enterale (NE) comporta l'apporto di sostanze nutritive direttamente nel tratto gastrointestinale. La NE rappresenta la metodica di prima scelta in tutti i pazienti che presentano un'indicazione all'intervento nutrizionale ed hanno un apparato gastrointestinale integro e funzionante (Figura 3). ${ }^{6}$ I vantaggi della NE sulla nutrizione parenterale (NP) sono ormai assodati: il mantenimento dell'integrità anatomo-funzionale della mucosa intestinale, il più fisiologico utilizzo dei substrati nutritivi, la ridotta incidenza di complicanze metaboliche o settiche, la facilità e la sicurezza di somministrazione e il minor costo.

La scelta della via di accesso enterale si basa sull'anatomia e sulla funzione dell'apparato gastrointestinale del paziente, sulla durata prevista della NE e sul rischio di aspirazione. Le sonde nasoenteriche rappresentano la metodica più comunemente usata di accesso enterale; possono essere posizionate nello stomaco, nel duodeno o nel digiuno. Le sonde da nutrizione sono indicate per

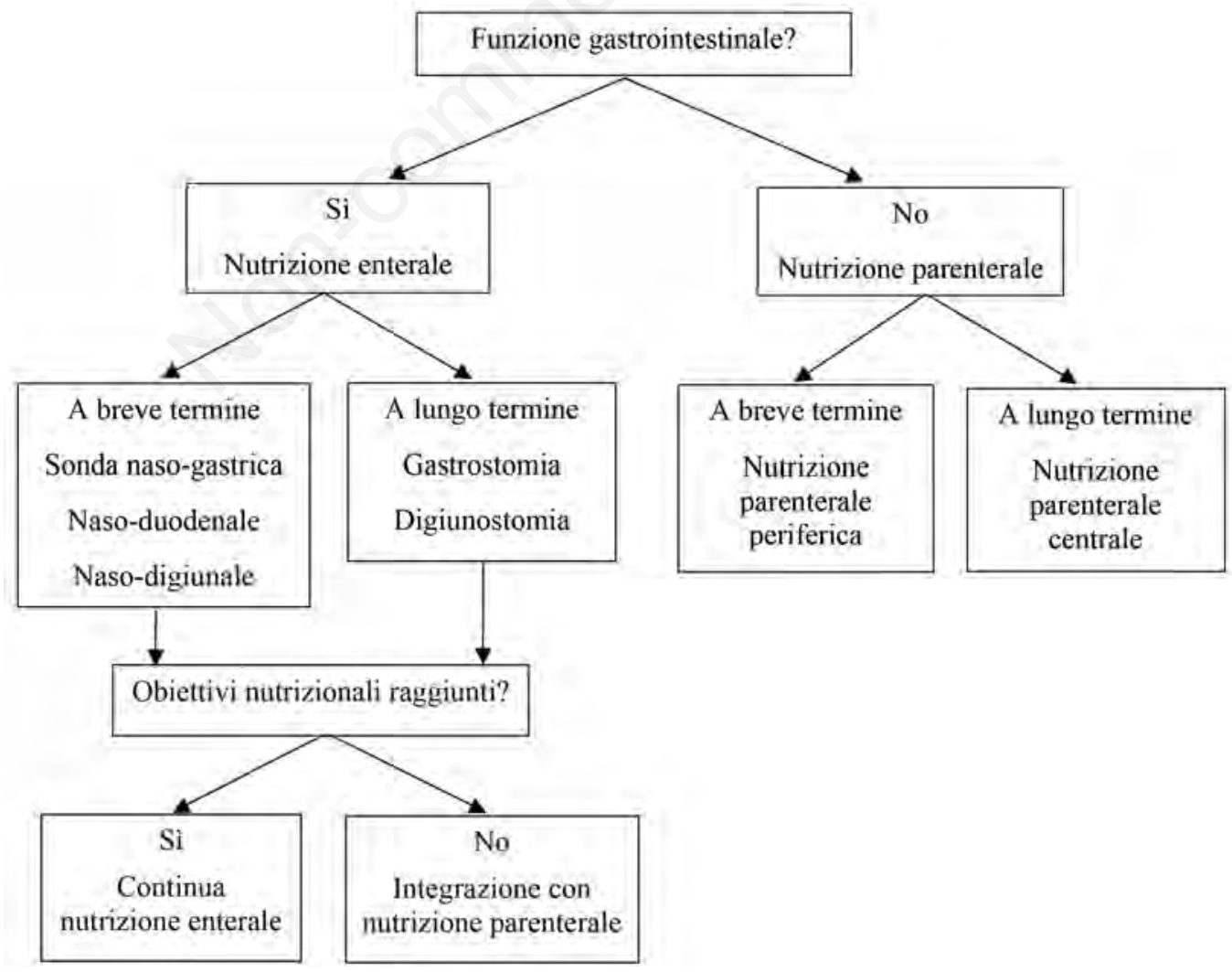

Figura 3. Algoritmo decisionale per il supporto nutrizionale specializzato. 
interventi nutrizionali a breve termine $(<4$ settimane) perché gravate da basso rischio di complicanze, relativamente poco costose e facili da posizionare. I pazienti che necessitano di una NE di lunga durata ( $>30$ giorni) dovrebbero invece ricevere un accesso permanente tramite il confezionamento di enterostomie. La gastrostomia è il metodo più comunemente utilizzato per instaurare un accesso a lungo termine. Nel paziente candidato all'intervento nutrizionale vi sono delle controindicazioni alla NE che vanno considerate ed escluse: la peritonite diffusa, l'occlusione intestinale, il vomito incoercibile, l'ileo paralitico, la diarrea profusa e l'ischemia gastrointestinale. ${ }^{6,10}$

La NP consiste nella somministrazione di sostanze nutritive per via endovenosa. È richiesto un accesso venoso preferibilmente centrale per fornire nutrienti a maggiori concentrazioni di quanto sia possibile effettuare con vene periferiche. La scelta della via di accesso parenterale più appropriato si basa sulla storia di precedenti accessi vascolari del paziente, sull'anatomia del sistema venoso, sullo stato di coagulazione, sulla durata prevista di NP, sul setting di cura e sulla tipologia di patologia sottostante. La NP è una terapia invasiva non scevra da complicanze. L'uso appropriato di questo approccio terapeutico nutrizionale massimizza il beneficio clinico, riducendo al minimo il potenziale rischio di eventi avversi. La NP deve essere utilizzata quando vi è indicazione all'intervento nutrizionale e la NE è controindicata o non tollerata. ${ }^{6,11}$

Una questione controversa è rappresentata dal momento ottimale di inizio dell'intervento nutrizionale. Sulla base dei dati disponibili, sembra ragionevole intraprendere un SNS quando l'apporto di nutrienti per via orale è inadeguato da 7-14 giorni o in quei pazienti in cui si prevede un insufficiente introito orale di nutrienti per un periodo di almeno 7-14 giorni. ${ }^{6}$

Il monitoraggio dei pazienti sottoposti a un SNS si rende necessario per valutare l'efficacia della terapia nutrizionale, individuare e prevenire le complicanze, valutare le variazioni delle condizioni cliniche e documentare i risultati clinici. Gli outcome clinici possono includere il mantenimento o la replezione di massa magra, la riduzione della morbilità e della mortalità, il miglioramento della qualità della vita, la riduzione della degenza in ospedale e la diminuzione dei costi sanitari. Il bilancio energetico, l'analisi della composizione corporea, le misurazioni del peso corporeo, dei parametri antropometrici, delle concentrazioni di parametri sierici, il bilancio proteico, lo stato funzionale, l'esame fisico accurato rientrano nella valutazione dello stato nutrizionale e dell'efficacia del SNS. Il paziente deve essere rivalutato periodicamente per determinare se è necessario il proseguimento della terapia nutrizionale e se devono essere apportate delle variazioni, soprattutto in caso di miglioramento dell'assunzione orale. ${ }^{6}$
Anche se il supporto nutrizionale è una terapia utile e salvavita in diverse condizioni cliniche, sia la nutrizione enterale che parenterale possono causare complicanze: la sindrome da rialimentazione, l'iperglicemia e l'ipoglicemia, anomalie dell'equilibrio acido-base, l'ipertrigliceridemia, l'eccessiva produzione di anidride carbonica, le complicanze epatobiliari e le patologie metaboliche dell'osso. Inoltre, la sepsi da accesso vascolare in pazienti trattati con NP è una complicanza frequente. Il reflusso gastroesofageo e l'aspirazione polmonare sono potenziali complicazioni della NE. Effetti avversi gastrointestinali, quali la diarrea, sono comuni durante NE. Queste complicanze possono essere minimizzate attraverso un attento monitoraggio del paziente da parte dei professionisti del supporto nutrizionale. ${ }^{6}$

\section{La malnutrizione nell'insufficienza renale cronica}

L'International Society of Renal Nutrition and Metabolism ha definito la malnutrizione proteico-energetica come una condizione di diminuita massa proteica corporea e diminuite riserve energetiche che coinvolge tessuto adiposo, tessuto muscolare e pool proteico viscerale. ${ }^{12}$ Il termine di malnutrizione proteico-energetica viene utilizzato per sottolineare che questa condizione non è sempre legata ad un inadeguato apporto o ad un incrementato dispendio dei nutrienti, ma più spesso è il risultato di numerosi meccanismi tra loro correlati che includono fattori nutrizionali e non (Tabella 2). ${ }^{13,14}$ Con la denominazione di sindrome infiammatorio-malnutrizionale uremica si indica la stretta associazione tra malnutrizione e stato infiammatorio, che è alla base dello sviluppo della malnutrizione proteico-energetica, tipica del paziente con insufficienza renale cronica (IRC). La prevalenza di malnutrizione proteico-energetica aumenta con la progressione del danno renale. ${ }^{14}$ I deficit nutrizionali protratti e lo stress ossidativo sono strettamente correlati alla progressiva perdita della funzione renale; essi variano dal 18-48\% nello stadio 3-4 di IRC (eGFR 60$15 \mathrm{~mL} / \mathrm{min}$ ) fino al $75 \%$ nello stadio 5. Per la diagnosi di malnutrizione proteico-energetica è necessaria la presenza di almeno 4 criteri tra quelli elencati nella Tabella $3 .{ }^{13}$ È importante riconoscere e prevenire questa condizione dal momento che la malnutrizione e l'infiammazione costituiscono forti predittori di outcome negativi nel paziente con IRC. ${ }^{15}$ Infatti, alterazioni dello stato nutrizionale sono stati descritti come forti predittori di mortalità in pazienti affetti da IRC. Alcuni studi riportano che solo i pazienti con ipoalbuminemia sono considerati a maggior rischio di mortalità nel follow-up rispetto ai pazienti con normali livelli di albumina. L'apporto dietetico sembra essere comunque compromesso non solo da un effetto anoressizzante diretto delle tossine uremiche, ma anche 
dall'influenza di mediatori del senso di sazietà a breve e lungo termine quali la serotonina, diverse citochine e la leptina. I livelli di citochine come l'IL-6, l'IL-1, il TNF- $\alpha$ e la proteina c-reattiva sono infatti notevolmente aumentati nei pazienti con progressiva perdita della funzione renale. ${ }^{13}$ Inoltre, l'alterata clearance renale della leptina può influenzare negativamente l'apporto calorico ed incrementare il rilascio di citochine pro-infiammatorie dal tessuto adiposo.
L'obiettivo principale del trattamento della malnutrizione proteico-energetica è la correzione dell'apporto dietetico di proteine. È indicata una dieta a basso contenuto proteico $(0,6 \mathrm{~g} / \mathrm{kg} / \mathrm{die})$ e con bassi livelli di potassio $(<2 \mathrm{~g} /$ die), sodio $(<2 \mathrm{~g} /$ die $)$, fosfati $(<1 \mathrm{~g} /$ die $)$ e liquidi $\left(<1 \mathrm{~L} /\right.$ giorno).$^{14}$ Una perdita di peso involontaria, la sarcopenia, la diminuzione dell'appetito, i livelli sierici di albumina $<4 \mathrm{~g} / \mathrm{dL}$ e il rapido declino della funzione renale richiedono interventi addizionali come la

Tabella 2. Cause di malnutrizione proteico-energetica in pazienti con insufficienza renale cronica.

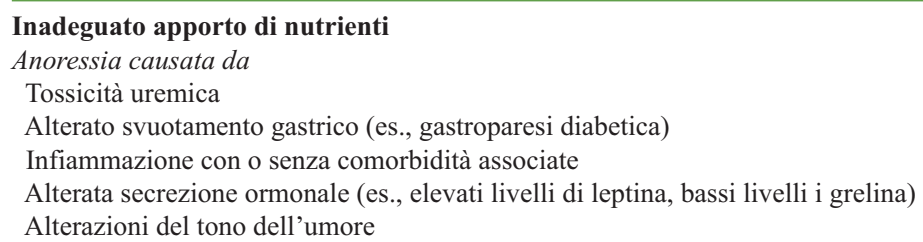

Scarsa aderenza alle prescrizioni dietetiche suggerite

Dieta a basso-molto basso contenuto proteico

Scarso apporto calorico (regimi a basso contenuto di potassio e fosfati

Dieta a basso apporto di sodio con restrizione idrica (per il controllo degli edemi)

Scarso apporto di grassi

Scarso apporto di carboidrati (es., in pazienti con diabete)

Aggravanti socio-economici: povertà, inadeguato apporto nutrizionale

Limitazioni fisiche: inabilità a preparare, mangiare o digerire gli alimenti

Scarsa dentizioni o alterazioni del cavo orale

Alterazioni neurologiche (es., dopo accidenti cerebrovascolari con alterazioni della deglutizione)

\section{Moderata o severa proteinuria}

Ipercatabolismo causato da malattie concomitanti

Malattie cardiovascolari

Complicazioni della malattia diabetica

Infezioni e/o sepsi

Altre co-morbidità associate

Ipercatabolismo associato allo stato uremico

Bilancio proteico negativo

Bilancio energetico negativo

Alterazioni endocrine correlate all' insufficienza renale

Insulino-resistenza

Resistenza al GH/IGF-1

Incrementati livelli sierici o aumentata sensibilità al glucagone

Iperparatiroidismo

Acidemia secondaria all'acidosi metabolica

Perdite ematiche concomitanti

Modificata da Kovesdy et al., 2013. ${ }^{14}$

Tabella 3. Diagnosi di malnutrizione proteico-energetica in pazienti con insufficienza renale cronica.

\begin{tabular}{lll}
\hline Apporto nutrizionale & Composizione corporea & Valori di laboratorio \\
\hline Diretto: diario alimentare & Indice di massa corporea & $\begin{array}{l}\text { Proteine (proteine di fase acuta negative, influenzate da assunzione dei } \\
\text { nutrienti): albumina, pre-albumina e trasferrina sieriche }\end{array}$ \\
\hline Indiretti: (raccolta urinaria 24 h) & $\begin{array}{l}\text { Misure antropometriche } \\
\text { cute e muscoli }\end{array}$ & $\begin{array}{l}\text { Lipidi: colesterolo, trigliceridi, altri lipidi e lipoproteine } \\
\text { Indicatori di massa muscolare e/o di apporto proteico: creatinina sierica, urea } \\
\end{array}$ \\
& $\begin{array}{l}\text { Fattori di crescita: GH, leptina } \\
\text { Conta cellulare periferica (linfociti, citochine proinfiammatorie: proteina } \\
\text { C-reattiva, TNF- } \alpha, \text { IL-6 }\end{array}$ \\
\hline
\end{tabular}


supplementazione dietetica con proteine ad alto valore biologico (aminoacidi essenziali e ketoacidi), la correzione dell'acidemia e dello stato infiammatorio qualora presenti. La somministrazione di ulteriori agenti farmacologici quali antidepressivi, anabolizzanti, antiossidanti, chelanti del potassio e dei fosfati, diuretici, modulatori del sistema renina-angiotensina e gli stimolanti dell'appetito, è da considerare per ciascun paziente in caso di mancata risposta al trattamento o di peggioramento del quadro clinico generale. ${ }^{14}$

\section{Malnutrizione negli anziani}

I disordini nutrizionali sono di notevole importanza nell'anziano. L'incidenza di malnutrizione nei pazienti geriatrici ospedalizzati è molto alta, di circa il 22-68\%, in base alla popolazione studiata e alla metodologia di valutazione utilizzata. ${ }^{16} \mathrm{I}$ dati derivanti da una meta-analisi che ha coinvolto circa 30.000 pazienti anziani identificati da uno specifico strumento di valutazione nutrizionale mostrano che la prevalenza media di malnutrizione è di circa l' $1 \%$ negli anziani sani, del $4 \%$ nei pazienti ambulatoriali, del $5 \%$ nei pazienti con malattia di Alzheimer e di oltre il 20\% in quelli ospedalizzati. ${ }^{16,17}$ Il processo di invecchiamento è comunque un fenomeno biologico caratterizzato da dinamiche spesso indipendenti dal controllo umano. ${ }^{18}$ L'invecchiamento determina ad esempio delle modificazioni della fisiologia umana, quali l'atrofia della mucosa buccale e linguale, cui consegue ipogeusia, la riduzione della secrezione gastrica e pancreatica, con conseguente riduzione della digestione e dell'assorbimento dei nutrienti. Inoltre, il decremento della massa magra totale e del tasso metabolico corporeo può contribuire allo sviluppo di una anoressia dell'età avanzata. Peraltro, il paziente anziano mostra spesso una físiologica diminuzione del senso della fame legata all'incremento dei livelli di colecistochinina e al ritardato svuotamento gastrico. In aggiunta a questi fattori fisiologici, ci sono altre cause di malnutrizione correlate alle patologie più frequentemente rappresentate nelle decadi più avanzate, quali le insufficienze d'organo, le malattie neoplastiche e/o l'utilizzo di farmaci che interferiscono con l'assorbimento dei nutrienti e/o farmaci che determinano alterazioni del gusto. La povertà, le difficoltà socio-economiche, l'istituzionalizzazione possono inoltre comportare un'alterata assunzione degli alimenti. Le cause di malnutrizione dell'anziano sono dunque numerosissime e possono essere divise in mediche, psicologiche e sociali (Tabella 4). ${ }^{19,20}$

Recentemente la ESPEN ha stabilito la differenza tra malnutrizione, cachessia e sarcopenia. La cachessia è una condizione metabolica complessa correlata ad una sottostante patologia e caratterizzata da perdita di massa muscolare con o senza perdita di massa grassa. La caratteristica clinica preminente della cachessia è la perdita di peso corporeo dell'adulto (corretta per la ritenzione di liquidi). La sarcopenia invece è una sindrome caratterizzata da una progressiva e generalizzata perdita di massa muscolare scheletrica correlata con il rischio di eventi avversi come disabilità fisica, peggioramento della qualità di vita e morte. ${ }^{21}$ La European Working Group on Sarcopenia in Older People raccomanda l'identificazione sia della scarsa massa muscolare che della diminuita funzione muscolare per porre diagnosi di sarcopenia. Alla cachessia sono spesso associate anoressia, infiammazione, resistenza all'insulina, aumento della disgregazione muscolare. La maggior parte degli individui cachettici sono dunque considerati anche sarcopenici, ma la maggior parte dei soggetti sarcopenici non sono cachettici. Pertanto, la malnutrizione osservata nei pazienti anziani ospedalizzati è spesso una combinazione

Tabella 4. Fattori di rischio per malnutrizione.

\begin{tabular}{ll}
\hline Fattori di rischio & \\
\hline Medici & Scarso appetito \\
& Edentulia o altri problemi locali \\
& Perdita del gusto e dell'olfatto \\
& Malattie respiratorie (bronchiti cronico-ostruttive, enfisema) \\
& Malattie endocrine (ipertiroidismo, diabete) \\
& Disordini neurologici (malattia di Parkinson, accidenti cerebrovascolari) \\
& Infezioni \\
& Disabilità fisiche (artrite, fratture osteoporotiche) \\
& Interazioni farmacologiche (digossina, metformina, lassativi, antibiotici, etc.) \\
& Malattie debilitanti quali ictus o neoplasie \\
\hline Sociali & Isolamento sociale \\
& Difficoltà economiche \\
& Inabilità a preparare il pasto \\
\hline Psicologici & Confusione \\
& Ansia \\
& Demenza \\
& Depressione \\
\hline
\end{tabular}


di cachessia (correlata alla malattia) e malnutrizione (consumo insufficiente di nutrienti). Le conseguenze della malnutrizione sulla salute dell'anziano possono essere divise in: i) dirette: ritardata guarigione delle ferite, ridotta motilità intestinale, diminuita funzionalità muscolare, depressione delle difese immunitarie, aumentato rischio di infezioni, fratture, ulcere e piaghe da decubito; ii) indirette: aumentata morbilità, maggiore durata della degenza ospedaliera e della riabilitazione, aumentato utilizzo di farmaci, peggioramento della qualità della vita, aumento della mortalità e dei costi sanitari.

\section{Valutazione nutrizionale nella malattia di Alzheimer}

Una categoria particolare di persone anziane a rischio di malnutrizione è rappresentata dai pazienti affetti da malattia di Alzheimer. Già nel 1907 Alois Alzheimer aveva descritto nei suoi primi pazienti una lenta e graduale diminuzione del peso corporeo, che è stata successivamente confermata in un gran numero di pazienti con Alzheimer. In letteratura è ancora dibattuto se la perdita di peso corporeo sia da considerare come un evento causale o come il risultato della malattia stessa. ${ }^{22}$ Alcuni autori, fautori della prima tesi, suggeriscono la possibilità che la carenza di micro e macro-nutrienti sia associata ad una più bassa performance cognitiva anche in soggetti senza demenza. Dall'altra parte, è altrettanto vero che potrebbe essere considerata come un effetto della malattia perché il processo neurodegenerativo che inizia prima della diagnosi clinica può essere esso stesso causa primaria della perdita di peso. ${ }^{23} \mathrm{Il}$ calo ponderale può anche essere parte della risposta adattativa del corpo allo stress dovuto alla malattia o essere il risultato di una forma di down-regulation dei fabbisogni energetici associata alla riduzione delle funzioni cerebrali. Pertanto, la cosiddetta perdita di peso non intenzionale sarebbe una conseguenza diretta della malattia, non solo per l'associazione tra demenza e disturbi comportamentali, ma anche perché le lesioni cerebrali tipiche della malattia di Alzheimer coinvolgono le aree del cervello responsabili della assunzione di cibo. ${ }^{24}$ Tuttavia, indipendentemente dalla causa, la perdita di peso corporeo in questi pazienti sembra essere inevitabile e strettamente associata alla fisiopatologia della malattia di Alzheimer. La prevenzione è senza dubbio fondamentale. È importante identificare i pazienti a rischio per valutare il loro stato nutrizionale e prevenire le conseguenze della malnutrizione sulle funzioni cognitive.

\section{Valutazione nutrizionale nel paziente anziano}

Il test MNA è il miglior test di screening validato e il più ampiamente utilizzato per la valutazione della malnutrizione nelle persone anziane. Il test MNA comprende 18 items suddivisi in 4 categorie: valutazione antropometrica, valutazione dello stato generale di salute, breve valutazione dietetica e valutazione del soggetto.

Oltre al test MNA sono stati validati altri test di screening per la malnutrizione, tuttavia non è ancora chiaro quale di questi sia il migliore nel predire gli outcome a lungo termine nei pazienti anziani ospedalizzati. È stata sviluppata e validata una forma ridotta del test MNA (MNA-short form, MNA-SF), per lo screening dei soggetti a basso rischio: questa è composta da 2 step con parametri simili a quelli del test MNA completo. Qualora il primo step sia predittivo di rischio di malnutrizione, deve essere eseguito il secondo step. La valutazione MNA-SF può essere usata facilmente come uno strumento di screening efficace per i soggetti residenti in comunità per anziani nel corso della loro valutazione geriatrica. Alcuni studi suggeriscono che può essere somministrato sia dai medici curanti, sia al momento del ricovero in ospedale (o assistenza domiciliare) per valutare in anticipo il rischio di malnutrizione ed individuare i pazienti che potrebbero trarre beneficio da un intervento nutrizionale precoce. ${ }^{25}$ Secondo le linee guida ASPEN, gli anziani sono considerati a rischio nutrizionale se è presente uno dei seguenti fattori: i) rischio attuale $\mathrm{e}$ potenziale per lo sviluppo di malnutrizione (perdita involontaria o incremento $\geq 10 \%$ del peso corporeo abituale negli ultimi 6 mesi o $\geq 5 \%$ del peso corporeo abituale in $1 \mathrm{mese}$; $\mathrm{BMI}<20 \mathrm{~kg} / \mathrm{m}^{2}$ ); ii) presenza di malattie croniche o maggiori esigenze metaboliche; iii) modifiche della dieta o programmi dietetici (soggetti in nutrizione parenterale totale o nutrizione enterale, recente intervento chirurgico, patologie, traumi); iv) inadeguato introito alimentare compresa la mancata assunzione di alimenti o prodotti nutrizionali (ridotta capacità di ingerire o assorbire adeguatamente il cibo) per un tempo $>7$ giorni. La denutrizione e il rischio di malnutrizione rappresentano indicazioni essenziali ed indipendenti per la nutrizione enterale in pazienti geriatrici. ${ }^{1}$

Le recenti linee guida della ESPEN ${ }^{11}$ definisce supplementi nutrizionali orali i prodotti utilizzati come supporto nutrizionale nella dieta e che sono raccomandati al fine di aumentare l'introito energetico, di proteine e micronutrienti nei pazienti ancora in grado di alimentarsi per via naturale. Questa strategia mira a ridurre la necessità di tecniche nutrizionali più invasive. In caso di incapacità a raggiungere un aumento di peso per via naturale, è consigliabile avvalersi della nutrizione mediante sonde da nutrizione. ${ }^{26}$ La nutrizione enterale mediante sonde è chiaramente indicata nei pazienti con disfagia su base neurologica. Al contrario, l'alimentazione mediante gastrostomia percutanea endoscopica (PEG) o sondino nasogastrico (NGT) non è indicata negli stadi terminali di malattia, tra cui la demenza 
avanzata. La scelta tra PEG e NGT resta controversa, ma la PEG sembra essere più efficiente.

I fattori più importanti per mantenere un buono stato nutrizionale nelle persone anziane con malattia di Alzheimer sono: adeguate tecniche di nutrizione, adeguata consistenza dei pasti e sfruttamento del tempo massimo cognitivo giornaliero. Quest'ultimo va solitamente dalla mattina presto fino al pomeriggio, così che la prima colazione e il pranzo risultano i momenti più opportuni per l'ottimizzazione dell'apporto nutrizionale. È necessario inoltre intervenire sullo stress psicologico del caregiver che può influenzare il comportamento dei pazienti.

\section{Malnutrizione nella cirrosi epatica}

La malnutrizione come complicanza della malattia epatica cronica ha importanti implicazioni prognostiche. Una malnutrizione proteico-calorica si riscontra nel $65-90 \%$ dei pazienti con malattia epatica avanzata e in quasi il $100 \%$ dei candidati a trapianto di fegato. ${ }^{27,28}$ I pazienti con malattia epatica cronica sviluppano spesso anche carenze di micronutrienti. I pazienti con malattia epatica colestatica sono soggetti a deplezione calorica e sono maggiormente predisposti a sviluppare un deficit di vitamine liposolubili, mentre i pazienti con malattia epatica non colestatica presentano prevalentemente una deplezione proteica. ${ }^{29}$

Le cause di malnutrizione nelle epatopatie sono: i) scarsa alimentazione a causa di alterazioni gustative, sazietà precoce relativa alla compressione meccanica dell'ascite massiva, aumento della concentrazione sierica di leptina, restrizioni dietetiche comunemente consigliate, astenia, encefalopatia di basso grado; ii) malassorbimento: malassorbimento di grassi dovuto ad una riduzione del pool dei sali biliari, proliferazione batterica, ipertensione portale, assunzione di farmaci che portano a malassorbimento (come la neomicina); iii) aumento della spesa energetica: la causa esatta di ipermetabolismo rimane poco chiara, ma alcuni fattori predisponenti sono stati identificati nelle infezioni e nell'ascite; iv) un alterato metabolismo dei nutrienti, con una rapida transizione dall'utilizzo di carboidrati all'uso di depositi di grasso come substrato per il metabolismo.

Molti dei parametri di malnutrizione comunemente utilizzati non sono utili per individuare il rischio di malnutrizione in questa popolazione di pazienti. La ritenzione di liquidi influenza il peso e la massa cellulare corporei. Molti dei marcatori tipici dello stato nutrizionale sono meno affidabili in pazienti con cirrosi: per esempio, la concentrazione di albumina e prealbumina potrebbe risultare ridotta a causa dei bassi livelli di sintesi. Dovrebbero essere presi in considerazione altri parametri, come la valutazione globale del soggetto. ${ }^{30}$

Gli obiettivi della terapia nutrizionale sono il mi- glioramento della malnutrizione proteico-calorica e la correzione delle carenze nutrizionali. Questo può essere realizzato mediante una nutrizione per via orale, enterale o parenterale oppure dalla combinazione di queste modalità. Un intervento tempestivo nelle prime fasi della malnutrizione può migliorare gli outcome.

Alcune evidenze suggeriscono che l'alimentazione parenterale potrebbe essere superiore alla nutrizione enterale nei pazienti con shunt porto-sistemico, poiché quest'ultima potrebbe peggiorare l'iperammoniemia in questa specifica popolazione di pazienti. ${ }^{31}$

La European Society for Clinical Nutrition and Metabolism ha formulato le linee guida per il raggiungimento degli obiettivi nutrizionali in pazienti con malattia epatica end-stage..$^{32}$ È raccomandato l'inizio della nutrizione enterale quando l'assunzione orale è inadeguata. Nei pazienti con cirrosi compensata, le linee guida raccomandano l'assunzione di 25-35 $\mathrm{kcal} / \mathrm{kg}$ di peso corporeo al giorno di apporto energetico non proteico e di 1-1,2 $\mathrm{g} / \mathrm{kg}$ di peso corporeo al giorno di proteine o aminoacidi. In pazienti con cirrosi scompensata associata malnutrizione, l'apporto energetico non proteico deve essere aumentato a $35-40 \mathrm{kcal} / \mathrm{kg}$ di peso corporeo al giorno e quello proteico a $1,5 \mathrm{~g} / \mathrm{kg}$ di peso corporeo al giorno. Secondo le linee guida, l'assunzione di proteine dovrebbe diminuire di $0,5-1,5 \mathrm{~g} / \mathrm{kg}$ di peso corporeo al giorno se è presente encefalopatia di I o II grado, e di $0,5 \mathrm{~g} / \mathrm{kg}$ di peso corporeo al giorno in caso di encefalopatia di III o IV grado. Le evidenze più recenti non raccomandano invece la restrizione proteica anche nell'encefalopatia epatica episodica.

Secondo alcuni autori, mangiare degli spuntini serali potrebbe ridurre lo spostamento verso l'ossidazione lipidica, riducendo la durata del digiuno. Una raccomandazione tipica per i pazienti con malattia epatica avanzata è quello di consumare 4-5 piccoli pasti al giorno, così come uno spuntino in tarda serata.

La somministrazione di aminoacidi a catena ramificata (BCAA) - leucina, isoleucina e valina - ha dimostrato influenzare positivamente l'espressione genica, il metabolismo delle proteine, l'apoptosi e la rigenerazione degli epatociti e l'insulino-resistenza. Essi inibiscono inoltre la proliferazione delle cellule di epatocarcinoma in vitro e sono essenziali per la proliferazione dei linfociti e la maturazione delle cellule dendritiche. Nei pazienti con malattia epatica cronica avanzata, le concentrazioni di BCAA sono basse, mentre le concentrazioni di amminoacidi aromatici (AAA) come la fenilalanina e la tirosina sono alte; un basso rapporto di Fisher (BCAA/AAA) si è dimostrato essere un marcatore di progressione della malattia epatica, mentre il rapporto di Fisher semplificato (BCAA/tirosina) è in grado di prevedere i livelli di albumina a un anno. ${ }^{33-35}$ Diversi studi clinici hanno suggerito che la supplementazione con BCAA migliora la prognosi dei pazienti cirrotici; una recente revisione 
conclude che la loro integrazione migliora lo stato nutrizionale e la qualità della vita nei pazienti con cirrosi avanzata per cui diverse linee guida internazionali ne consigliano l'utilizzo. ${ }^{36}$ Un'altra meta-analisi raccomanda la somministrazione orale di BCAA nell'encefalopatia epatica, soprattutto in combinazione con disaccaridi non assorbibili. ${ }^{37} \mathrm{Nel}$ carcinoma epatocellulare la supplementazione con BCAA migliora la qualità della vita ed aiuta a preservare la funzione epatica durante la terapia. ${ }^{38}$

\section{La gestione del paziente con malnutrizione: razionale e obiettivi}

La malnutrizione è una condizione altamente prevalente in ospedale con un'incidenza di circa il $40 \%$. La presenza di malnutrizione è associata con outcome negativi sia per la comparsa di complicanze sia per gli incrementati costi sanitari. Obiettivo di questa monografia è quindi quello di fornire raccomandazione evidence-based recommendations per la prevenzione, l'identificazione, la diagnosi e il trattamento del paziente con malnutrizione attraverso l'analisi delle linee guida ad oggi disponibili. Non è oggetto di questa monografia la trattazione della malnutrizione del bambino.

\section{La gestione del paziente con malnutrizione: metodologia}

$\mathrm{Al}$ fine di fornire raccomandazioni evidence-based per la gestione del paziente con malnutrizione, abbiamo innanzitutto verificato l'esistenza di linee guida in merito.

Abbiamo, pertanto, condotto una ricerca utilizzando i seguenti database di linee guida:

- Scottish Intercollegiate Guidelines Network (SIGN)

- Institute for Clinical Systematic Improvement (ICSI)

- National Institute for Health and Clinical Excellence (NICE) (NHS evidence)

- National Guideline Cleringhouse (NGC)

- Agency for Healthcare Research and Quality (AHRQ)

- Canadian Medical Association, CMA infobase

- New Zeland Guidelines Group

- Sistema Nazionale Linee Guida (SNLG)

- Clinical Practice Guidelines Portal

- eGuidelines

La ricerca è stata eseguita da 2 autori, indipendentemente, utilizzando come key-words i termini malnutrizione, quando il sito prevedeva la funzione di ricerca; negli altri casi abbiamo scorso manualmente la lista delle linee guida archiviate nel database o fatto riferimento alla sezione patologie gastro-intestinali. I risultati ottenuti separatamente sono poi stati confrontati e discussi insieme.

Le linee guida così ottenute sono state valutate utlizzando lo strumento Appraisal of Guidelines, Research and Evaluation II (AGREE II) da 2 autori indipendentemente, al fine di identificare la/e linee guida qualitativamente migliori. AGREE II valuta il rispetto di 23 requisiti, riuniti in 6 domini che vanno dall'esplicitazione dello scopo alla chiarezza espositiva, dal coinvolgimento di tutte le parti interessate al rigore nello sviluppo, dall'applicabilità all'indipendenza editoriale più due considerazioni finali di valutazione complessiva. Ciascun autore valuta il rispetto di ognuno dei requisiti con un punteggio da 1 (disaccordo completo) a 7 (accordo completo); i punteggi assegnati da ciascun autore vengono sommati all'interno dei singoli domini e rapportati con il massimo e il minimo punteggio possibile all'interno del dominio in base al numero di requisiti inclusi e al numero dei valutatori.

È stata infine condotta una ricerca delle evidenze disponibili in letteratura dalla data di termine della ricerca bibliografica della/e linee guida scelta/e ai nostri giorni per aggiornare le evidenze sull'argomento in esame.

\section{La gestione del paziente con malnutrizione: risultati}

Attraverso i databases su elencati abbiamo identificato e selezionato per la valutazione 11 linee guida.

La qualità globale delle linee guida selezionate è stata valutata da 2 autori separatamente utilizzando lo strumento AGREE II. Le linee guida prodotte dalla $\mathrm{Ca}$ nadian Clinical Practice sono ben strutturate (punteggio globale 5,78). La maggior parte delle raccomandazioni sono chiare e facilmente comprensibili. Sono però indirizzate solo alla gestione della malnutrizione nei pazienti in ventilazione meccanica. Le linee guida ASPEN includono tre linee guida: ASPEN guidelines nutrition screening, assessment and intervention, ASPEN parenteral nutrition ordering ASPEN guidelines parenteral and enteral nutrition. Le ASPEN guidelines nutrition screening, assessment and intervention sono chiare e supportate da solide evidenze scientifiche (score 6) con buon equilibrio tra i vari domini. Le ASPEN parenteral nutrition ordering sono focalizzate solo su una tipologia di nutrizione (la parenterale) e mancano dei sommari che possono guidarne l'uso (score 4). Le ASPEN guidelines parenteral and enteral nutrition sono estremamente dettagliate $\mathrm{e}$ accurate (score 6). Approfondiscono anche l'approccio al paziente malnutrito concomitante a particolari condizioni come la gravidanza, l'età avanzata, l'obesità, patologie renali, pancreatiche, cardiache ed epatiche. La divisione in paragrafi con evidenziate le principali raccomandazioni infine ne facilita l'uso. Le ASPEN critically ill patient affronta la problematica della malnu- 
trizione nel paziente critico. Le raccomandazioni sono specifiche, non ambigue e facilmente identificabili (score 6,17). Un ulteriore punto di forza e la rigorosità nella metodologia di sviluppo. Sono presenti 4 linee guida ESPEN. Le linee guida ESPEN guidelines on enteral nutrition liver si focalizza esaustivamente sulla nutrizione enterale ma su un sottotipo di paziente, l'epatopatico (score 4,5). L'uso di tabelle consente agilmente di identificare le principali raccomandazioni. Le ESPEN guidelines on enteral nutrition geriatrics sono chiare ma focalizzate solo sulla nutrizione enterale del paziente anziano fragile, neoplastico e demente (score $3,8)$. Le ESPEN guidelines on parenteral nutrition (score 3,8$)$ si focalizzano anche esse solo su un aspetto, ossia la nutrizione parenterale nel paziente in terapia intensiva. Il target pertanto è limitato e, seppure sono chiare e le principali raccomandazioni sono facilmente identificabili, il rigore metodologico è scarso. Le ESPEN nutritional screening 2002 sono chiare e succinte ma focalizzate solo sullo screening nutrizionale (score 3,5). La maggior parte dei domini AGREE non risultano identificabili. Le linee guida inoltre sono aggiornate al 2002. Le linee guida NICE sono le linee guida che hanno ottenuto il maggior punteggio (score $6,29)$. Sono ben strutturate e di facile applicabilità. Il rigore metodologico è soddisfatto. Hanno pertanto ottenuto buon punteggio in tutti i domini. Le Guidelines of National System se pur molto dettagliate sono di scarsa applicabilità pratica (score 3 ). Inoltre sono rivolte alla popolazione pediatrica e quindi non di competenza internistica. Le Guidelines New Zealand sono principalmente organizzate sotto forma di schemi (score 4,85) e pertanto di facile consultazione. Le linee guida italiane sulla nutrizione artificiale (score 4,77) nel paziente anziano sono chiare e comprensibili in quanto schematizzate in raccomandazioni chiavi. La lingua utilizzata è l'italiano e questo ne limita la diffusione.

In conclusione le linee guida che affrontano la problematica della malnutrizione per tutti i tipi di pazienti e per tutti i tipi di setting (ospedaliero, domiciliare e ambulatoriale) sono le linee guida prodotte dalla NICE e dal National System and Guidelines of New Zealand. Sulla base della nostra valutazione con metodo AGREE le linee guida prodotte dalla NICE sono quelle qualitativamente migliori e la cui implementazione nella pratica clinica risulta auspicabile.

\section{Approccio clinico al paziente con malnutrizione}

Il processo di cura nutrizionale deve essere diviso in una serie di step (Figura 1). Il piano di cura nutrizionale deve prevedere oltre una fase di screening per l'eventuale rischio di malnutrizione, anche una valutazione sullo stato nutrizionale e se indicato l'avvio di un piano nutrizionale.
Pertanto noi consigliamo i seguenti step:

- Tutti i pazienti ospedalizzati o degenti in strutture devono essere valutati all'accettazione per il rischio di malnutrizione. Dati obiettivi come l'altezza, il peso, eventuali recenti modifiche del peso, il problema clinico attuale e i dati anamnestici devono essere utilizzati per effettuare uno screening nutrizionale e valutare se il paziente è malnutrito $\mathrm{o}$ a rischio di malnutrizione. Una perdita di peso involontaria $\geq 10 \%$ rispetto al peso usuale negli ultimo 6 mesi o una perdita di peso $\geq 5 \%$ rispetto al peso usuale negli ultimo 3 mesi o un peso inferiore o superiore al $20 \%$ rispetto al peso ideale soprattutto in presenza di una malattia cronica o di fronte a incrementate richieste metaboliche o ad un inadeguato introito alimentare ad esempio conseguente a difficoltà deglutitorie o ad un inadeguato assorbimento intestinale sono fattori indicativi di malnutrizione. ${ }^{6}$

- Tutti i pazienti identificati con lo screening nutrizionale come malnutriti o a rischio di malnutrizione devono essere sottoposti ad una valutazione dello loro stato nutrizionale attraverso una combinazione di parametri clinici e laboratoristici per confermare la presenza di malnutrizione. Sono componenti della valutazione nutrizionale: i) dati anamnestici (età, sesso, la storia anamnestica attuale e pregressa, interventi chirurgici, farmaci assunti, uso di alcolici, dati psicosociali come lo stato economico, il livello educazionale, l'occupazione lavorativa, il livello di attività fisica e le attività giornaliere); ii) anamnesi dietologica (diario alimentare, osservazione del paziente durante i pasti) e attenzione ad eventuali problematiche connesse alla masticazione (dentizione) e alla deglutizione (disfagia); iii) valutazione clinica; iv) dati antropometrici: peso, altezza, BMI, circonferenza addominale; v) dati laboratoristici: proteine sieriche (prealbumina, albumina, transferrina), emocromo (conta linfocitaria) e dosaggio vitaminico - È necessario avviare un supporto nutrizionale per tutti i pazienti identificati come malnutriti o a rischio di malnutrizione. La nutrizione per via enterale deve essere la modalità di scelta. La nutrizione parenterale può essere utilizzata quando il tratto gastro-intestinale non è funzionante $o$ in pazienti che non sono adeguatamente nutriti attraverso una nutrizione orale o enterale.

\section{Gli strumenti della clinical governance: percorsi diagnostico-terapeutici-assistenziali e audit}

I professionisti sanitari sono quotidianamente chiamati a prendere decisioni relative a situazioni complesse, che possono riguardare la gestione di condizioni patologiche definite (ad esempio la malnutrizione), di problemi clinici (ad esempio la dispnea), di aspetti squi- 
sitamente organizzativi (es., organizzazione servizio di ecocardiografia) oppure la scelta di test diagnostici (ad esempio la scintigrafia miocardica) o di specifici trattamenti terapeutici (ad esempio trombolisi).

Le decisioni dei professionisti sanitari, di fronte alle medesime situazioni cliniche o organizzative, possono però soffrire di alcuni limiti come la variabilità, i difetti di congruità, appropriatezza e integrazione delle cure, che possono dipendere sia dalla soggettività delle scelte del singolo che dalle differenti condizioni in cui il professionista sanitario si trova ad operare. ${ }^{39}$

Le linee guida forniscono a questo proposito degli indirizzi di comportamento, delle raccomandazioni, suffragate da un livello più o meno alto di evidenze scientifiche, allo scopo di assistere il professionista sanitario nelle decisioni della sua attività quotidiana e di rendere quanto più possibile omogenee le scelte cliniche-assistenziali.

Le raccomandazioni delle linee guida e le evidenze derivanti da altri studi clinici che rappresentano la migliore pratica clinica a cui tendere devono però essere necessariamente contestualizzate nella realtà locale attraverso la costruzione di percorsi diagnostico-terapeutici-assistenziali (PDTA) (in inglese clinical o critical pathways) che rappresentano il migliore percorso attuabile per l'approccio ad una definita condizione patologica compatibilmente con le risorse locali disponibili.

I PDTA provengono, con le dovute modifiche, dal mondo industriale, proprio come altri strumenti di politica sanitaria (ad esempio l'audit clinico).

Così come per il mondo industriale, la traslazione dei PDTA nella medicina prevede che essi definiscano con chiarezza obiettivi, ruoli e compiti degli operatori sanitari, così da uniformare le prestazioni erogate e la loro riproducibilità, garantendo al contempo chiarezza nelle informazioni fornite agli utenti allo scopo di ridurre ritardi e sprechi, contenere le variazioni non necessarie nei trattamenti, assicurare la continuità e il coordinamento dell'assistenza, ridurre al minimo i rischi per i pazienti e migliorare gli esiti clinici. ${ }^{40}$

I passaggi necessari per costruire un PDTA sono i seguenti: i) scelta del tema; ii) Costituzione del gruppo di lavoro multiprofessionale e multidisciplinare; iii) analisi del percorso effettivo; iv) analisi del percorso ideale; v) creazione del percorso di riferimento e fase pilota; vi) diffusione, implementazione e aggiornamento del percorso assistenziale; vii) valutazione periodica degli indicatori di struttura/processo/risultato.

La scelta del tema è un momento basilare nella progettazione di un PDTA e consiste in un'attenta analisi dei bisogni della realtà in cui verrà applicato; in particolare il tema intorno al quale si decide di costruire un PDTA deve essere scelto sulla base della presenza di almeno una delle seguenti caratteristiche: i) alti volumi (qualcosa che viene fatto routinaria- mente o comunque con elevata frequenza); ii) alti costi (qualcosa che impieghi un'elevata quota di risorse); iii) alta rischiosità (qualcosa che espone a rischi elevati operatori e/o pazienti); iv) alta complessità (qualcosa che richiede un elevato livello organizzativo o clinicoassistenziale); v) alta variabilità (qualcosa che è soggetto a notevole eterogeneità di applicazione); vi) difetti di integrazione tra vari settori, come ad esempio tra ospedale e territorio.

La scelta del tema non può inoltre prescindere dalla disponibilità di linee guida pertinenti e di alta qualità.

Una volta ottenuta la fotografia della pratica clinica finora attuata (percorso effettivo) e l'orizzonte teorico a cui volgere lo sguardo (percorso ideale) va elaborato un percorso che sia il migliore possibile nella nostra realtà professionale, quello che chiameremo percorso di riferimento.

Per individuare la best practice si ricorre alla letteratura scientifica ed in particolare alle linee guida e, laddove queste non coprano tutti gli aspetti del percorso assistenziale, a revisioni sistematiche e studi clinici che rispondano ai quesiti in sospeso.

Il gruppo di lavoro esegue una complessa attività di adattamento al contesto locale delle raccomandazioni estrapolate dalla letteratura scientifica scelta come riferimento.

Questa è la fase più critica del progetto e per evitare di elaborare un prodotto inapplicabile è necessario, non solo che tutte le raccomandazioni siano evidence-based, ma che siano condivise dal gruppo di lavoro multiprofessionale e multidisciplinare ${ }^{41,42} \mathrm{e}$ che venga eseguita una simulazione del percorso così da identificare gli ostacoli applicativi che possono essere rappresentati da caratteristiche strutturali e/o organizzative, mancanza di tecnologie, carenze professionali (es., numero di operatori sanitari inadeguato, non adeguata competence del personale, ecc.), sociali, culturali, geografiche (es., interprete non disponibile in alcune fasce orarie, ecc.) e infine legati alle normative vigenti (es., note AIFA, ecc.). ${ }^{43}$

Se il documento guida ci dice what to do (che cosa fare), la creazione del percorso di riferimento esplicita who (chi), when (quando), how (come), where (dove), riducendo al minimo la possibilità di confusione e fraintendimenti.

Una delle modalità per descrivere schematicamente un PDTA prevede l'impiego dei diagrammi di flusso, rappresentazione grafica di un processo inteso come una sequenza di attività e snodi decisionali, realizzato secondo modalità standard in modo da rendere più semplice e immediata la comunicazione e la comprensione del processo a tutte le persone coinvolte. ${ }^{39}$

Esiste un'altra possibilità di raffigurare un percorso assistenziale: la rappresentazione a matrice. Questa più complessa tipologia nasce dal diagramma 
funzionale e, a differenza del diagramma di flusso semplice, permette in modo molto conciso di chiarire contemporaneamente le attività, gli attori coinvolti nella loro esecuzione, il luogo in cui devono essere svolte e le risorse impiegabili. ${ }^{39,40,44,45}$

Il documento inoltre, a partire dalle raccomandazioni o criteri scelti dalle linee guida ed adattati per essere applicati nella realtà locale, deve prevedere l'identificazione di alcuni indicatori, da valutare prima e dopo la messa a regime del percorso, per dimostrare la sua effettiva applicazione ed efficacia in termini di esito.

Le raccomandazioni o criteri, cioè la definizione esplicita di ciò che si ritiene utile misurare attraverso gli indicatori, devono essere evidence based, chiari, espliciti, condivisi dai professionisti, correlati ad aspetti rilevanti dell'assistenza sanitaria, traducibili in un indicatore e dunque misurabili, quantificabili.

Per ciascun criterio/indicatore deve essere individuato uno standard, cioè il valore soglia, il livello minimo accettabile a cui tendere nella soddisfazione del criterio/indicatore stesso nella realtà operativa presa in considerazione; è generalmente espresso in valore percentuale e deve essere, così come il criterio, Evidence based, condiviso dai professionisti, realistico e adattato al contesto locale.

L'indicatore è un rapporto tra due misure elementari, un numeratore ed un denominatore e permette di misurare le performance sanitarie al fine di confrontarle con lo standard precedentemente individuato.

Esistono tre possibili tipologie di indicatori quelli di struttura, processo ed esito.

A priori vanno stabiliti anche le modalità con cui dovranno essere raccolti i dati numerici per calcolare gli indicatori (raccolta di tipo prospettico o retrospettivo o mista) e quali fonti andranno consultate. È inoltre indispensabile stabilire il periodo di raccolta dei dati, cioè quanto deve durare la fase di raccolta dei dati ovvero che arco temporale deve coprire. Nel caso la raccolta sia di tipo prospettico non dovrebbero essere superate le 6-8 settimane per evitare un calo nella motivazione dei professionisti coinvolti, mentre ben più ampi sono i margini nel caso di modalità di raccolta dei dati di tipo retrospettivo.

Insieme agli altri elementi appena elencati va programmata anche la dimensione campionaria, cioè il numero di pazienti che dovrà essere valutato per poter giungere a conclusioni statisticamente valide, ricorrendo in alcuni casi anche a tecniche statistiche.

Alla stesura del percorso di riferimento deve far seguito una fase pilota che consiste nella implementazione del progetto solo in un sottoinsieme della realtà a cui esso sarà poi destinata per individuare aree di criticità non emerse durante la fase di stesura, identificare azioni incongruenti e analizzare l'effettivo impatto attraverso gli indicatori specifici.

Una volta che la fase pilota è stata ultimata con esito positivo è il momento di diffondere il progetto e successivamente di verificarne l'applicazione reale.

In particolare l'attività di verifica degli indicatori deve essere eseguita più volte nel tempo perché è ampiamente documentato dalla letteratura scientifica il manifestarsi di un fisiologico progressivo calo dell'attenzione dei professionisti nei confronti del percorso, con un conseguente rapido decadimento delle performance precedentemente ottenute.

Il calcolo degli indicatori ha lo scopo di produrre dei valori numerici che, come abbiamo già visto, devono essere confrontati con i valori standard a cui si dovrebbe tendere.

Infatti una volta ottenuta una fotografia della real practice (calcolo degli indicatori) va effettuato il confronto con la best practice (standard) e tramite l'impiego di tecniche statistiche relativamente semplici si ottengono stime quantitative dell'inappropriatezza sia in difetto che in eccesso.

Nel caso in cui si notino delle importanti discordanze tra il valore di uno o più indicatori e lo standard stabilito a priori, diventa importante mettere in atto delle strategie per facilitare il cambiamento dei comportamenti e migliorare la qualità delle cure e dell'assistenza.

Uno strumento, nato proprio con questo obiettivo, è l'audit clinico attraverso il quale, una volta identificate le criticità del processo in studio, il gruppo di lavoro stila un piano di azione che permetta di attuare il cambiamento e che definisca le azioni proposte, i responsabili di ciascuna azione, i tempi e le strategie di implementazione che accompagneranno le attività di miglioramento così da massimizzarne l'impatto.

Una volta effettuato lo sforzo volto a migliorare gli aspetti in cui sono emerse le performance più basse si passa poi alla fase di re-audit, quella che consente la valutazione e quantificazione dell'efficacia dei miglioramenti apportati e consiste nella ripetizione delle attività di rilevazione degli indicatori di processo ed esito e confronto con gli standard.

È molto importante che i cambiamenti positivi ottenuti vengano mantenuti nel tempo o, in altre parole, che il progetto sia inserito in un sistema di miglioramento continuo della qualità. Il team dovrà infatti sviluppare dei sistemi per monitorare e mantenere (o migliorare) nel tempo i risultati raggiunti.

\section{Razionale per la costruzione di un percorsi diagnostico-terapeutici-assistenziali sulla malnutrizione}

Abbiamo deciso di scegliere come argomento la gestione della malnutrizione in quanto soddisfa molti dei criteri necessari per la costruzione di un PDTA, già elencati nel paragrafo precedente: i) si tratta di un problema con alti volumi, infatti, come visto precedentemente, la malnutrizione in ospedale ha una incidenza 
del $30-55 \%$ a seconda delle casistiche; ${ }^{46}$ ii) la malnutrizione incrementa i costi che aumentano del 35-75\% rispetto a quelli richiesti dai pazienti non malnutriti; $; 7$ iii) vi è una alta variabilità nella gestione di questa problematica come dimostrato da studi internazionali; $6,7,48$ iv) sono disponibili linee guida recenti sulla gestione della malnutrizione e numerosi tools utilizzabili per lo screening e la diagnosi di questo problema. ${ }^{1,5,9,49}$

\section{Il progetto}

Il nostro progetto ha come primo obiettivo quello di scattare una fotografia istantanea delle modalità di individuazione e di gestione della malnutrizione nel paziente ricoverato presso 60 (Unità Operative di Medicina Interna diffuse in tutto il territorio italiano (tot al Nord, tot al Centro, tot al Sud). La nostra impressione, nata dal semplice confronto, è che le modalità di gestione di questo problema, in modo simile a quanto individuato nella letteratura internazionale, ${ }^{11}$ siano alquanto eterogenee.

Lo scopo di questa fase esplorativa è quello di individuare la prevalenza dei seguenti criteri: i) metodi standardizzati (MUST, etc.) utilizzati per lo screening dello stato nutrizionale dei pazienti con patologie croniche ricoverati nelle UO di Medicina Interna; ii) metodi standardizzati (MNA, subjective nutritional assessment, etc.) usati per diagnosticare una malnutrizione in pazienti con patologie croniche ricoverati nelle UO di Medicina Interna che risultano a rischio di malnutrizione con i metodi di screening; iii) interventi nutrizionali nei pazienti che risultano malnutriti sulla base dei metodi diagnostici utilizzati; iv) rivalutazione nutrizionale e degli intervalli tra una valutazione e l'altra durante il ricovero giudicati non a rischio di malnutrizione al momento del ricovero.

Per verificare i punti appena elencati sarà stabilito un giorno indice, il Nutrition Day, senza preavviso agli operatori sanitari, in cui un medico internista, che lavora nella UO a conoscenza dello studio in questione analizzerà le cartelle cliniche dei pazienti ricoverati affetti da patologie croniche relativamente alla presenza delle seguenti informazioni: i) la presenza di documentazione attestante la valutazione del rischio nutrizionale (screening nutrizionale) al momento del ricovero; ii) la presenza di documentazione della diagnosi di malnutrizione in pazienti giudicati a rischio di malnutrizione con $\mathrm{i}$ test di screening nutrizionale al momento del ricovero; iii) i metodi di screening nutrizionale utilizzati; iv) i metodi utilizzati per la diagnosi di malnutrizione; v) la presenza di documentazione di un piano nutrizionale specifico previsto in pazienti giudicati a rischio di malnutrizione o già malnutriti; vi) la documentazione di rivalutazione nutrizionale del paziente giudicato non a rischio di malnutrizione al momento del ricovero.

Ogni medico internista coinvolto sarà tenuto a compilare una scheda di raccolta dati in format cartaceo, successivamente registrerà i dati raccolti in un database elettronico, precedentemente fornitogli.

I dati di ogni Centro coinvolto verranno pertanto centralizzati per avere una stima globale degli indicatori di processo, oltrechè una stima relative ad ogni Centro (Tabella 5).

I dati ottenuti verrano sommati per valutare la stima globale per ciascun indicatore rispetto allo standard di riferimento ma verranno anche scorporati per singolo centro e nelle realtà in cui si individueranno scostamenti dagli standard verranno costruiti PDTA, cioè le raccomandazioni selezionate dalle linee guida per costruire gli indicatori verranno poi contestualizzate nei singoli Centri e rese esplicite sotto forma di percorso da applicare.

In particolare in accordo con la call to action del feedM.E. Global Study Group, ${ }^{50}$ gruppo internazionale esperto in materia di nutrizione, le linee generali del PDTA che verrà costruito per singolo Centro, ove necessario, saranno le stesse del clinical pathway proposto dal feedM.E. Global Study Group da applicare al

\section{Tabella 5. Indicatori di processo.}

Numero dei pazienti ricoverati sottoposti a screening per la valutazione del rischio di malnutrizione al momento del ricovero/numero totale dei pazienti ricoverati

Numero dei pazienti ricoverati giudicati a rischio di malnutrizione sottoposti a valutazione nutrizionale per la conferma di malnutrizione/ numero totale dei pazienti ricoverati giudicati a rischio di malnutrizione con i test di screening

Numero dei pazienti ricoverati affetti da malnutrizione per i quali è stato previsto un intervento nutrizionale adeguato/numero totale dei pazienti malnutriti

Percentuali dei diversi metodi utilizzati per lo screening e per la diagnosi di malnutrizione; descrizione dei metodi usati (questionari [MUST, MNA, NRS-2002], misure antropometriche (indice di massa corporea, spessore plica cutanea, ecc.), dati bioumorali (prealbumina, conta dei linfociti, ecc.)

La documentazione della rivalutazione nutrizionale nei pazienti giudicati non a rischio di malnutrizione al momento del ricovero

Numero di pazienti non a rischio di malnutrizione al momento del ricovero che sono stati nuovamente rivalutati con lo stesso metodo di screening/numero totale dei pazienti giudicati non a rischio di malnutrizione al momento del ricovero

MUST, malnutrition universal screening tool; MNA, mini nutritional assessment; NRS-2002, nutritional risk screening 2002. 
paziente ricoverato al momento, durante il ricovero e alla dimissione.

Per ciò che concerne la diagnosi il clinical pathway proposto dal feedM.E. Global Study Group suggerisce l'utilizzo del subjective global assessment per tutti gli adulti e il MNA per persone anziane; una volta individuato il paziente con malnutrizione lo stesso clinical pathway raccomanda un trattamento nutrizionale personalizzato entro 24-48 ore.

Successivamente allo sviluppo e all'implementazione del PDTA gli stessi indicatori verificati prima dell'applicazione dello stesso dovranno essere rimisurati ciclicamente e, in caso di persistenza degli scostamenti, messe in atto strategie di implementazione quali riunioni multi professionali e multidisciplinari e gruppi di miglioramento per discutere sul percorso e sulle variabilità gestionali individuate al fine di trovare delle strategie per migliorare le performance.

\section{Conclusioni}

L'attenzione alla nutrizione è un elemento imprescindibile per una pratica clinica di buona qualità che migliora gli esiti dei pazienti e riduce i costi legati alle complicanze.

Studi internazionali hanno già dimostrato che questo problema è purtroppo globalmente sottostimato e sottodiagnosticato nei pazienti ospedalizzati, ma non esistono evidenze scientifiche specifiche per il paziente ricoverato nelle UO di Medicina Interna, tipologia di pazienti spesso a rischio di malnutrizione o già malnutriti al momento del ricovero.

Il nostro progetto consiste nel documentare le modalità di screening, di diagnosi e di terapia della malnutrizione utilizzate in tot centri di Medicina Interna diffusi su tutto il territorio nazionale e nel caso in cui, come è probabile, si ravvedano delle incongruenze rispetto alle linee guida internazionali, nel seguire la call to action del feedM.E. Global Study Group attraverso lo sviluppo nei dettagli del clinical pathway proposto dallo stesso gruppo sottoforma di PDTA locali.

Il progetto prevede il controllo della reale applicazione di tali PDTA attraverso il calcolo di indicatori di processo che verrano ciclicamente calcolati; l'obiettivo è quello di avvicinare gli indicatori agli standard di riferimento, per fare ciò, nel caso di scostamenti, verranno messi in atto strumenti quali riunioni multi professionali e multidisciplinari e gruppi di miglioramento volti a migliorare l'implementazione dei PDTA.

\section{Bibliografia}

1. Mueller C, Compher C, Ellen DM. American Society for Parenteral and Enteral Nutrition (A.S.P.E.N.) Board of Directors. A.S.P.E.N. clinical guidelines: Nutrition screening, assessment, and intervention in adults. JPEN J Parenter Enteral Nutr 2011;35:16-24
2. Constans T, Bacq Y, Breechot JF, et al. Protein-energy malnutrition in elderly medical patients. J Am Geriatr Soc 1992;40:263-8.

3. Morley JE, Thomas DR. Anorexia and aging: pathophysiology. Nutrition 1999;15:499-503.

4. Kondrup J, Allison SP, Elia M, et al. ESPEN guidelines for nutrition screening 2002. Clin Nutr 2003;22:415-21.

5. White JV, Guenter P, Jensen G, et al. Consensus statement of the Academy of Nutrition and Dietetics/American Society for Parenteral and Enteral Nutrition: characteristics recommended for the identification and documentation of adult malnutrition (undernutrition). J Acad Nutr Diet 2012;112:730-8.

6. ASPEN Board of Directors and the Clinical Guidelines Task Force. Guidelines for the use of parenteral and enteral nutrition in adult and pediatric patients. JPEN J Parenter Enteral Nutr 2002;26:1SA-138SA.

7. Vetta F, Ronzoni S, Taglieri G, et al. The impact of malnutrition on the quality of life in the elderly. Clin Nutr 1999;18:259-67.

8. National Institutes of Health. Clinical guidelines on the identification, evaluation, and treatment of overweight and obesity in adults-the evidence report. Obes Res 1998;6:51S-209S.

9. McClave SA, Martindale RG, Vanek VW, et al. Guidelines for the provision and assessment of nutrition support therapy in the adult critically ill patient: Society of Critical Care Medicine (SCCM) and American Society for Parenteral and Enteral Nutrition (A.S.P.E.N.). JPEN J Parenter Enteral Nutr 2009;33:277-316.

10. Kirby DF, Delegge MH, Fleming CR. American Gastroenterological Association technical review on tube feeding for enteral nutrition. Gastroenterology 1995; 108:1282-301.

11. Singer P, Berger MM, Van den Berghe G, et al. ESPEN guidelines on parenteral nutrition: intensive care. Clin Nutr 2009;387-400.

12. K/DOQI, National Kidney Foundation. Clinical practice guidelines for nutrition in chronic renal failure. Am J Kidney Dis 2000;35:S1-140.

13. Bamgbola FO, Kaskel FJ. Uremic malnutrition-inflammation syndrome in chronic renal disease: a pathobiologic entity. J Ren Nutr 2003;13:250-8.

14. Kovesdy CP, Kopple JD, Kalantar-Zadeh K. Management of protein-energy wasting in non-dialysis-dependent chronic kidney disease: reconciling low protein intake with nutritional therapy. Am J Clin Nutr 2013; 97:1163-77.

15. Chung SH, Carrero JJ, Lindholm B. Causes of poor appetite in patients on peritoneal dialysis. J Ren Nutr 2011; 21:12-5.

16. Dent E, Visvanathan R, Piantadosi C, et al. Nutritional screening tools as predictors of mortality, functional decline, and move to higher level care in older people: a systematic review. J Nutr Gerontol Geriatr 2012;31:97-145.

17. McWhirter JP, Pennington CR. Incidence and recognition of malnutrition in hospital. BMJ 1994;308:945-8.

18. Gorman M. Development and the rights of older people. In: Randel J, ed. The ageing and development report: poverty, independence and the world's older people. London: Earthscan Publications Ltd.; 1999. pp 3-21.

19. Morley JE, Mooradian AD, Silver AJ, et al. Nutrition in the elderly. Ann Intern Med 1988;109:890-904. 
20. Roubenoff R. The pathophysiology of wasting in the elderly. J Nutr 1999;129:256S-9S.

21. Muscaritoli M, Anker SD, Argilés J, et al. Consensus definition of sarcopenia, cachexia and pre-cachexia: joint document elaborated by Special Interest Groups (SIG) "cachexia-anorexia in chronic wasting diseases" and "nutrition in geriatrics". Clin Nutr 2010;29:154-9.

22. Inelmen EM, Sergi G, Coin A, et al. An open-ended question: Alzheimer's disease and involuntary weight loss: which comes first? Aging Clin Exp Res 2010,22:192-7.

23. Barret-Connor E, Edelstein SL, Corey-Bloom J, et al. Weight loss precedes dementia in community-dwelling older adults. J Am Geriatr Soc 1996;44:1147-52.

24. Grundman M, Corey-Bloom J, Jernigan T, et al. Low body weight in Alzheimer's disease is associated with mesial temporal cortex atrophy. Neurology 1996;46: 1585-91.

25. Gazzotti C, Arnaud-Battandier F, Parello M, et al. Prevention of malnutrition in older people during and after hospitalisation: results from a randomised controlled clinical trial. Age Ageing 2003;32:321-5.

26. Lauque S, Arnaud-Battandier F, Mansourian R, et al. Protein-energy oral supplementation in malnourished nursing-home residents. A controlled trial. Age Ageing 2000;29:51-6.

27. Merli M, Riggio O, Dally L. Does malnutrition affect survival in cirrhosis? PINC (Policentrica Italiana Nutrizione Cirrosi). Hepatology 1996;23:1041-6.

28. Alberino F, Gatta A, Amodio P, et al. Nutrition and survival in patients with liver cirrhosis. Nutrition 2001;17:445-50.

29. Zaina FE, Parolin MB, Lopes RW, et al. Prevalence of malnutrition in liver transplant candidates. Transplant Proc 2004;36:923-5.

30. Alvares-da-Silva MR, Reverbel da Silveira T. Comparison between handgrip strength, subjective global assessment, and prognostic nutritional index in assessing malnutrition and predicting clinical outcome in cirrhotic outpatients. Nutrition 2005;21:113-7.

31. Wicks C, Somasundaram S, Bjarnason I, et al. Comparison of enteral feeding and total parenteral nutrition after liver transplantation. Lancet 1994;344:837-40.

32. Plauth M, Merli M, Kondrup J, et al. ESPEN guidelines for nutrition in liver disease and transplantation. Clin Nutr 1997;16:43-55.

33. Campollo O, Sprengers D, McIntyre N. The BCAA/AAA ratio of plasma amino acids in three different groups of cirrhotics. Rev Invest Clin 1992;44:513-8.

34. Steigmann F, Szanto PB, Poulos A, et al. Significance of serum aminograms in diagnosis and prognosis of liver diseases. J Clin Gastroenterol 1984;6:453-60.

35. Watanabe A, Higashi T, Sakata T, et al. Serum amino acid levels in patients with hepatocellular carcinoma. Cancer 1984;54:1875-82.
36. Tajiri K, Shimizu Y. Branched-chain amino acids in liver diseases. World J Gastroenterol 2013;19:7620-9.

37. Gluud LL, Dam G, Borre M, et al. Oral branched-chain amino acids have a beneficial effect on manifestations of hepatic encephalopathy in a systematic review with meta-analyses of randomized controlled trials. J Nutr 2013;143:1263-8.

38. Takeshita S, Ichikawa T, Nakao K, et al. A snack enriched with oral branched-chain amino acids prevents a fall in albumin in patients with liver cirrhosis undergoing chemoembolization for hepatocellular carcinoma. Nutr Res 2009;29:89-93.

39. Jensen GL, Bistrian B, Roubenoff R, Heimburger DC. Malnutrition syndromes: a conundrum vs continuum. JPEN J Parenter Enteral Nutr 2009;33:710-6.

40. Centers for Medicare \& Medicaid Services. Acute inpatient prospective payment system, DRG resources. Available from: http://www.cms.hhs.gov/AcuteInpatientPPS/

41. Agenzia Regionale per i Servizi Sanitari, Regione Piemonte. Raccomandazioni per la costruzione di percorsi diagnostico terapeutici assistenziali (PDTA) e profili integrati di cura (PIC) nelle aziende sanitarie della regione Piemonte; 2007.

42. Casati G, Panella M, Di Stanislao F, et al. Gestione per processi professionali e percorsi assistenziali. Manuale 1. Roma-Ancona: Progetto Formazione Qualità ISS, ARM, MS; 2005.

43. Grol R. Successes and failures in the implementation of evidence-based guidelines for clinical practice. Med Care 2001;39:II46-54.

44. Cinotti R. Manuale per gruppi di miglioramento. Bologna: Editore Clue; 2006.

45. GIMBE. Workshop "Dalle linee guida ai percorsi assistenziali”. Bologna; 2010.

46. Wilson J. Integrated care management. Br J Nurs 1998; 7:201-2.

47. Russo R. Profili di cura e profili assistenziali: obiettivi e metodologia. Politiche Sanitarie 2000:182-95.

48. Kaiser MJ, Bauer JM, Ramsch C, et al. Frequency of malnutrition in older adults: a multinational perspective using the mini nutritional assessment. J Am Geriatr Soc 2010;58:1734-8.

49. van Venrooij LM, van Leeuwen PA, Hopmans W, et al. Accuracy of quick and easy undernutrition screening tools-short nutritional assessment questionnaire, malnutrition universal screening tool and modified malnutrition universal screening tool-in patients undergoing cardiac surgery. J Am Diet Assoc 2011;111:1924-30.

50. Schindler K, Pernicka E, Laviano A, et al. How nutritional risk is assessed and managed in European hospitals: a survey of 21,007 patients findings from the 2007-2008 cross-sectional nutrition day survey. Clin Nutr 2010;29:552-9. 


\title{
La gestione del paziente con malattia celiaca: razionale e obiettivi
}

\author{
Tiziana Marcella Attardo, ${ }^{1}$ Elena Magnani, ${ }^{2}$ Carlotta Casati, ${ }^{3}$ Danilo Cavalieri, ${ }^{4}$ Pietro Crispino,${ }^{5}$ Federica Fascì Spurio, ${ }^{6}$ \\ Stefano De Carli, ${ }^{7}$ Daniela Tirotta, ${ }^{8}$ Paola Gnerre ${ }^{9}$
}

${ }^{1}$ UO di Medicina Interna, Ospedale Barone Lombardo di Canicattì, Asp 1 Agrigento; ${ }^{2} \mathrm{UO}$ di Medicina Interna, Ospedale M. Bufalini, Cesena AUSL Romagna, Cesena (FC); ${ }^{3} \mathrm{UO}$ di Medicina Interna, AOU Careggi, Firenze; ${ }^{4}$ Scuola di specializzazione in Medicina Interna, Policlinico Universitario Campus Bio-Medico, Roma; ${ }^{5}$ UO di Medicina Interna e d'Urgenza, ASP Potenza, PO di Lagonegro (PZ); ${ }^{6} \mathrm{UO}$ di Medicina Interna, Ospedale dell'Angelo di Mestre, Asl 12 Veneziana, Mestre (VE); ${ }^{7} \mathrm{SOC}$ II Medicina Interna, Ospedale S. Maria della Misericordia, ASUI di Udine; ${ }^{8}$ UO di Medicina Interna, Ospedale Cervesi, AUSL Romagna, Cattolica (RN); ${ }^{9}$ Medicina 2, Ospedale San Paolo, Savona, Italia

\section{RIASSUNTO}

La malattia celiaca (MC) è un disordine multigenico complesso che coinvolge fattori genetici - sia geni human leukocyte antigen complex (HLA) che non HLA -, fattori ambientali, l'immunità innata e adattiva, ed una forte componente autoimmunitaria cronica T-mediata. Di conseguenza, la MC non può più essere considerata una rara enteropatia ma deve essere inquadrata come una frequente patologia multiorgano, con manifestazioni sia gastrointestinali che extraintestinali, a patogenesi multifattoriale, caratterizzata da una forte predisposizione genetica, associata, in particolare, all' $H L A-D Q 2$ e $D Q 8$. L'obiettivo principale della presente monografia, avente come argomento la $\mathrm{MC}$, è stato quello di definire un approccio metodologico alla malattia, caratterizzata da un frequente ritardo nella diagnosi, sensibilizzando il clinico al management della stessa, nelle sue differenti presentazioni cliniche e nei diversi pazienti. È stata dedicata una particolare attenzione ai test specifici diagnostici al fine di definirne un corretto ed appropriato utilizzo e al follow-up della malattia e delle possibili complicanze. Inoltre uno spazio dedicato è stato assegnato alle forme di celiachia non responsiva o refrattaria ed all'ipersensibilità al glutine non celiaca. È stato anche inserito un sintetico excursus sugli aspetti legislativi in Italia che concernono la MC, considerata ancora al rango di malattia rara. La revisione delle linee guida inerenti la MC e la valutazione delle stesse attraverso l'Appraisal of Guidelines, Research and Evaluation II (AGREE II) ci ha permesso di catalogare le varie linee guida come adottabili o meno in relazione alla capacità di coinvolgimento degli stakeholders, alla loro applicabilità, al rigore metodologico, alla chiarezza espositiva e all'indipendenza editoriale. Infine è stata eseguita la ricerca delle più attuali evidenze scientifiche in ambito di MC al fine di produrre una monografia completa degli update più recenti.

\section{Introduzione}

Con la presente monografia sulla malattia celiaca (MC) ci siamo posti i seguenti obiettivi: i) sintetizzare i meccanismi fisiopatologici alla base della malattia; ii) offrire uno strumento pratico per definire un corretto iter diagnostico, anche grazie ad una approfondita conoscenza dei test specifici; iii) definire un approccio metodologico alla malattia appropriato ed integrato da nuove strategie, che agevoli il clinico nella diagnosi della malattia e nel suo management e lo faciliti nella valutazione e gestione dei casi non responders.

Corrispondente: Tiziana Marcella Attardo, UO di Medicina Interna, Ospedale Barone Lombardo di Canicattì, via Giudice Saetta, Canicattì, Asp 1 Agrigento, Italia.

Fax: $+39.0922 .733395 / 830125$

E-mail: claudia.fantucchio@alice.it

Articolo pubblicato secondo la Creative Commons Attribution NonCommercial 4.0 License (CC BY-NC 4.0).

CCopyright T.M. Attardo et al., 2016

Licensee PAGEPress, Italy

QUADERNI - Italian Journal of Medicine 2016; 4(3):71-96

\section{Definizione}

La MC o celiachia (dal greco кoı $\lambda i ́ a$, addome, ventre) è un'intolleranza alimentare autoimmune permanente, scatenata in soggetti geneticamente predisposti, dall'ingestione del glutine ${ }^{1}$ che è la frazione proteica alcol solubile del grano.

La principale proteina del glutine è la gliadina (AGA), di cui si distinguono quattro isoforme in base alla mobilità elettroforetica $(\alpha, \beta, \gamma$ ed $\omega)$.

Sebbene il termine glutine indichi propriamente solo il complesso proteico alcool solubile estratto dal grano, questo termine viene comunemente esteso alle corrispondenti proteine della segale e dell'orzo, rispettivamente ordeina e secalina, e dell'avena in considerazione della loro omologia di sequenze aminoacidiche e dell'effetto tossico che scatena nei celiaci. ${ }^{2}$

È, dunque, una reazione immunitaria verso il glutine che colpisce principalmente l'intestino tenue nei soggetti con una predisposizione genetica e che si risolve con esclusione del glutine dalla dieta. ${ }^{3}$

L'European Society for Pediatric Gastroenterology, Hepatology and Nutrition (ESPGHAN) nelle linee guida (LG) del 2012 ha sottolineato come negli anni la definizione della MC sia, in realtà, cambiata 
per cui da una rara enteropatia si è giunti a considerarla una frequente patologia multiorgano a genesi multifattoriale, caratterizzata, comunque, da una forte predisposizione genetica associata, in particolare, al sistema di istocompatibilità human leukocyte antigen complex (HLA)-DQ2 e HLA-DQ8. ${ }^{4}$

In essa, infatti, possono essere presenti sia sintomi gastrointestinali (dolore addominale, stipsi e/o diarrea croniche, nausea, vomito, distensione addominale) che extraintestinali (anemia cronica, demineralizzazione ossea con osteoporosi/osteopenia ed aumentato rischio fratturativo, difetti dello smalto dentario, irritabilità, astenia, neuropatia, artriti/artralgie, amenorrea, infertilità, ritardata pubertà, difetto staturale e/o deficit ponderale, elevazioni degli enzimi epatici, dermatite erpetiforme, stomatite aftosa, ecc). ${ }^{4}$

\section{Epidemiologia}

I primi studi epidemiologici sulla $\mathrm{MC}$, risalenti agli anni ' 50 , definivano la stessa come una malattia rara e quasi esclusivamente tipica dell'età pediatrica, con una prevalenza compresa all'incirca tra 1:4000 e 1:8000 tra gli Europei. ${ }^{5}$

In realtà questi studi si basavano su diagnosi fatte su quadri sintomatici di malassorbimento conclamati. Successivamente si è presa consapevolezza delle forme paucisintomatiche o asintomatiche di MC e, grazie all'introduzione nella pratica clinica dei test sierologici, è stato possibile comprendere la vera epidemiologia della MC.

Le forme sintomatiche di MC rappresentano soltanto la punta di un iceberg se si stima che, in linea teorica, per ogni caso con sintomi evidenti di malassorbimento, vi siano circa sette casi non clinicamente evidenti. Si calcola che, negli adulti, la diagnosi della malattia avvenga almeno dieci anni dopo l'insorgenza dei primi sintomi. ${ }^{6}$ In uno dei più vasti studi epidemiologici sulla popolazione pediatrica (17.201 bambini in età scolare, tra i 6 e i 15 anni) coinvolgente diverse regioni d'Italia e che ha utilizzato come test di screening il dosaggio degli anticorpi anti-AGA, la prevalenza di MC è risultata intorno a 1:184, con un rapporto tra casi diagnosticati e casi non diagnosticati pari a 1:7. ${ }^{7}$

Gli studi epidemiologici attuali, basati su test sierologici e conferma bioptica, suggeriscono una prevalenza della malattia compresa tra 1:70 e 1:300 nella maggior parte dei Paesi. ${ }^{8}$

La malattia è prevalente nel sesso femminile, con un rapporto maschi-femmine di 1:2,5.7

Studi di popolazione hanno riportato una certa variabilità nella prevalenza di $\mathrm{MC}$ tra le diverse popolazioni che non sempre trova una correlazione con la distribuzione del gene predisponente $D Q 2 / D Q 8$, né con un differente consumo di glutine.

Un'indagine multicentrica ${ }^{9}$ condotta su 29.212 bambini e adulti in diversi Paesi Europei (Finlandia,
Germania, Italia e Regno Unito) con uniformità di criteri diagnostici [screening della popolazione con anticorpi anti-transglutaminasi e conferma con anticorpi anti-endomisio (EmA) per i casi positivi o borderline] e con centralizzazione del dosaggio degli anticorpi, ha confermato la forte variabilità all'interno dei Paesi Europei della prevalenza della malattia nella popolazione generale.

La prevalenza globale in Europa nella popolazione adulta è risultata intorno all' $1 \%$, ma con un significativo range di variabilità che va dal $2,4 \%$ della Finlandia allo $0,3 \%$ della Germania, passando per lo $0,7 \%$ dell'Italia.

In Africa, nelle zone del Sahara Occidentale al confine tra Mauritania, Marocco e Algeria, i Sarahawi rappresentano una popolazione con la più alta prevalenza di malattia $(5,6 \%)$, scaturita da una frequenza del DQ2 superiore al $40 \%$ e dall'aumentato consumo di glutine nella dieta. Al contrario, nell'Africa subsahariana, il riscontro di casi è sporadico. ${ }^{10}$

Gli studi epidemiologici osservano anche un aumento di prevalenza della malattia con l'aumentare dell'età. Una survey italiana ha documentato che circa il 15\% delle nuove diagnosi riguarda pazienti ultrasessantacinquenni, come pure uno studio finlandese ha evidenziato una prevalenza di $\mathrm{MC}$ del $2 \%$ in persone asintomatiche tra i 52 e i 74 anni, con una prevalenza di MC nell'anziano stimabile superiore all' $1 \% .^{11,12}$

Esistono poi gruppi di persone, come i pazienti con diabete di tipo 1 , quelli con patologie autoimmuni della tiroide, le sindromi di Turner e di Down, i parenti di primo grado di pazienti con MC o con diabete di tipo 1 che, per fattori predisponenti, sono più a rischio di malattia e che possono arrivare a tassi di incidenza del $5-10 \%$. $^{13-16}$

In uno studio americano del $2003^{17}$ eseguito su 13.145 soggetti (4508 parenti di primo grado di pazienti con MC, 1275 parenti di secondo grado, 3236 pazienti sintomatici e 4126 individui non a rischio), la prevalenza della malattia è stata la seguente: i) a rischio, parenti di primo grado: 1 su 10; ii) a rischio, parenti di secondo grado: 1 su 39; iii) a rischio, pazienti sintomatici: 1 su 56; iv) gruppi non a rischio: 1 su $100 .{ }^{17}$

Alcuni studi, infine, sostengono che l'epidemiologia della MC stia cambiando, non solo per via dell'aumentata sensibilità diagnostica verso questa patologia, ma per un reale incremento della sua incidenza. ${ }^{18}$

\section{Eziopatogenesi}

La MC è un disordine multigenico complesso che coinvolge fattori genetici - sia geni HLA che non HLA -, fattori ambientali, l'immunità innata e adattiva, ${ }^{19}$ ed una forte componente autoimmunitaria cronica T-mediata. ${ }^{20}$ La relazione tra la $\mathrm{MC}$ e l'autoimmunità è supportata da studi immunologici che mostrano un legame tra la stessa e le malattie 
autoimmuni, in particolare il diabete mellito di tipo 1 e la tiroidite di Hashimoto. ${ }^{19}$

La suscettibilità alla MC è fortemente associata alle molecole di classe II dell'HLA, in particolare dall'HLA-DQ2 e HLA-DQ8, ${ }^{21}$ glicoproteine della membrana cellulare codificate dai geni $H L A-D Q A 1$ e $H L A-D Q B 1$, localizzati nella regione cromosomica $6 \mathrm{p} 21.3$.

Sebbene oltre il 90\% degli affetti da MC presenti questi due alleli, ${ }^{22}$ non tutte le persone HLA DQ2 e DQ8 positive sono affette da celiachia. La discrepanza nel tasso di concordanza tra i gemelli monozigoti e i gemelli dizigoti HLA-identici suggerisce il coinvolgimento di geni non-HLA, ${ }^{23}$ oltre che di fattori di suscettibilità ambientale.

La maggior parte di questi geni non-HLA, cui è attribuito solo il 3-4\% della suscettibilità genetica complessiva, codifica per proteine immunologicamente rilevanti che interessano la funzione della cellule presentanti l'antigene (APC) e dei linfociti T. ${ }^{23}$

L'alterazione immunologica dei pazienti celiaci determina lo sviluppo di anticorpi diretti contro la $\mathrm{AGA},{ }^{21}$ ma anche anticorpi anti-EmA e anti-transglutaminasi 2 (tTG2), enzima endogeno in grado di legare la AGA. ${ }^{23}$ La transglutaminasi tissutale (TG2 o TTG, autoantigene specifico della celiachia, fa parte di un gruppo di enzimi (appunto le transglutaminasi) in grado di catalizzare la formazione di legami covalenti tra un gruppo aminico libero (ad esempio di proteine o peptidi che presentano residui di lisina) ed il gruppo $\gamma$-carbossiamidico di proteine che presentano residui di glutammina.

Due sono le caratteristiche che renderebbero la gliadina in grado di innescare la risposta immune: per primo, l'alto contenuto in prolina che rende la molecola resistente alla degradazione delle proteasi salivari e gastriche, cosa che pertanto le permette di arrivare al lume intestinale come un lungo frammento di 10-50 amminoacidi; in secondo luogo, questo lungo frammento rappresenta il substrato per la TG2, la quale converte i residui di glutammina in glutammato, processo noto col nome di deamidazione. Questo processo rende la molecola elettronegativa e ne incrementa la capacità di legame con gli HLA DQ2 e DQ8.

La modifica post-traslazionale del glutine ad opera della TG2 si ritiene abbia un ruolo cruciale nella risposta CD4+ specifica, attraverso la creazione di un neo-antigene, ${ }^{23}$ che potrebbe risultare dal legame AGA-TG2 e dunque nella creazione degli anticorpi anti-TG2.

Le cellule T-CD4+ che riconoscono i peptidi deamidati presentati dalle molecole di HLA-DQ2 e DQ8 producono gamma interferone (IFN $\gamma$ ) che causa infiammazione e atrofia dei villi.

Inoltre il glutine stesso, indipendentemente dalla presentazione del complesso maggiore di istocompa- tibilità, può attivare le T-cell CD8+ della lamina propria (linfociti intra-epiteliali, IEL), espandendone la popolazione. $^{23}$

Le IELs attivate sono capaci di indurre l'apoptosi e incrementare l'espressione e attivazione dell'epidermal growth factor receptor. Alcuni studi hanno anche dimostrato la capacità da parte dei peptidi di AGA di attivare le molecole e le cellule dell'immunità innata, come i toll-like receptor 4 e le cellule natural killer (NK), e quindi di indurre la produzione di IFN $\alpha$ e di interleukina-15 (IL-15). ${ }^{23}$ L'IL-15 attiva i recettori delle cellule NK nei linfociti intraepiteliali (IELs); i IELs attivati distruggono l'epitelio attraverso la citolisi e la secrezione di IFN $\gamma$. Il trattamento con IFN $\alpha$ per l'epatite $\mathrm{C}$ può associarsi all'induzione della risposta infiammatoria anti-glutine e alla generazione di anticorpi anti-tTG. ${ }^{24}$ Per lo stesso motivo è forte l'associazione con la sindrome di Down: il gene che codifica per il recettore dell'IFN $\alpha$ è situato sul cromosoma $21 .^{25}$

Jabri e Sollid hanno ipotizzato che le cellule dendritiche intestinali stimolate dai mediatori pro-infiammatori come l'IL-15 e l'IFN $\alpha$ perdano il loro fenotipo di tolleranza genica e promuovano la differenziazione dei linfociti-T. ${ }^{23}$

Tra i fattori ambientali il primo è sicuramente l'assunzione di glutine. ${ }^{19}$

Alcuni autori hanno posto l'accento sulle infezioni da rotavirus; ricorrenti infezioni sono capaci di incrementare l'incidenza di MC, ${ }^{26,27}$ particolarmente nei pazienti con polimorfismi sfavorevoli in geni coinvolti nelle risposte virali. ${ }^{19}$

In uno studio, invece, sia la singola infezione da Citomegalovirus (CMV) che l'infezione combinata di CMV, Epstein Barr virus e/o Herpes simplex virus 1 erano associate in maniera inversamente proporzionale alla positività degli anticorpi tTG2, ipotizzando un effetto protettivo di alcune infezioni virali nella patogenesi della MC. ${ }^{28}$

Interesse crescente infine ha suscitato negli ultimi anni lo studio del microbiota intestinale, anche se allo stato attuale vi sono risultanti contrastanti.

Infatti mentre alcuni autori non hanno trovato differenze statisticamente significative tra pazienti con $\mathrm{MC}$ e i controlli sani, ${ }^{29}$ altri hanno riscontrato, nel microbiota proveniente da biopsie duodenali nei pazienti con celiachia, una riduzione di specie benefiche per l'organismo ed un aumento di quelle potenzialmente patogene, comparato con i controllo sani; tale disbiosi persisterebbe, anche se in misura minore, dopo l'inizio della dieta priva di glutine. ${ }^{30}$

\section{Presentazione clinica}

La MC è spesso difficile da riconoscere, con ritardo di diagnosi, per l'ampia variabilità di sintomi e segni con cui può presentarsi, con una probabilità di sintomaticità che va da 1 su 3 a 1 su 7 adulti con 
celiachia. ${ }^{31}$ I sintomi infatti possono presentarsi in qualsiasi età, dall'infanzia, all'adolescenza, all'età adulta.

La MC è una delle più comuni cause di malassorbimento intestinale. ${ }^{3}$ Il danno a carico dei villi del piccolo intestino provoca un ridotto assorbimento di micronutrienti quali le vitamine liposolubili, il ferro e, potenzialmente, l'acido folico e la vitamina B12. Di conseguenza diarrea, perdita di peso o mancato accrescimento in età pediatrica, dolore addominale e meteorismo rappresentano i più frequenti sintomi della MC. In altri casi la sintomatologia può essere più sfumata, interessare altri organi, piuttosto che l'intestino, o essere completamente assente (celiachia silente). ${ }^{32}$
Molti adulti, poi, affetti dalla malattia accusano solo astenia ed anemia (celiachia atipica). ${ }^{5}$

La Tabella 1 elenca le condizioni che si riscontrano nei celiaci più frequentemente rispetto alla popolazione generale (prevalenza almeno due volte superiore) e/o che possono trarre benefico da una dieta aglutinata (GFD) ${ }^{3}$

\section{Approccio diagnostico}

La Tabella 2 sintetizza i soggetti da sottoporre ai test diagnostici per MC [American College of $\mathrm{Ga}$ stroenterlogy (ACG) guidelines]. ${ }^{3}$

Tabella 1. Condizioni associate frequentemente a malattia celiaca e/o che possono trarre benefico da una dieta aglutinata.

\begin{tabular}{ll}
\hline Associazioni comuni & Associazioni meno comuni \\
\hline Malassorbimento sintomatico & Emosiderosi polmonare \\
\hline Diarrea con perdita ponderale & Infertilità inspiegata maschile o femminile \\
\hline Diarrea cronica con o senza dolore addominale & Dispepsia \\
\hline Ipoferritinemia con o senza anemia & Amenorrea \\
\hline Alterato metabolismo minerale ed osteoporosi precoce & Astenia cronica \\
\hline Meteorismo intestinale e flatulenza & Malassorbimento di terapia tiroidea sostitutiva \\
\hline Perdita ponderale inspiegata & Epilessia o atassia \\
\hline Ipertransaminasemia & Stipsi \\
\hline Accidentale riscontro endoscopico e istologico di atrofia dei villi intestinali & Coliche addominali ricorrenti \\
\hline Dermatite erpetiforme & \\
\hline Neuropatia periferica & \\
\hline Ulcere aftose del cavo orale & \\
\hline Difetto di accrescimento & \\
\hline Tireopatie & \\
\hline
\end{tabular}

Sindrome del colon irritabile

Discromie o perdita dello smalto dentario

Sindrome di Down e/o Turner

Tradotta e modificata da Rubio-Tapia et al., 2009. ${ }^{3}$

Tabella 2. Soggetti da sottoporre a test diagnostici per malattia celiaca.

Pazienti con sintomi, segni o esami di laboratorio suggestivi di malassorbimento, come ad esempio diarrea cronica con perdita di peso, steatorrea, dolore addominale post-prandiale o gonfiore addominale (raccomandazione forte, alto livello di evidenza)

Pazienti con sintomi, segni o esami di laboratorio per i quali la malattia celiaca rappresenta una possibile causa trattabile (per es., anemia sideropenica) (raccomandazione forte, moderato livello di evidenza)

Pazienti con un familiare di I grado che ha già una diagnosi certa di malattia celiaca in presenza di segni o sintomi o evidenze laboratoristiche compatibili con malattia celiaca (raccomandazione forte, alto livello di evidenza)

Parenti asintomatici con un familiare di I grado con diagnosi certa di celiachia (raccomandazione condizionale, alto livello di evidenza)

Presenza di rialzo delle aminotransferasi sieriche in mancanza di altra eziologia compatibile (raccomandazione forte, alto livello di evidenza)

Pazienti con diabete mellito di tipo I anche in assenza di sintomi digestivi o segni o evidenze di laboratorio compatibili con malattia celiaca (raccomandazione forte, alto livello di evidenza)

Tradotta e modificata da Rubio-Tapia et al., 2009. 


\section{Test diagnostici}

Il gold standard per la diagnosi è rappresentato dall'associazione tra sierologia e biopsia intestinale concordi, ${ }^{5}$ con una validità maggiore dei due test quando il paziente sta assumendo una dieta contenente glutine. Infatti, nei pazienti che già stanno effettuando una GFD, i test sierologici risultano negativi, mentre le biopsie possono risultare aspecifiche, mostrando solo una linfocitosi intraepiteliale, senza quindi le caratteristiche alterazioni strutturali. ${ }^{33} \mathrm{E}$ fondamentale quindi che il paziente continui ad assumere una dieta contenente glutine fino alla fine dei test diagnostici per evitare falsi negativi.

In alcuni casi selezionati, come nei pazienti con valori discordanti tra la sierologia e l'istologia, nei pazienti che stanno già effettuando una dieta gluten-free e non hanno precedentemente mai effettuato un test o quando vi siano riscontri istologici suggestivi (Marsh I-II) in pazienti sieronegativi, è raccomandato l'utilizzo di test ancillari, quali la ricerca dell'HLA-DQ2/DQ8. ${ }^{3}$

Vista la presenza di una predisposizione genetica, è raccomandata l'esecuzione dei test diagnostici anche per i pazienti asintomatici che però abbiano un rischio incrementato per celiachia, come ad esempio i pazienti affetti da diabete mellito tipo 1, deficit selettivo da immunogloguline A (IgA), epatiti autoimmuni, sindrome di Down, sindrome di Turner e di William, nonché i familiari di pazienti con MC diagnosticata. ${ }^{4}$

\section{Analisi anticorpale}

Il riconoscimento del glutine da parte degli HLA DQ2/DQ8 comporta l'attivazione della risposta immunitaria contro il glutine stesso, con conseguente comparsa a livello sierico di anticorpi specifici, principalmente di tipo IgA, diretti contro l'EmA, l'AGA e la tTG.

I marker sierici di celiachia comprendono, infatti, un ampio spettro di anticorpi, alcuni dei quali come gli anticorpi antireticolina R1 e gli anticorpi AGA sono test ormai superati e conservano solo poche indicazioni sul piano pratico, altri come gli anticorpi anti-EmA ed antitTG sono test altamente predittivi ed utilizzati nell'uso di routine, ed altri ancora come gli anticorpi diretti verso i peptidi deamidati di gliadina (DGP-AGA) sono test di recente introduzione con ottime prospettive per il futuro della diagnostica sierologica della celiachia. ${ }^{34,35}$

Gli anticorpi appartengono alla classe IgA ed IgG, ma in generale solamente gli anticorpi di classe IgA possono essere considerati marker altamente sensibili e specifici per l'intolleranza al glutine. L'impiego dei marker di classe IgG è spesso fuorviante a causa dell'elevata percentuale di falsi positivi ed il loro uso dovrebbe essere limitato ai pazienti con deficit di IgA, condizione strettamente associata alla celiachia.

Gli anticorpi anti-AGA, la cui determinazione è stata introdotta all'inizio degli anni ' 80 , sono stati il primo marcatore sierologico ad essere utilizzato nella pratica clinica. Il dosaggio degli AGA, sia IgG che IgA, con metodiche immunoenzimatiche (ELISA), pur avendo elevata sensibilità e specificità, rappresenta un test con una variabilità analitica molto elevata. Infatti non sono disponibili standard internazionali di riferimento per cui è esperienza diffusa il riscontro di risultati anche molto diversi da un laboratorio all'altro. ${ }^{36,37}$

La recente introduzione di metodi per la determinazione degli anti-tTG ha ridotto notevolmente l'impiego clinico degli AGA, anche se si può ritenere importante il loro utilizzo nella fascia di età da 0 a 5 anni, in considerazione delle evidenze di sieroconversione autoanticorpale riportate recentemente per la MC (tra i 5 e i 7 anni). ${ }^{38}$

$\mathrm{Al}$ momento i due test più validi per la diagnostica sierologica della celiachia sono gli EmA e gli antitTG. Gli EmA IgA, ricercati in immunofluorescenza indiretta (IFL), consentono di identificare il 94\% dei celiaci con una specificità praticamente assoluta. Positività fluttuanti sono stati descritte in parenti di primo grado di celiaci ed in pazienti con diabete mellito tipo 1. Gli EmA sono considerati il gold standard sierologico della celiachia nei laboratori di riferimento, mentre risultati deludenti sono frequenti nei laboratori senza esperienza per la lettura dei test in IFL. ${ }^{34,35,39}$

Il confronto fra EmA e anti-tTG mostra chiaramente che, sebbene il primo test sia più specifico, il secondo deve essere utilizzato come esame di prima scelta per lo screening della celiachia per la più elevata sensibilità, riproducibilità e disponibilità di substrato. Nella maggior parte dei laboratori gli EmA vengono attualmente utilizzati come test di conferma per i casi positivi per gli anti-tTG. ${ }^{34,35,30}$

Pertanto, attualmente il test di scelta nei pazienti di età superiore ai 2 anni è rappresentato dalla ricerca delle IgA dirette anti-tTG, ${ }^{4}$ a meno che non sia presente o sospetto un deficit da $\operatorname{Ig} \mathrm{A}$; in tal caso è ragionevole la ricerca di entrambe le immunoglobuline (IgA e IgG) verso le tTG come le IgG verso i DGP. ${ }^{40,41}$ Un deficit da IgA deve essere inoltre sospettato in caso di valori di tTG-IgA non determinabili. ${ }^{42,43}$ Tuttavia, in caso di normali valori sierici di $\operatorname{IgA}$, una positività isolata per le IgG degli anticorpi per la celiachia non ha la stessa rilevanza clinica, né specificità. ${ }^{44,45}$

La diagnostica sierologica della celiachia si è arricchita recentemente di un nuovo interessante marcatore, rappresentato dai DGP-AGA. La sensibilità di questo test è pari all' $84 \%$ sia per gli anticorpi di classe IgA che IgG, ma il dato più interessante è indubbiamente l'elevata specificità in particolare per la classe $\operatorname{IgG}(99 \%)$. Il confronto fra questo nuovo anticorpo ed i test tradizionali ha mostrato che i DGP-AGA hanno un'accuratezza diagnostica marcatamente più elevata di quella 
dei tradizionali AGA; inoltre, sebbene i DGP-AGA mostrino una sensibilità inferiore rispetto agli EmA e agli anti-tTG, la loro specificità per la classe $\mathrm{IgG}$, è così elevata da raggiungere quella degli EmA IgA e da superare quella degli anti-tTG IgA (Tabella 3). ${ }^{39}$

Può pertanto proporsi nel prossimo futuro una strategia anticorpale basata sulla determinazione combinata di anti-tTG IgA e DGP-AGA IgG. In questo modo i DGP-AGA IgG consentirebbero non solo di confermare la specificità degli anti-tTG ( $9 \%$ di falsi positivi), ma anche di identificare la presenza di celiachia nei pazienti con deficit di IgA. Inoltre, i DGP-AGA di classe IgG si sono rivelati un eccellente marcatore anticorpale per identificare i celiaci al di sotto dei due anni di età. La strategia anticorpale basata sulla ricerca combinata di anti-tTG IgA e DGP-AGA di classe IgG consentirebbe di ridurre il numero dei test necessari per lo screening sierologico di celiachia, eliminando in un sol colpo la necessità per EmA IgA, anti-tTG IgG ed AGA IgA (Tabella 3 e Figura 1). ${ }^{39}$

Infine gli anticorpi antiactina di classe IgA, ricercati in IFL, sono risultati positivi nel $50 \%$ circa dei celiaci con severo danno della mucosa intestinale e solo nel $10 \%$ dei pazienti con celiachia con lesioni intestinali minime (sensibilità media $30 \%$ ), ma sono dotati di elevata specificità per la celiachia. Sebbene gli anticorpi antiactina di classe IgA non possano sostituirsi agli EmA e agli anti-tTG come test di screening per la celiachia a causa della loro assai bassa sensibilità, il loro riscontro in soggetti che non possono essere sottoposti alla biopsia intestinale per una severa controindicazione (cardiopatia ischemica severa, gravi coagulopatie, insufficienza respiratoria, ecc.) può essere considerato un ulteriore elemento a supporto della esistenza di un severo danno dei villi intestinali compatibile con una condizione di MC (Tabella 3). ${ }^{39}$

In definitiva l'analisi anticorpale risulta utile sia per confermare la diagnosi di celiachia in pazienti con un'enteropatia durante l'assunzione di glutine, sia per selezionare i pazienti che dovranno essere sottoposti alla biopsia duodenale ${ }^{5}$ non dimenticando comunque che l'analisi anticorpale risulta negativa nel 6-22\% di casi di celiachia. ${ }^{46-49}$

Pertanto un ultimo importante messaggio da applicare nella pratica clinica è che se esiste un motivato sospetto clinico di celiachia fondato, ad esempio, sulla presenza di un'evidente sindrome da malassorbimento, bisogna procedere con la biopsia intestinale, anche in presenza di negatività dei marcatori anticorpali di celiachia, dal momento che una percentuale, anche se minima, di pazienti con celiachia presenta una sierologia del tutto negativa. ${ }^{39}$

La Tabella 4 riassume i criteri diagnostici anticorpali per MC. ${ }^{3}$

\section{Biopsia duodenale}

L'analisi morfologica del prelievo bioptico duodenale è uno strumento fondamentale per diagnosticare o escludere la MC, graduare la gravità del danno e identificare le possibili complicanze della patologia. Oltre alla conferma della diagnosi, l'esame istologico risulta essere di fondamentale importanza nella diagnosi differenziale con pattern endoscopici simili alla MC (Tabella 5).

Le biopsie dovrebbero essere prelevate a livello del bulbo (almeno 1) e dalla seconda e dalla terza porzione del duodeno (almeno 4). ${ }^{3}$ Una biopsia mirata del

Tabella 3. Confronto tra i marker sierologici per la diagnosi di celiachia.

\begin{tabular}{lccccccc}
\hline & & Caratteristiche diagnostiche & & & \multicolumn{2}{c}{ Caratteristiche tecniche } \\
\hline Anticorpo & Sensibilità (\%) & Specificità (\%) & $\begin{array}{c}\text { Valore pred. } \\
\text { pos. (\%) }\end{array}$ & $\begin{array}{c}\text { Valore pred. } \\
\text { neg. (\%) }\end{array}$ & Riproducibilità & Disponiblilità & Metodica \\
\hline Anti-tTG IgA & 97 & 91 & 91 & 97 & Elevata & Illimitata & $\begin{array}{c}\text { ELISA } \\
\text { (automatizzata) }\end{array}$ \\
\hline EmA IgA & 94 & 100 & 100 & 94 & $\begin{array}{c}\text { Medio-bassa } \\
\uparrow \text { Variabilità } \\
\text { interobserver }\end{array}$ & $\begin{array}{c}\text { Limitata carenza } \\
\text { substrati }\end{array}$ & $\begin{array}{c}\text { IFL indiretta } \\
\text { (manuale) }\end{array}$ \\
\hline AGA IgA & 73 & 87 & 84 & 77 & Elevata & Illimitata & $\begin{array}{c}\text { ELISA } \\
\text { (automatizzata) }\end{array}$ \\
\hline DPG AGA IgA & 84 & 90 & 89 & 85 & Elevata & Illimitata & $\begin{array}{c}\text { ELISA } \\
\text { (automatizzata) }\end{array}$ \\
\hline DPG AGA IgG & 84 & 99 & 98 & 87 & Elevata & Illimitata & ELISA \\
(automatizzata)
\end{tabular}

Anti-tTG, anticorpi antitransglutaminasi; EmA, antiendomisio; AGA, antigliadina; DPG-AGA, antipeptidi deamidati di gliadina. Modificata da Volta, $2009 .{ }^{39}$ 
bulbo duodenale, dalla posizione 9 alla 12 dell'orologio, aggiunta a quelle del duodeno, ha una sensibilità del $96 \%$ nella diagnosi di celiachia. ${ }^{44}$

Dal punto di vista istologico, la mucosa intestinale normale è costituita da un sottile strato di tessuto mu- scolare (muscolaris mucosae) ricoperto dalla lamina basale; verso la parte luminale sono presenti i villi intestinali, mentre verso la parte basale sono presenti le cripte o avvallamenti. In condizioni normali il rapporto villi: cripte è maggiore o uguale a 3:1, mentre in caso

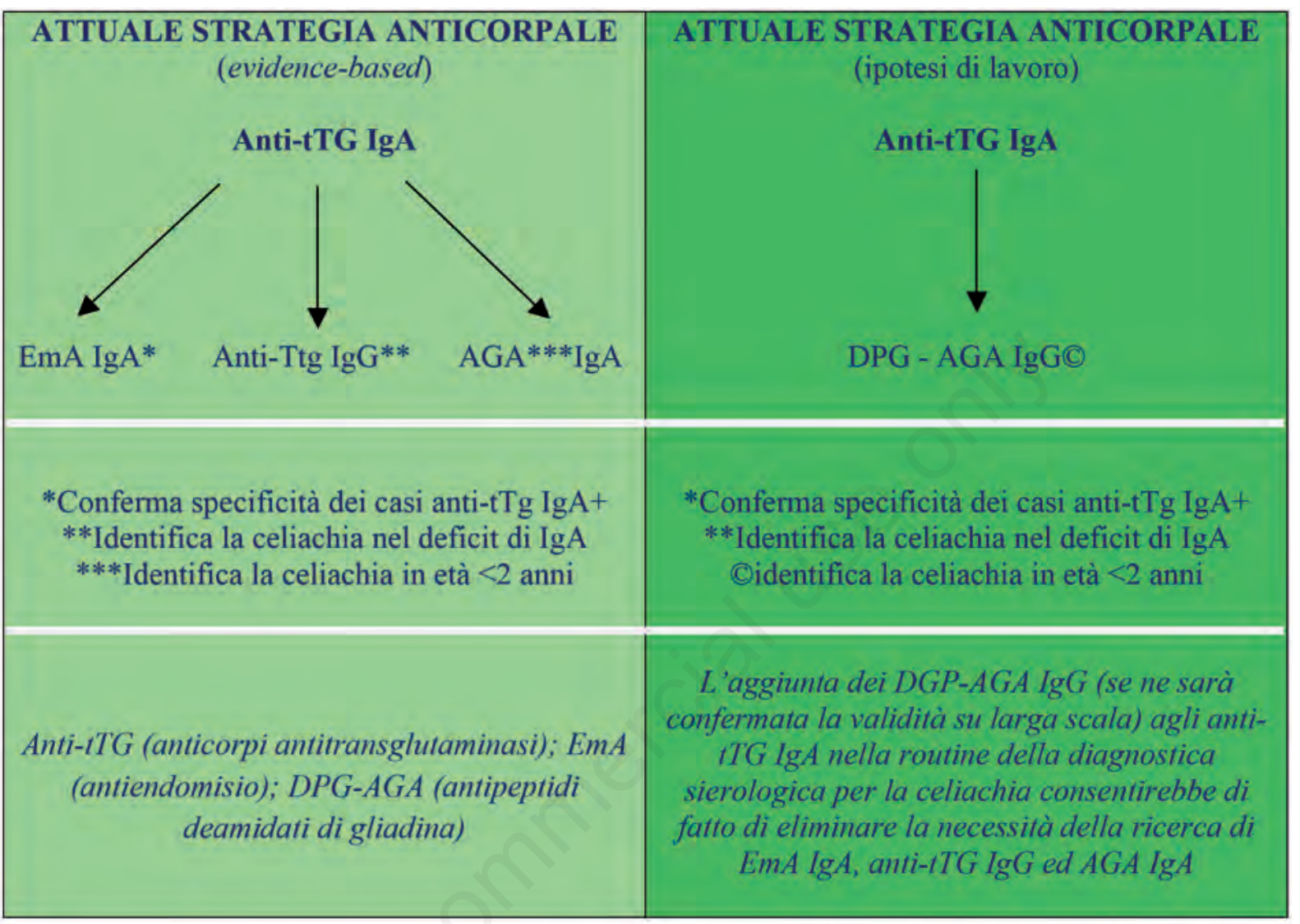

Figura 1. Confronto fra la strategia anticorpale attuale e quella ipotizzabile in un prossimo futuro per la diagnostica sierologica della celiachia. Modificata da Volta, 2009. ${ }^{39}$

Tabella 4. Diagnosi anticorpale di malattia celiaca.

\section{Raccomandazioni}

1. Anticorpi immunoglobuline $\mathrm{A}(\mathrm{IgA})$ anti-transglutaminasi (tTG) sono il test di scelta per la diagnosi di MC in soggetti con più di due anni di età (raccomandazione forte, alto livello di evidenza).

2. In casi di alta probabilità di MC, considerare la possibilità di deficit di IgA e determinare le IgA totali o, in alternativa, includere sia le IgA che le IgG, così come le DGP - IgG, nei pazienti ad alta probabilità di diagnosi di MC (raccomandazione forte, moderato livello di evidenza).

3. In pazienti con basse IgA o con deficit selettivo di IgA, eseguire determinazione di IgG (DGPs IgG e tTgIgG) (raccomandazione forte, moderato livello di evidenza).

4. Se il sospetto di MC è alto, eseguire biopsia intestinale anche se la sierologia è negativa (raccomandazione forte, moderato livello di evidenza).

5. Nei pazienti a regime alimentare contenente glutine, devono essere eseguiti tutti i test sierologici (raccomandazione forte, alto livello di evidenza).

6. Non sono raccomandati per la diagnosi di MC gli anticorpi anti gliadina (AGA) (raccomandazione forte, alto livello di evidenza)

7. Test combinati al posto delle sole TTG IgA possono marginalmente aumentare la sensibilità per MC ma riducono la specificità e quindi non sono raccomandati nella popolazione a basso rischio (raccomandazione condizionata, moderato livello di evidenza)

8. Quando si effettua lo screening per MC nei bambini con età inferiori ai due anni, la determinazione delle IgA tTG deve essere combinata a quella degli anti DGP (IgA and $\operatorname{IgG}$ ) (raccomandazione forte, moderato livello di evidenza)

Tradotta e modificata da Rubio-Tapia et al., 2009. ${ }^{3}$ 
di MC si osserva un progressivo appiattimento della mucosa fino ad arrivare alla completa atrofia dei villi, associata a ipertrofia delle cripte, con infiltrazione di cellule infiammatorie (plasmacellule, linfociti, eosinofili e mastociti) a livello della lamina propria e aumento della presenza di immunoglobuline (IgA, IgG ed $\mathrm{IgM}) .{ }^{50}$ Un altro effetto correlato allo sviluppo della malattia è la modificazione delle giunzioni strette (tight junctions) tra gli enterociti della mucosa intestinale. In condizioni normali queste giunzioni impediscono il passaggio di macromolecole verso la lamina propria fungendo da barriera impermeabile, mentre in presenza di MC si evidenzia una modificazione citoscheletrica degli enterociti che permette la migrazione dei linfociti verso le APC che in questo modo possono attivarsi. ${ }^{51}$

Il danno istologico riscontrato, però, è da considerarsi caratteristico ma non patognomonico, potendo essere, appunto, associato ad altre numerose patologie (Tabella 5).

Nella $\mathrm{MC}$, in genere, l'interessamento è prevalente a livello della mucosa della porzione prossimale del piccolo intestino, andando poi a decrescere in severità verso la porzione distale dello stesso, anche se talvolta è possibile avere un interessamento nelle porzioni più distali $i^{52,53} \mathrm{o}$ addirittura interessare la mucosa gastrica e rettale.

Normalmente, la severità e l'estensione del danno istologico sono correlate all'intensità dei sintomi clinici. ${ }^{54}$ Vi sono soggetti, poi, che possono presentare un quadro mucosale completamente normale, pur in presenza di positività anticorpale..$^{55-57}$
Esiste quindi uno spettro molto ampio dei possibili pattern istologici, variando dal mantenimento della normale architettura dei villi fino all'atrofia severa. ${ }^{58}$ Particolare attenzione deve essere fatta quando le biopsie vengono prelevate a livello del bulbo duodenale, dove la presenza di ghiandole del Brunner può portare ad una falsa diagnosi di atrofia: in questi casi è consigliato il confronto con le biopsie delle porzioni distali, soprattutto nelle fasi iniziali della malattia in cui si ha una progressione del processo patologico in senso cranio-caudale. ${ }^{59}$

Inoltre l'atrofia deve essere certa e non una pseudoatrofia legata ad un non corretto orientamento e taglio dei villi. In questi casi è consigliata la valutazione dei IELs che nella MC è sempre patologica ( $>25 / 100$ cellule epiteliali) ed è consigliabile effettuare in questi casi anche la colorazione immunoistochimica per CD3 in quanto consente una migliore visualizzazione dei linfociti. ${ }^{59}$

Un ulteriore elemento può essere la valutazione dei linfociti mediante anticorpi monoclonali anti-CD8; ciò è particolarmente utile nelle forme refrattarie di $\mathrm{MC}$, ovvero non rispondenti alla dieta (in particolare dei soggetti anziani), da molti considerate manifestazioni pre-linfomatose, nelle quali i linfociti $\mathrm{T}$ non esprimono il CD8. ${ }^{60}$

La classificazione istologica secondo Marsh, universalmente riconosciuta e validata, ${ }^{53,61}$ valuta l'orientamento dei villi, la presenza o meno di villi normali, il grado di atrofia degli stessi, la profondità delle cripte, il rapporto villo/cripta e il numero dei IELs.

Di recente, è stata proposta, a completamento, una

Tabella 5. Altre cause di atrofia dei villi nel duodeno.

\begin{tabular}{l}
\hline Sprue tropicale \\
\hline Overgrowth batterica del piccolo intestino \\
\hline Snteropatia autoimmune \\
\hline Morbo di Whipple \\
\hline Sprue collagena \\
\hline Enteropatia associata a farmaci (ad es., olmesartan, farmaci anti-infiammatori non-steroidei, chemioterapici, micofenolato) \\
\hline Morbo di Crohn \\
\hline Enterite eosinofila \\
\hline Linfoma intestinale \\
\hline Tubercolosi intestinale \\
\hline Enterite infettiva (ad es., da Giarda, citomegalovirus) \\
\hline Graft versus host disease \\
\hline Malnutrizione \\
\hline Enteropatia da sindrome dell'immunodeficienza acquisita \\
\hline Infezione da Helicobacter pylori \\
Tradotta e modificata da Rubio-Tapia et al, 2009. ${ }^{3}$
\end{tabular}

Tradotta e modificata da Rubio-Tapia et al., 2009.3 
modifica da parte di Oberhuber e coll. ${ }^{62,63}$ che prevede la suddivisione della lesione di tipo 3 di Marsh in tre sottogruppi.

Secondo questa classificazione, i pattern possono essere distinti in infiltrativi, iperplastici e atrofici (Tabella 6).

\section{Analisi genetica}

La suscettibilità alla celiachia è determinata, come sopra definito, in gran parte dal sistema HLA che, tuttavia, spiega soltanto il $30-40 \%$ del rischio genetico dato che, sebbene l'assenza sia di DQ2 che di DQ8 implichi l'impossibilità quasi certa di sviluppare la patologia, la loro presenza non comporta automaticamente l'insorgenza della stessa.

Sulla base dell'elevato valore predittivo negativo, la ricerca di questi tipi di HLA può, quindi, aiutare nell'esclusione della diagnosi di MC..$^{53,64,65}$

La ricerca di questi particolari HLA va riservata all'esclusione di MC in casi selezionati, quali, ad esempio, un riscontro istologico di reperti equivoci (Marsh I-II) in pazienti sieronegativi, la valutazione in pazienti che stanno già effettuando una dieta gluten-free in cui non sono mai stati effettuati altri test precedentemente, oppure nei pazienti in cui vi sia una discordanza tra istologia e sierologia specifica per MC o ancora in quei pazienti in cui vi sia il sospetto di celiachia refrattaria ma la diagnosi originaria di MC era dibattuta. ${ }^{3}$

L'utilità dei test per HLA in alcuni gruppi a rischio come i diabetici di tipo 1 o i parenti di I grado è limitata a causa dell'alta frequenza di alleli di suscettibilità per MC in questi soggetti (per esempio il 73\% dei parenti di I grado ha l'HLA-DQ2). ${ }^{3} \mathrm{Nel}$ caso, invece, dei soggetti con sindrome di Down l'HLA-DQ2 è presente solo nel 16\% nei pazienti EmA negativi, ma nel $88 \%$ in quelli EmA positivi per cui lo screening HLA può tornare utile in questi soggetti tenendo conto che negli Stati Uniti la prevalenza di MC nei soggetti Down è del 10\%. ${ }^{66}$

Un algoritmo diagnostico della $\mathrm{MC}$ è presentato nella Figura 2. ${ }^{3}$

\section{Ruolo della videocapsula endoscopica nella diagnostica della malattia celiaca}

La capsula endoscopica permette una visualizzazione non invasiva della mucosa del piccolo intestino. ${ }^{67}$ I risultati di una meta-analisi del 2012 evidenziano che la videocapsula endoscopica, presentando una sensibilità del $89 \%$ ed una specificità del $95 \%$ nella diagnostica della MC, può rappresentare una metodica diagnostica alternativa, specialmente in quei pazienti che non possono o non vogliono sottoporsi ad esame gastroscopico. ${ }^{67}$ Essa ha una maggiore (92 vs 55\%) sensibilità dell'esame endoscopico tradizionale nella valutazione delle lesioni atrofiche dei villi macroscopicamente evidenti, mentre la sua sensibilità è inferiore quando l'atrofia dei villi è parziale e nelle lesioni non atrofiche (stadio Marsh I-II); inoltre è in grado di diagnosticare le complicanze gravi della $\mathrm{MC}$ (quali stenosi, erosioni, ulcere e linfoma), come le lesioni associate alle forme di celiachia refrattaria di tipo II (vedi sotto) e quelle della celiaca non responsiva.

Nelle raccomandazioni delle linee guida ACG $2013^{3}$ l'utilizzo della videocapsula trova un limitato impiego per la valutazione della mucosa del piccolo intestino nei pazienti con forme complicate di celiachia (raccomandazione forte, moderato livello di evidenza).

\section{Ipersensibilità al glutine non celiaca}

L'ipersensibilità al glutine non celiaca (NCGS) o intolleranza al glutine è una condizione di cui non è ancora chiara la frequenza, la fisiopatologia, la storia naturale e la relazione con la MC, seppure esse siano ormai considerate in un unico spettro di disordini correlati al glutine. ${ }^{68}$

Nello studio prospettico multicentrico di Volta del $2014^{69}$ condotto su 486 pazienti, risulta una forte associazione tra NCGS, sesso femminile ed età adulta. La prevalenza è risultata leggermente maggiore rispetto alla MC ma si associa frequentemente alla Sin-

Tabella 6. Classificazione istologica della malattia celiaca.

\begin{tabular}{|c|c|c|c|c|}
\hline $\begin{array}{l}\text { Marsh modificata } \\
\text { (Oberhuber) }\end{array}$ & $\begin{array}{l}\text { Aumento dei linfociti } \\
\text { intraepiteliali* }\end{array}$ & $\begin{array}{c}\text { Criteri istologici } \\
\text { Iperplasia delle cripte }\end{array}$ & Atrofia dei villi & Corazza \\
\hline Tipo 0 & No & No & No & Nessuno \\
\hline Tipo 1 & Sì & No & No & Grado A \\
\hline Tipo 2 & Sì & Sì & No & \\
\hline Tipo 3a & Sì & Sì & Sì (parziale) & Grado B1 \\
\hline Tipo $3 b$ & Sì & Sì & Sì (subtotale) & \\
\hline Tipo 3c & Sì & Sì & Sì (totale) & Grado B2 \\
\hline
\end{tabular}

*>40 linfociti intraepiteliali per 100 enterociti per la classificazione di Marsh modificata (Oberhuber); >25 linfociti intraepiteliali per 100 enterociti per la classificazione di Corazza. Tradotta e modificata da Rubio-Tapia et al., 2009. ${ }^{3}$ 
drome dell'intestino irritabile (47\%), intolleranze alimentari (35\%), allergie IgE mediate (22\%) e ad altre malattie autoimmuni (14\%). Non si è riscontrata una correlazione significativa tra NCGS e positività per HLA-DQ2/-DQ8. Gli anticorpi IgG anti-AGA sono stati riscontrati nel $25 \%$ dei soggetti.

In questi pazienti, sono frequenti sintomi quali astenia psico-fisica, sonnolenza, sensazione di pienezza, dolore addominale o crampi, diarrea e talvolta costipazione ma in essi il glutine non causa i tipici danni alla mucosa del piccolo intestino, né le complicanze.

In una recente revisione sistematica è riportata una percentuale di prevalenza per NCGS molto ampia, tra 0,5-13\%. Nei pazienti con NCGS l'aplotipo HLADQ2/DQ8 è stato ritrovato nel $44 \%$ ed è stata rinvenuta una maggiore familiarità per $\mathrm{MC}$ e disordini autoimmuni. La dieta senza glutine è risultata migliorare in modo significativo la frequenza delle evacuazioni in pazienti con sindrome del colon irritabile variante diarroica e HLA-DQ2 positività. ${ }^{70}$ Non è possibile quindi differenziare la MC da NCGS dai soli sintomi o dalla scomparsa di questi con una dieta priva di glutine. ${ }^{71}$ Tuttavia al momento non esistono test diagnostici specifici e rimane quindi una diagnosi di esclusione una volta che $\mathrm{i}$ test diagnostici per la celiachia o per l'allergia al grano siano risultati negativi.

Nelle LG ACG $2013^{3}$ la diagnosi d'ipersensibilità al glutine potrebbe essere considerata dopo l'esclusione della MC con testi appropriati, sierologici e istologici (forte raccomandazione, moderato livello di evidenza).

La NCGS, infatti, presenta sintomi simili a quelli della celiachia che si risolvono con una dieta glutenfree, ma a differenza di essa, non presenta una predisposizione genetica, non è chiaro il coinvolgimento del sistema immunitario, non è associata a malassorbimento o deficit vitaminici o di nutrienti e non è associata ad un aumentato rischio di disordini autoimmunitari o a neoplasie intestinali. ${ }^{29}$ Pertanto queste significative differenze nella storia naturale della malattia e negli outcomes, impongono la differenzazione tra la MC e la NCGS. Infatti i celiaci, a differenza dei pazienti affetti da NCGS, devono essere informati dell'importanza di eseguire il follow-up della malattia, della necessità di praticare una stretta aderenza alla GFD e di sottoporre ai test per la celiachia i propri parenti di I grado.

La Tabella 7 confronta la MC con la NCGS e l'allergia al grano.

\section{Complicanze e follow-up}

La MC generalmente ha un decorso benigno e questo è avvalorato dai tassi di sopravvivenza a 5 anni che vanno dall' 80 al $96 \%$. $^{71,72}$

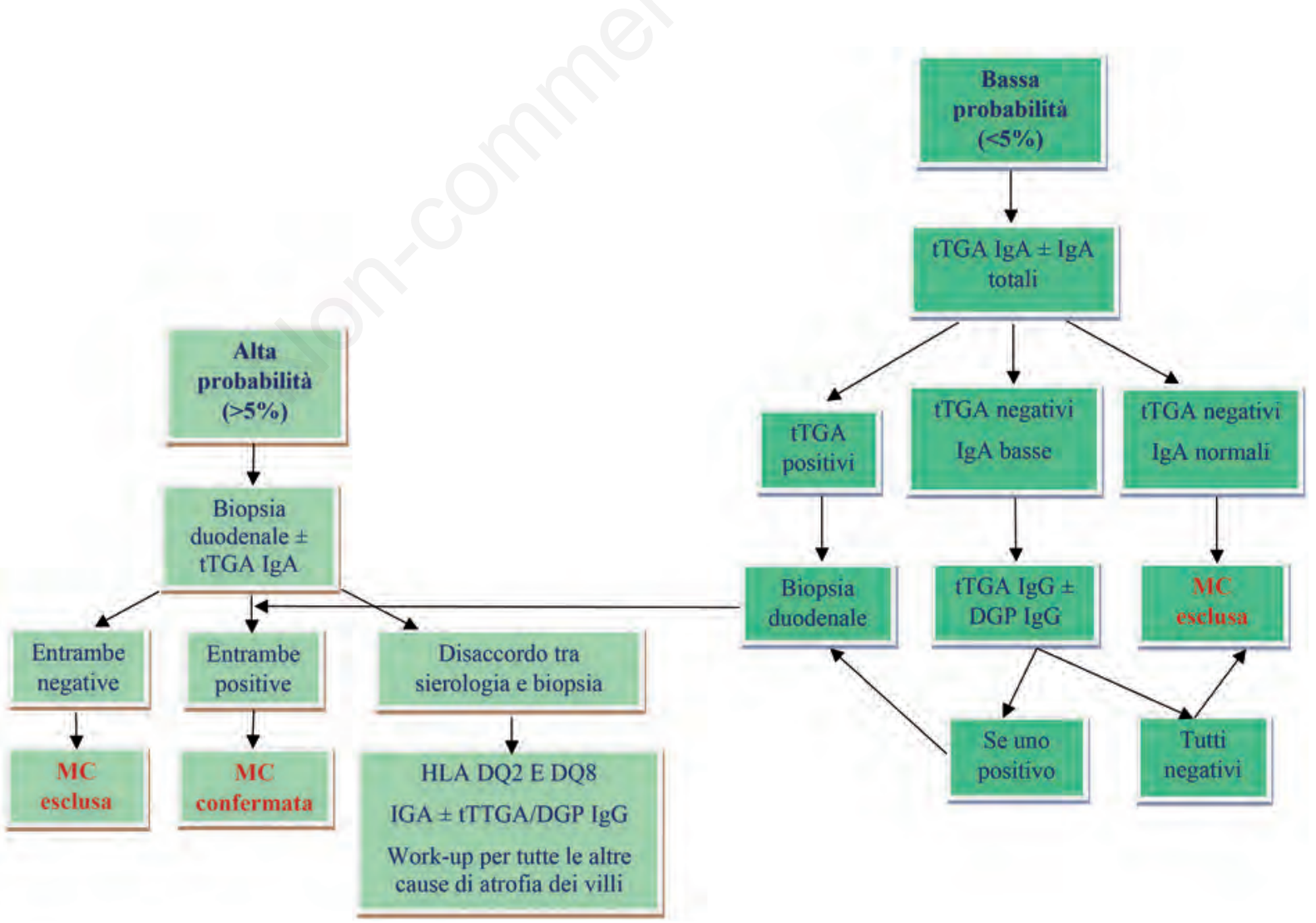

Figura 2. Algoritmo diagnostico per malattia celiaca (MC). Tradotta e modificata da Rubio-Tapia et al., 2009. ${ }^{3}$ 
La dieta priva di glutine è l'unico trattamento riconosciuto come efficace e allo stato attuale non esistono farmaci che, in maniera significativa e senza effetti collaterali, possano prevenire o risolvere il danno a carico della mucosa intestinale causato dalla esposizione al glutine. Sebbene il termine gluten-free implichi una completa eliminazione di tutte le fonti di glutine, in realtà ciò non è possibile a causa di possibile contaminazione degli alimenti con tracce di glutine. Pertanto il termine si riferisce, in maniera pratica, ad una dieta che contenga glutine in una quantità inferiore al livello massimo tollerato. Tale esatto livello al di sopra del quale il glutine diventa dannoso per la mucosa intestinale non è conosciuto, ma una recente review suggerisce che in molti pazienti quantità inferiori a $10 \mathrm{mg}$ al giorno potrebbero essere ben tollerate senza causare danno. ${ }^{73,74}$

Le uova non sono tossiche in più del $95 \%$ dei pazienti con $\mathrm{MC}$, anche se c'è un piccolo gruppo $(>5 \%)$ che non le tollera. Inoltre, in alcuni paesi c'è una certa reticenza a considerare l'introito libero di uova a causa delle difficoltà di garantire che le uova in commercio siano completamente assenti di contaminanti del grano. ${ }^{5}$

La dieta priva di glutine conduce, nella maggioranza dei casi, alla risoluzione dei sintomi e alla riparazione del danno della mucosa intestinale causata dalla precedente esposizione a tale proteina. La mancata aderenza alla dieta priva di glutine può condurre ad un progressivo incremento dell'incidenza di complicazioni con conseguenze sullo stato di salute dei paziente $\mathrm{e}$, in generale, ne aumenta il rischio di mortalità. In particolare nei pazienti con MC non trattati o non aderenti alla dieta priva di glutine risulta aumentato il rischio di complicanze neoplastiche, quali l'adenocar- cinoma del piccolo intestino, il cancro esofageo e il linfoma non-Hodgkin a cellule B e T. ${ }^{75}$ Infatti numerose evidenze suggeriscono che l'aumento della mortalità e della incidenza di neoplasia si riduca in tutti quei pazienti che aderiscano scrupolosamente alla dieta priva di glutine. ${ }^{76-78}$ Esiste evidenza, inoltre, che la dieta priva di glutine migliori i parametri nutrizionali negli adulti e nei bambini sintomatici, includendo un incremento del peso corporeo, del body mass index e della mineralizzazione ossea. ${ }^{79}$

La MC non trattata, invece, si associa ad un aumento della prevalenza di condizioni da ridotta densità minerale ossea (osteopenia ed osteoporosi) ed, in generale, è la causa principale di un aumentato rischio di fratture ossee in questi pazienti. ${ }^{80-83} \mathrm{Le}$ donne affette da MC hanno, poi, un aumentato rischio di infertilità, di aborti spontanei, di parti pre-termine e di partorire neonati con basso peso alla nascita. Il trattamento delle donne affette da MC con la GFD riduce questi rischi a tassi simili a quelli della popolazione generale..$^{84-87}$

Pazienti con $\mathrm{MC}$ non trattata sono più frequentemente carenti di micronutrienti rispetto alla popolazione sana, includendo carenza di ferro, ${ }^{88,89}$ acido folico, ${ }^{90}$ vitamina B12 e B6. ${ }^{91-93}$ La bassa densità minerale ossea nei pazienti con $\mathrm{MC}$ non trattati è in larga parte spiegabile alla luce di bassi valori di vitamina $D$, legati ad una deficienza dei processi di assorbimento intestinale. Altre condizioni di carenza di micronutrienti descritti nei paziente con MC includono il deficit di rame, di zinco e di carnitina. ${ }^{94,95}$ Alcune di queste carenze possono persistere, anche per un certo periodo di tempo, dopo l'instaurarsi di una corretta ed adeguata dieta priva di glutine ${ }^{96,97}$ Nei pazienti affetti da MC, sarebbe utile testare eventuali carenze di micronu-

Tabella 7. Confronto tra i disordini correlati al glutine.

\begin{tabular}{|c|c|c|c|}
\hline & Malattia celiaca & Non-celiac gluten sensitivity & Allergia al grano \\
\hline Definizione & $\begin{array}{l}\text { Disordine genetico ed autoimmune; } \\
\text { l'ingestione di glutine produce } \\
\text { un danno al piccolo intestino }\end{array}$ & $\begin{array}{l}\text { Intolleranza al glutine o ad un altro } \\
\text { componente del grano senza danno } \\
\text { al piccolo intestino }\end{array}$ & $\begin{array}{l}\text { Risposta immune ad una } \\
\text { o più delle proteine del grano }\end{array}$ \\
\hline Sintomi gastrointestinali & $\begin{array}{l}\text { Diarrea, gonfiore, } \\
\text { dolore addominale }\end{array}$ & $\begin{array}{l}\text { Diarrea, gonfiore, } \\
\text { dolore addominale }\end{array}$ & $\begin{array}{l}\text { Nausea, vomito, diarrea, gonfiore, } \\
\text { irritazione della bocca o della gola }\end{array}$ \\
\hline Segni extra-intestinali & $\begin{array}{l}\text { Perdita di peso, malnutrizione, } \\
\text { deficit di ferro, carie dentali, osteoporosi, } \\
\text { manifestazioni cutanee, disordini } \\
\text { neurologici, insufficienza epatica, } \\
\text { stanchezza, dolore articolare, } \\
\text { perdita di capelli }\end{array}$ & $\begin{array}{c}\text { Stanchezza fisica e mentale, } \\
\text { dolore articolare, } \\
\text { disordini neurologici }\end{array}$ & $\begin{array}{l}\text { Orticaria, vomito, diarrea, } \\
\text { congestione nasale, } \\
\text { irritazione oculare, dispnea }\end{array}$ \\
\hline $\begin{array}{l}\text { Positività dei test } \\
\text { autoanticorpali }\end{array}$ & Sì & Variabile (?) & No \\
\hline $\begin{array}{l}\text { Biopsia intestinale } \\
\text { patologica }\end{array}$ & Sì & No & No \\
\hline Trattamento & $\begin{array}{l}\text { Stretta aderenza ad una dieta } \\
\text { priva di glutine }\end{array}$ & $\begin{array}{c}\text { Aderenza variabile ad una dieta } \\
\text { priva di glutine/grano }\end{array}$ & $\begin{array}{l}\text { Stretta aderenza ad una dieta } \\
\text { priva di grano }\end{array}$ \\
\hline
\end{tabular}


trienti, sia al momento della diagnosi che dopo qualche tempo dall'inizio della dieta priva di glutine, per identificare la carenza potenziale di qualcuno di questi nutrienti, non altrimenti colmabile con la sola dieta.

Esiste un'universale condivisione sulla necessità di effettuare un monitoraggio a lungo termine dei pazienti affetti da MC. ${ }^{90} \mathrm{Il}$ controllo dei sintomi - se presenti -, dei fattori che facilitano l'aderenza alla dieta priva di glutine, la prevenzione o la diagnosi precoce delle complicanze, rappresentano un obiettivo fondamentale del monitoraggio della malattia dopo la diagnosi. ${ }^{98}$

Una review sistematica supporta il ruolo della stretta aderenza alla dieta priva di glutine nel controllo dei sintomi, nel miglioramento della qualità della vita di ciascun paziente e nella diminuzione del rischio di complicanze. ${ }^{99}$

Non è ancora del tutto chiaro se, nell'ambito di tutti i pazienti affetti da MC, sia utile perfezionare un follow-up specifico per alcuni soggetti.

A confermare l'efficacia della stretta sorveglianza, un follow-up annuale eseguito su una popolazione di 2245 pazienti che avevano uno stretto programma di sorveglianza, si associava ad un aumento della percentuale di negativizzazione degli anticorpi antitransglutaminasi del $99 \% .{ }^{100}$

Non ci sono sufficienti evidenze a supporto del ruolo centrale di un consulto dietologico nei casi di MC non rispondente a GFD o nei casi di sospetto di contaminazione da glutine. ${ }^{101,102}$

Ci sono numerosi metodi utili per stabilire la corretta aderenza alla dieta priva di glutine: esame clinico e dietologico, la sierologia, il follow-up istologico e la sorveglianza clinica. ${ }^{103,104}$

Una diminuzione del valori del test sierologico è attesa dopo alcuni mesi di stretta aderenza alla dieta priva di glutine. L'assenza di diminuzione o di normalizzazione dei valori sierologici dopo un anno di dieta priva di glutine è fortemente suggestiva di contaminazione dietetica da glutine. ${ }^{101}$ Non sempre, però, la sieroconversione dopo dieta priva di glutine coincide perfettamente con la guarigione delle lesioni della mucosa ${ }^{104,105}$ e l'unico metodo accurato per verificare che ciò sia accaduto è la ristadiazione istologica della malattia.

Tutti i pazienti con sintomi persistenti e ricorrenti, nonostante la dieta priva di glutine, richiedono studi clinici e strumentali, in aggiunta al semplice followup sierologico, al fine di eseguire una diagnosi precoce di malattia celiaca refrattaria (MCR). Ciò è corroborato dal fatto che negli adulti spesso, nonostante l'assenza dei sintomi e la negativizzazione della sierologia, è difficile ottenere la guarigione completa della mucosa intestinale. ${ }^{104-106}$ Ciò potrebbe aumentare il rischio di sviluppare negli anni successivi il linfoma intestinale, malattie secondarie del metabolismo osseo e una forma stabile di celiachia refrattaria. ${ }^{104,107}$

Pertanto, è ragionevole pensare ad un follow-up bioptico della mucosa digiunale dopo due anni dall' $i-$ nizio della dieta priva di glutine in tutti i pazienti con sierologia negativa ed assenza di sintomi per assicurarsi della completa guarigione della mucosa.

La persistenza di anticorpi antitransglutaminasi dopo GFD è significativamente associata a persistenza di lesioni istologiche ed è fortemente sospetta di scarsa aderenza alla dieta priva di glutine, ${ }^{108,109}$ ad un'eventuale anemia sideropenica refrattaria ${ }^{110} \mathrm{e}$ a carenza di rame.

L'aderenza a lungo termine alla dieta priva di glutine si associa ad un significativo miglioramento della densità ossea, specialmente in quei soggetti che aderiscono strettamente alle prescrizioni dietetiche. ${ }^{110}$ Anche se tali dati sono robusti, rimane sempre l'associazione della $\mathrm{MC}$ con un maggior rischio di fratture ossee $^{111-114} \mathrm{e}$ non ci sono evidenze tali da supportare i benefici protettivi della dieta priva di glutine nel ridurre il rischio di successive lesioni ossee.

Una carenza di vitamina B12 è presente in circa il $12 \%$ dei pazienti con $\mathrm{MC}$ che dovrebbe essere colmata con una adeguata dieta priva di glutine. ${ }^{91}$

La Tabella 8 elenca le principali raccomandazioni per il monitoraggio della MC.

\section{Malattia celiaca non responsiva o refrattaria}

La MCR può essere definita dalla persistenza dei sintomi e delle anomalie dei dati di laboratorio tipiche della celiachia anche dopo 6-12 mesi di dieta priva di glutine. ${ }^{102,115-117}$ La MCR è presente in percentuale variabile dal 7 al 30\% dei pazienti celiaci trattati con GFD. ${ }^{102,115,116} \mathrm{Ci}$ sono svariate cause che possono favorire l'insorgenza di una MCR di cui l'accidentale ingestione di glutine è la causa più frequente e, a seguire, la concomitanza con altre intolleranze alimentari, incluse quelle al lattosio ed al fruttosio, l'overgrowth batterico, la presenza di una concomitante colite microscopica, una concomitante insufficienza pancreatica, la malattia del intestino irritabile, oppure una vera e propria mancata risposta alla dieta priva di glutine. ${ }^{9,14,107,115,118-121}$

Per tale motivo, un'accurata valutazione è necessaria in tutti quei pazienti trattati che non mostrano una risoluzione clinica della malattia. ${ }^{102,115-117}$

Il primo step della valutazione di questi pazienti consiste nell'ottenere la conferma della diagnosi iniziale di celiachia, sottoponendoli a rivalutazione sierologica, endoscopica ed istologica. Se la diagnosi non è corretta, è mandatorio considerare altre diagnosi senza aspettare un'eventuale successiva risposta alla dieta priva di glutine. ${ }^{122}$

Nei casi in cui sia riconfermata la presenza della malattia, l'ingestione accidentale di glutine è la causa più frequente di MCR. ${ }^{102,115}$ In questi casi le indagini sierologiche possono essere di aiuto, se positive, a diagnosticare con certezza un'accidentale esposizione al 
glutine come causa di MCR. ${ }^{115}$ Ciò nonostante, siccome una sierologia normale non permette di escludere forme di MCR legate a piccole e discontinue contaminazioni dietetiche con glutine, in questi casi, è necessaria un'accurata valutazione delle abitudni alimentari da parte di un dietista specializzato nel management della MC. La valutazione deve inoltre comprendere la ricerca della coesistenza di intolleranze alimentari, come quella al fruttosio ed al lattosio. Quando qualsiasi causa dietetica di MCR è stata esclusa, è necessario integrare le indagini con una valutazione endoscopica ed istologica della malattia.

La presenza di un'enteropatia con atrofia dei villi intestinali può essere compatibile con MCR, overgrowth batterico intestinale o altre cause di atrofia dei villi. ${ }^{72,102,116,119}$ Un dato istologico anormale deve inoltre portare a ricercare altre possibili cause di MCR come la colite microscopica. ${ }^{102,115,116}$ Va precisato che sebbene non ci sono evidenze per ricercare in tutti i pazienti affetti da colite microscopica una $\mathrm{MC}$, una diagnosi di celiachia deve essere considerata in tutti quei casi in cui la colite microscopica non risponde al trattamento instaurato o sia associata a sintomi che sono indipendenti da questa e fortemente suggestivi di MC. ${ }^{123}$

In definitiva la MCR può essere definita come una condizione caratterizzata dalla persistenza o dalle frequenti recidive di sintomi o segni compatibili con malassorbimento, associate a dimostrazione istologica di atrofia dei villi intestinali, nonostante sia stata instaurata per più di 12 mesi una dieta priva di glutine ed in assenza di altri disordini, inclusi il linfoma intestinale. ${ }^{16,124,125}$

È possibile classificare la MCR in due forme distinte: i) la MCR di tipo 1, in cui l'infiltrazione dei linfociti nella mucosa del piccolo intestino è simile a quella dei soggetti con MC non trattata; ${ }^{126,127}$ ii) la MCR di tipo 2, in cui i linfociti T CD3-positive intrae- piteliali esibiscono un immunofenotipo anormale o atipico con la perdita dell'espressione dei normali markers di differenziazione presenti sulla superficie cellulare come quelli dei CD 8. ${ }^{126,127}$ Inoltre, l'analisi dei recettori delle T-cellule potrebbero rilevare una espansione oligoclonale presente in tutta la superficie della mucosa intestinale. ${ }^{126,127}$ La presenza di queste anormalità nelle cellule linfocitarie T nella MCR di tipo II è associata ad una prognosi nettamente sfavorevole rispetto a quella stimata per i pazienti con forme di MCR di tipo 1. ${ }^{119,120}$

Il management della MCR di tipo 1 include l'esclusione di un'ingestione accidentale di glutine come causa di una non conosciuta attività della malattia ed include una valutazione e conseguente eventuale trattamento di eventuali deficit nutrizionali. ${ }^{115,119,128}$ Spesso è necessario un trattamento sintomatico della diarrea al fine di ridurne l'impatto sulla qualità di vita dei pazienti. Nei casi più severi il trattamento medico tradizionale consiste nell'uso di steroidi sistemici quali il prednisone. Nei pazienti con risposta incompleta allo steroide o quando si evidenzi una ripresa o peggioramento dei sintomi nella graduale riduzione del dosaggio di questi farmaci, l'uso di farmaci immunosoppressori, come l'azatioprina, possono essere utili. Recenti reports hanno evidenziato che la budesonide o la mesalazina a meccanismo di rilascio nel piccolo intestino potrebbero essere efficaci nel trattamento di queste forme con il vantaggio di avere minori effetti collaterali. ${ }^{129-131}$

Il management della MCR di tipo 2 è lo stesso di quello decritto per il tipo $1^{72,118-120} \mathrm{ma}$ i sintomi e i segni di questa forma sono più severi e può essere richiesto, nei casi più gravi, un supporto nutrizionale parenterale. È questa sicuramente una forma più frequentemente gravata da un aumento delle mortalità che riguarda, in particolare, la trasformazione in

Tabella 8. Principali raccomandazioni per il monitoraggi della malattia celiaca.

\section{Raccomandazioni}

I pazienti con MC dovrebbero essere monitorizzati regolarmente sia per la comparsa di sintomi nuovi o residui, per valutare se aderenti o meno alla dieta priva di glutine e per diagnosticare precocemente le eventuali complicanze

Nei bambini, è raccomandata particolare attenzione alla comparsa o alla persistenza disegni o sintomi di mancata risposta alla dieta aglutinata al fine di assicurare una normale crescita e un corretto sviluppo staturo-ponderale

Un periodico follow-up medico dovrebbe essere eseguito da personale medico specializzato per la diagnosi e la cura della MC. Un consulto da parte di uno specialista dietologo dovrebbe essere prescritto a tutti quei pazienti in cui ci sia un sospetto di dieta contaminata da tracce di glutine

La verifica dell'aderenza alla dieta priva di glutine dovrebbe basarsi sulla storia anamnestica e clinica del paziente e sui dati sierologici [IgA tTG o IgA (o IgG) DGP anticorpi]

Una esofagogastroduodenoscopia con biopsie digiunali è raccomandata in tutti quei casi ove si verifichi una mancata risposta o una ripresa dei sintomi nonostante la corretta osservanza della dieta prive di glutine

Il monitoraggio dei pazienti con MC dovrebbe includere la verifica della normalizzazione dei dati laboratoristici specifici verificati come anomali durante la prima visita ambulatoriale o al ricovero

Tradotta e modificata da Rubio-Tapia et al., 2009. ${ }^{3}$ 
linfoma della malattia, la malnutrizione e la sepsi. I farmaci valutati nel trattamento di questa forma includono la budesonide con formulazioni enteroprotette, l'azatioprina o la 6-mercaptopurina, il methotrexate, la ciclosporina, gli anticorpi anti-TNF o la cladribina. ${ }^{118,128,132-135}$ La potenziale trasformazione in enteropatia associata a linfoma a cellule $\mathrm{T}$, a seconda dei casi, può richiedere anche un trattamento chirurgico, la chemioterapia o il trapianto di midollo osseo. ${ }^{136,137}$ Il linfoma T cellulare associato a MCR ha un decorso indolente con segni e sintomi non particolarmente aggressivi ma, a lungo termine, la prognosi globale, sia per le forme più aggressive sia per quelle indolenti, rimane infausta. ${ }^{137}$

\section{Complicanze neoplastiche}

La MCR è associata ad una prognosi infausta nella storia naturale della $\mathrm{MC}$ con una mortalità a 5 anni dal $44 \mathrm{al} 58 \% .^{71,72}$ Questo elevato tasso di mortalità è stato largamente attribuito alla sovrapposizione con il linfoma a cellule $\mathrm{T}$ che si riscontra in percentuali dal 33 al $52 \%$ entro i 5 anni dalla diagnosi. ${ }^{138,139}$ In particolare la MCR di tipo 2 è più frequentemente associata allo sviluppo del linfoma a cellule $\mathrm{T}$, in quanto la refrattarietà è substrato per l'accumulo di IELs nella mucosa intestinale con un fenotipo francamente aberrante ${ }^{126}$ che, quindi, si discosta dal normale fenotipo cellulare. Infatti questo fenotipo presenta la perdita dei normali markers espressi sulla superficie cellulare (Cd3, Cd14, Cd19 e Cd56) e manca dell' espressione del $\mathrm{Cd} 3$ intracellulare presente nelle normali cellule linfocitarie

T, B, NK e nelle altre cellule linfoidi. ${ }^{126}$ Di enorme rilevanza, per comprendere il ruolo della MCR nella genesi del linfoma, è l'espressione comune a queste cellule aberranti nel recettore funzionale dell'interleuchina 15 (IL-15). C'è evidenza, infatti, che nella MCR di tipo 2 esiste una up-regolazione di citochine del tipo IL-15 che viene prodotta dagli enterociti e che è causa della continua attivazione immunitaria dei IELs. ${ }^{140}$ L'aumento della risposta all'IL-15 ha come risultato sia l'espressione di proteine citotossiche sia uno stimolo alla produzione di IFN- $\gamma$ e NKG2D diretti contro gli enterociti. Il forte effetto anti-apoptotico dell'IL15 potrebbe essere spiegato dall'accumulo e dalla espansione di queste cellule a dispetto della loro bassa capacità proliferativa espressa in situ. ${ }^{141} \mathrm{Il}$ concetto della perdita della normale capacità di controllo dell'apoptosi da parte di queste cellule come conseguenza della crescita del segnale anti-apoptotico indotto dall'IL-15 è attraente e suggerisce la formulazione di un modello multistep che prevede che cellule aberranti sopravvivano grazie alla produzione incontrollata di citochine anti-apoptotiche. Nelle fasi successive della linfoma-genesi, questo substrato di cellule aberranti si espande in maniera clonale ed, infine, quando ap- paiono delle aberrazioni cromosomiche, queste cellule di trasformano con un fenotipo linfomatoso maligno.

Un regolare follow-up, che includa l'osservazione istologica delle biopsie digiunali, l'enterotomografia computerizzata o risonanza magnetica nucleare, o una tomografia a emissione di positroni, sono necessari per effettuare una diagnosi precoce. Il trattamento della MCR di tipo 2 rimane l'unico provvedimento in grado di prevenire la trasformazione linfomatosa. Come nella forma di MCR di tipo 1 gli eventuali deficit nutrizionali devono essere corretti; a differenza della forma di MCR di tipo 1 non c'è indicazione all'uso del farmaci immunosoppressori. ${ }^{142}$ Inoltre l'azatioprina potrebbe accelerare il rischio di una sovrapposizione linfomatosa di forme di MCR. ${ }^{71,143,144}$ Sebbene gli steroidi possono esercitare effetti clinici benefici, essi non hanno alcuna influenza nel frenare la possibile trasformazione in enteropatia associata a linfoma a cellule $\mathrm{T}$ e, specialmente, la pronta risposta terapeutica a tali farmaci non può escludere una sottostante condizione linfomatosa. ${ }^{142}$

Dato questo possibile sviluppo nei pazienti con MCR di tipo 2 di enteropatia associata a linfoma a cellule $\mathrm{T}$, l'obiettivo del trattamento è quello di distruggere la popolazione di cellule aberranti che in futuro potrebbero trasformarsi in linfoma. Gli IELs aberranti sono cellule con bassa capacità proliferative e quindi l'uso di farmaci citostatici non hanno dimostrato un reale beneficio nella cura di questa condizione. In realtà, la cladribina (2-clorodeossiadenosina) (2-A), una purina sintetica con nucleoside omologo, eserciterebbe il suo effetto citostatico inibendo la proliferazione e la divisione delle cellule linfoidi. ${ }^{145}$ Pertanto tale farmaco particolarmente attivo contro quelle forme maligne a basso grado di proliferazione, come la leucemia a cellule capellute, potrebbero essere efficaci anche nel trattamento delle forma di MCR di tipo $2 .{ }^{145}$

La Tabella 9 elenca le raccomandazioni per la MCR.

\section{Il paziente con malattia celiaca: gli aspetti legislativi}

Con il Decreto del Ministero della Sanità 18 maggio 2001, n. 279 la celiachia è stata inserita nell'elenco delle malattie rare con il codice RI0060, assieme alla dermatite erpetiforme. ${ }^{146}$ Questo nonostante la celiachia non potesse strettamente definirsi una patologia rara. Infatti, allora, la prevalenza della MC era stimata di 1:250 abitanti, mentre la definizione di malattia rara corrisponde ad una prevalenza non superiore a 1:2000 abitanti.

La normativa ministeriale prevedeva l'esenzione dal pagamento del ticket delle indagini, anche di tipo genetico necessarie per la diagnosi di patologia. Tale diritto era esteso anche ai familiari di primo grado (ge- 
nitori, figli, fratelli) del paziente affetto da celiachia. Nello stesso decreto si demandava alle regioni il compito di definire i centri che avessero le competenze per poter diagnosticare e certificare le patologie rare. Si istituiva, inoltre, la rete nazionale delle malattie rare con il compito di raccogliere la casistica, i dati dei pazienti (garantendone l'anonimato), i dati clinici e di laboratorio. Si affidavano inoltre ai centri la definizione della prescrizione delle prestazioni di diagnosi e di cura erogabili in esenzione dalla partecipazione al costo, secondo non meglio definiti criteri di efficacia e di appropriatezza rispetto alle condizioni cliniche individuali, facendo riferimento a protocolli emanati dagli stessi centri, in collaborazione con i presidi di rete.

Il Decreto Ministeriale emanato meno di un mese dopo, l'8 giugno 2001, ha invece permesso l'erogazione a carico del Servizio Sanitario Nazionale degli alimenti dei soggetti celiaci. Precedentemente, infatti, il legislatore aveva emanato norme finalizzate a riconoscere la peculiarità dell'alimentazione dei soggetti celiaci con l'intento di garantire la possibilità di seguire una GFD, in particolare con la garanzia dell'etichettatura dei prodotti dietetici destinati a popolazioni particolari, ma non erano previsti supporti economici per gli alimenti senza glutine certificati, ovvero contenenti una concentrazione di glutine inferiore a 20 parti per milione. Gli alimenti senza glutine hanno un costo economico aggiuntivo e tendono ad essere notevolmente più costosi di quelli convenzionali. Anche in molti altri Paesi i pazienti ricevono un'assistenza economica per compensare questo eccesso di costo. Tuttavia, tale assistenza varia notevolmente da Paese a Paese e anche all'interno di diverse regioni dello stesso stato, potendo essere completamente finanziato, deducibile dalle tasse, oppure, come supporto mensile che in Europa varia dai 20 ai 200 euro. ${ }^{147}$ In Italia si è scelta quest'ultima opzione, differenziando l'entità del contributo in base al sesso e all'età del paziente, ovvero in funzione del fabbisogno calorico: ${ }^{148}$ i) da 6 mesi a 1 anno, maschi $€ 45,00$ femmine $€ 45,00$; ii) fino a 3,5 anni, maschi $€ 62,00$ femmine $€ 62,00$; iii) fino a 10 anni, maschi $€ 94,00$ femmine $€ 94,00$; iv) età adulta, maschi $€ 144,00$ femmine $€ 99,00$.

Come malattia rara la definizione delle prestazioni da eseguirsi in regime di esenzione in fase diagnostica e difollow-up era demandata alle strutture abilitate alla certificazione di malattia. Alcune regioni, come il Piemonte, il Veneto e il Friuli-Venezia Giulia hanno quindi definito dei protocolli diagnostici e di followup della patologia, specificando anche le indagini che si possono eseguire per la diagnosi e il follow-up in regime di esenzione; altre invece non hanno prodotto alcun documento.

Con un documento datato 31 dicembre 2012, ${ }^{149}$ il Ministero della Salute ha aggiornato l'elenco delle strutture accreditate per la certificazione e per i centri di riferimento di secondo livello in Italia. Da questo documento emerge come ogni regione abbia definito una propria rete di centri in possesso dei requisiti per la certificazione. Tra queste si segnala come la regione Emilia-Romagna non abbia invece attribuito a specifiche Unità Operative la competenza di certificazione, permettendo pertanto a qualsiasi struttura di poterlo fare, come per le altre patologie invalidanti croniche. L'avvento dei nuovi livelli essenziali di assistenza (LEA) ha infatti in programma di classificare la celiachia da patologia rara a malattia cronica invalidante, ma desta perplessità che abbia escluso dall'elenco delle malattie rare anche le complicanze, in particolare la sprue refrattaria che invece hanno una prevalenza compatibile con la definizione. Tuttavia, rispetto alle patologie croniche invalidanti, nella proposta dei LEA, non sono definiti in modo vincolante le indagini da eseguirsi per il follow-up in regime di esenzione, definendo genericamente che lo sono tutte le indagini che il prescrivente ritenga utile. Con la pubblicazione del documento in Gazzetta Ufficiale n. 191 del 19 agosto 2015, ${ }^{150}$ il Ministero della Salute ha delegato a un gruppo di esperti il compito di definire linee guida di diagnosi e di fol-

Tabella 9. Raccomandazioni per il management della malattia celiaca refrattaria.

\section{Raccomandazioni}

I pazienti con malattia celiaca refrattaria (MCR) dovrebbero essere valutati accuratamente al fine di identificare e trattare la condizioni di non responsività secondo la specifica eziologia in ogni paziente

I primi step nella valutazione del paziente refrattario dovrebbero includere la valutazione dei testi sierologici specifici per MC ed una revisione specialistica delle abitudini dietetiche dello stesso, condotte da un dietista con esperienza nel management della MC

I fattori che consentono di stabilire la differenziazione tra MC refrattaria di tipo I e II deve essere ricercati con accuratezza in quanto ciò può influire sul decorso clinico della malattia e sulla prognosi

Il trattamento con farmaci, in associazione alla dieta priva di glutine, deve essere preso in considerazione in tutti i pazienti considerati nonresponders

I pazienti con MCR dovrebbero essere strettamente monitorizzati ed avere un supporto nutrizionale intensivo, includendo anche la nutrizione parenterale totale, laddove é indicato

Tradotta e modificata da Rubio-Tapia et al., 2009. ${ }^{3}$ 
low-up nazionali sulla celiachia mediante un consensus. In particolare è stata differenziata la diagnostica pediatrica, dove non sempre è necessaria la biopsia digiunale, da quella dell'adulto. Sono stati elencati i sintomi e le patologie più frequentemente associate alla celiachia, con l'intento di favorirne la diagnosi precoce. È cruciale il dosaggio delle IgA totali e del titolo anticorpale antitransglutaminasi che dev'essere eseguito in prima istanza, mentre non trovano indicazione gli anti-AGA. Gli EmA giocano, secondo tale protocollo, un ruolo in caso di debole positività del primo test, fornendo quindi indicazione all'esecuzione della biopsia digiunale, che, nell'adulto, invece, rimane essenziale per la diagnosi. Viene inoltre definita la cadenza del follow-up, ovvero un primo controllo a 6-12 mesi dalla diagnosi, controlli successivi ogni 1-2 anni, e non necessariamente ogni anno. Sono indicati quali esami ematochimici di approfondimento siano necessari alla diagnosi, ovvero quelli del metabolismo del ferro (sideremia, ferritina) e i folati che vanno eseguiti dopo il primo controllo solo se alterati o solo se l'emocromo è suggestivo di una loro carenza. Solo in questo caso andranno ripetuti annualmente fino a normalizzazione. Anche il dosaggio dell'ormone tireotropo e anticorpi antiperossidasi sono previsti alla diagnosi e, se normali, ripetuti ogni 3 anni. Il protocollo indica, inoltre, l'opportunità di eseguire nell'adulto, dopo i 18 mesi di GDF, una densitometria ossea, riservando i controlli successivi a discrezione del curante. I curatori del protocollo danno, comunque, la possibilità allo specialista di definire gli esami eventualmente necessari per il monitoraggio della patologia, delle complicanze e delle patologie correlate, mentre sottolineano cosa è sicuramente inappropriato: i) eseguire troppo precocemente, una volta avviata la dieta, il controllo del titolo degli anti-transglutaminasi, o eseguirlo troppo frequentemente; ii) sospettare la celiachia per sintomi acuti, anafilattici, anche gastrointestinali, che appaiono in stretta relazione temporale con l'assunzione del glutine; iii) iniziare una GFD come test di verifica, senza aver posto diagnosi di celiachia; iv) eseguire la tipizzazione della HLA come unica indagine diagnostica.

Il protocollo si sofferma inoltre sulla complicanza dell'iposplenismo, specie nel paziente con diagnosi tardiva, ma non indica l'opportunità di screening ecografico.

Non è invece previsto un ruolo diagnostico dell'indagine endoscopica con videocapsula e la cosa non stupisce essendo, attualmente, in Italia approvata solamente in caso di sanguinamento digestivo oscuro. ${ }^{151}$

\section{La gestione del paziente con malattia celiaca: metodologia}

Al fine di fornire raccomandazioni evidence-based per la gestione del paziente con $M C$, abbiamo innan- zitutto verificato l'esistenza di linee guida in merito.

Abbiamo, pertanto, condotto una ricerca utilizzando i seguenti database di linee guida:

- Scottish Intercollegiate Guidelines Network (SIGN)

- Institute for Clinical Systematic Improvement (ICSI)

- National Institute for Health and Clinical Excellence (NICE) (NHS evidence)

- National Guideline Cleringhouse (NGC)

- Agency for Healthcare Research and Quality (AHRQ)

- Canadian Medical Association, CMA infobase

- New Zeland Guidelines Group

- Sistema Nazionale Linee Guida (SNLG)

- Clinical Practice Guidelines Portal

- eGuidelines

La ricerca è stata eseguita da sei medici, indipendentemente, utilizzando come key words il termine celiac disease, quando il sito prevedeva la funzione di ricerca; negli altri casi, abbiamo scorso manualmente la lista delle linee guida archiviate nel database a partire dal 2007 fino al 2014.

I risultati ottenuti separatamente sono, poi, stati confrontati e discussi insieme.

Le linee guida così ottenute sono state valutate utilizzando lo strumento Appraisal of Guidelines, Research and Evaluation II (AGREE II) ${ }^{152}$ da cinque colleghi (quindi tutti i componenti del gruppo tranne una che si è dedicata, come vedremo, alla ricerca dei lavori per la valutazione post hoc), in maniera indipendente, al fine di identificare la/e linee guida qualitativamente migliore/i sull'argomento e il cui utilizzo è raccomandabile.

L'AGREE II è costituito da 23 item raggruppati in 6 dimensioni, oltre a 2 item di valutazione complessiva.

Esso è stato, infatti, sviluppato per gestire adeguatamente la variabile qualità delle LG grazie alla valutazione di sei differenti dimensioni o domini: gli obiettivi e gli ambiti di applicazione (analizza l'obiettivo generale della LG, i quesiti clinico-assistenziali a cui risponde la LG e la popolazione target - item 1-3), il coinvolgimento dei soggetti portatori di interesse (verifica l'entità del coinvolgimento di tutti gli stakeholders, oltre che il punto di vista dei potenziali utenti della LG - item 4-6), il rigore metodologico (analizza metodi e strumenti utilizzati per la ricerca bibliografica, la valutazione critica e la selezione delle evidenze scientifiche, la formulazione delle raccomandazioni cliniche e l'aggiornamento delle LG - item 7 14), la chiarezza espositiva (esamina il linguaggio, la struttura ed il formato delle LG - item 15-17), l'applicabilità delle stesse (analizza le possibili barriere e i fattori facilitanti l'implementazione delle LG, le possibili strategie per favorime l'adozione, l'implicazione sulle risorse economiche conseguenti alla loro applicazione - item 18-21) e, infine, l'indipendenza editoriale per escludere eventuali conflitti di interesse (item 
22-23). I due item di valutazione complessiva permettono, inoltre, di assegnare un punteggio alla qualità delle linea guida e di raccomandarne o meno l'utilizzo (sì, sì con modifiche, no).

Ciascun autore ha valutato il rispetto dei singoli requisiti con un punteggio da 1 (disaccordo completo) a 7 (accordo completo). I punteggi assegnati da ciascun autore sono stati sommati all'interno dei singoli domini e rapportati con il massimo e il minimo punteggio possibile all'interno del dominio in base al numero di requisiti inclusi e al numero dei valutatori.

Per l'assegnazione dello score di qualità, poi, abbiamo fatto riferimento al manuale AGREE II nella sua versione italiana di cui di seguito (Figura 3$)^{153}$ riportiamo le modalità di assegnazione.

Inoltre, un altro autore ha condotto una ricerca post-hoc delle evidenze disponibili in letteratura al fine di ottenere un elaborato aggiornato.

\section{La gestione del paziente con malattia celiaca: risultati}

Attraverso i database sopraelencati abbiamo identificato 9 linee guida che sono state successivamente valutate con il metodo AGREE II.

I risultati della valutazione sono riportati nella Tabella 10 da cui risulta che: i) la Linea guida $A C G C l i$ nical Guidelines: Diagnosis and Management of Celiac Disease del $2013^{3}$ è stata valutata adottabile da tutti gli autori, anche se con modifiche per tre di essi. Ha raggiunto elevati punteggi nella prima $(94,57 \%)$,

IV. Assegnazione dello score

Per ciascuna delle 6 dimensioni di AGREE II viene calcolato uno score di qualità. Gli score assegnati alle 6 dimensioni sono indipendenti e non devono essere aggregati in uno score unico.

\section{i) Calcolo dello score}

Lo score di ciascuna dimensione viene determinato sommando tutti gli score dei singoli item che la compongono, calcolando il totale come percentuale del punteggio massimo possibile per quella dimensione.

$$
\text { Esempio }
$$

\begin{tabular}{ccccc} 
& Item 1 & Item 2 & Item 3 & Totale \\
\hline Valutatore 1 & 5 & 6 & 6 & 17 \\
Valutatore 2 & 6 & 6 & 7 & 19 \\
Valutatore 3 & 2 & 4 & 3 & 9 \\
Valutatore 4 & 3 & 3 & 2 & 8 \\
\hline Totale & 16 & 19 & 18 & 53
\end{tabular}

Punteggio massimo possibile $=7$ (accordo totale) $\times 3$ (item) $\times 4$ (valutatori) $=84$

Punteggio minimo possibile $=1$ (disaccordo totale) $\times 3$ (item) $\times 4$ (valutatori) $=12$

Il punteggio calcolato della dimensione è:

Punteggio ottenuto - Punteggio minimo possibile

Punteggio massimo possibile - Punteggio minimo possibile

$\frac{53-12}{84-12} \times 100=\frac{41}{72} \times 100=0,5694 \times 100=57 \%$

Se alcuni item non vengono inclusi è necessario apportare le opportune modifiche nel calcolo dei punteggi massimi e minimi.

Figura 3. Modalità di calcolo dello score di qualità per ciascuna dimensione di AGREE II. ${ }^{153}$ 
nella quarta $(95,6 \%)$ e nella sesta dimensione $(85 \%)$; più bassi punteggi, invece, nelle restanti dimensioni. È stata la nostra LG di riferimento per la stesura della presente monografia, data la chiarezza delle raccomandazioni e la pronta applicabilità; ii) la linea guida World Gastroenterology Organisation Global Guidelines. Celiac Disease del $2013^{5}$ è stata giudicata adottabile per 4 su 5 valutatori. Essa ha conseguito elevati punteggi in tutte le dimensioni; iii) la linea guida European Society for Pediatric Gastroenterology, Hepatology, and Nutrition Guidelines for the Diagnosis of Coeliac Disease del $2012^{4}$ è stata valutata adottabile da tutti gli autori, anche se con modifiche per due di essi. Ha raggiunto elevati punteggi in tutte le dimensioni, tranne che per l'applicabilità dove il punteggio è stato del $50 \%$. Di rilievo il rigore metodologico nella stesura della presente linea guida che è mirata, comunque, all'ambito pediatrico; iv) la linea guida Diagnosis and management of adult coeliac disease: guidelines from the British Society of Gastroenterology ${ }^{154}$ é stata giudicata adottabile da tutti gli autori (da uno però con modifiche). Ha riportato elevati punteggi in tutte le dimensioni. Si distingue per la chiarezza espositiva e la ricchezza di algoritmi e tabelle: v) la linea guida $N A$ SPGHAN Guidelines del $2010^{155}$ è stata giudicata non adottabile da tutti gli autori. Essa ha ricevuto bassi punteggi, soprattutto nella terza dimensione che esplora il rigore metodologico e la sesta che valuta l'indipendenza editoriale; vi) la linea guida Joint BSPGHAN and Coeliac UK guidelines for the diagnosis and management of celiac disease in children del $2013^{156} \mathrm{è} \mathrm{di}$ ambito pediatrico. Essa è stata giudicata adottabile solo da un autore, con modifiche da altri due, mentre altri due autori l'hanno giudicata non adottabile. La linea guida in esame ha ricevuto bassi punteggi, al di sotto del $50 \%$, nella terza e nella quinta dimensione; alto, invece il punteggio per quanto riguarda la dimensione che esplora la chiarezza espositiva $(85,5 \%)$; vii) la linea guida NICE Coeliac disease Recognition and assessment of coeliac disease del $2009^{157}$ è stata valutata adottabile da tutti gli autori, anche se con modifiche per uno di essi. È la linea guida che ha ottenuto il più alto punteggio complessivo, con il $100 \%$ nella terza dimensione che esplora il rigore metodologico. Essa ha il merito, inoltre, di occuparsi del punto di vista del paziente e delle sue preferenze, come è caratteristico delle linee guida NICE; viii) la linea guida Linee guida celiachia - valutazione morfologica - AIC del $2008^{158} \mathrm{si}$ occupa unicamente della valutazione morfologica nella MC. Essa è stata giudicata non adottabile da tutti i valutatori, tranne che per uno che l'ha valutata adottabile ma dopo modifiche; ix) la linea guida AIC (Associazione Italiana Celiachia) Linee guida per la diagnosi ed il monitoraggio della celiachia e relative patologie associate e complicanze del $2008^{159}$ è stata giudicata non adottabile da tutti i valutatori, tranne uno. Ha rice- vuto punteggi molto bassi in tutte le dimensioni; nella terza dimensione, che riguarda il rigore metodologico, il punteggio è stato di appena $11 \%$.

\section{Analisi post hoc}

A completamento delle evidenze riportate dalle linee guida sulla MC è stata effettuata un'ulteriore ricerca su Pubmed e sono stati selezionati studi clinici randomizzati - controllati e revisioni sistematiche, pubblicati tra il 2013 e 2015, in lingua inglese, rispondenti al termine MESH celiac disease.

L'analisi ha compreso anche la valutazione delle LG NICE sulla MC edite a settembre 2015.

La nostra valutazione post hoc si è focalizzata sui nuovi dati epidemiologici, sul ruolo di fattori ambientali scatenanti quali la modalità di introduzione del glutine nello svezzamento, l'allattamento materno, sull'esposizione a certi a farmaci e il ruolo del microbiota intestinale.

Sono state analizzate alcune aree grigie ancora presenti nelle linee guida per l'inquadramento e la gestione dell'alterato metabolismo osseo nella MC.

Infine sono state riportate due delle nuove proposte farmacologiche ad integrazione della dieta senza glutine.

\section{Epidemiologia}

La review di Altobelli e colleghi del 2014 ha rivalutato i dati di prevalenza e incidenza di $\mathrm{MC}$ in Europa, considerando tutti gli studi condotti tra il $1970 \mathrm{e}$ il 2014 con l'impiego della ricerca sierologica specifica. Si riporta un'incidenza media compresa tra 0,1 e $3,7 / 1000$ nati vivi nella popolazione pediatrica e tra 1,3 e 39/100.000/anno nella popolazione adulta, con lo $0,5-1 \%$ di casi non diagnosticati.

Nell'ultima decade l'aumento di diagnosi che viene registrata è correlabile sia al miglioramento dell'accuratezza dei test sierologici (tTG ed EmA) che, in parte, ad una aumentata sensibilità medica alla diagnosi di MC. ${ }^{160}$ Vi sono differenze significative nella prevalenza di MC intra e inter-continente, in parte spiegabile con minori ricerche e studi di malattia in alcuni paesi. È però evidente un aumento del numero assoluto di nuovi casi diagnosticati e la predisposizione genetica ne risulta il fattore determinante. ${ }^{161}$

La meta-analisi di Yuan e colleghi sulla distribuzione di MC nella popolazione cinese ha evidenziato che il numero di casi riscontrati è, come noto, estremamente basso, imputabile, almeno in parte, alla scarsità di studi e ad una sottodiagnosi. Vi sarebbe, infatti, soprattutto in certe aree del paese, una maggiore prevalenza di predisposizione genetica per MC - in particolare in aree del Nord Ovest della Cina contrariamente a quanto ritenuto in passato (frequenza 
del $10,5 \%$ dell'allele DQB1*0201). Inoltre i consistenti cambiamenti alimentari nella popolazione, con l'aumento dell'introduzione di grano, soprattutto nelle aree rurali a nord del fiume YangTze, potrebbero in futuro contribuire ad una esposizione maggiore della popolazione allo sviluppo di malattia. ${ }^{162,163}$

A sfavore di un supposto maggior rischio generale di patologie e di mortalità nella popolazione con $\mathrm{MC}$ versus la popolazione generale, uno studio retrospettivo su 10.825 pazienti inglesi con MC, tra il 1998 e il 2012, ha documentato che nella popolazione con MC non vi era un maggior rischio di patologie digestive, respiratorie e neoplastiche, né un incremento della mortalità generale cardio-respiratoria. ${ }^{164}$

\section{Eziopatogenesi}

Sul contributo dei fattori ambientali nell'espressione di MC in soggetti geneticamente predisposti, due ampi trials clinici multicentrici randomizzati europei (Prevent CD e CELIPREV), pubblicati nel 2014 sul NEJM, non hanno dimostrato un' associazione si-

Tabella 10. Riepilogo degli score attribuiti dai valutatori alle linee guida selezionate sulla malattia celiaca per le diverse dimensioni secondo lo strumento AGREE II.

\begin{tabular}{|c|c|c|c|c|c|c|c|}
\hline Linee guida & $\begin{array}{c}\text { Dominio } 1 \\
\text { Obiettivo e } \\
\text { motivazione }\end{array}$ & $\begin{array}{c}\text { Dominio } 2 \\
\text { Coinvolgimento } \\
\text { delle parti } \\
\text { interessate }\end{array}$ & $\begin{array}{c}\text { Dominio } 3 \\
\text { Rigore nella } \\
\text { elaborazione }\end{array}$ & $\begin{array}{c}\text { Dominio } 4 \\
\text { Chiarezza } \\
\text { nell'esposizione }\end{array}$ & $\begin{array}{c}\text { Dominio } 5 \\
\text { Applicabilità }\end{array}$ & $\begin{array}{c}\text { Dominio } 6 \\
\text { Indipendenza } \\
\text { editoriale }\end{array}$ & $\begin{array}{l}\text { Giudizio } \\
\text { complessivo } \\
\text { (adottabile) } \\
\text { sì, sì con } \\
\text { modifiche, no }\end{array}$ \\
\hline $\begin{array}{l}\text { ACG Clinical Guidelines: } \\
\text { Diagnosis and Management } \\
\text { of Celiac Disease - } 2013^{3}\end{array}$ & $\begin{array}{l}102 / 105 \\
94,57 \%\end{array}$ & $\begin{array}{l}66 / 105 \\
56,7 \%\end{array}$ & $\begin{array}{c}177 / 245 \\
67,9 \%\end{array}$ & $\begin{array}{c}101 / 105 \\
95,6 \%\end{array}$ & $\begin{array}{c}92 / 140 \\
60 \%\end{array}$ & $\begin{array}{l}61 / 70 \\
85 \%\end{array}$ & $\begin{array}{c}\text { Adottabile nel } \\
100 \% \text { dei casi } \\
\text { (in } 3 / 5 \text { con } \\
\text { modifiche) }\end{array}$ \\
\hline $\begin{array}{l}\text { World Gastroenterology } \\
\text { Organisation Global } \\
\text { Guidelines }-2013^{5}\end{array}$ & $\begin{array}{l}92 / 105 \\
85,6 \%\end{array}$ & $\begin{array}{c}78 / 105 \\
70 \%\end{array}$ & $\begin{array}{c}166 / 245 \\
62,4 \%\end{array}$ & $\begin{array}{l}83 / 105 \\
75,5 \%\end{array}$ & $\begin{array}{c}117 / 140 \\
80,8 \%\end{array}$ & $\begin{array}{c}55 / 70 \\
75 \%\end{array}$ & $\begin{array}{l}\text { Adottabile nel } \\
80 \% \text { dei casi } \\
\text { (in } 2 / 5 \text { con } \\
\text { modifiche) }\end{array}$ \\
\hline $\begin{array}{l}\text { European Society for } \\
\text { Pediatric Gastroenterology, } \\
\text { Hepatology, and Nutrition } \\
\text { Guidelines for the Diagnosis } \\
\text { of Coeliac Disease 2012 }\end{array}$ & $\begin{array}{l}98 / 105 \\
92,2 \%\end{array}$ & $\begin{array}{l}95 / 105 \\
88,9 \%\end{array}$ & $\begin{array}{c}191 / 245 \\
90,9 \%\end{array}$ & $\begin{array}{c}96 / 105 \\
90 \%\end{array}$ & $\begin{array}{c}80 / 140 \\
50 \%\end{array}$ & $\begin{array}{l}60 / 70 \\
83,3 \%\end{array}$ & $\begin{array}{c}\text { Adottabile nel } \\
100 \% \text { dei casi } \\
\text { (in } 2 / 5 \text { con } \\
\text { modifiche) }\end{array}$ \\
\hline $\begin{array}{l}\text { Diagnosis and management } \\
\text { of adult coeliac disease: } \\
\text { guidelines from the British } \\
\text { Society of Gastroenterology } \\
2014^{154}\end{array}$ & $\begin{array}{l}77 / 105 \\
85,6 \%\end{array}$ & $\begin{array}{l}75 / 105 \\
83,3 \%\end{array}$ & $\begin{array}{c}229 / 245 \\
92,3 \%\end{array}$ & $\begin{array}{c}96 / 105 \\
90 \%\end{array}$ & $\begin{array}{c}116 / 140 \\
80 \%\end{array}$ & $\begin{array}{c}45 / 70 \\
75 \%\end{array}$ & $\begin{array}{l}\text { Adottabile nel } \\
100 \% \text { dei casi } \\
\text { (in } 1 / 5 \text { con } \\
\text { modifiche) }\end{array}$ \\
\hline $\begin{array}{l}\text { A Summary of the } \\
\text { NASPGHAN Guidelines } \\
2010^{155}\end{array}$ & $\begin{array}{l}46 / 105 \\
34,4 \%\end{array}$ & $\begin{array}{l}32 / 105 \\
18,9 \%\end{array}$ & $\begin{array}{l}62 / 245 \\
12,8 \%\end{array}$ & $\begin{array}{l}58 / 105 \\
47,8 \%\end{array}$ & $\begin{array}{l}51 / 140 \\
25,8 \%\end{array}$ & $\begin{array}{l}18 / 70 \\
13,3 \%\end{array}$ & $\begin{array}{c}\text { Non adottabile } \\
\text { nel } 100 \% \\
\text { dei casi }\end{array}$ \\
\hline $\begin{array}{l}\text { Joint BSPGHAN and } \\
\text { Coeliac UK guidelines } \\
\text { for the diagnosis and } \\
\text { management of celiac } \\
\text { disease in children } 2013^{156}\end{array}$ & $\begin{array}{l}70 / 105 \\
77,7 \%\end{array}$ & $\begin{array}{l}57 / 105 \\
63,3 \%\end{array}$ & $\begin{array}{l}83 / 245 \\
39,5 \%\end{array}$ & $\begin{array}{l}77 / 105 \\
85,5 \%\end{array}$ & $\begin{array}{l}50 / 140 \\
41,6 \%\end{array}$ & $\begin{array}{l}46 / 70 \\
76,7 \%\end{array}$ & $\begin{array}{c}\text { Adottabile nel } \\
60 \% \text { dei casi } \\
\text { (in } 2 / 5 \text { solo con } \\
\text { modifiche) }\end{array}$ \\
\hline $\begin{array}{l}\text { Coeliac disease - Recognition } \\
\text { and assessment of coeliac } \\
\text { disease NICE - 2009157 }\end{array}$ & $\begin{array}{c}101 / 105 \\
95,6 \%\end{array}$ & $\begin{array}{l}88 / 105 \\
81,1 \%\end{array}$ & $\begin{array}{c}245 / 245 \\
100 \%\end{array}$ & $\begin{array}{l}90 / 105 \\
83,3 \%\end{array}$ & $\begin{array}{c}115 / 140 \\
79,2 \%\end{array}$ & $\begin{array}{l}66 / 70 \\
93,3 \%\end{array}$ & $\begin{array}{l}\text { Adottabile nel } \\
100 \% \text { dei casi } \\
\text { (in } 1 / 5 \text { con } \\
\text { modifiche) }\end{array}$ \\
\hline $\begin{array}{l}\text { Linee guida Celiachia } \\
\text { Valutazione morfologica } \\
\text { - AIC }-2008^{158}\end{array}$ & $\begin{array}{l}61 / 105 \\
51 \%\end{array}$ & $\begin{array}{l}39 / 105 \\
26,7 \%\end{array}$ & $\begin{array}{c}77 / 245 \\
20 \%\end{array}$ & $\begin{array}{l}64 / 105 \\
54,4 \%\end{array}$ & $\begin{array}{l}64 / 140 \\
36,7 \%\end{array}$ & $\begin{array}{c}22 / 70 \\
20 \%\end{array}$ & $\begin{array}{c}\text { Adottabile nel } \\
20 \% \text { dei casi } \\
\text { (solo in } 1 / 5 \\
\text { adottabile ma } \\
\text { con modifiche) }\end{array}$ \\
\hline $\begin{array}{l}\text { Linee guida per la diagnosi } \\
\text { ed il follow-up della celiachia } \\
- \text { AIC }-2008^{159}\end{array}$ & $\begin{array}{l}53 / 105 \\
42,2 \%\end{array}$ & $\begin{array}{l}38 / 105 \\
25,6 \%\end{array}$ & $\begin{array}{c}58 / 245 \\
11 \%\end{array}$ & $\begin{array}{l}66 / 105 \\
56,7 \%\end{array}$ & $\begin{array}{l}47 / 145 \\
21,6 \%\end{array}$ & $\begin{array}{l}20 / 70 \\
16,7 \%\end{array}$ & $\begin{array}{l}\text { Adottabile nel } \\
20 \% \text { dei casi } \\
\text { (solo in } 1 / 5 \\
\text { adottabile ma } \\
\text { con modifiche) }\end{array}$ \\
\hline
\end{tabular}


gnificativa tra insorgenza di $\mathrm{MC}$ e modalità di introduzione del glutine nello svezzamento infante, né un ruolo protettivo o negativo del latte materno. L'introduzione precoce di piccole quantità di glutine (dal sesto mese) non ha ridotto il rischio di MC a tre anni in bambini geneticamente predisposti e con rischio familiare elevato e l'allattamento al seno materno, sia esclusivo che parziale, non ha dimostrato un effetto protettivo significativo. ${ }^{165}$ L'introduzione tardiva del glutine, pur non significativa nel ridurre l'insorgenza di malattia, si è associata, tuttavia, ad un ritardo di comparsa della malattia. ${ }^{166}$ Nell'editoriale a commento dei suddetti studi, visto l'aumento evidente di 4-5 volte negli ultimi 50 anni, si ipotizza che altri fattori ambientali debbano contribuire allo sviluppo della $\mathrm{MC}$, quali il parto cesareo, le infezioni perinatali e dell'infanzia, alcuni farmaci e soprattutto la lavorazione industriale della farina bianca. ${ }^{167}$

Per quanto riguarda il ruolo dei farmaci, in un ampio studio di popolazione caso-controllo svedese, è risultata una forte associazione tra $\mathrm{MC}$ e prescrizione di farmaci inibitori di pompa protonica (IPP) [odd ratio (OR) 4,79; 95\% intervallo di confidenza (IC) 4,17-5,51]. Lo studio, sebbene comprendesse anche tutti i celiaci che assumono questi medicamenti per il controllo dei sintomi della malattia stessa, mostrerebbe un maggior rischio di sviluppare MC dopo l'esposizione a IPP e anti-H2 (OR 5,96; 95\% IC $3,58-9,91)$. L'ipotesi è che, sia l'aumento del $\mathrm{pH}$ gastrico che l'aumento di permeabilità sulla mucosa dato da queste molecole, possano compromettere la digestione peptica e l'assorbimento di antigeni alimentari, con possibile ruolo nell'attivazione autoimmune della malattia nei soggetti predisposti. ${ }^{168}$

In un altro ampio studio caso controllo svedese si è evidenziata una correlazione positiva (OR 1,30 IC 95\%) tra esposizione ad antibiotici e MC che troverebbe una spiegazione nella disbiosi iatrogena in grado di alterare il microbiota intestinale e i suoi riconosciuti effetti immunologici. ${ }^{153}$ Però, gli autori non traggono conclusioni definitive sul ruolo dei fattori iatrogeni nella MC in quanto la patologia riconosce una multifattorialità causale, con processi ancora in parte sconosciuti; inoltre l'analisi causa-effetto è confondente in quanto questi farmaci di per sé stessi sono utilizzati spesso in conseguenza alla malattia stessa.

Il microbiota intestinale è oggetto di studio per il possibile contributo patogenetico in svariate patologie, $\mathrm{MC}$ inclusa. Nei pazienti celiaci si è riscontrata una modificazione dell'ecosistema intestinale rispetto ai non celiaci, con un aumento di Bacteroides ed Escherichia coli e una riduzione di Bifidobacteria e, soprattutto, di Lattobacilli che avrebbero un ruolo protettivo sull'integrità dell'epitelio dal danno da AGA. ${ }^{169}$ Lo studio di Olivares e colleghi ha analizzato le feci di 22 bambini di un mese non ancora giunti in contatto con glutine che possedevano un elevato rischio familiare (parenti di primo grado con predisposizione genetica). Nelle feci di bambini DQ2 positivi è risultata presente una proporzione maggiore di Firmicutes e Proteobatteri e una più bassa proporzione di Actinobatteri rispetto alle feci di bambini HLA-DQ2 e DQ8 negativi.

Pertanto l'alterazione del microbiota non sarebbe la conseguenza ma risponderebbe ad una predisposizione genetica. ${ }^{170}$

\section{Presentazione clinica}

Nel corso del tempo l'espressione clinica della celiachia ha visto un aumento dei fenotipi non classici e subclinici (66\%) vs i classici (34\%). È l'analisi eseguita dall'Università di Bologna su 770 casi diagnosticati per MC dal 1998 al 2012. ${ }^{171,172}$ Nella casistica la principale manifestazione extraintestinale di malattia è stata l'osteopenia/osteoporosi, con il 52\% di riscontri.

La ricerca e gestione delle alterazioni del metabolismo osseo, legato nel paziente celiaco al malassorbimento di calcio e vitamina $\mathrm{D}$, non trova univocità nelle LG a causa di insufficienti dati conclusivi. Non esistono, per esempio, allo stato attuale marcatori clinici e biochimici per selezionare il sottogruppo di soggetti che non ottengono la normalizzazione del metabolismo osseo con la GFD e che conservano comunque un alto rischio fratturativo; così come non c'è chiara indicazione su quale sia il trattamento ottimale e il follow-up corretto.

Nella review di Corazza e colleghi gli autori propongono di iniziare tempestivamente il trattamento per l'osteoporosi nelle forme di MC con manifesto malassorbimento e in quei soggetti con malattia silente o asintomatici di età oltre il di picco di massa ossea, se in presenza di fattori di rischio addizionali per l'alterazione del metabolismo. Nei soggetti con malattia silente o asintomatici che non hanno ancora raggiunto l'età di picco di massa ossea si indica prima l'esecuzione di Densitometria ossea. ${ }^{173}$

Un ampio studio comprendente ben 26.995 pazienti che ha analizzato l'associazione tra $\mathrm{MC}$ e autismo non ha trovato una correlazione significativa tra criteri per autismo e MC ricercata a livello siero-istologico. È però documentata una significativa presenza dei più aspecifici anticorpi AGA IgG-IgA, senza poterne definire un sicuro significato. ${ }^{174}$

La psoriasi si associa in modo significativo a diverse patologie autoimmuni ed è rinvenuta un'associazione positiva anche con la celiachia (OR 2,2). Gli autori di queste analisi consigliano di sottoporre a screening sierologico per MC i soggetti con psoriasi solo in presenza di sintomi correlabili alla celiachia. La dieta senza glutine quale ausilio al trattamento della psoriasi ha dato però scarso vantaggio. ${ }^{175}$

Un recente studio di popolazione svedese ha analizzato le conseguenze cliniche in soggetti con persi- 
stenza di atrofia dei villi, nonostante GFD (quadro patologico riscontrato nel $43 \%$ dei casi $(n=3317)$. È rinvenuto in questo gruppo un rischio maggiore di disordini linfoproliferativi (OR 2,25, 1,18-4,34) e di fratture ossee. Non si sono invece dimostrate differenze in termini di mortalità generale, outcomes cardiovascolari, complicanze ostetriche nelle donne in gravidanza. ${ }^{176}$

\section{Nuovi trattamenti}

I due studi di fase II di Larazotide e ALV003, farmaci integrativi della dieta senza glutine, hanno evidenziato una parziale efficacia a dimostrazione che $\mathrm{i}$ fattori coinvolti nella cascata patogenetica della MC sono molteplici e quindi i farmaci indirizzati su specifici target esitano in una ridotta efficacia.

Larazotide acetato ha un'azione di protettore di membrana poiché ne riduce la permeabilità, risultando efficace nel ridurre i sintomi correlati alla MC. Si tratta di un peptide ad assunzione orale, che antagonizza l'azione della zonulina, una proteina transmembrana, coinvolta nel trasporto della AGA, iperespressa nella $\mathrm{MC}$, che contribuisce a scatenare la risposta immunologica dell'organismo. Sono stati condotti due trials randomizzati (270 pazienti) di Larazoide $v s$ placebo. Non c'è stata una differenza significativa nelle variazioni della permeabilità intestinale, ma il gruppo con Larazotide ha registrato un calo significativo dei livelli di TTG e una riduzione significativa dei sintomi. ${ }^{177}$

ALV003 è una combinazione di endopeptidasi ed endoproteasi, ad assunzione orale, che migliora la degradazione del glutine in peptidi non tossici. Nello studio randomizzato di fase II è stata comparata la sua assunzione $v$ s placebo in 34 pazienti con MC che assumevano $2 \mathrm{~g}$ di glutine al giorno (metà di una fetta standard di pane), nel contesto di una dieta senza glutine. I soggetti randomizzati con ALV003 non hanno riportato una riduzione significativa dell'altezza dei villi su biopsia intestinale al contrario dei soggetti con placebo che, come atteso, hanno riportato un danno intestinale. ${ }^{178}$

\section{Linee guida NICE sulla malattia celiaca (settembre 2015)}

Infine le ultime LG NICE, pubblicate a settembre 2015, sottolineano diversi aspetti: l'appropriatezza della ricerca sierologica per TTG con kit certificati, la necessità di definire nei Laboratori un corretto protocollo per la ricerca di EmA, convogliando i prelievi in centri con esperienza o avviando una precisa formazione interna. Inoltre si è posto l'accento sulla scarsità di evidenze nel management dell'alterazione del metabolismo osseo e nella definizione di un programma di follow-up. ${ }^{179}$

\section{Bibliografia}

1. Merese B, Malamut G, Cerf-Bensussan N. Celiac disease: an immunological jigsaw. Immunity 2012;36:907-19.

2. Jabri B, Kasarda DD, Green PH. Innate and adaptive immunity: the yin and yang of celiac disease. Immunol Rev 2005;206:219-31.

3. Rubio-Tapia A, Hill ID, Kelly CP, et al. Diagnosis and management of celiac disease. Am J Gastroenterol 2013;108:656-76.

4. Husby S, Koletzko S, Korponay-Szabó IR, et al. European Society for Pediatric Gastroenterology, Hepatology, and Nutrition guidelines for the diagnosis of coeliac disease. J Pediatr Gastroenterol Nutr 2012;54:136-60.

5. Van Heel DA, West J. Recent advances in coeliac disease. Gut 2006;55:1037-46.

6. Bai JC, Fried M, Corazza GR, et al. World gastroenterology organisation global guidelines on celiac disease. J Clin Gastroenterol 2013;47:121-6.

7. Catassi C, Fabiani E, Rätsch IM, et al. The coeliac iceberg in Italy. A multicentre antigliadin antibodies screening for coeliac disease in school-age subjects. Acta Paediatr Suppl 1996;412:29.

8. Gujral N, Freeman HJ, Thomson AB. Celiac disease: prevalence, diagnosis, pathogenesis and treatment. World J Gastroenterol 2012;18:6036-59.

9. Mustalahti K, Catassi C, Reunanen A, et al. Coeliac EU cluster, project epidemiology. The prevalence of celiac disease in Europe: results of a centralized, international mass screening project. Ann Med 2010;42:587-95.

10. Catassi C, Anderson RP, Hill ID, et al. World perspective on celiac disease. J Pediatr Gastroenterol Nutr 2012;55:494-9.

11. Patel D, Kalkat P, Baisch D, Zipser R. Celiac disease in the elderly. Gerontology 2005;51:213.

12. Vilppula A, Collin P, Mäki M, et al. Undetected coeliac disease in the elderly: a biopsy-proven populationbased study. Dig Liver Dis 2008;40:809.

13. Bao F, Yu L, Babu S, et al. One third of HLA DQ2 homozygous patients with type 1 diabetes express celiac disease associated transglutaminase autoantibodies. J Autoimmunity 1999;13:143-8.

14. Larizza D, Calcaterra V, De Giacomo C, et al. Celiac disease in children with autoimmune thyroid disease. $\mathrm{J}$ Pediatr 2001;139:738-40.

15. Hadithi M, de Boer H, Meijer JW, et al. Coeliac disease in Dutch patients with Hashimoto's thyroiditis and vice versa. World J Gastroenterol 2007;13:1715-22.

16. Hansson T, Dahlbom I, Rogberg S, et al. Antitissue transglutaminase and antithyroid autoantibodiesin children with Down syndrome and celiac disease. J Pediatr Gastroenterol Nutr 2005;40:170-4.

17. Fasano A, Berti I, Gerarduzzi T, et al. Prevalence of celiac disease in at-risk and not-at-risk groups in the United States: a large multicenter study. Arch Intern Med 2003; 163:286-92.

18. Not T, Horvath K, Fasano A, et al. Celiac disease risk in the USA: high prevalence of antiendomysium antibodies in healthy blood donors. Scand J Gastroenterol 1998;33:494-8

19. Abadie V, Barriero LB, Jabri B. Integration of genetic and immunologic insights into a model of celiac disease 
pathogenesis. Annu Rev Immunol 2011;29:493-525.

20. Sollid LM. Coeliac disease: dissecting a complex inflammatory disorder. Nat Rev Immunol 2002;2:647-55.

21. Kasper DL, Braunwald E, Hauser S. Harrison's principles of internal medicine. 16th Ed. New York, USA: McGraw-Hill Medical Publishing Division; 2005.

22. Green PH, Jabri B. Coeliac disease. Lancet 2003;362: 383-91.

23. Jabri B, Sollid LM. Tissue-mediated control of immunopathology in coeliac disease. Nat Rev Immunol 2009; 9:858-70.

24. Cammarota G, Cuoco L, Gasbarrini G, et al. Onset of coeliac disease during treatment with interferon for chronic hepatitis C. Lancet 2000;356:1494-5.

25. Gerdes AM, Horder M, Bonnevie-Nielsen V. Increased IFN- $\alpha$-induced sensitivity but reduced reactivity of 2,5oligoadenylate synthetase (2,5AS) in trisomy 21 blood lymphocytes. Clin Exp Immunol 1993;93:93-6.

26. Troncone R, Auricchio S. Rotavirus and celiac disease: clues to the pathogenesis and perspectives on prevention. J Pediatr Gastroenterol Nutr 2007;44:527-8.

27. Stene LC, Hoffenberg EJ, Haas JE, et al. Rotavirus infection frequency and risk of celiac disease autoimmunity in early childhood: a longitudinal study. Am J Gastroenterol 2006;101:2333-40.

28. Jansen MA, Van der Zwet KV, Moll HA, et al. Herpes virus infections and transglutaminase type 2 antibody positivity in childhood: the generation R study. J Pediatr Gastroenterol Nutr 2016. [Epub ahead of print]

29. Nistal E, Herran AR, Casquiero J, et al. Study of duodenal bacterial communities by 16 sr rna gene analysis in adults with active celiac disease versus non celiac disease controls. J Appl Microbiol 2016;120:1691-700.

30. Marasco G, Schiumarini R, Colecchia A, et al. Gut microbiota and celiac disease. Dig Dis Sci 2016;61: 1461-72.

31. Mustalahti K, Sulkanen S, Holopainem P, et al. Celiac disease among healthy members of multiple case coeliac disease families. Scand J Gastroenterol 2002;37:161-5.

32. Di Sabatino A, Corazza GR, Coeliac disease. Lancet 2009;373:1480-93.

33. Hammer ST, Greenson JK. The clinical significance of duodenal lymphocytosis with normal villus architecture. Arch Pathol Lab Med 2013;137:1216-9.

34. Volta U, Granito A, Fiorini E, et al. Usefulness of antibodies to deamidated gliadin peptides in celiac disease diagnosis and follow-up. Dig Dis Sci 2008;53:1582-8.

35. Korponay-Szabo IR, Dahlbom I, Laurila K, et al. Elevation of IgG antibodies against tissue transglutaminase as a diagnostic tool for coeliac disease in selective IgA deficiency. Gut 2003;52:1567-71.

36. Berger R, Schmidt G. Evaluation of six anti-gliadin antibody assays. J Immunol Methods 1996;191:7786.

37. Tonutti E, Visentini D, Bizzaro N, et al. Linee guida per la diagnosi di laboratorio e istologica della malattia celiaca. Riv Itc Med Lab 2005;2:110-22. [Article in Italian]

38. Hoffemberg EJ, MacKenzie T, Barriga, et al. A prospective study of the incidence of childhood celiac disease. J Pediatr 2003;143:308-14.

39. Volta U. La sierologia: utilità e significato dei test anticorpali. In: Volta U, Ubaldi E, eds. La malattia celiaca in medicina generale. Pisa: Pacini Editore; 2009. pp 16-9.

40. Villalta D, Alessio MG, Tampoia M, et al. Testing for
IgG class antibodies in celiac diagnostic accuracy of 9IgG anti-tissue transglutaminase, 1 IgG anti-gliadin and $1 \mathrm{IgG}$ anti-deaminatedgliadin peptide antibody assay. Clin Chim Acta 2007;382:95-9.

41. Villalta D, Tonutti E, Prause C, et al. IgG antibodies against deamidated gliadin peptides for diagnosis of celiac disease in patient with IgA deficiency. Clin Chem Acta 2010;56:464-8.

42. Lowbeer $\mathrm{C}$, Wallinder $\mathrm{H}$. Undetectable anti-tissue transglutaminase $\operatorname{IgA}$ antibody measured with EliAceliakey indicates selective IgA deficiency. Clin Chim Acta 2010;411:612.

43. Sinclair D, Saas M, Turk A, et al. Do we need to measure total serum IgA to exclude IgA deficiency in celiac disease? J Clin Pathol 2006;59:736-9.

44. Rostom A, Dubé C, Cranney A, et al. Celiac disease. Evid Rep Technol Assess (Summ) 2004;104:1-6.

45. Giersiepen K, Lelgemann M, Korponay-Szabò IR, et al. ESPGHAN Working Group on Coeliac Disease Diagnosis. Accuracy of diagnostic antibody test for coeliac disease in children: summary from an evidence report. European Society fo Pediatric Gastroenterology, Hepatology and Nutrition (ESPHAGAN) Working Group on Coeliac Diagnosis. J Pediatr Gastroenterol Nutr 2012; 54:229-41.

46. Rashtak S, Ettore MW, Homburger HA, et al. Comparative usefulness of deamidated gliadin antibodies in the diagnosis of celiac disease. Clin Gastroenterol Hepatol 2008;6:426-32.

47. Collin P, Kaukinen K, Vogelsang H, et al. Antiendomysial and antihuman recombinant tissue transglutaminase antibodies in the diagnosis of coeliac disease: a biopsyproven European multicentre study. Eur J Gastroenterol Hepatol 2005; 17:85-91.

48. Hopper AD, Cross SS, Hurlstone DP, et al. Pre-endoscopy serological testing for coeliac disease: evaluation of a clinical decision tool. BMJ 2007;334:729.

49. Dickey W, Hughes DF, McMillan SA. Reliance on serum endomysial antibody testing underestimates the true prevalence of coeliac disease by one fifth. Scad J Gastroenterol 2000;35:181-3.

50. Rosekrans PC, Meijer CJ, Polanco I, et al. Long-term morphological and immunohistochemical observations on biopsy specimens of small intestine from children with gluten sensitive enteropathy. J Clin Pathol 1981; 34:138-44.

51. Clemente MG, De Virgilis S, Fasano A, et al. Early effects of gliadin on enterocyte intracellular signalling involved in intestinal barrier function. Gut 2003;52: 218-23.

52. Smecuol E, Bai JC. Diagnosis of celiac disease. World Gastroenterol News E-EGN 2011;16:7-10.

53. Marsh MN. Gluten major histocompatibility complex and the small intestine. Gastroenterology 1992;102:330-54.

54. Ciclitira PJ. Celiac disease: a techinical review. Gastroentetology 2001;120:1526-40.

55. Kurppa K, Collin P, Viljamaa M, et al. Diagnosing mild enteropathy celiac disease: a randomzed, controlled clinical study. Gastroenterology 2009;136:816-23.

56. Paparo F, Petrone E, Tosco A, et al. Clinical, HLA, and small bowel immunohistochemical features of children with positive serum anti-endomysium antibodies and architecturally normal small intestinal mucosa. Am J Gastroenterol 2005;100:2294-8. 
57. Simell S, Hoppu S, Hekkala A, et al. Fate of five celiac disease-associated antibodies during normal diet in genetically at-risk children observed from birth in a natural history study. Am J Gastroenterol 2007;102:2026-35.

58. Marsh MN. Grains of truth: evolutionary changes in small intestinal mucosa in response to enviromental antigen challenge. Gut 1990;31:111-4.

59. Villanacci V. Linee guida. Celiachia valutazione morfologica. 2008. Available from: http://www.celiachia.it/public/bo/upload/aic\%5Cdoc/linee guida biopsia 2008.pdf

60. Patey-Mariaud De Serre N, Cellier C, Jabri B, et al. Distinction between coeliac disease and refractory sprue: a simple immunohistochemical method. Histopathology 2000;37:70-7.

61. Marsh MN, Crowe PT. Morphology of the mucosal lesion in gluten sensitivity. Baillières Clin Gastroenterol 1995;9:273-93.

62. Obberhuber G, Granditsch G, Vogelsang H. The histopathology of celiac disease: time for a standardized report scheme for pathologists. Eur J Gastroenterol Hepatol 1999;11:1185-94.

63. Antonioli DA. Celiac disease: a progress report. Mod Pathol 2003;16:342-6.

64. Sollid LM, Thorsby E. HLA susceptibility genes in celiac disease: genetic mapping and role in pathogenesis. Gastroenterology 1993;105:910-22.

65. Abadie V, Sollid L, Barriero LB, et al. Integration of genetic and immunological insights into a model of celiac disease pathogenesis. Annu Rev Immunol 2011;29: 493-525.

66. Book L, Hart A, Black J, et al. Prevalence and clinical characteristics of celiac disease in Down syndrome in a US study. Am J Genet 2001;98:70-4.

67. Rokkas T, Niv Y. The role of video capsule endoscopy in the diagnosis of celiac disease: a meta-analysis. Eur J Gastroenterol Hepatol 2012;24:303-8.

68. Lebwohl B, Ludvigsson JF, Green PHR. Celiac disease and non-celiac gluten sensitivity. BMJ 2015;351:h4347.

69. Volta U, Caio G, Stanghellini V, et al. The changing clinical profile of celiac disease: a 15-year experience (1998-2012) in an Italian referral center. BMC Gastroenterol 2014;14:194

70. Molina-Infante J, Santolaria S, Sanders DS, FernandezBanares F. Systematic review: non coeliac gluten sensitivity. Aliment Pharmacol Ther 2015;41:807-20.

71. Al-Toma WHM, Hadithi VM, Von Blomberg BME, Mulder CJJ. Survival in refractory coeliac disease and enteropathy-associated T-cell lymphoma: retrospective evaluation of single-centre experience. Gut 2007;56: 1373-8.

72. Rubio-Tapia A, Kelly DG, Lahr BD, et al. Clinical staging and survival in refractory celiac disease: a single center experience. Gastroenterology 2009;136:99-107.

73. Akobeng AK, Thomas AG. Systematic review: tolerable amount of gluten for people with coeliac disease. Aliment Pharmacol Ther 2008;1:1044-52.

74. Ansaldi N, Tavassoli K, Faussone D, et al. Clinico-histological behavior of celiac patients after gluten load following the definitive diagnosis. Pediatr Med Chir 1988;10:3-6.

75. Ludvigsson JF. Mortality and malignancy in celiac disease. Gastrointest Endosc Clin Nam 2012;22:705-22.

76. West J, Logan RF, Smith CJ, et al. Malignancy and mortality in people with coeliac disease: population based cohort study. BMJ 2004;329:716-9.

77. Askling J, Linet M, Gridley G, et al. Cancer incidence in a population based cohort of individuals hospitalized with celiac disease or dermatitis herpetiformis. Gastroenterology 2002;123:1428-35.

78. Corrao G, Corazza GR, Bagnardi V, et al. Mortality in patients with coeliac disease and their relatives: a cohort study. Lancet 2001;358:356-61.

79. Bardella MT, Fredella C, Prampolini L, et al. Body composition and dietary intakes in adult celiac disease patients consuming a strict gluten-free diet. Am J Clin Nutr 2000;72:937-9.

80. Kemppainen T, Kroger H, Janatuinen E, et al. Osteoporosis in adult patients with celiac disease. Bone 1999;24:249-55.

81. Sategna-Guidetti C, Grosso SB, Grosso S, et al. The effects of 1-year gluten with drawal on bone mass, bone metabolism and nutritional status in newly-diagnosed adult coeliac disease patients. Aliment Pharmacol Ther 2000; 14:35-43.

82. Vasquez H, Mazure R, Gonzalez D, et al. Risk of fractures in celiac disease patients: a cross-sectional, casecontrol study. Am J Gastroenterol 2000;95:183-9.

83. West J, Logan RF, Card TR, et al. Fracture risk in people with celiac disease: a population-based cohort study. Gastroenterology 2003;125:429-36.

84. Choi JM, Lebwohl B, Wang J, et al. Increased prevalence of celiac disease in patients with unexplained infertility in the United States. J Reprod Med 2011;56:199-203.

85. Norgard B, Fonager K, Sorensen HT, et al. Birth outcomes of women with celiac disease: a nation wide historical cohort study. Am J Gastroenterol 1999;94:2435-40.

86. Ludvigsson JF, Montgomery SM, Ekbom A. Celiac disease and risk of adverse fetal outcome: a populationbased cohort study. Gastroenterology 2005;129:454-63.

87. Khashan AS, Henriksen TB, Mortensen PB, et al. The impact of maternal celiac disease on birth weight and preterm birth: a Danish population-based cohort study. Hum Reprod 2010;25:528-34.

88. Mody RJ, Brown PI, Wechsler DS. Refractory iron deficiency anemia as the primary clinical manifestation of celiac disease. J Pediatr Hematol Oncol 2003;25:169-72.

89. Corazza GR, Valentini RA, Andreani ML, et al. Subclinical coeliac disease is a frequent cause of iron-deficiency anaemia. Scand J Gastroenterol 1995;30:153-6.

90. Howard MR, Turnbull AJ, Morley P, et al. A prospective study of the prevalence of undiagnosed coeliac disease in laboratory defined iron and folate deficiency. J Clin Pathol 2002;55:754-7.

91. Dickey W. Low serum vitamin B12 is common in coeliac disease and is not due to autoimmune gastritis. Eur J Gastroenterol Hepatol 2002;14:425-7.

92. Dahele A, Ghosh S. Vitamin B12 deficiency in untreated celiac disease. Am J Gastroenterol 2001;96:745-50.

93. Reinken L, Zieglauer H. Vitamin B-6 absorption in children with acute celiac disease and in control subjects. J Nutr 1978;108:1562-5.

94. Tikkakoski S, Savilahti E, Kolho KL. Undiagnosed coeliac disease and nutritional deficiencies in adults screened in primary health care. Scand J Gastroenterol 2007;42:60-5.

95. Halfdanarson TR, Kumar N, Hogan WJ, et al. Copper 
deficiency in celiac disease. J Clin Gastroenterol 2009; 43:162-4.

96. Botero-Lopez JE, Araya M, Parada A, et al. Micronutrient deficiencies inpatients with typical and atypical celiac disease. J Pediatr Gastroenterol Nutr 2011;53:265-70.

97. Bottaro G, Cataldo F, Rotolo N, et al. The clinical pattern of subclinical/silent celiac disease: an analysis on 1026 consecutive cases. Am J Gastroenterol 1999;94:691-6.

98. Pietzak MM. Follow-up of patients with celiac disease: achieving compliance with treatment. Gastroenterology 2005;128:S135-41.

99. Haines ML, Anderson RP, Gibson PR. Systematic review: the evidence base for long-term management of coeliac disease. Aliment Pharmacol Ther 2008;28:1042-66.

100. Zanini B, Lanzarotto F, Mora A, et al. Five year time course of celiac disease serology during gluten free diet: results of a community based "CD-Watch" program. Dig Liver Dis 2010;42:865-70.

101. Leffler DA, Dennis M, Hyett B, et al. Etiologies and predictors of diagnosis in nonresponsive celiac disease. Clin Gastroenterol Hepatol 2007;5:445-50.

102. Abdulkarim AS, Burgart LJ, See J, et al. Etiology of non responsive celiac disease: results of a systematic approach. Am J Gastroenterol 2002;97:2016-21.

103. Koop I, Ilchmann R, Izzi L, et al. Detection of autoantibodies against tissue transglutaminase in patients with celiac disease and dermatitis herpetiformis. Am J Gastroenterol 2000;95:2009-14.

104. Rubio-Tapia A, Rahim MW, See JA, et al. Mucosal recovery and mortality in adults with celiac disease after treatment with a gluten-free diet. Am J Gastroenterol 2010;105:1412-20.

105. Kaukinen K, Sulkanen S, Maki M, et al. IgA-class transglutaminase antibodies in evaluating the efficacy of gluten-free diet in coeliac disease. Eur J Gastroenterol Hepatol 2002;14:311-5.

106. Lanzini A, Lanzarotto F, Villanacci V, et al. Complete recovery of intestinal mucosa occurs very rarely in adult coeliac patients despite adherence to gluten-free diet. Aliment Pharmacol Ther 2009;29:1299-308.

107. Wahab PJ, Meijer JW, Mulder CJ. Histologic followup of people with celiac disease on a gluten-free diet: slow and incomplete recovery. Am J Clin Pathol 2002;118:459-63.

108. Kaukinen K, Peraaho M, Lindfors K, et al. Persistent small bowel mucosal villous atrophy without symptoms in coeliac disease. Aliment Pharmacol Ther 2007;25: $1237-45$

109. Dipper CR, Maitra S, Thomas R, et al. Anti-tissue transglutaminase antibodies in the follow-up of adult coeliac disease. Aliment Pharmacol Ther 2009;30:236-44.

110. Saez LR, Alvarez DF, Martinez IP, et al. Refractory irondeficiency anemia and gluten intolerance response to gluten-free diet. Rev Esp Enferm Dig 2011;103:349-54.

111. Bai JC, Gonzalez D, Mautalen C, et al. Long-term effect of gluten restriction on bone mineral density of patients with coeliac disease. Aliment Pharmacol Ther 1997;11:157-64.

112. Sanchez MI, Mohaidle A, Baistrocchi A, et al. Risk of fracture in celiac disease: gender, dietary compliance, or both? World J Gastroenterol 2011;17:3035-42.

113. Jafri MR, Nordstrom CW, Murray JA, et al. Long-term fracture risk in patients with celiac disease: a popula- tion-based study in Olmsted County, Minnesota. Dig Dis Sci 2008;53:964-71.

114. Ludvigsson JF, Michaelsson K, Ekbom A, et al. Coeliac disease and the risk of fractures-a general populationbased cohort study. Aliment Pharmacol Ther 2007;25: 273-85.

115. Leffler DA, Dennis M, Hyett B, et al. Etiologies and predictors of diagnosis in non responsive celiac disease. Clin Gastroenterol Hepatol 2007;5:445-50.

116. O' Mahony S, Howdle PD, Losowsky MS. Review article: management of patients with non-responsive coeliac disease. Aliment Pharmacol Ther 1996;10:671-80.

117. Fine KD, Meyer RL, Lee EL. The prevalence and causes of chronic diarrhea in patients with celiac sprue treated with a gluten-free diet. Gastroenterology 1997;112:1830-8.

118. Malamut G, Afchain P, Verkarre V, et al. Presentation and long-term follow-up of refractory celiac disease: comparison of type I with type II. Gastroenterology 2009; 136:81-90.

119. Roshan B, Leffler DA, Jamma S, et al. The incidence and clinical spectrum of refractory celiac disease in a North American referral center. Am J Gastroenterol 2011;106:923-8.

120. Cellier C, Delabesse E, Helmer C, et al. Refractory sprue, coeliac disease, and enteropathy-associated Tcell lymphoma. French Coeliac Disease Study Group. Lancet 2000;356:203-8.

121. Tursi A, Brandimarte G, Giorgetti G. High prevalence of small intestinal bacterial overgrowth in celiac patients with persistence of gastrointestinal symptoms after gluten withdrawal. Am J Gastroenterol 2003;98:839-43.

122. Pallav K, Leffler DA, Tariq S, et al. Non coeliac enteropathy: the differential diagnosis of villous atrophy in contemporary clinical practice. Aliment Pharmacol Ther 2012;35:380-90.

123. Pardi DS, Kelly CP. Microscopic colitis. Gastroenterology 2011;140:1155-65.

124. Ludvigsson JF, Leffler DA, Bai JC, et al. The Oslo definitions for coeliac disease and related terms. Gut 2013;62:43-52.

125. Trier JS, Falchuk ZM, Carey MC, et al. Celiac sprue and refractory sprue. Gastroenterology 1978;75:307-16.

126. Cellier C, Patey N, Mauvieux L, et al. Abnormal intestinal intraepithelial lymphocytes in refractory sprue. Gastroenterology 1998;114:471-81.

127. Daum S, Weiss D, Hummel M, et al. Frequency of clonal intraepithelial $\mathrm{T}$ lymphocyte proliferations in enteropathy-type intestinal $\mathrm{T}$ cell lymphoma, coeliac disease and refractory sprue. Gut 2001;49:804-12.

128. Gerrard JW, Ross CA, Smellie JM. Coeliac disease: results of late treatment with gluten-free wheat diet. Lancet 1955;268:587-9.

129. Daum S, Ipczynski R, Heine B, et al. Therapy with budesonide in patients with refractory sprue. Digestion 2006;73:60-8.

130. Brar P, Lee S, Lewis S, et al. Budesonide in the treatment of refractory celiac disease. Am J Gastroenterol 2007;102:2265-9.

131. Jamma S, Leffler DA, Dennis M, et al. Small intestinal release mesalamine for the treatment of refractory celiac disease type I. J Clin Gastroenterol 2011;45:30-3.

132. Maurino E, Niveloni S, Chernavsky A, et al. Azathio- 
prine in refractory sprue: results from a prospective, open-label study. Am J Gastroenterol 2002;97:2595-602.

133. Wahab PJ, Crusius JB, Meijer JW, et al. Cyclosporin in the treatment of adults with refractory coeliac diseasean open pilot study. Aliment Pharmacol Ther 2000;14: 767-74.

134. Tack GJ, Verbeek WH, Al-Toma A, et al. Evaluation of Cladribine treatment in refractory celiac disease type II. World J Gastroenterol 2011;17:506-13.

135. Abdallah H, Leffler D, Dennis M, et al. Refractory celiac disease. Curr Gastroenterol Rep 2007;9:401-5.

136. Sieniawski M, Angamuthu N, Boyd K, et al. Evaluation of enteropathy associated T-cell lymphoma comparing standard therapies with a novel regimen including autologous stem cell transplant. Blood 2010;115:3664-70.

137. Chandesris MO, Malamut G, Verkarre V, et al. Enteropathy-associated T-cell lymphoma: a review on clinical presentation, diagnosis, therapeutic strategies and perspectives. Gastroenterol Clin Biol 2010;34:590-605.

138. Gale J, Simmonds PD, Mead GM, et al. Enteropathytype intestinal T-cell lymphoma: clinical features and treatment of 31 patients in a single center. J Clin Oncol 2000; $18: 795-803$.

139. Van de Water J, Cillessen S, Visser O, et al. Enteropathy associated T-cell lymphoma and its precursor lesions. Best Pract Res Clin Gastroenterol 2010;24:43-56.

140. Schmitz F, Tjon J, Lai Y, et al. Identification of a potential physiological precursor of aberrant cells in refractory coeliac disease type II. Gut 2013;62:509-19.

141. Mention J, Ahmed M, Begue B, et al. Interleukin 15: a key to disrupted intraepithelial lymphocyte homeostasis and lymphomagenesis in celiac disease. Gastroenterology 2003;125:730-45.

142. Malamut G, Meresse B, Cellier C, et al. Refractory celiac disease: from bench to bedside. Seminars in Immunopathology 2010;34:601-13.

143. Rubio-Tapia A, Murray J. Classification and management of refractory coeliac disease. Gut 2010;59:547-57.

144. Goerres MS, Meijer JWR, Wahab PJ, et al. Azathioprine and prednisone combination therapy in refractory coeliac disease. Aliment Pharmacol Ther 2003;18:487-94.

145. Robak T, Wierzbowska A, Robak E. Recent clinical trials of cladribine in hematological malignancies and autoimmune disorders. Rev Recent Clin Trials 2006;1: 15-34.

146. Ministero della Sanità. Decreto ministeriale. Regolamento di istituzione della rete nazionale delle malattie rare e di esenzione dalla partecipazione al costo delle relative prestazioni sanitarie ai sensi dell'articolo 5 , comma 1, lettera b) del decreto legislativo 29 aprile 1998, n. 124. In: Gazzetta Ufficiale, 12/07/2001, n. 160, Supplemento Ordinario n. 180/L.

147. García-Manzanares A, Lucendo AJ. Nutritional and dietary aspects of celiac disease. Nutr Clin Pract 2011; 26:163.

148. Ministero della Sanità. Decreto ministeriale. Assistenza sanitaria integrativa relativa ai prodotti destinati ad una alimentazione particolare. D.M 8 giugno 2001. In: Gazzetta Ufficiale n. 157, 05/07/2001.

149. Ministero della Sanità. Rete nazionale di presidi sanitari e centri interregionali di riferimento per la prevenzione, la sorveglianza, la diagnosi e la terapia delle malattie rare; 2001. Available from: http://www.salute.gov.it/ imgs/C_17_dossier_22_listaFile_itemName_0_file.pdf
150. Presidenza del Consiglio dei Ministri. Accordo, ai sensi dell'articolo 4, del decreto legislativo 28 agosto 1997, n. 281, tra il Governo, le regioni e le province autonome di Trento e di Bolzano sul «Protocollo per la diagnosi e il follow up della celiachia». Proceedings della Conferenza Permanente per i rapporti tra lo Stato, le Regioni e le Province autonome di Trento e Bolzano, 30 luglio 2015. Available from: http://www.statoregioni.it/Documenti/ DOC_048313_125\%20CSR\%20PUNTO\%209\%20OD G.pdf

151. Bernardini F, Cerbo M, Jefferson T, et al. HTA report: wireless capsule endoscopy in the diagnosis of small bowel disease. Age.na.s, Sezione ISS. Rome, Italy: 2008. Available from: http://www.salute.gov.it/portale/ temi/documenti/dispositiviMedici/C_17_pagineAree_1 202 listaFile_itemName_ 3 file.pdf

152. AGREE Next Step Consortium. AGREE II. Checklist per valutare la qualità delle linee guida. Bologna: Fondazione GIMBE; Aprile 2011.

153. Marild K, Lebwohl B, Green PH, et al. Antibiotic exposure and the development of coeliac disease: a nation wide case-control study. BMC Gastroenterol 2013;13:109.

154. Ludvigson J, Bai J, Biagi F, et al. Diagnosis and management of adult coeliac disease: guidelines from the British Society of Gastroenterology. Gut 2014;63:1210-28.

155. North American Society for Pediatric Gastroenterology, Hepatology and Nutrition (NASPGHAN). Diagnosis and treatment of celiac disease in children: clinical practice guideline summary; 2010. Available from: http://www.naspghan.org/content/51/en/professionaleducation/resources/celiac-disease

156. Murch S, Jenkins H, Auth M, et al. Joint BSPGHAN and Coeliac UK guidelines for the diagnosis and management of celiac disease in children. Arch Dis Child 2013;98:806-11.

157. National Institute for Health and Care Excellence (NICE). Coeliac disease: recognition and assessment. NICE guidelines [CG86]; Published date: May 2009. Available from: https://www.nice.org.uk/guidance /cg86?unlid=50950412420166601429

158. Associazione Italiana Celiachia (Aic). Linee guida celiachia valutazione morfologica; 2008. Available from: http://www.celiachia.it/Aic/AIC.aspx?SS=351\&M=867

159. Ministero della Salute - Comitato Nazionale Sicurezza Alimentare (C.N.S.A.) - Consulta Scientifica Per La Sicurezza Alimentare; Associazione Italiana Celiachia (AIC). Linee guida per la diagnosi ed il monitoraggio della celiachia e relative patologie associate e complicanze (a cura del Comitato Scientifico Nazionale dell'AIC). Edizione 2009. supplemento ordinario alla In: G.U. suppl. ord., 7/2/2008, ser. gen. n. 32. Available from: http://www.celiachia.it/aic/res/doc/lineee_guida_ followup_it.pdf

160. Altobelli E, Paduano R, Petrocello R, Di Orio F. Burden of celiac disease in Europe: a review of its childhood and adulthood prevalence and incidence as of September. Ann Ig 2014;26:485-98.

161. Kang JY, Kang AH, Gwee KA, Ho KY. Systematic review: worldwide variation in the frequency of celiac disease and changes over time. Clin Ther 2013;35:578-83.

162. Yuan J, Gao J, Li X, et al. The tip of the "celiac iceberg" in China: a systematic review and meta-analysis. PloS One 2013;8:e81151. 
163. Freeman HJ. Celiac disease: a disorder emerging from antiquity, its evolving classification and risk, and potential new treatment paradigms. Gut Liver 2015;9:28-37.

164. Abdul Sultan A, Crooks CJ, Card T, et al. Causes of death in people with coeliac disease in England compared with the general population: a competing risk analysis. Gut 2015;64:1220-6.

165. Vriezinga SL, Auricchio R, Bravi E, et al. Randomized feeding intervention in infants at high risk for celiac disease. N Engl J Med 2014;371:1304-15.

166. Lionetti E, Castellaneta S, Francavilla R, et al. Introduction of gluten, HLA status, and the risk of celiac disease in children. N Engl J Med 2014;371:1295-303.

167.Ludvigsson JF, Green PH. The missing environmental factor in celiac disease. N Engl J Med 2014;371: 1341-3.

168. Lebwohl B, Spechler SJ, Wang TC, et al. Use of proton pump inhibitors and subsequent risk of celiac disease. Dig Liver Dis 2014;46:36-40.

169. De Sousa, Moraes LF, Gouveia Peluzio Mdo C, et al. Intestinal microbiota and probiotics in celiac disease. Clin Microbiol Rev 2014;27:482-9.

170. Olivares M, Neef A, Castillejo G, et al. The HLA-DQ2 genotype selects for early intestinal microbiota composition in infants at high risk of developing celiac disease. Gut 2015;64:406-17.

171. Volta U, Caio G, Stanghellini V, et al. The changing clinical profile of celiac disease: a 15-year experience (1998-2012) in an Italian referral center. BMC Gastroenterol 2014;14:194.
172. Volta U, Parisi C, Fiorini E, et al. Celiachia: approccio razionale alla diagnosi. Ital J Med 2007;2:60-6.

173. Di Stefano M, Megoli C, Corazza R, et al. Bone mass and minera lmetabolism alterations in adult celiac disease: pathophysiology and clinical approach. Nutriens 2013;5:4786-99.

174. Ludvigsson JF, Reichenberg A, Hultman CM, et al. A nation wide study of the association between celiac disease and the risk of autistic spectrum disorders. JAMA Psychiatry 2013;70:1224-30.

175. Bhavnit K, Jillian W, Wilson L, et al. Diet and psoriasis: part 2. Celiac disease and role of free diet. J Am Acad Dermatol 2014;71:350-8.

176. Lebwohl B, Murray JA, Rubio-Tapia A, et al. Predictors of persistent villous atrophy in celiac disease: a population-based study. Aliment Pharmacol Ther 2014;39: 488-95.

177 Kelly CP, Green PH, Murray JA, et al. Larazotide acetate in patients with coeliac disease undergoing a gluten challenge: a randomised placebo-controlled study. Aliment Pharmacol Ther 2013;37:252-62.

178. Lahdeaho ML, Kaukinen K, Laurila K, et al. Glutenase ALV003 attenuates gluten-induced mucosal injury in patients with celiac disease. Gastroenterology 2014;146: 1649-58.

178. National Institute for Health and Care Excellence (NICE). Coeliac disease: recognition, assessment and management. NICE guidelines [NG20]; Published date: September 2015. Available from: https://www.nice.org. uk/guidance/ng20 


\section{LINEE GUIDA PER GLI AUTORI}

I Quaderni dell'Italian Journal of Medicine (Quaderni ITJM), costituiscono una collana supplementare solo online annessa alla rivista Italian Journal of Medicine contenente lavori solo in lingua italiana.

I Quaderni ITJM pubblicano:

- Monografie ad hoc individuate dal Presidente FADOI, dal Consiglio Direttivo, dal Board Scientifico o dall'Editor in Chief dell'Italian Journal of Medicine, in funzione del contesto scientifico-istituzionale attuale.

- Monografie ad hoc su temi di particolare rilevanza scientifica a cura della Commissione FADOI Giovani, coordinata dalla Dr.ssa Paola Gnerre.

- Traduzioni in italiano di alcuni lavori pubblicati sui numeri standard dell'Italian Journal of Medicine, di particolare interesse per la comunità scientifica. La selezione è a cura dell'Editor-inChief, Prof. Roberto Nardi

\section{STESURA DEI LAVORI}

I lavori dovranno essere redatti in modo conforme alle linee guida sotto riportate:

- I manoscritti devono essere scritti interamente in lingua italiana, su documento di Word, con carattere Times New Roman/Arial, dimensione 12, formato A4, interlinea doppia e margini $2,54 \mathrm{~cm}$. Parole totali: max 4000; Sommario/Abstract: $\max 250$ parole; Bibliografia: $\min 40$ voci; Tabelle e Figure: $3 / 5$ totali (le tabelle non devono superare n. 1 pagina del documento in Word).

- La strutturazione del contenuto deve attenersi agli standard internazionali per la Rassegna (Review): i) Abstract riassuntivo dell'intero lavoro; ii) Introduzione al tema trattato; iii) Criteri e strumenti di ricerca (criteri di inclusione/esclusione, banche dati consultate, ...); iv) i successivi paragrafi devono illustrare le più recenti scoperte scientifiche nel settore; v) Conclusioni; vi) Bibliografia.

- La prima pagina deve riportare: i) titolo (in stampatello minuscolo), senza acronimi; ii) nome e cognome per esteso di ciascun autore; iii) affiliazione(i) di ciascun autore, numerate con numeri arabi; iv) eventuali ringraziamenti; v) nome e indirizzo postale completi dell'autore corrispondente, corredati da telefono, fax, e-mail; vi) da 3 a 5 parole chiave, separate da virgola. La seconda pagina può riportare: i) contributi degli autori, e.g. informazioni relative a contributi sostanziali delle persone coinvolte nello studio (http://www.icmje.org/\#author); ii) dichiarazione relativa a potenziali conflitti d'interesse; iii) ulteriori informazioni (e.g. fondi, esposizioni durante conferenze...).

- In caso di utilizzo di tabelle, queste devono essere tutte numerate con numeri arabi e citate nel testo in ordine consecutivo (e.g. NON nominare le tabelle come Tabella $1 \mathrm{~A}, 1 \mathrm{~B}, \ldots$ o $1.0,1.1, \ldots$. . Le tabelle devono essere presentate in formato editabile. Ciascuna tabella deve essere corredata da una breve didascalia; in caso di abbreviazioni, riportare una nota a piè di CIASCUNA tabella che spieghi TUTTE le abbreviazioni presenti in ognuna.

- In caso di utilizzo di figure, queste devono essere inviate in formato .tiff o .jpg, allegate al manoscritto in singoli files, secondo le seguenti specifiche:

i) a colori (salvate in modalità CMYK): minimo 300 dpi di risoluzione;

ii) in bianco e nero: minimo 600 dpi di risoluzione;

iii) minimo $17,5 \mathrm{~cm}$ di larghezza.

Ciascuna figura deve essere corredata da una breve didascalia.

$N B$ : In caso di Tabelle/Figure riprese e/o modificate da altri lavori già pubblicati, sarà cura degli autori accertarsi se tali materiali siano o meno coperti da copyright e procurarsi i permessi necessari per la riproduzione. Tali permessi dovranno essere allegati alla versione definitiva del lavoro. L'ufficio editoriale si riserva la facoltà di rimuovere Tabelle/Figure coperte da copyright, se sprovviste dei necessari permessi.

- In caso di utilizzo di abbreviazioni, la prima volta che esse sono citate è necessario scrivere per esteso la definizione+abbreviazione tra parentesi tonde [e.g. risonanza magnetica $(\mathrm{RMN})]$, a seguire si dovrà riportare solo l'abbreviazione (unica eccezione: nei titoli e nelle didascalie di tabelle e figure NON si utilizzano abbreviazioni).

\section{BIBLIOGRAFIA}

Le voci bibliografiche devono essere formattate secondo lo stile Vancouver.

Nella sezione Bibliografia, le voci bibliografiche devono essere numerate consecutivamente nell'ordine in cui appaiono per la prima volta nel testo (NON in ordine alfabetico) e, nel testo, devono essere indicate con numeri arabi in apice. Voci bibliografiche riferite a comunicazioni personali o dati non pubblicati devono essere incorporate nel testo e NON inserite tra le voci numerate [e.g. (Wright 2011, dati non pubblicati) o (Wright 2011, comunicazione personale)]. Le voci bibliografiche nella sezione Bibliografia devono tassativamente essere preparate come segue:

i) più di 3 autori, citare 3 autori, et al. Se il lavoro contiene solo 4 autori, citarli tutti e 4 ;

ii) titolo del lavoro in stampatello minuscolo;

iii) nome della rivista, senza punti, abbreviato secondo gli standard internazionali; in caso di dubbi sulla corretta abbreviazione, fare riferimento ai seguenti siti:

a. ISI Journal Abbreviations Index (http://library.caltech.edu/ reference/abbreviations/);

b. Biological Journals and Abbreviations (http://home.ncifcrf. gov/research/bja/);

c. Medline List of Journal Titles (ftp://ftp.ncbi.nih.gov/pubmed/J_Medline.txt);

iv) inserire l'anno di pubblicazione subito dopo il nome della rivista, seguito da punto e virgola;

v) NON inserire giorno o mese di pubblicazione;

vi) citare solo il volume, seguito dai due punti (NON citare il fascicolo tra parentesi);

vii) abbreviare le pagine, e.g. 351-8

Per accertarsi di aver correttamente formattato le voci bibliografiche, confrontarle con le citazioni in PubMed (http://www.ncbi. nlm.nih.gov/pubmed).

Esempi (prestare attenzione anche alla punteggiatura):

Articolo standard su Rivista

Halpern SD, Ubel PA, Caplan AL. Solid-organ transplantation in HIV-infected patients. N Engl J Med 2002;347:284-7.

Proceedings

Christensen S, Oppacher F. An analysis of Koza's computational effort statistic for genetic programming. In: Foster JA, Lutton E, Miller J, Ryan C, Tettamanzi AG, eds. Genetic programming. EuroGP 2002: Proceedings of the 5th European Conference on Genetic Programming, 2002 Apr 3-5, Kinsdale, Ireland. Berlin: Springer; 2002. pp 182-91.

Articoli i cui autori sono Organizzazioni

Diabetes Prevention Program Research Group. Hypertension, insulin, and proinsulin in participants with impaired glucose tolerance. Hypertension 2002;40:679-86.

Libri

Murray PR, Rosenthal KS, Kobayashi GS, Pfaller MA. Medical microbiology. 4th ed. St. Louis, MO: Mosby; 2002. (CITAZIONE DEL LIBRO INTERO)

Meltzer PS, Kallioniemi A, Trent JM. Chromosome alterations in human solid tumors. In: Vogelstein B, Kinzler KW, eds. The genetic basis of human cancer. New York, NY: McGraw-Hill; 2002. pp 93113. (CITAZIONE DI UN CAPITOLO)

\section{MODALITÀ D'INVIO DEI LAVORI}

Monografie

Gli Autori dovranno fare riferimento all'Editor-in-Chief o alle persone da lui designate nelle lettere di invito a scrivere gli articoli programmati.

Per gli articoli inviati da giovani internisti, gli Autori dovranno fare riferimento alla Dr.ssa Paola Gnerre (e-mail: pgnerre@yahoo.it) e agli eventuali altri referenti da lei designati, nelle prime fasi di stesura dei manoscritti, revisioni e correzioni. 


\section{QUADERNI}

dell'Italian Journal

of Medicine

La Dr.ssa Gnerre raccoglierà poi le versioni definitive dei lavori di ciascuna monografia e provvederà all'invio di tutti i materiali all'ufficio editoriale.

I lavori solo nella loro versione definitiva e approvata dalla Commissione FADOI Giovani dovranno pervenire all'ufficio editoriale già pronti per l'impaginazione e immediata pubblicazione (già corredati da eventuali permessi per la riproduzione di tabelle e immagini).

\section{Traduzioni}

Previo invito dell'Editor-in-Chief, gli Autori dovranno far pervenire all'ufficio editoriale la versione tradotta in italiano, al seguente indirizzo e-mail: paola.granata@pagepress.org

Il file in formato Word dovrà essere formattato secondo gli standard editoriali della rivista ufficiale ed essere già pronto per impagina- zione e immediata pubblicazione (corredato da eventuali permessi per la riproduzione di tabelle e immagini).

Si prega di inviare le eventuali tabelle in formato editabile e le figure in alta definizione secondo gli standard sopra riportati.

\section{NOTA PER GLI AUTORI}

I lavori pubblicati sui Quaderni ITJM non verranno indicizzati, ma saranno liberamente disponibili in un'apposita sezione del sito FADOI (http://www.fadoi.org/).

Gli Autori i cui lavori siano accettati per la pubblicazione sui Quaderni ITJM e che fossero interessati a vederli pubblicati anche sulla rivista ufficiale, dovranno sottomettere attraverso il sito dell'ITJM (www.italjmed.org) la versione (già tradotta) in inglese e redatta in modo conforme alle linee guida della rivista; seguiranno poi la procedura di selezione tramite peer review e, se accettati, saranno inseriti nel piano editoriale standard.

\section{STAFF EDITORIALE}

Paola Granata, Journal Manager

paola.granata@pagepress.org

Claudia Castellano, Production Editor

Tiziano Taccini, Technical Support
PUBBLICATO DA

PAGEPress Publications

via G. Belli 7

27100 Pavia, Italy

T. +39.0382 .464340$

F: +39.0382 .34872$

\section{agepress}

www.pagepress.org info@pagepress.org

\section{QUADERNI - ITALIAN JOURNAL OF MEDICINE}

Tutti gli articoli pubblicati sui QUADERNI - Italian Journal of Medicine sono redatti sotto la responsabilità degli Autori. La pubblicazione o la ristampa degli articoli della rivista deve essere autorizzata per iscritto dall'editore. Ai sensi dell'art. 13 del D.Lgs 196/03, i dati di tutti i lettori saranno trattati sia manualmente, sia con strumenti informatici e saranno utilizzati per l'invio di questa e di altre pubblicazioni e di materiale informativo e promozionale. Le modalità di trattamento saranno conformi a quanto previsto dall'art. 11 del D.Lgs 196/03. I dati potranno essere comunicati a soggetti con i quali PAGEPress intrattiene rapporti contrattuali necessari per l'invio delle copie della rivista. Il titolare del trattamento dei dati è PAGEPress Srl, via Belli 7 - 27100 Pavia, al quale il lettore si potrà rivolgere per chiedere l'aggiornamento, l'integrazione, la cancellazione e ogni altra operazione di cui all'art. 7 del D.Lgs 196/03.

Editore: PAGEPress srl, via G. Belli 7, 27100 Pavia, Italy www.pagepress.org

Pubblicato: agosto 2016. 